\title{
Tree cavity abundance and nest site selection of cavity nesting birds in a natural boreal forest of West Khentey, Mongolia
}

\author{
Dissertation \\ zur Erlangung des Doktorgrades \\ der Mathematisch-Naturwissenschaftlichen Fakultäten \\ der Georg-August-Universität zu Göttingen
}

\author{
vorgelegt von \\ Mei-Ling Bai \\ aus Taipei
}

Göttingen 2005 
D 7

Referent:

Prof. Dr. M. Mühlenberg

Korreferent:

Prof. Dr. M. Schaefer

Tag der mündlichen Prüfung: $\quad$ Mittwoch, 27. April 2005 


\section{Table of Contents}

1 INTRODUCTION ....................................................................................1

1.1 Roles of Cavity-Nesting Birds .................................................................... 1

1.2 Present Studies about Cavity-Nesting Birds ............................................... 3

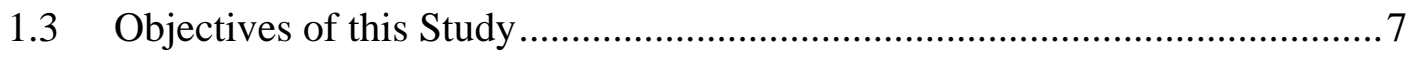

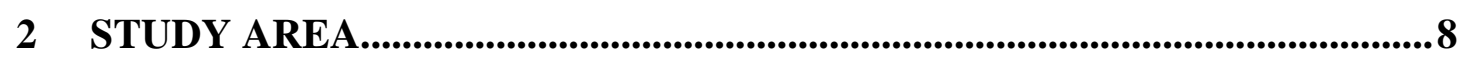

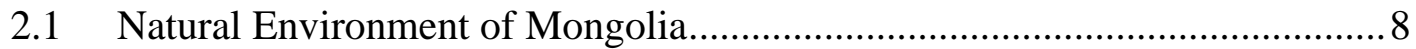

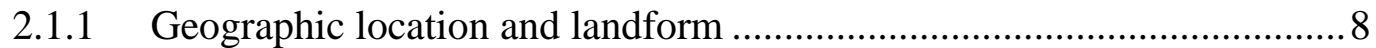

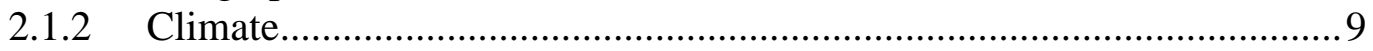

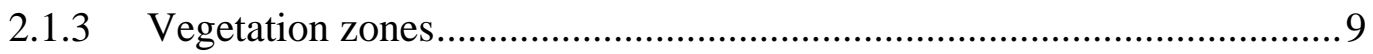

2.2 The Khan Khentey Strictly Protected Area ................................................... 10

2.2.1 Geographic location, topography and hydrology ................................ 10

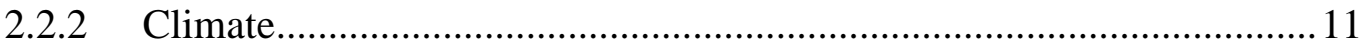

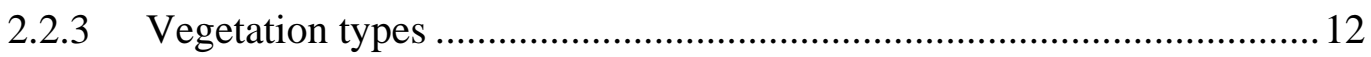

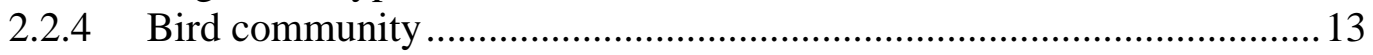

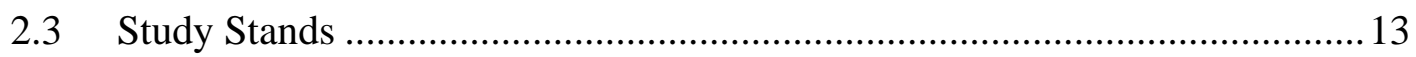

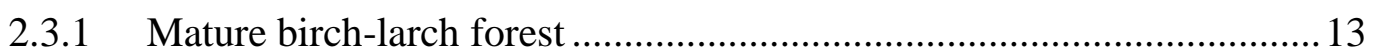

2.3.2 Young birch-larch forest after recent fire ............................................. 14

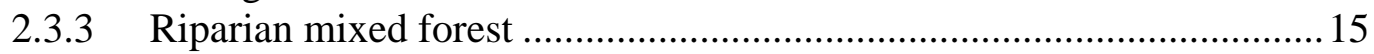

2.3.4 Spruce-fir coniferous forest ....................................................... 15

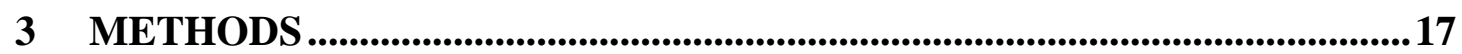

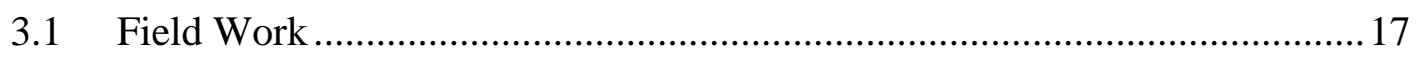

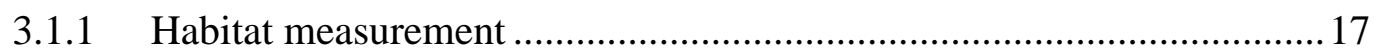

3.1.2 Cavity search .............................................................................. 19

3.1.3 Nest cavity search and measurement................................................. 21

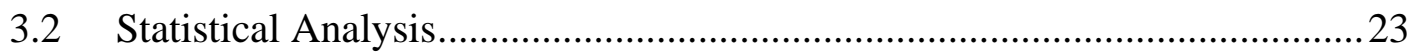

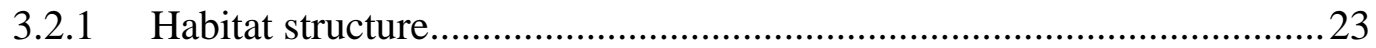

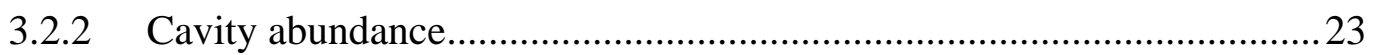

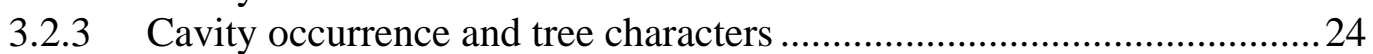

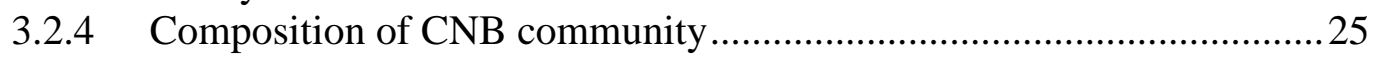

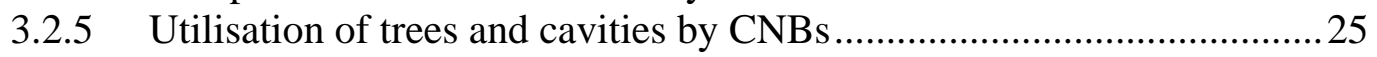

3.2.6 Nest site selection of individual species ............................................26

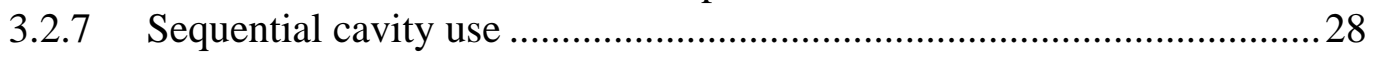

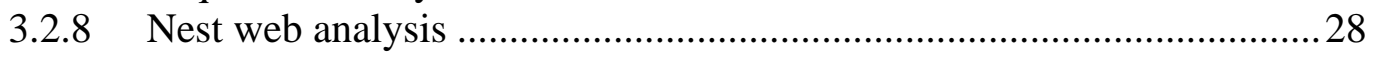

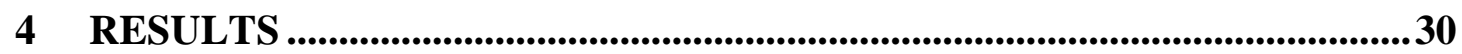

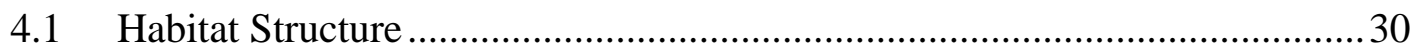




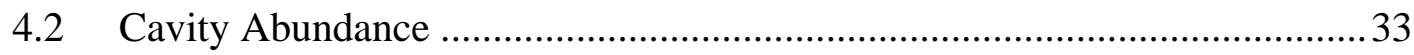

4.3 Cavity Occurrence and Tree Characters ...................................................... 36

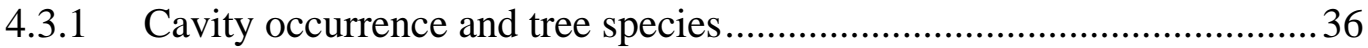

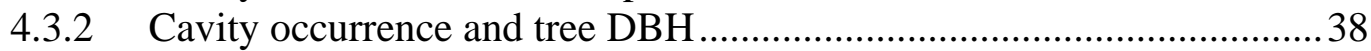

4.3.3 Cavity occurrence and tree condition ............................................... 41

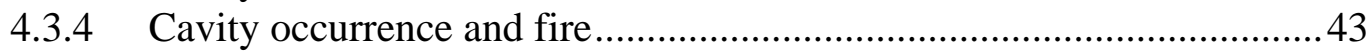

4.3.5 Cavity occurrence and fungi .............................................................. 44

4.3.6 Predicting cavity occurrence with tree characters .............................. 46

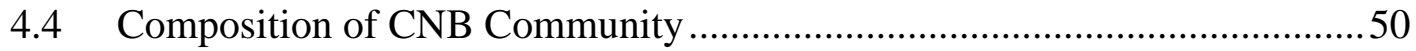

4.4.1 CNB composition in the study area ...................................................50

4.4.2 Relationship between CNB abundance and habitat variables ................51

4.4.3 Species abundance distribution ......................................................5

4.5 Utilisation of Trees and Cavities by CNBs................................................56

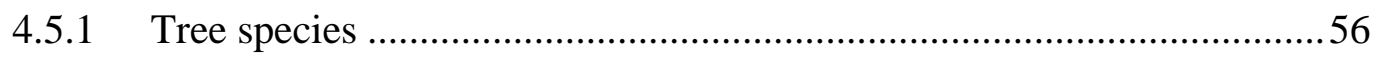

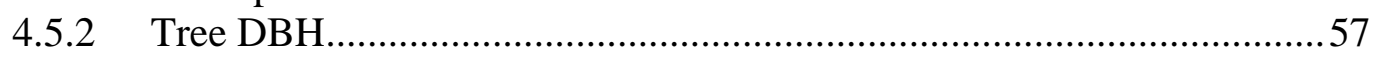

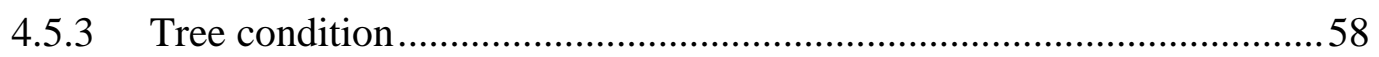

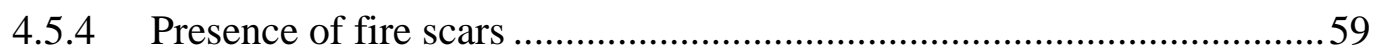

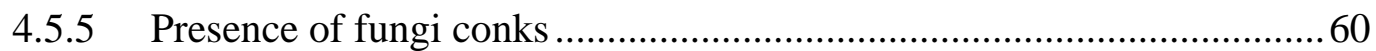

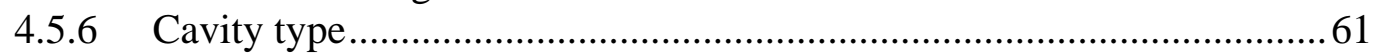

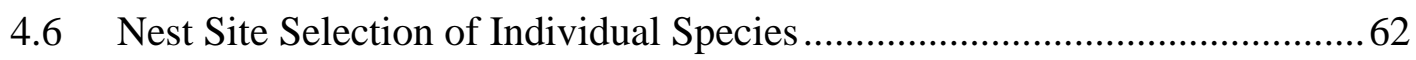

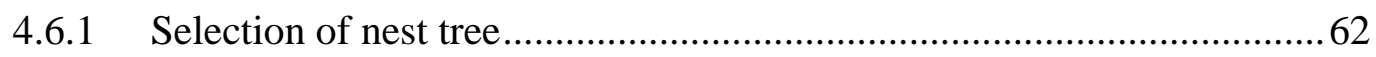

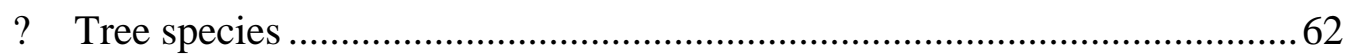

? Tree DBH

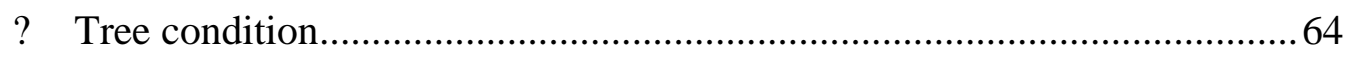

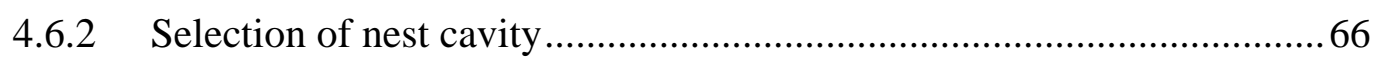

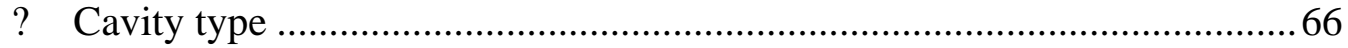

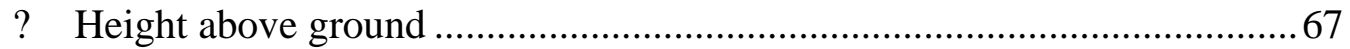

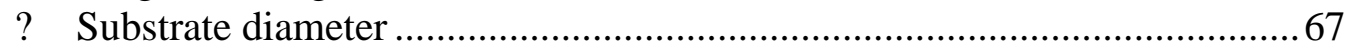

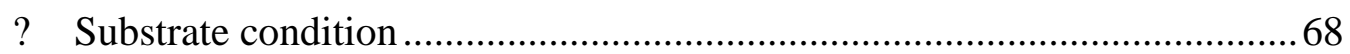

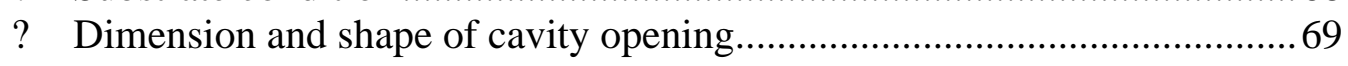

4.6.3 Multivariate summary of nest niche overlap ...................................... 70

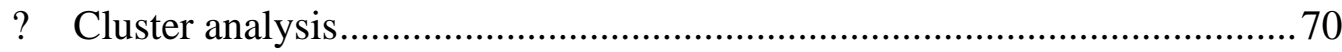

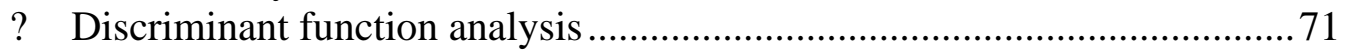

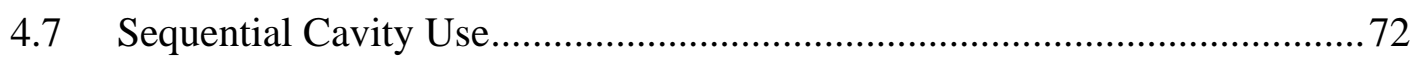

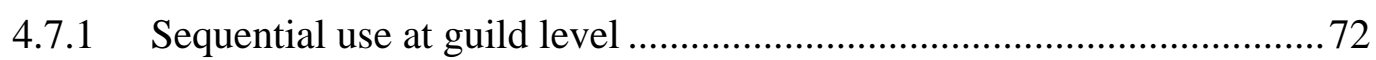

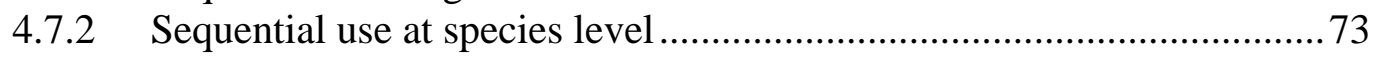

4.7.3 Characters of reused cavities .......................................................... 74

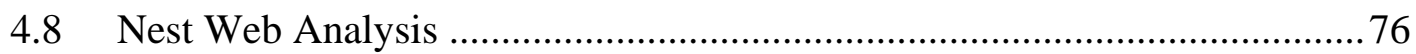

4.8.1 Nest web of CNB community in West Khentey....................................76

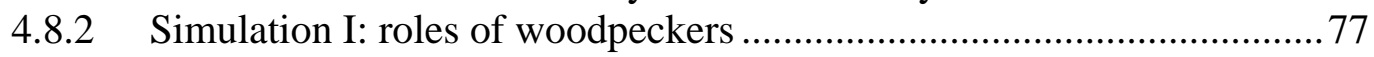

4.8.3 Simulation II: roles of some tree species ......................................... 79 
5 DISCUSSION 81

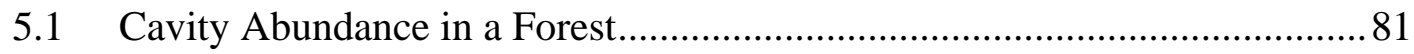

5.1.1 Cavity abundance in natural boreal forest ........................................... 81

5.1.2 Cavity abundance vs. forest type and management ..............................83

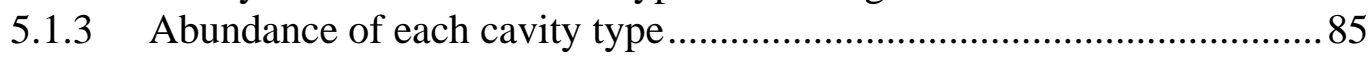

5.1.4 Cavity abundance and habitat-level variables ................................... 87

5.1.5 Cavity abundance and succession................................................... 88

5.2 Factors Influencing Cavity Formation in a Tree ......................................... 91

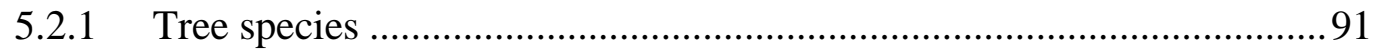

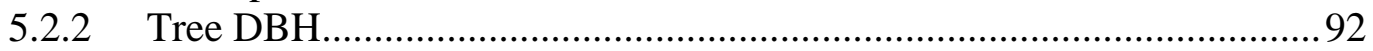

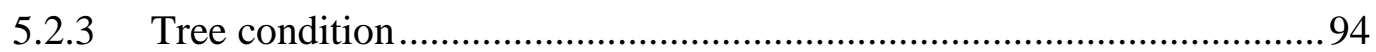

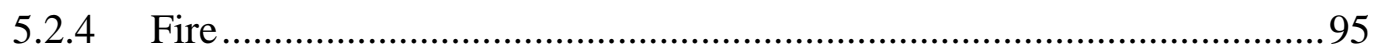

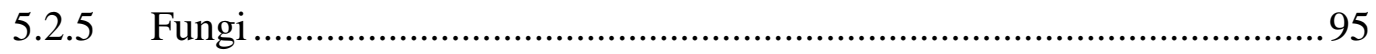

5.2.6 Predictive model of cavity occurrence ............................................. 97

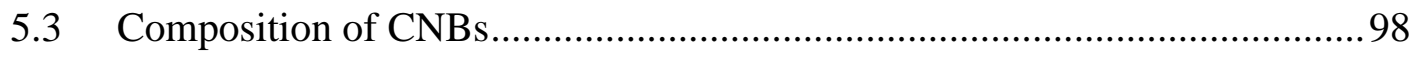

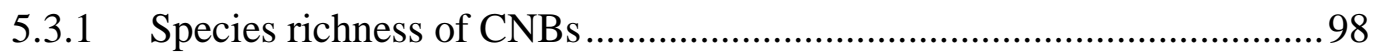

5.3.2 CNB density vs. forest type and management ................................... 99

5.3.3 CNB abundance and habitat-level variables....................................... 100

5.3.4 Cavity occupancy - Are cavities limiting? ......................................... 102

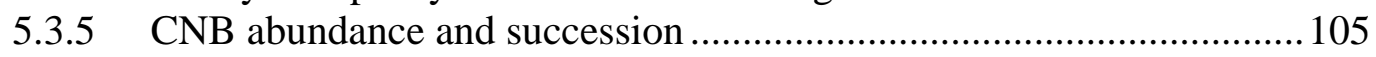

5.4 Factors influencing Tree and Cavity Use ............................................. 108

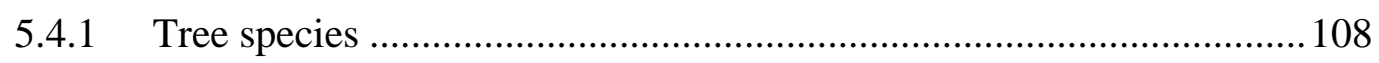

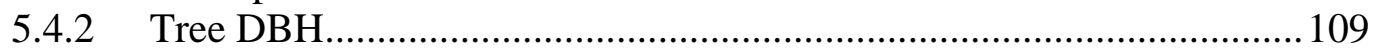

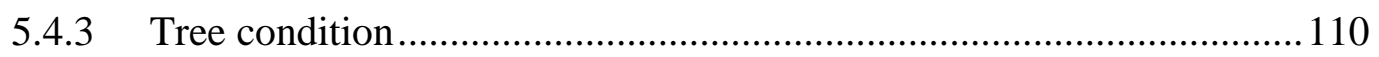

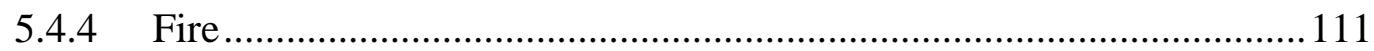

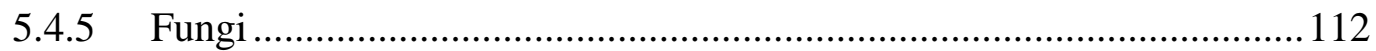

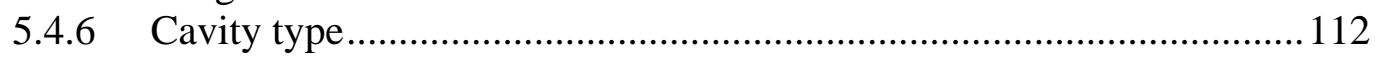

$5.5 \quad$ Nest Site selection of Individual Species............................................... 113

5.5.1 Nest site selection of PCN species.................................................... 113

5.5.2 Nest site selection of SCN species................................................... 115

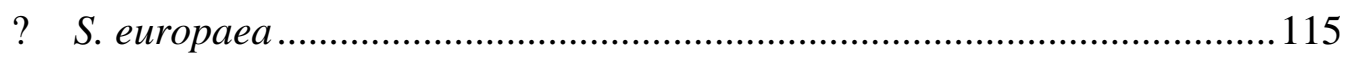

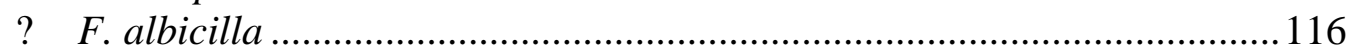

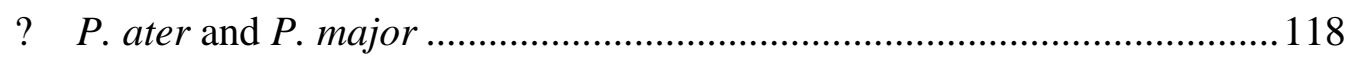

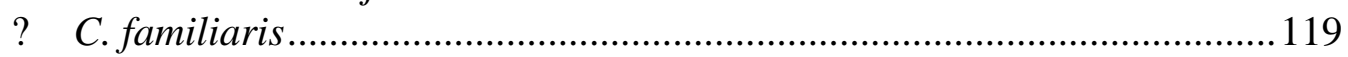

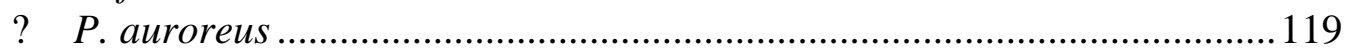

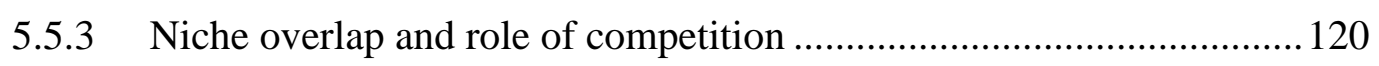

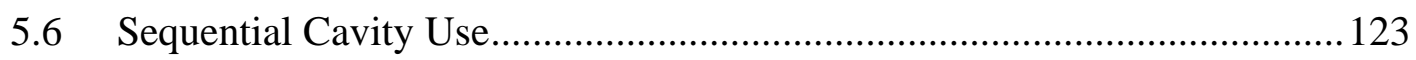

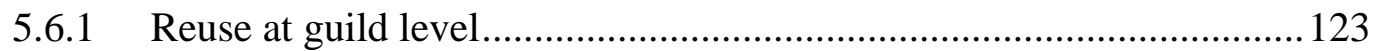

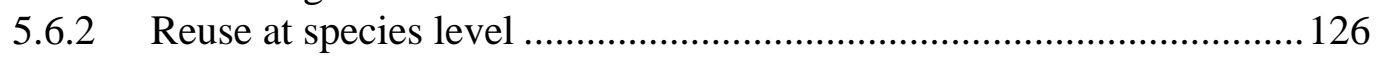

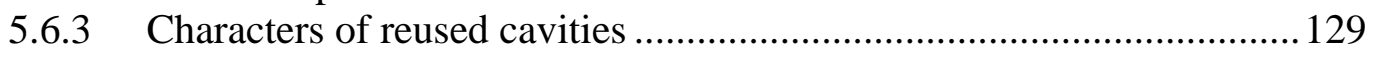

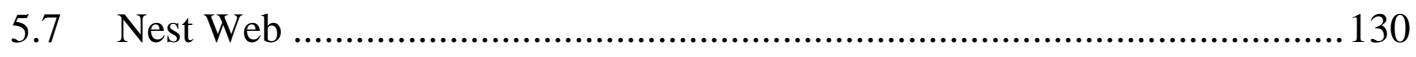


5.7.1 Structure of the nest web in West Khentey

5.7.2 The role of woodpeckers

5.7.3 The role of birch

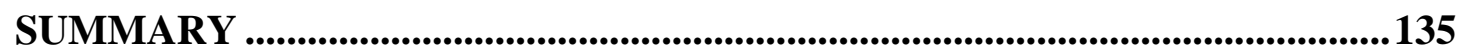

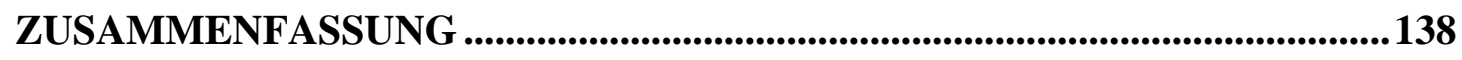

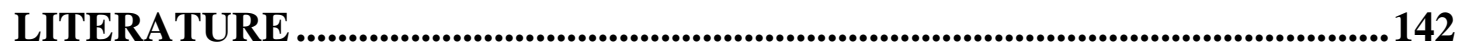

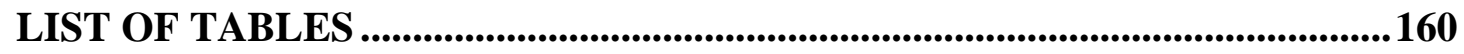

LIST OF FIGURES ................................................................................................162

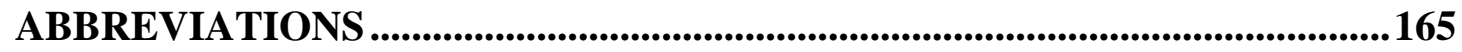

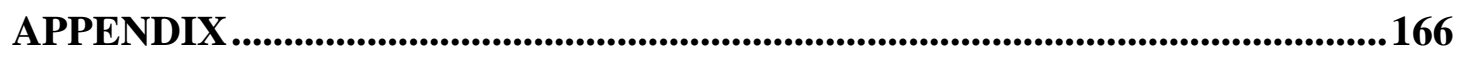

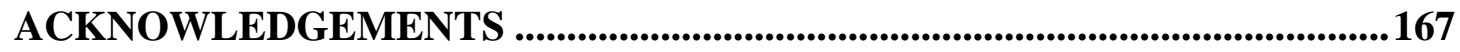




\section{INTRODUCTION}

\subsection{Roles of Cavity-Nesting Birds}

Cavity-nesting birds (CNBs) comprise a major component of many forest bird communities. In Europe and North America, $14 \%$ and $10 \%$ of the avifauna use tree cavities for breeding (NEWTON 1994). If confined to forest avifauna, CNBs generally constitute about $20-30 \%$ of breeding bird species in Palaearctic and Nearctic forests (VON HAartman 1957, MCClelland et al. 1979, GiBbs et al. 1993, MARTin et al. 2004).

Cavity-nesting species can be classified into different guilds according to their mode of cavity acquisition. Woodpeckers, or primary cavity nesters (PCNs), excavate cavities in trees for nesting and roosting. Secondary cavity nesters (SCNs) require cavities but cannot excavate by their own, and thus rely on the cavities constructed by excavators or formed through decay process. In recent years, some studies suggested the division of a third group, weak primary cavity nesters (WPCNs). These birds may excavate their own cavities in decayed trees, use naturally occurring ones, or use cavities from other species. Due to their potential flexibility, they may have different relationships with birds in other guilds, or show different response to the changing availability of nest site resources. Therefore some authors strongly suggested to consider them as a separate group when studing the structure within $\mathrm{CNB}$ communities (MARTIN \& EADIE 1999, MARTIN et al. 2004).

Great research efforts have been placed in the study of CNBs for the following reasons:

\section{- CNBs as interesting groups for comparative studies}

Due to their difference in nest site, CNBs and open-nesters may face different constraints, such as nest predation pressure, nest-site availability and microclimate of their nest sites (BRUSH 1983, BRAWN \& BALDA 1988, MARTIN \& GHALAMBOR 1999, SANIGA 2003). PCNs and SCNs may further differ from each other, as the former are less dependent on existing cavities and their nest site seems to be safer (LI \& MARTIN 1991). With that background many hypotheses were tested, e.g. for clutch size (VON HaARTMAn 1957, Slagsvold 1982, MARTin \& Li 1992, MARTin 1993, MARTin \& 
Clobert 1996), duration of incubation and nestling periods (MARTIN \& Li 1992, MARTIN \& CLOBERT 1996), egg colour (VON HAARTMAN 1957), sexual dimorphism (SigurjónsdótTir 1981, MARTin \& BADYAeV 1996, Figuerola \& GREen 2000), courtship and territory behaviour (VON HAARTMAN 1957), foraging behaviour (AlERSTAM \& HÖGSTEDT 1981, GREENWOOD 1985), incubation feeding (MARTIN \& GHALAMBOR 1999) and coloniality (EBERHARD 2002).

\section{- CNBs as biological indicators}

For their close association with trees and cavities, CNBs are one of the most sensitive groups to the alteration of forest structure (SCOTT \& OLDEMEYER 1983, IMBEAU et al. 1999, 2001). Thus they are suggested to be indicators suitable for detecting and monitoring impacts of forestry (WINKEL 1996, HAUSNER et al. 2003). Among them, the habitat requirements of woodpeckers have been most detailed studied. Many woodpecker species depend on certain tree resources, e.g. large trees, decayed trees or deciduous trees, which are often firstly removed in managed forests (WESOLOWSKI \& Tomialojc 1986, Aulén 1988, Blume 1990, Stenberg 1990, PechaceK 1995). Several species specialise on certain stages of succession, which are often eliminated due to human intervention in natural dynamics (JAMES et al. 1997, MiKUSINSKI 1997). Therefore woodpecker diversity or the occurrence of certain woodpecker species is considered as indicators of several forest qualities, such as tree species diversity, density of snags or stand age (ANGELSTAM 1990, WeISS 1990, MiKUSINSKI \& ANGElSTAM 1998, SCHERZINGER 1998, NILSSON et al. 2001, WÜBBENHORST \& SÜDBECK 2003, LAMMERTINK 2004). Woodpecker species richness is also suggested as an indicator of forest bird diversity (MIKUSINSKI et al. 2001).

\section{- The needs for conservation}

As another consequence of their sensitivity to forest structure alteration, modern forestry exerts great influence on CNBs. The plantation of conifers, fragmentation of landscape and installation of nest boxes do cause the expansion of some species which inhabit coniferous stands, prefer forest edges or are well adapted to nest boxes (VAN BALEN et al. 1982, Wesolowski \& TomialojC 1986, Mikusinski 1995). However, many CNB species decline in numbers or even go regionally extinct, as the result of lacking suitable nest sites, lacking suitable foraging substrates or increased 
competition with edge species (PETTERsson 1985, ReED 1990, HAVELKA \& RUGE 1993, WeSOLOWSKi 1995a, JeDicke 1997, MiKusinsKi \& ANGELSTAM 1997, WiKTANDER et al. 2001, KoENIG 2003). Such situation in Europe is profound due to long-term anthropogenic habitat change. At the continent scale, six out of ten European woodpecker species showed negative trends over the last decades (RUGE 1993, SAARI \& MiKUSINSKI 1996, MiKUSINSKI \& ANGELSTAM 1997). In Germany, 15 CNB species are placed in the Red List. In the forest bird community of Germany, about $29 \%$ of CNB species are placed in the Red List, while only $16 \%$ of open nesting species are in the list (BAUER et al. 2002).

\subsection{Present Studies about Cavity-Nesting Birds}

As the consequence of their importance in scientific study, conservation and management, CNBs have become one of the most intensively studied bird groups. However, our knowledge of them is still far from complete, and in some aspects even heavily biased, as data from natural cavities and natural forests are rare, quantitative information is usually incomplete, and the relationships among species are largely ignored.

\section{- Lack of studies with natural cavities}

So far most of our knowledge about CNBs is gathered from the studies of birds in nest boxes. Nest box studies of birds are very productive, because boxes can usually be designed to attract the desired species, and provide large samples of easily found nests in accessible and standardised sites. Moreover, the catch of individuals, the monitoring of breeding success and the manipulation of nest-site variables can be handled without difficulty. Therefore, since 1920s, the studies with nest boxes have become popular, especially in the managed forests of Europe (MøLLER 1989, NEWTON 1994, WESOLOWSKI \& STANSKA 2001). Not surprisingly, some box-nesting species, such as the Great Tit Parus major and the Pied Flycatcher Ficedula hypoleuca, are now some of the best-known birds in the world. The long-term data from nest boxes have further formed the basis for the development of many important ideas in several fields, such as population regulation, sexual selection, habitat selection, site fidelity and life history evolution (e.g. LACK 1966, MINOT 1981, 
AlATALO et al. 1986, GuSTAFSSON 1986, NuR 1986, KRIŠTín \& ŽILINEC 1997, TRIPET \& RICHNER 1997).

However, there are substantial differences between the characters of nest boxes and that of natural cavities. Nest boxes are usually designed to be safer from predation. The old nests in nest boxes are often artificially removed, which may influence parasite loads. The microclimate in the nest boxes may differ from that in natural cavities. Nest boxes tend to be uniform, with usually one variable of dimension or location experimentally manipulated each time. While natural cavities occur in diverse shape, dimension and location, and these properties are correlated. Furthermore, nest boxes usually cause higher density of specific host species population in the nest box area, which may influence the predation and parasitism patterns as well as behaviour of box users (VAN BALEN et al. 1982, NILSSON 1984a, GREENWOOD 1985, WESOLOWSKI et al. 1987, MøLLER 1989, WESOLOWSKI \& STANSKA 2001, MitrUS 2003). Recent comparative studies have found that laying date, clutch size, predation rate, main predator species, parasite loads, breeding success and population fluctuations differed between the nest box populations and those breeding in natural cavities (PURCELL et al. 1997, CZESZCZEWIK et al. 1999, WesolowsKi \& STANSKa 2001, Evans et al. 2002, CZESZCZEWIK 2004), and the response differed from species to species.

As nest boxes have not become widely available until several decades ago, some traits of the birds breeding in nest boxes may not yet be adaptive, and the sequential generalisations might be misleading. Though some CNB species may locally breed almost exclusively in nest boxes, the majority of the individuals of any species still breed in natural cavities. Thus the observations of box-breeding populations may not represent the species properly (WESOLOWSKI \& STANSKA 2001). Therefore studies of CNBs breeding in natural cavities are highly in need (VAN BALEN et al. 1982, WESOLOWSKI 1989)

\section{- Lack of studies in natural forests}

As the importance of the studies with natural cavities is gradually being concerned, most of the studies were carried out in managed woodlands, especially in Europe (WESOLOWSKI 1989). In managed forests, several important factors may be totally 
different to the primeval conditions. Managed forests usually have impoverished snag density and cavity abundance (MORIARTY \& MCCOMB 1983, ZEEDYK 1983, NEWTON 1994, GRAVES et al. 2000). Predator abundance and potential predator species also differ between managed forests and natural ones. Even in unmanaged forest fragments surrounded by modified landscape, forest edge species usually dominate CNB communities (VAN BALEN et al. 1982, JOHNSSON et al. 1993), and the extent and the pattern of predation may differ from that under natural conditions (SANDSTRÖM 1991, WALANKIEWICZ 2002a, WeSOLOWSKI 2002). Actually, to what extent and in which direction does the situation in managed forests differ from that in pristine conditions are still largely unknown, as there is too few information available about the CNBs breeding in the primeval habitats (WESOLOWSKI 1989).

As species were evolved in and adapted to natural habitats, evolutionary interpretations should be preceded by observations in natural habitats (CZESZCZEWIK $\&$ WALANKIEWICZ 2003). From the viewpoint of conservation, with the emergence of the idea of ecological forestry since 1990s, the goal of forest management is aimed towards a "near-nature" system (HANSEN et al. 1991, FUJIMORI 2001). However, this could not be achieved without knowledge of natural conditions. Thus there is an increasing and urgent need of understanding biodiversity and its maintenance in natural forests, so that such knowledge can be incorporated into management guidelines.

In boreal forests, one further point addresses the importance of studying CNBs in natural forests. Boreal forests have been a dynamic system in the past due to fire. Due to their close association with forest structure, $\mathrm{CNBs}$ as a group is highly sensitive to post-fire succession (MURPHY \& LEHNHAUSEN 1998, SAAB \& DUDLEY 1998, IMBEAU et al. 1999, SAAB et al. 2004). However, large areas of boreal forests are no longer dynamic in natural process. Fire suppression is conducted in managed forests as well as most of the protected areas in Europe and North America (ChAndler et al. 1983, GoldAMmer \& FuryaeV 1996, MCRAE \& Lynham 2000, GRANSTROM 2001). In Fennoscandia, for example, it is nearly impossible to find sufficient successional stages for ecological study (HELLE \& NIEMI 1996). Information from forests not only of natural structure but also under natural processes is necessary to evaluate the consequence of human intervention in natural dynamics. 


\section{- Lack of quantitative habitat survey}

A further flaw in the studies of CNB nest-site selection is that most studies did not quantitatively survey the forest structure and cavity availability (e.g. MCCLELLAND et al. 1979, WesOlOWSKI \& TOMIALOJC 1986, WesOlOWSKI 1989, JOHNSSON et al. 1993, MeYer \& MEYER 2001, WieSNER 2001, GiBbOnS et al. 2002). The availability of suitable trees for nest excavation and the availability of suitable nesting cavities have often been suggested as the factor limiting the population of several PCN and SCN species, respectively (GuSTAFSSON 1986, AULÉN 1988, HÅLAND \& UGELVIK 1990, Pogue \& Schnell 1994, Poysa \& Poysa 2002). But this point was often assumed instead of proved. Data on availability of nest substrates or nest cavities were largely lacking.

The information on forest structure and cavity availability according to different tree attributes is also essential to demonstrate the preference of birds. The observed pattern of PCN species frequently using certain trees might be due to the abundance of such trees in the habitat. As cavities occurrence highly dependant on tree species, age and decay condition (VAN BALEN et al. 1982, NOEKE 1990), the observed tree utilisation pattern of SCN species is further confounded by the availability of cavities. Without taking the entire resource availability into account, the selection or preference cannot be properly clarified. This is especially important in the natural forests, as trees and cavities are present in diverse forms, and many attributes are correlated. Yet nest-site selection studies with consideration on resource availability were few (SANDSTRÖM 1992, WALANKIEWICZ 1991).

\section{- Lack of information at the community level}

Though the nest-site selection of CNBs has been intensively investigated, most studies focused only on single species (e.g. Korol \& HUTTO 1984, Dow \& FREDGA 1985, Muldal et al. 1985, Belthoff \& Ritchison 1990, RudolPH \& CONNER 1991, Daily 1993, SMith 1997, Rolstad et al. 2000, Mitrus \& Socko 2004). These efforts resulted in detailed information valuable for setting up individual conservation guidelines. However, analyses of nest-site use at the community level were few, and interspecific relationships were largely ignored (MARTIN \& EADIE 1999, BEDNARZ et al. 2004). Some studies filled the gap by surveying the nest sites of several sympatric 
PCNs or SCNs, which provided the information to investigate the relative preference of each species, extent of niche overlap and the potential for competition (e.g. VAN BAlen et al. 1982, StAufFer \& Best 1982, Peterson \& GAUTHIER 1985, WESOLOWSKI 1989, CARLSON et al. 1998). While CNBs were composed of PCNs and SCNs, which have different constraints but are intimately related, an overall consideration is critical for demonstrating ecological links among species and drawing up comprehensive conservation plans.

Some recent trends of studying CNBs within broader ecological context include studies of sequential cavity use and nest web analysis. Patterns of cavity reuse are central to understand the population ecology and evolution of cavity nesting birds (SEDGWICK 1997). Yet studies on cavity reuse were mostly focused on the reuse tendency of certain species (e.g. BARCLAY 1988, MAZGAJSKI 2003, STANBACK \& ROCKWELL 2003), or the sequential use of specific woodpecker holes (e.g. KÜHLKE 1985, JoHnSSON et al. 1993, BONAR 2000, MEYER \& MEYER 2001, WIESNER 2001, KotAKa \& MATSUOKA 2002). Only since SEDGWICK (1997) has the reuse pattern of the whole CNB community been concerned. Nest web is a newly emerged approach in structuring CNB communities analogous to food webs (MARTIN \& EADIE 1999). It reveals direct and indirect interactions among species and may predict the response of the community to perturbations or change. Yet so far only the nest web of British Columbia has been worked out (MARTIN \& EADIE 1999, AITKEN et al. 2002)

\subsection{Objectives of this Study}

The objectives of this study were:

- to investigate cavity abundance in different types of natural boreal forest,

- to identify the characteristics of cavity trees,

- to survey CNB composition in different types of natural boreal forest,

- to observe the characteristics of trees and cavities utilised by CNBs,

- to study the nest-site selection of individual species,

- to investigate the pattern of sequential cavity use, and

- to construct the nest web for the CNB community. 


\section{STUDY AREA}

\subsection{Natural Environment of Mongolia}

\subsubsection{Geographic location and landform}

Bordering the Russian Federation in the north and the People's Republic of China in the east, south and west, Mongolia is a landlocked country which covers an area of 1.56 million $\mathrm{km}^{2}$. It extends $1236 \mathrm{~km}$ from north to south, stretches $2405 \mathrm{~km}$ from east to west, and is the seventh largest country in Asia (MNE et al. 1998).

Mongolia is a typical highland (Fig. 2.1). About $85 \%$ of its territory is situated higher than $1000 \mathrm{~m}$, and the average elevation is $1580 \mathrm{~m}$ above sea level. The relief is characterised by a highly wavy plateau which is crossed by the Altai mountains in the west and the Khangai-Khentey mountain area in the north. The rivers originating from the northern slopes of the Khangai-Khentey mountains flow into the Arctic Ocean. The area east of the Khentey mountains belongs to the drainage basin of the Pacific Ocean. The central and southern parts of the country have few rivers and other water resources, and they usually situated in depressions without any outflow, forming part of inland drainage of Central Asia (MNE et al. 1998).

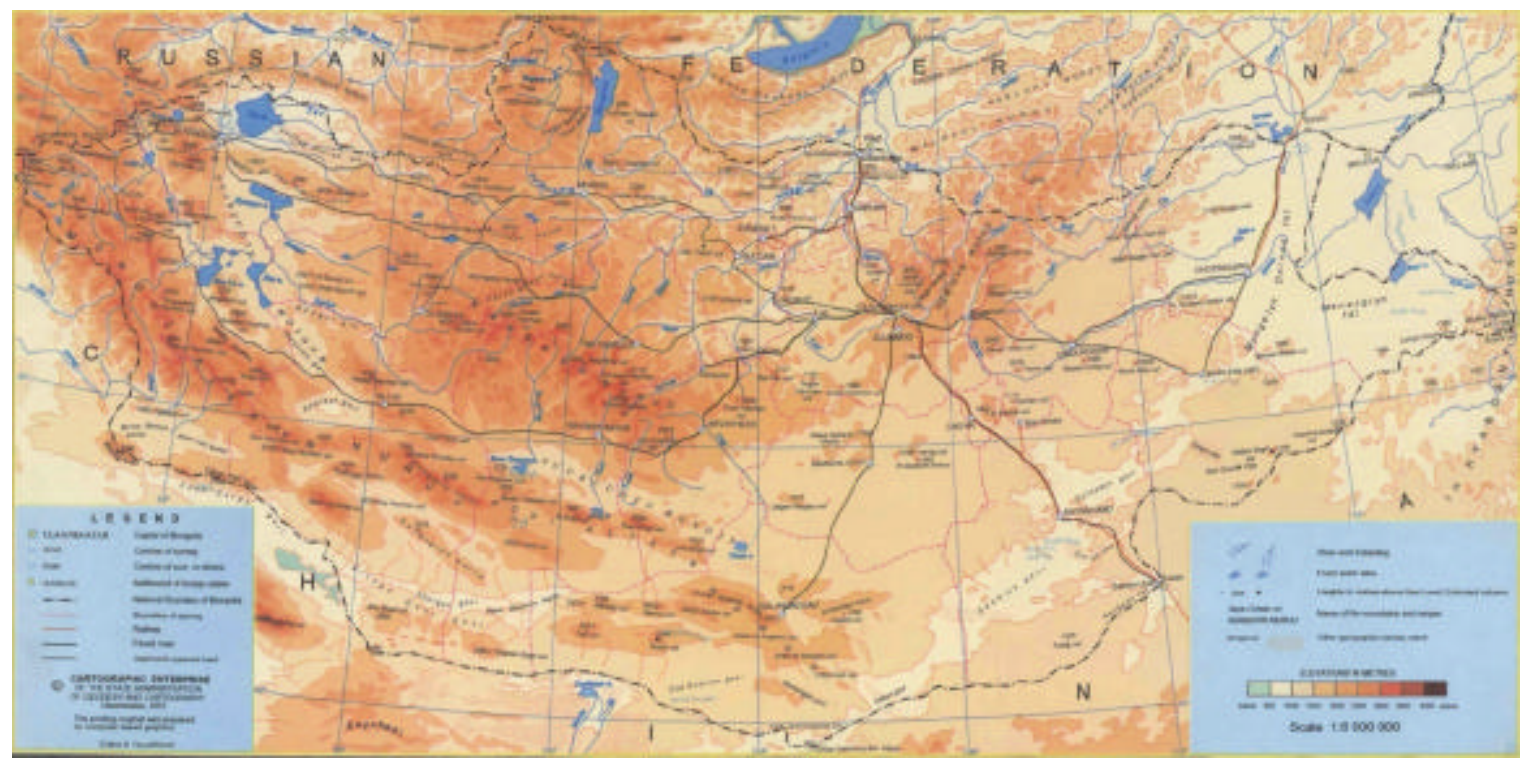

Fig. 2.1 Physical map of Mongolia (OYUnKHAND 2001). 


\subsubsection{Climate}

The main characteristics of Mongolia's harsh continental weather are long and cold winter, low precipitation and great annual and diurnal fluctuations in temperature. The mean temperature in January is -20 to $-35^{\circ} \mathrm{C}$, but the extreme temperature ever recorded reaches $-58^{\circ} \mathrm{C}$. In July, the mean temperature ranges between $15^{\circ} \mathrm{C}$ in the mountains and 20 to $30^{\circ} \mathrm{C}$ in the south, while the extreme temperature higher than $40^{\circ} \mathrm{C}$ has been recorded (MNE et al. 1998).

The annual precipitation averages approximately $400 \mathrm{~mm}$ in the northern mountainous region and decreases to less than $100 \mathrm{~mm}$ in the south. 75 to 85 percent of the precipitation falls in the three summer months (MNE et al. 1996, 1998).

\subsubsection{Vegetation zones}

Mongolia can be divided into six basic vegetation zones: alpine, mountain taiga, mountain forest steppe, arid steppe, desert-steppe and desert (Fig. 2.2). These zones differ in their flora, fauna and soil quality, which are adapted to the geographic and climatic conditions (LAVRENKO 1979; MNE et al. 1996, 1998).

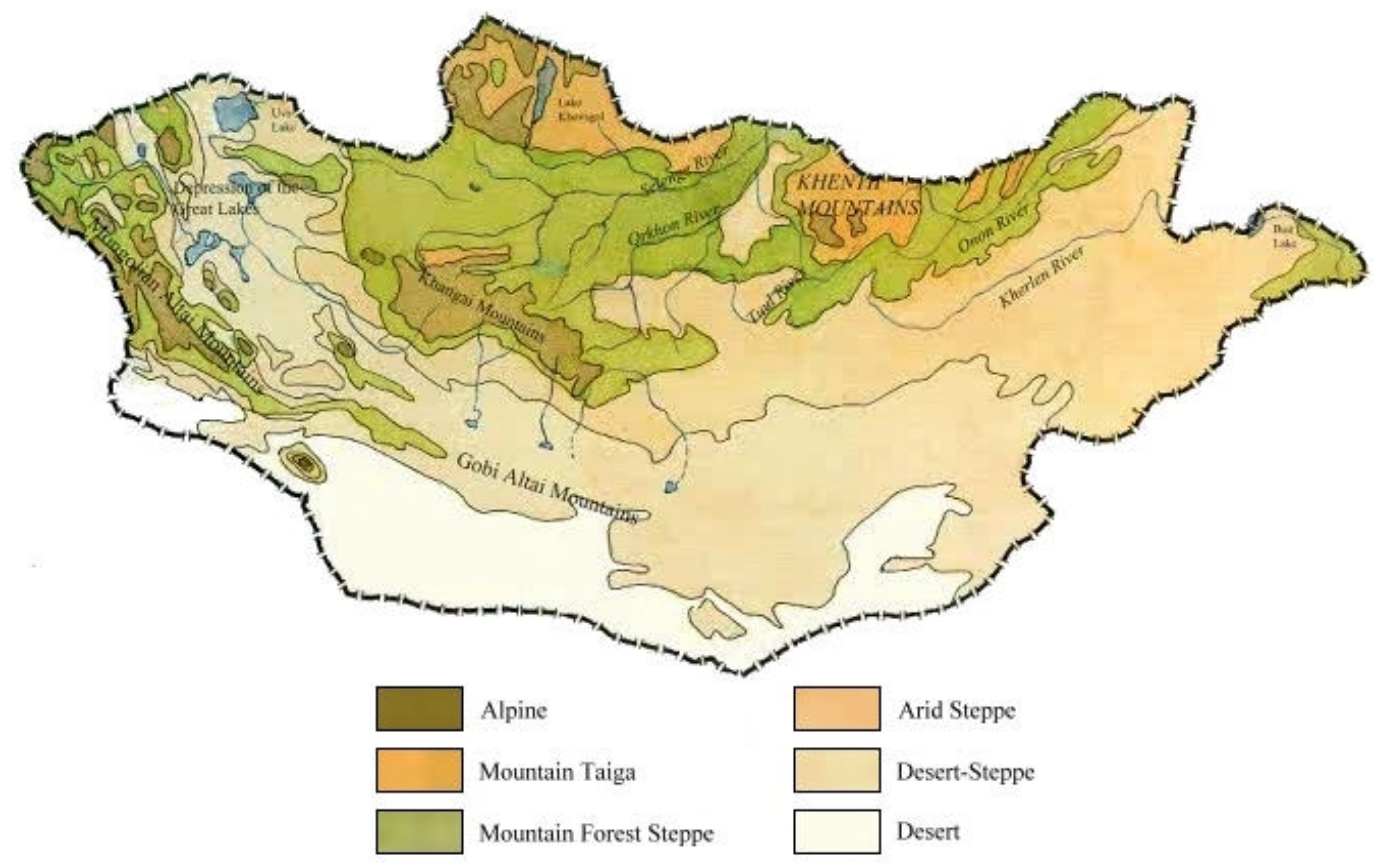

Fig. 2.2 The vegetation zones of Mongolia (MNE et al. 1996). 
The alpine zone rises above the tree line in the Altai, Khangai and Khentey mountains. It is characterised by tundra, alpine-sedge meadows and highland swamps. The mountain taiga zone of Mongolia is the southern edge of the Siberian taiga, the largest continuous forest system in the world. The forests in this zone consist mainly of Siberian pine Pinus sibirica and Siberian larch Larix sibirica, and hold a relatively rich flora and fauna. The mountain forest steppe zone is the ecotone of Siberian taiga and Central Asian steppe. The taiga tree species distribute over the northern slopes, while the steppe vegetation occupies the southern slopes. This zone covers about $26 \%$ of Mongolia's area. The arid steppe zone is characterised by flat plains and rolling hills covered in feather grass and shrubs. The vegetation in desert-steppe zone is dominated by low grasses and semi-shrubs. In the desert zone, the extreme climate hinders the growth of plants. Most parts consist of bare sandy plains and rocky mountains (MNE 1996).

\subsection{The Khan Khentey Strictly Protected Area}

\subsubsection{Geographic location, topography and hydrology}

The Khan Khentey Strictly Protected Area (KKSPA), situated in the northeast of Mongolia, was founded in 1992 (Fig. 2.3). This huge uninhabited area, stretching from the Russian border to the northeast of Ulaanbaatar, lies between $48^{\circ} \mathrm{N}$ and $49^{\circ} \mathrm{N}$ and extends from $107^{\circ} \mathrm{E}$ to $110^{\circ} \mathrm{E}$. It covers 1.2 million ha and is the fourth largest protected area in Mongolia (MYAGMARSUREN 2000). Compared with the protected boreal ecosystems in Europe, it is as large as the complete protected forests of Fennoscandia (VON VELSEN-ZERWECK 2002). Under the cooperation of the Göttingen University and the Ulaanbaatar University, in 1999 the research station Khonin Nuga was established by the side of the Eröö river in the western buffer zone of the KKSPA (Fig. 2.3).

The KKSPA comprises the rugged Khentey mountains, a northeast-southwest branch of Transbaikal mountain range. The terrain undulates from around $900 \mathrm{~m}$ at the river valleys to almost $2800 \mathrm{~m}$ at the highest peak (MNE \& WWF 1994). As the region where the watersheds of the Arctic Ocean and the Pacific Ocean intersect, it plays important hydrological roles. In the western part of the area, the rivers Eröö, Minsh 


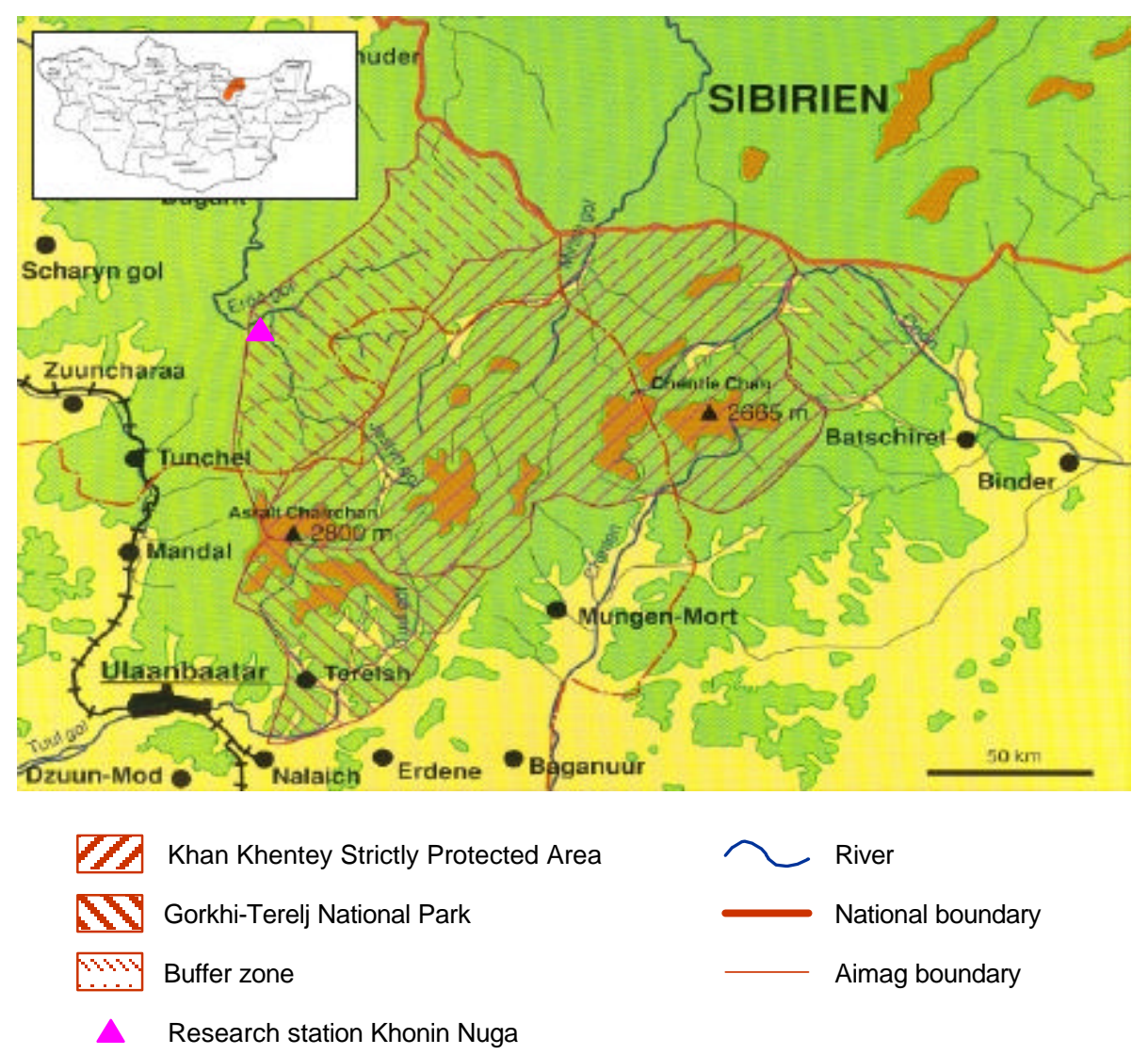

Fig. 2.3 The location of Khan Khentey Strictly Protected Area and research station Khonin Nuga (after MNE \& WWF 1994).

and Tuul originate. These rivers form the headwaters of the Selenge river, which is the major inflow of the Baikal Lake. Thus the KKSPA is interlinked with the largest and oldest freshwater lake on earth (MüHLENBERG et al. 2001). In the eastern part, the rivers Onon and Cherlen run eastwards through the eastern steppes of Mongolia, then pour into the Amur river, which flows into the Pacific Ocean. Therefore the KKSPA is crucial in nourishing the large area of Mongolia's eastern steppes with precious water resource (VON VELSEN-ZERWECK 2002).

\subsubsection{Climate}

Situated more than $1400 \mathrm{~km}$ away from the closest ocean, the climate of the Khentey mountains is strongly continental. Under the influence of the Siberian high pressure, the winter is cold, clear and dry with little snowfall. In summer, the warm air from Central Asia meets the cold air of the north, and the precipitation increases. Thus the climate of the KKSPA is characterised by moderate, humid, short summer and cold, 
dry, long winter. The mean temperature in July is about $12^{\circ} \mathrm{C}$. In January, the mean temperature averages $-24^{\circ} \mathrm{C}$, but can drop to the extreme of $-45^{\circ} \mathrm{C}$. The annual precipitation reaches $400-500 \mathrm{~mm}$ in the higher zone, which is one of the precipitation-richest areas in Mongolia. $80 \%$ of the precipitation falls in July and August (DöLLE et al. 2002).

The local climate varies greatly according to elevation and aspect. Temperature drops and precipitation rises with increasing altitude. The northern slopes are the windward side in the region, while the southern slopes expose to the sun. Therefore the northern slopes are cooler and have relatively higher precipitation. These variations shape the characteristic mosaic of vegetation cover (DULAMSUREN 2004).

\subsubsection{Vegetation types}

The KKSPA defines the southern edge of Siberian taiga and is the transition zone where the vast Siberian taiga meets the broad Central Asian steppe. This region belongs predominantly to the mountain taiga zone, with the mountain forest steppe in the south and the alpine zone at the high peaks (LAVRENKO 1979).

The mountain taiga zone surrounding Khonin Nuga is classified into three groups: the upper mountain level at the elevation 1200-1600 m, the lower mountain level at 900$1300 \mathrm{~m}$ and the riparian vegetation at the riverside (DULAMSUREN 2004). The upper mountain level is covered by dark mountain taiga mainly dominated by Siberian pine. In the lower mountain level, forests cover only the northern slopes, while shrubs or herbs occupy the drier southern slopes. In more shaded and humid stands with fertile soil, the forests of the northern slopes is dark mountain taiga dominated by Siberian spruce Picea obovata and Siberian fir Abies sibirica. The most widespread forest type is, however, light subtaiga, consisting mainly of whitespire birch Betula platyphylla and Siberian larch Larix sibirica. The riparian vegetation appears in diverse forms, including riparian forests, bushes and riverine meadows. The riparian forest is dominated by birch, spruce, Scots pine Pinus sylvestris, laurel poplar Populus laurifolia or willow Salix spp. depending on soil conditions (DöLLE et al. 2002, DULAMSUREN 2004). 


\subsubsection{Bird community}

In the whole Khentey mountains, 253 bird species have been recorded, among which 180 species breed in the area (BOLD 1984). 185 species of 38 families have been registered around Khonin Nuga, with 137 species as breeding birds (WICHMANN \& POKROVSKAYA 2004). The high number of breeding species is contributed by the high habitat diversity and naturalness (WICHMANN 2001).

The biogeographic component of breeding bird community is primarily Palaearctic $(45 \%)$. The rests are composed mainly of Holarctic (17\%), Central-and-East Asian (14\%) and Southeast Asian (14\%) species. Main bird species in the open area are Black-faced Bunting Emberiza spodocephala, Yellow-breasted Bunting E. aureola, Dusky Warbler Phylloscopus fuscatus, Common Rosefinch Carpodacus erythrinus and Daurian Redstart Phoenicurus auroreus. Dominant species in the most prevalent forest type, the birch-larch forest, are Willow Tit Parus montanus, Nuthatch Sitta europaea, Red-throated Flycatcher Ficedula albicilla, P. auroreus, Olive-backed Pipit Anthus hodgsoni and Pallas's Warbler Phylloscopus proregulus (WICHMANN 2001).

\subsection{Study Stands}

Considering the representative forest types and their accessibility, the field work was carried out in four different forest stands, including two birch-larch forests of different successional stages, the riparian mixed forest and the spruce-fir coniferous forest (Fig. 2.4). The former three stands are situated close to the research station Khonin Nuga, while the coniferous stand is located about $20 \mathrm{~km}$ southeast from the others, because around the Khonin Nuga the birch-larch forests cover most of the area.

\subsubsection{Mature birch-larch forest (BLm; Fig. 2.5(a)):}

This deciduous stand lies on a gentle northern slope. The surveyed area covered about 52 ha, and the elevation ranges from 950 to $1100 \mathrm{~m}$. Canopy is dominated by birch with scattered emergent larch trees. Aspen is patchily abundant.

The ground cover is characterised by rich and diverse herbs. The main species include brome Bromopsis pumpellianus, sedge Carex amgunensis, dwarf iris Iris ruthenica and vetchling Lathyrus humilis. 


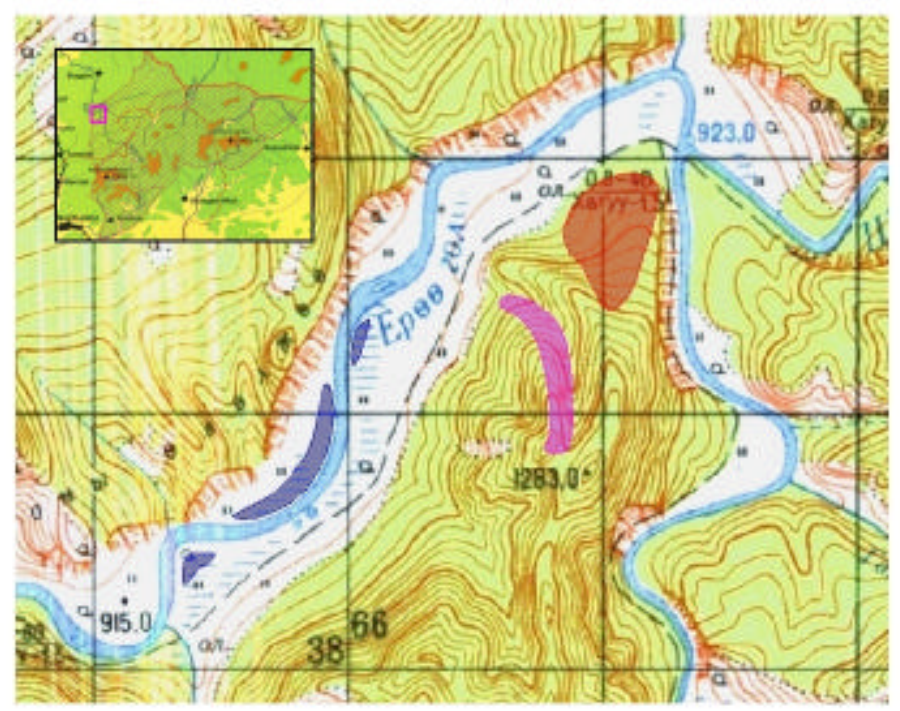

Mature birch-larch forest Young birch-larch forest Riparian mixed forest

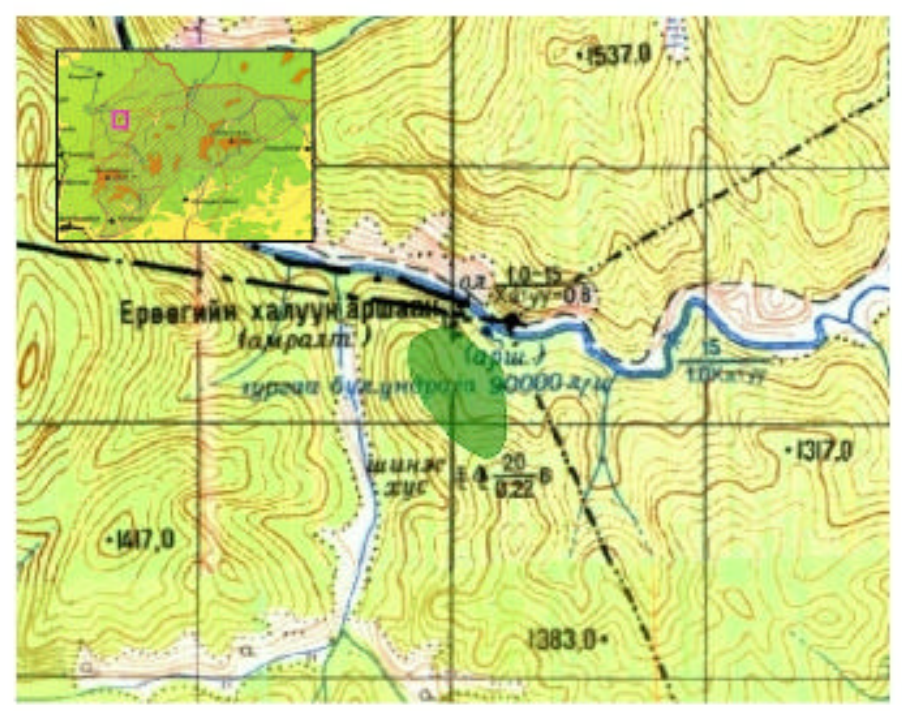

Spruce-fir forest
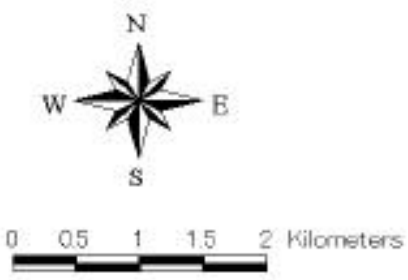

Fig. 2.4 The location of study stands.

\subsubsection{Young birch-larch forest after recent fire (Bly; Fig. 2.5(b)):}

This stands is located on a steep northeastern slope with an area of approximately 25 ha. The elevation ranges between 1000 and $1250 \mathrm{~m}$. The dominance of birch is similar to that in the previous habitat, but is composed of thinner and closely spaced stems. Larch scatters among the birch, large Scots pine patchily dominates the upper part of eastern slope, and aspen forms small and disperse patches.

This stand is characterised by obvious signs of fire. Over $95 \%$ of all living stems, even the young ones, were scarred by fire. The impact of fire is spatially 
heterogeneous: in some patches and along the ridge, most of the trees were killed and canopy is open; while close to the valley, the fire progressed in the form of surface fire, keeping most trees alive with fire scars at the bottom. Density of standing dead trees is high.

The composition of ground cover is similar to that in the previous habitat. In patches where the canopy is open, shrubs such as Dauricum rhododendron Rhododendron dauricum and prickly rose Rosa acicularis form dense clumps.

\subsubsection{Riparian mixed forest (RM; Fig. 2.5(c)):}

This habitat forms thin belts on the alluvial side of rivers. The surveyed area included three blocks, with a total area of 23 ha. The relief is rather flat, and the elevation lies at about $920 \mathrm{~m}$. Tree species composition and forest structure are diverse. Birch, poplar and Scots pine dominate different patches, while willow, larch and spruce are also patchily frequent.

Shrub layer is well developed in the riparian mixed forest. The main species include redhaw hawthorn Crataegus sanguinea, bird cherry Padus asiatica, bush cinquefoil Potentilla fruticosa, red currant Ribes rubrum and bridewort Spiraea salicifolia.

\subsubsection{Spruce-fir coniferous forest (SF; Fig. 2.5(d)):}

This coniferous stand is situated on a moderate northeastern slope. The surveyed area covered approximately 53 ha. The dominant tree species is spruce. Fir, Siberian pine, birch and old larch are scattered, and Scots pine occupies upper slopes. Deadfalls (dead wood on the ground) are abundant.

Moss forms the characteristic ground layer in this habitat. Typical species include bog groove-moss Aulacomnium palustre, tree-moss Climacium dendroides, crisped fork-moss Dicranum bonjeanii and spiky bog-moss Sphagnum squarrosum. 
(a)

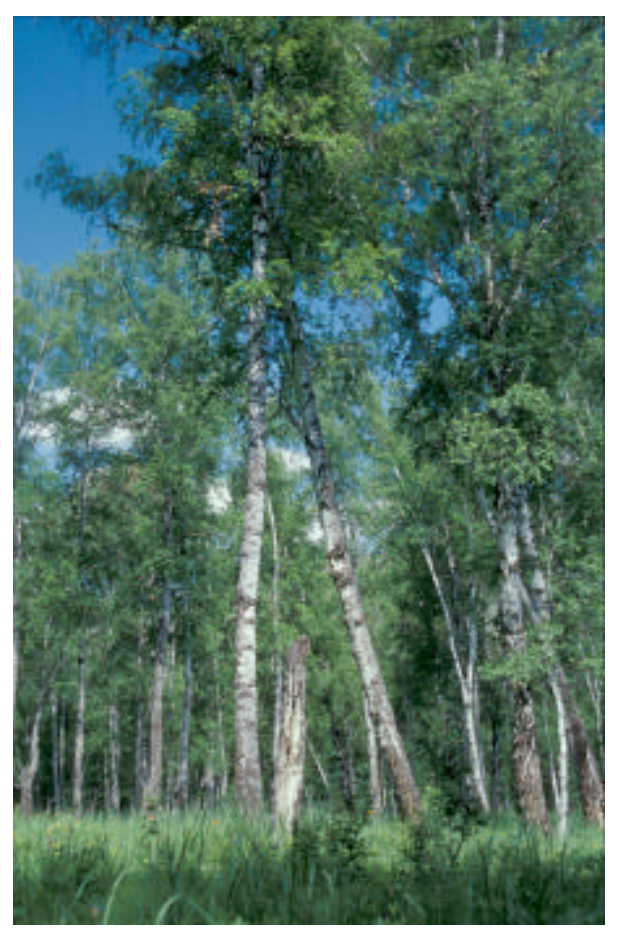

(c)

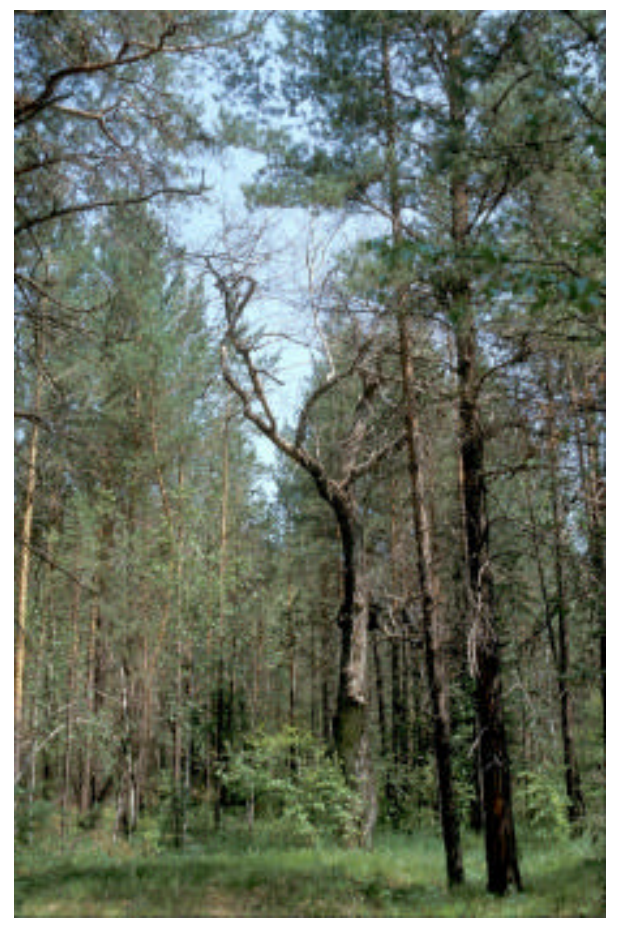

(b)

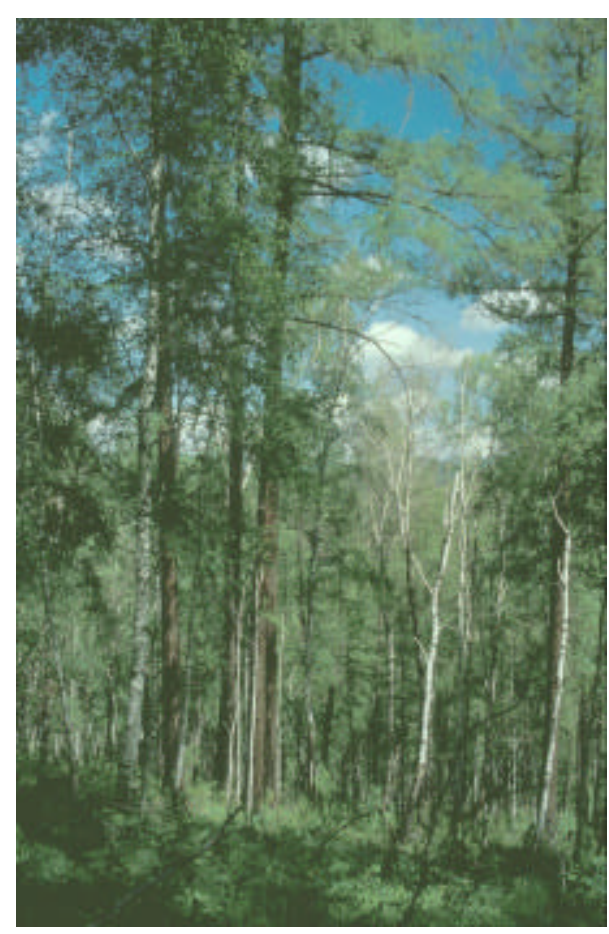

(d)

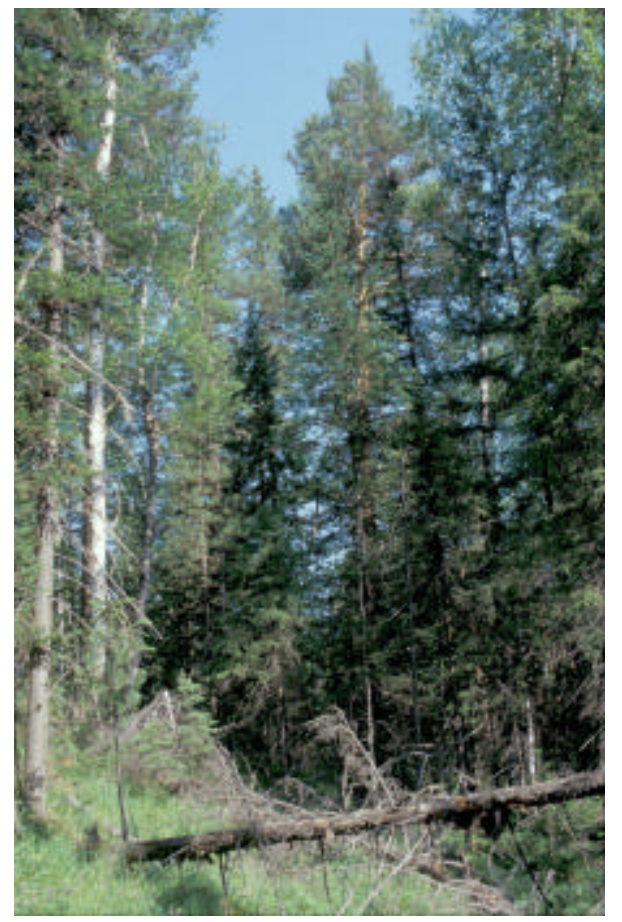

Fig. 2.5 The study stands (a) the mature birch-larch forest, (b) the young birch-larch forest, (c) the riparian mixed forest, and (d) the spruce-fir coniferous forest. 


\section{METHODS}

\subsection{Field Work}

\subsubsection{Habitat measurement}

In each of the four habitats, five 1 ha plots $(50 \times 200 \mathrm{~m})$ were established for detailed study and quantitative comparison among habitats. The plots were orientated so that the distance between neighbouring plots was at least $100 \mathrm{~m}$. Each plot was marked at intervals of $25 \mathrm{~m}$ along the boundary and the long axis, in order to help locating individual trees and mapping the territories of birds.

In each plot, two points on the long axis, each of which lied $50 \mathrm{~m}$ apart from one end, were taken for carrying out habitat measurements. Elevation, slope, topographic position, canopy height, shrub coverage, amount of lying dead wood were registered at each sampling point (see Table 3.1 for description). Standing stems (diameter at breast height $(\mathrm{DBH}) \geq 5 \mathrm{~cm})$ were sampled by the plotless method with the help of a dendrometer (GROSENBAUGH 1952). This method was adopted instead of the fixedarea plot sampling, because the probability a tree being sampled is proportional to its DBH in the former method. Therefore it is more efficient in collecting the information of large trees, especially in heterogeneous natural forests where the occurrence of a tree is usually negatively correlated to its DBH. The data at each sample point can be transformed into per unit area based information without bias (AкÇA 2000). For each sampled tree, the following items were recorded:

(1) tree species;

(2) $\mathrm{DBH}$, registered in $5 \mathrm{~cm}$ rank;

(3) tree condition, categorised as 1 . healthy living tree, 2. living tree, in state of decline, 3. dead tree, branches intact, 4. dead tree, few or no branches, 5. dead tree, broken top, 6. dead tree, shortened snag (Fig. 3.1; after MASER et al. 1988, GunN and HaGan 2000);

(4) if the tree had fire scars; and

(5) if the tree carried fruit bodies of fungi.

These single-tree measurements were then sorted into forest structure variables of each sampling point as listed in Table 3.1. 
Table 3.1 The habitat variables recorded in each sampling point.

\begin{tabular}{ll}
\hline Variable & Definition \\
\hline Elevation & Measured with a GPS $(\mathrm{m})$ \\
Slope & Measured with a clinometer (degree) \\
Topographic position & Assigned to one of the five levels: 1: ridge, 2: upper slope, 3: middle slope, 4: \\
& lower slope, 5: flat plain \\
Canopy height & Measured with a dendrometer $(\mathrm{m})$ \\
Shrub coverage & Percentage of shrub (height $=50 \mathrm{~cm})$-covered area in a circle of 10 m radius \\
& $(\%)$ \\
Lying dead wood & Number of woody debris $($ diameter $=15 \mathrm{~cm})$ in a circle of 10 m radius \\
Stem density & Number of standing stems pro hectare $(\mathrm{n} / \mathrm{ha})$ \\
Prop. decid. & Percentage of deciduous stems $(\%)$ \\
Prop. large & Percentage of trees with DBH $=40 \mathrm{~cm}(\%)$ \\
Prop. dead & Percentage of dead trees $($ tree condition category = 3) $(\%)$ \\
Prop. fire & Percentage of stems with fire scars $(\%)$ \\
Prop. fungi & Percentage of stems with fungi conk $(\%)$ \\
Birch & Basal area of birch $\left(\mathrm{m}^{2} / \mathrm{ha}\right)$ \\
Aspen & Basal area of aspen $\left(\mathrm{m}^{2} / \mathrm{ha}\right)$ \\
Poplar & Basal area of poplar $\left(\mathrm{m}^{2} / \mathrm{ha}\right)$ \\
Willow & Basal area of willow $\left(\mathrm{m}^{2} / \mathrm{ha}\right)$ \\
Rowan & Basal area of rowan $\left(\mathrm{m}^{2} / \mathrm{ha}\right)$ \\
Larch & Basal area of larch $\left(\mathrm{m}^{2} / \mathrm{ha}\right)$ \\
Scots pine & Basal area of Scots pine $\left(\mathrm{m}^{2} / \mathrm{ha}\right)$ \\
Siberian pine & Basal area of Siberian pine $\left(\mathrm{m}^{2} / \mathrm{ha}\right)$ \\
Fir & Basal area of fir $\left(\mathrm{m}^{2} / \mathrm{ha}^{2}\right)$ \\
Spruce & Basal area of spruce $\left(\mathrm{m}^{2} / \mathrm{ha}\right)$ \\
\hline &
\end{tabular}

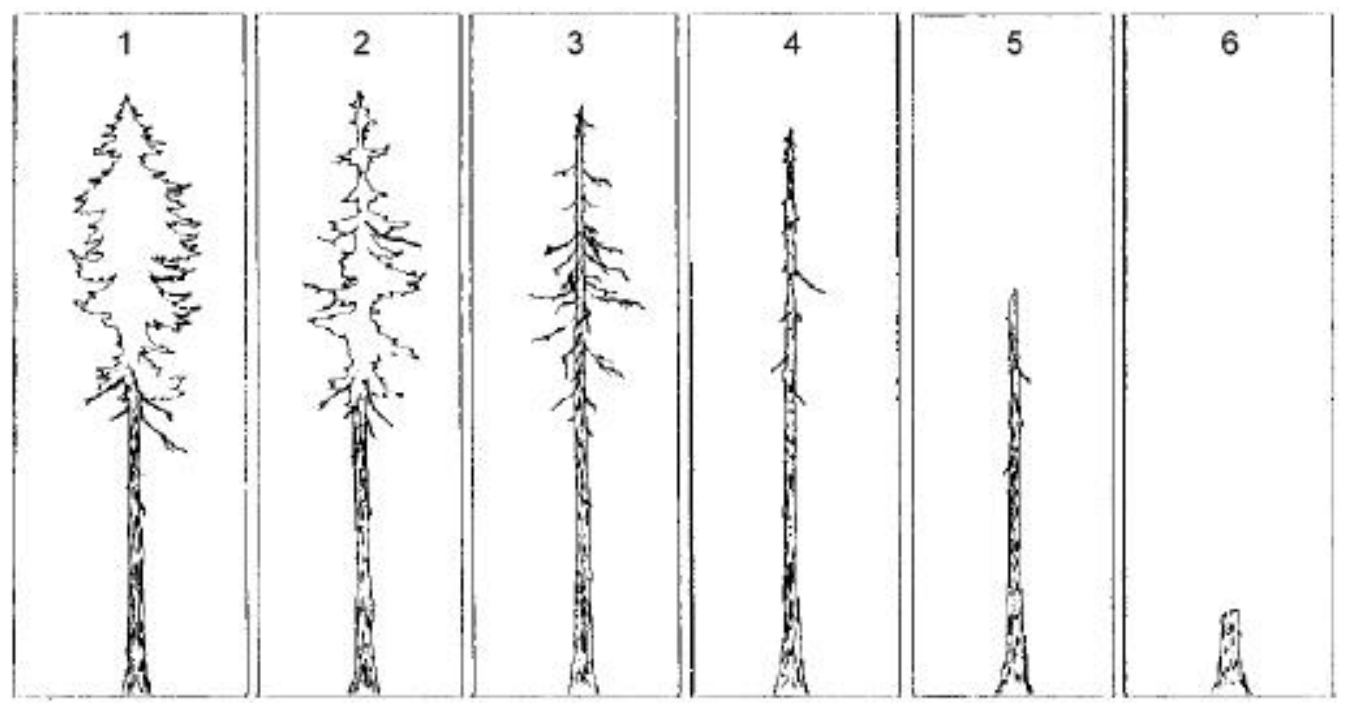

Fig. 3.1 Tree condition: 1 . healthy living tree, 2. living tree, in state of decline, 3. dead tree, branches intact, 4 . dead tree, few or no branches, 5. dead tree, broken top, 6. dead tree, shortened snag (after MASER et al. 1988, GUNN and HAGAN 2000). 


\subsubsection{Cavity search}

Each standing stem sampled in habitat measurement was searched for cavities in autumn 2002, when deciduous trees had lost their leaves. Cavities were located by examining from the ground with the help of a binocular, and each tree was observed from at least three directions. Trees with cavities found were referred as cavity trees.

Cavities were classified into one of the following types (after CARLSON et al. 1998):

(1) Woodpecker hole (Fig. 3.2(a)): excavated by woodpeckers for nesting or roosting. In the study area, this might be constructed by the Black Woodpecker Dryocopus martius, the Grey-headed Woodpecker Picus canus, the Great Spotted Woodpecker Dendrocopos major, the White-backed Woodpecker D. leucotos, the Lesser Spotted Woodpecker D. minor or the Three-toed Woodpecker Picoides tridactylus.

(2) Other bird-induced hole (Fig. 3.2(b)): including all other excavated cavities that were apparently not the nesting or roosting holes of woodpeckers. This category included cavities excavated by the Willow Tit Parus montanus for nesting and cavities of any origin but followed by the destruction of woodpeckers.

(3) Branch hole (Fig. 3.2(c)): originating from a fallen limb and showing no signs of processing by birds.

(4) Bark crevice (Fig. 3.2(d)): formed under loose bark.

The former two types were referred as excavated cavity, and the others as nonexcavated cavity. The excavating species, including six woodpecker species and $P$. montanus, were referred as primary cavity nesters (PCNs). The other non-excavating species were referred as secondary cavity nesters (SCNs). In the analysis of sequential cavity use (Section 4.7) and nest web (Section 4.8), P. montanus, which could either excavate by itself or use existing cavities, was referred separately as weak primary cavity nester (WPCN). 
(a)

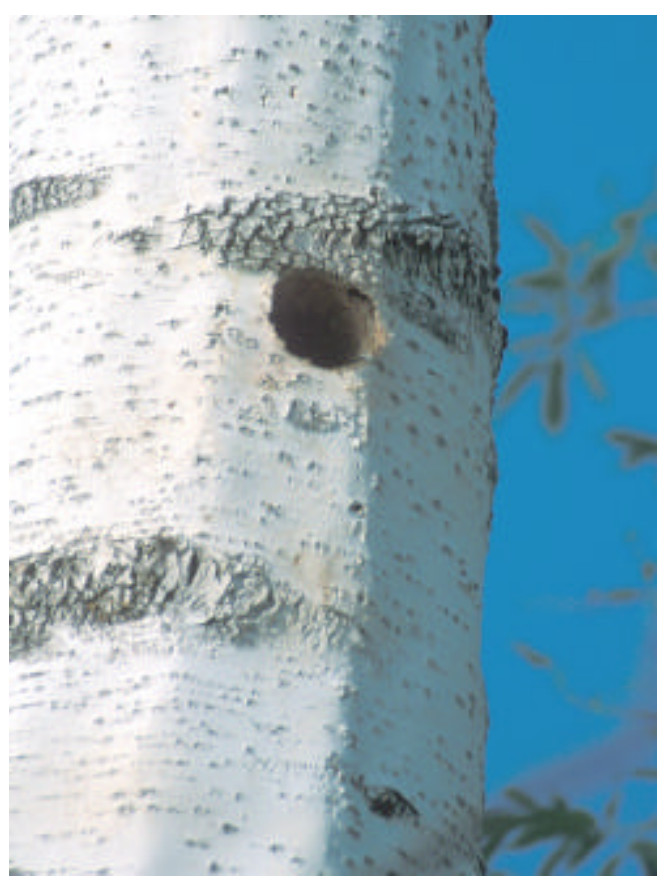

(c)

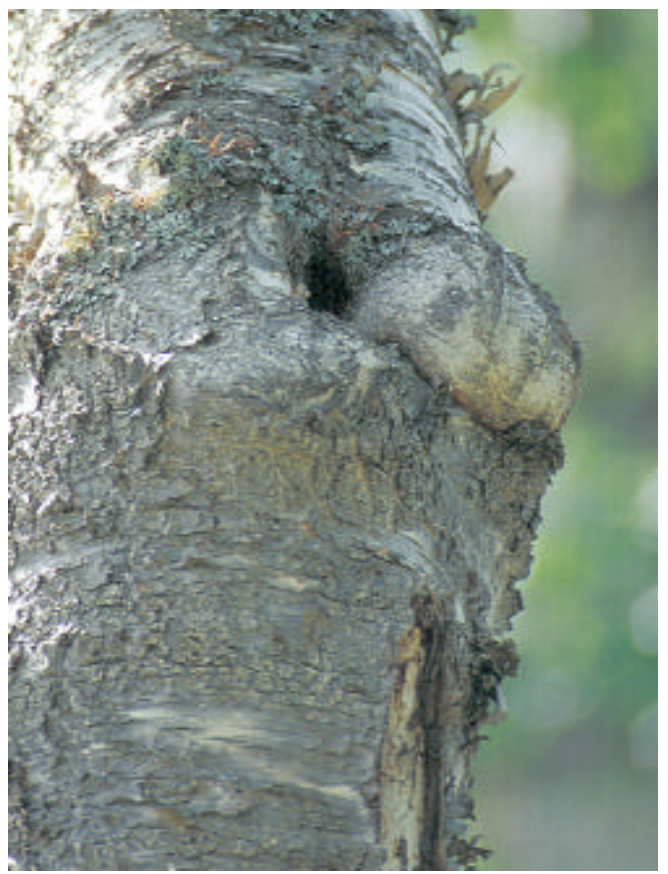

(b)

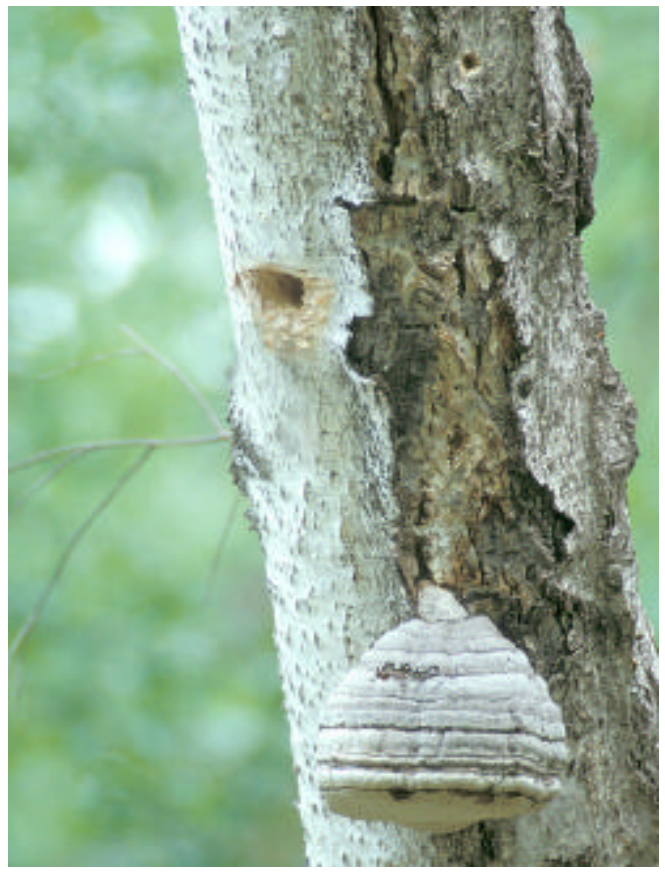

(d)

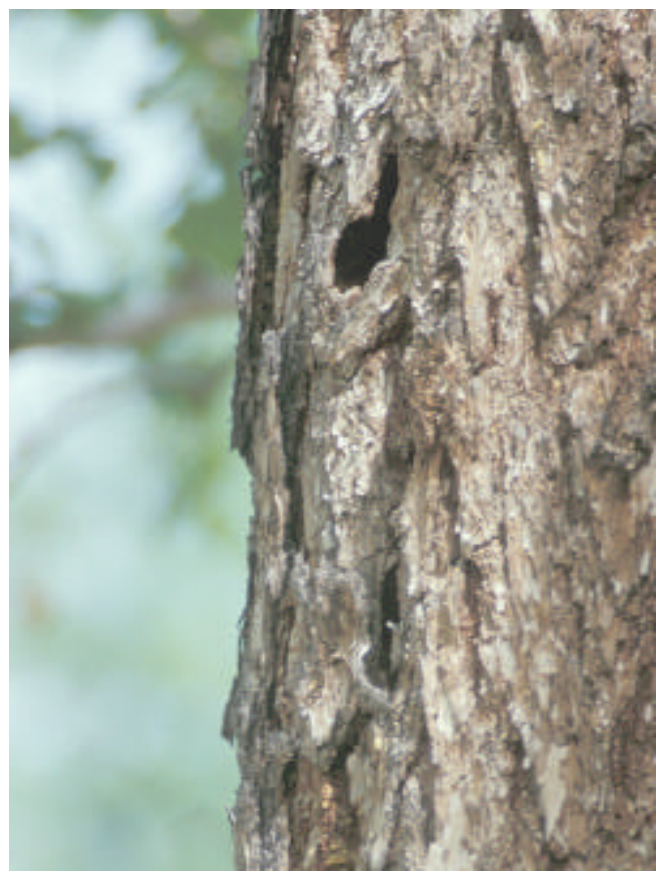

Fig. 3.2 Different cavity types: (a) woodpecker hole, (b) other bird-induced hole, (c) branch hole and (d) bark crevice. 


\subsubsection{Nest cavity search and measurement}

Nests of all cavity-nesting bird (CNB) species were searched from the last week of April to the first week of July in 2002 and 2003. Given the northern latitude, harsh winter and late-coming spring of the study area, most resident and migratory CNBs did not begin nesting until the first week of May (WICHMANN, pers. com.). This was in correspondence to the phenology of CNBs in the boreal forests of Fennoscandia (CARLSON et al. 1998) and Canada (MARTIN et al. 2004).

Nests were located by observing breeding behaviour, listening for excavating PCNs or begging chicks and scratching or knocking cavity trees. A nest cavity was defined when an adult bird was observed bringing in nesting material or food. For species such as D. martius, P. canus and the Wryneck Jynx torquilla, of which the food carriage could hardly be observed, frequently entering a cavity was taken as the evidence of an active nest. As for ducks such as B. clangula, of which the youngs fledge soon after hatched, the female entering a cavity in the daytime was regarded as the presence of a nest. The observations of birds displaying or defending a cavity were not considered as signs of cavity occupancy (WESOLOWSKI 1989, MARTIN \& EADIE 1999, BONAR 2000). In the quantitative plots, nest search was confirmed with territory mapping, in order to locate all the nest cavities in the plots. Nest cavities found outside the plots were recorded as well. A tree with a nest cavity was referred as the nest tree, and the part of trunk or branch in which the nest cavity was located was referred as the substrate.

For each nest, variables were recorded according to three different scales (GIBBONS et al. 2002):

(1) Habitat variables: the same procedure as taking habitat measurement was carried out, but using the nest tree as the centre point instead (POGUE \& SCHNELL 1994, MARTIN \& EADIE 1999). Elevation, slope, topographic position, canopy height, shrub coverage, amount of lying dead wood and composition of surrounding standing stems were registered (see Section 3.1.1).

(2) Nest tree variables: tree species, tree DBH (in $\mathrm{cm}$ ), tree condition (as defined in Section 3.1.1), the presence of fire scars and fruit bodies of fungi were recorded; 
(3) Nest cavity variables: including cavity type, cavity height above ground, substrate diameter, substrate condition (categorised as living or dead), cavity opening length and cavity opening width.

The types of nest cavities were categorised into woodpecker hole, other bird-induced hole, branch hole and others. The former four types followed the definition as described above, while the last category "others" covered all other less common nest sites, which encountered in this study included bark crevices, hollows on broken top (chimneys), holes originated from side fire and vertical slits in trunk due to the shear force when the snag broke.

The cavity height was measured from the ground to the middle of the cavity opening with a dendrometer. The substrate diameter, cavity opening length and cavity opening width were estimated from ground using the size of adult birds as a reference (PETERS \& GRUBB 1983). The ratio of opening length to opening width was calculated as an index of opening shape. The opening shape of a cavity was termed "slit-like" when the ratio was larger than 1.25 , "flat" when the ratio was smaller than 0.8 , and "round" for an intermediate value.

The distance and direction to the next plot mark of each nest tree were recorded. Together with the tree and cavity variables recorded, all nest cavities could be relocated (SEDGWICK 1997). The nest cavities found in 2002 were checked in 2003, and the utilisation of each was recorded as occupied, unoccupied or unusable. Unusable cavities included those that had destructed walls or those that were lost due to the collapse of the tree or limb containing the cavity (SEDGWICK 1997). The nest cavities located outside the plots were revisited less often, thus a nest which failed in the early stage of breeding might not be observed. 


\subsection{Statistical Analysis}

\subsubsection{Habitat structure}

Kruskal-Wallis test was used to compare habitat variables among four habitats (ZAR 1999). When the among-habitat difference of a variable was found (significance level 0.05), Mann-Whitney U test was further applied for pairwise comparison.

A habitat could be viewed as a complex of all the interlinked variables, which were individually measured (Pogue \& SCHNELl 1994, ROTENBERRY \& WIENS 1998, MCGARIGAL et al. 2000). Thus the principal component analysis (PCA) was applied to the correlation matrix of 22 habitat variables (Table 3.1), for summarising the variations of these variables. The major trends of variation were represented in the first few principal components. These principal components could be interpreted by their component loadings. Each of the 20 plots was then projected onto the main components according to its component score. Such a graphic could represent the ecological relationship among habitats and indicate the important dimensions of available habitat space (ROTENBERRY \& WIENS 1998).

\subsubsection{Cavity abundance}

To compare the density of different cavity types and the cavity density in different habitats, Kruskal-Wallis test (for number of groups > 2) and Mann-Whitney U test (for number of groups =2) were applied.

The relationship between cavity abundance and habitat variables was checked with correlation analysis (SANDSTRÖM 1992). Pearson correlation coefficients between the density of each cavity type and habitat variables were calculated. Bonferroni probability was used to test the null hypothesis of zero correlation.

Cavity density was also correlated with major principal components from the PCA of habitat structure. Cavity density of each plot was projected onto the main components, for representing the variation of cavity abundance across major environmental gradients. 


\subsubsection{Cavity occurrence and tree characters}

While the previous section was to exam cavity occurrence at habitat level, here the cavity occurrence according to five tree-level variables: tree species, tree $\mathrm{DBH}$, tree condition, the presence of fire scars and the presence of fungi conks was examined.

The distribution of cavities across each tree variable was compared to the distribution of all sampled stems across the same variable with chi-square test (ZAR 1999). If significant difference was found (significance level 0.05) and the variable had more than two classes, further comparisons were conducted with one class versus other classes pooled, for identifying whether the class was disproportionately rich or poor in cavities. Two classes were compared pairwise when the difference of cavity occurrence between specified classes was interested. Comparisons were also conducted between excavated cavities and non-excavated cavities. In all above comparisons, Yates corrected chi-square test was applied when a $2 \times 2$ table was encountered.

Cavity holding rate was defined as the percentage of stems with cavities, which was calculated by the number of cavity-holding stems divided by the number of total stems. This was different from the number of cavities divided by the number of stems, since one stem might hold more than one cavity.

Tree DBH was grouped into five classes in the analysis, i.e. $<15 \mathrm{~cm}, 15-30 \mathrm{~cm}, 30-$ $45 \mathrm{~cm}, 45-60 \mathrm{~cm}$ and $>60 \mathrm{~cm}$. Tree condition was treated as six classes (Fig. 3.1) in the overall analysis. When examining the interactions between variables, tree condition was further pooled into three classes: living tree (classes 1 and 2 in Fig. 3.1), dead tree with intact top (class 3 and 4) and dead tree with broken top (class 5 and 6), to avoid too small sample size in each class.

After considering the five tree variables separately, stepwise logistic regression was applied to model the probability of cavity occurrence in a tree (JOBSON 1992). Whether the tree was deciduous (binary variable), tree DBH (in 5 ranks), tree condition (in 3 ranks), the presence of fire scars (binary variable), the presence of fungi conks (binary variable) and the habitat where the tree stood (as 3 dummy 
variables), were used as independent variables. Backward stepwise selection was used to select the variables (significance level 0.05).

\subsubsection{Composition of CNB community}

Density of CNBs was compared between habitats with Mann-Whitney U test. To compare the species composition in different habitats, Sorensen's similarity coefficient were applied (KREBS 1989):

$$
S_{s}=\frac{2 c}{a+b}
$$

where $S_{s}=$ Sorensen's similarity coefficient

$a=$ number of species in habitat $\mathrm{A}$

$b=$ number of species in habitat $\mathrm{B}$

$c=$ number of species in habitat $\mathrm{A}$ and $\mathrm{B}$ (joint occurrences)

Correlation analysis was than applied between CNB density and habitat variables, habitat principal components and cavity density. CNB density was then projected onto the main components to investigate the variation of CNB density across major environmental gradients.

The species abundance distribution of the CNB community was compared with lognormal and logseries model with chi-square goodness of fit test (MAGURRAN 1988). Comparisons of species abundance pattern with other studies were also conducted, including the CNB communities in natural forests, in managed woodlands and the CNBs nesting in nest boxes.

\subsubsection{Utilisation of trees and cavities by CNBs}

In this section, CNBs were considered as a whole instead of individual species. The main purpose was to determine to which extent the trees and cavities were utilised by CNBs, and whether the utilisation was related to tree variables (tree species, tree $\mathrm{DBH}$, tree condition, presence of fire scars and fungi conks) and cavity type.

Data from different habitats were pooled. Only the nests located in plots were included in the analysis, so that nest data from each habitat had the same contribution 
and could be compared with the pooled tree measurements. The difference between years was firstly examined. Since the utilisation pattern of each variable did not differ between years, data for both years were pooled. Utilisation patterns of PCNs and SCNs were also compared, and they were treated separately if there was a significant difference.

For each variable, the distribution of nests was compared with the distribution of all sampled stems. When significant difference arose for a variable of more than two classes, comparison of one class versus other classes pooled was conducted to find out whether the class was utilised overproportionally or underproportionally. The distribution of SCN nests was further compared with the distribution of cavities across the same variable to test whether cavities were selected according to the variable concerned. Chi-square test was used in all above comparisons, and Yates correction was applied when a $2 \times 2$ table was encountered.

\subsubsection{Nest site selection of individual species}

Both nests located inside and outside the plots were used in this part of analysis. Bird species of sample size less than 10 were excluded. Thus only 9 species were studied, including 3 PCNs (D. major, D. minor and P. montanus) and 6 SCNs (the Daurian Redstart Phoenicurus auroreus, the Red-throated Flycatcher Ficedula albicilla, the Coal Tit Parus ater, the Great Tit P. major, the Nuthatch Sitta europaea and the Treecreeper Certhia familiaris).

For each tree and cavity variable, comparison were conducted between bird species to reveal their relative preference. For the variables tree species, tree $\mathrm{DBH}$, tree condition and cavity type, of which the availability were known, the utilisation pattern of each bird species was also contrasted with the availability to investigate the real selection. However, for variables such as tree species, which differed greatly among habitats, comparison could not be made directly, since this would be largely influenced by the number of nests found in each habitat.

For continuous variables, Mann-Whitney U test was applied to compare between species, and F test was applied to compare the variance, which indicated the niche 
breadth. For categorical variables, chi-square test was used. Niche breadth was measured by Levins' index (KREBS 1989):

$$
B=\frac{1}{\sum^{n} p_{i}^{2}}
$$

where $B=$ Levins' measure of niche breadth

$p_{i}=$ proportion of individuals found in or using resource state $i$

$n=$ total number of resource states

The range of Levins' $\mathrm{B}$ is between 1 and $\mathrm{n}$. Minimum occurs when all individuals use only one resource state, and maximum occurs when the same numbers of individuals are found in each resource state.

Niche overlap was indicated by the Renkonen index of percentage similarity (KREBS 1989):

$$
P_{j k}=\left[\sum^{n} \min \left(p_{i j}, p_{j k}\right)\right] \times 100
$$

where $P_{j k}=$ percentage overlap between species $j$ and $k$

$p_{i j}, p_{i k}=$ proportions resource state $i$ is of the total resources used by species $j$ and species $k$

$n \quad=$ total number of resource states

ABRAMS (1980) recommended the Renkonen index of percentage similarity as the best measure of niche overlap. One strength of this index is that it is not sensitive to how one divides up the resource states, since human observers may recognise resource categories different from that animals or plants do.

After checking each variable separately, a cluster analysis was applied to summarise the overall similarity of nest sites among species (JOBSON 1992). Tree species (as 5 dummy variables), tree $\mathrm{DBH}$, tree condition (in 3 ranks), cavity type (as 3 dummy variables), cavity height above ground, substrate diameter, substrate condition (binary variable), cavity opening length and cavity opening width were used to calculate the nest site similarity between species. 
A discriminant function analysis was then performed based on these 15 variables (JOBSON 1992). Backward selection was used to select the variables which maximised separation among bird species. The reclassification matrix from discriminant functions could imply the extent of niche overlap between species.

\subsubsection{Sequential cavity use}

This part of analysis was based on all the nests found in 2002. Beside overall reuse rate, proportion of reuse by the same species (constancy) and reuse by different species (usability) were considered (SEDGWICK 1997). The reuse pattern was compared at both guild level (between PCN, WPCN and SCN) and at species level with chi-square test.

All tree and cavity variables of reused cavities were compared with that of cavities which were not reused. Continuous variables were compared with Mann-Whitney U test, and categorical variables with chi-square test. Logistic regression with backward stepwise selection was than applied to determine which variables could best predict the reuse of cavities.

\subsubsection{Nest web analysis}

While the previous section was a time sequence observation of interspecific links from cavity suppliers' side, the nest web analysis was a snap shot approach from cavity demanders' view. All the nests found in both years were used in the analysis.

Actors in the nest web included all CNB species as well as trees and cavities which were utilised by CNBs (MARTIN \& EADIE 1999, MARTIN et al. 2004). Tree species formed the fundamental level in the nest web. PCNs and non-excavated cavities constituted the second level. A PCN species was linked to a tree species if it excavated in the tree. The strength of the linkage was indicated by the proportion of nests of this PCN species excavated in this tree species. Non-excavated cavities were also linked to tree species depended on the proportion of cavities located in each tree species. SCNs represented the third level in the nest web. A SCN species was linked to a PCN species if it utilised the cavity created by the PCN, or linked to nonexcavated cavities if it nested in them. The strength of linkage was also decided by 
the percentage of nest use. However, when a SCN was found nesting in a middlesized woodpecker hole, in most of the cases the excavator species could not be confirmed. Thus middle-sized woodpeckers were grouped when linked with SCNs. WPCNs stood at an intermediate level between PCNs and SCNs. They might be linked to a tree species when they excavated in the tree by their own, or be linked to a PCN species or to non-excavated cavities, when they nested in the cavity created by the PCN in non-excavated cavities, respectively.

The nest web was than applied to test the roles of woodpeckers and some tree species in the CNB community. 


\section{RESULTS}

\subsection{Habitat Structure}

The mature birch-larch forest (BLm) contained 724 stems/ha (Table 4.1). About 68\% was deciduous trees composed of birch, and the remaining 32\% was larch. Aspen, Scots pine and few young spruce also occurred in this habitat, but was not included in the sample due to the limited sample size. Of all the standing stems, 5\% were large trees of DBH $>40 \mathrm{~cm}, 3 \%$ were dead, and about $31 \%$ showed signs of past fire.

The young birch-larch forest (BLy) had 725 stems/ha (Table 4.1). Birch (70\%) and aspen (1\%) comprised the deciduous part, and the remainders were larch (23\%) and Scots pine (6\%). Only about $2 \%$ of the trees had DBH $>40 \mathrm{~cm}$, which were mainly old larches and Scots pines surviving the past fires. This habitat contained highest proportions of standing dead stems (35\%; Kruskal-Wallis, $\mathrm{H}=10.04$, df $=3, \mathrm{p}<0.05)$ and fire-scarred trees (96\%; Kruskal-Wallis, $\mathrm{H}=14.61$, $\mathrm{df}=3, \mathrm{p}<0.01)$.

The tree density in the riparian mixed forest (RM) was 591 stems/ha (Table 4.1). Tree composition in descending order of stem number was birch (55\%), Scots pine (23\%), poplar (8\%), spruce (7\%), willow $(6 \%)$ and larch (1\%). But when considering the basal area, Scots pine $\left(5.8 \mathrm{~m}^{2} / \mathrm{ha}\right)$, birch $\left(5.1 \mathrm{~m}^{2} / \mathrm{ha}\right)$ and poplar $\left(4.5 \mathrm{~m}^{2} / \mathrm{ha}\right)$ formed codominance. $6 \%$ of the standing stems were large trees, $9 \%$ were dead, and $21 \%$ were scarred by fire. Shrub coverage in this habitat (46\%) was the highest (Kruskal-Wallis, $H=10.72, \mathrm{df}=3, \mathrm{p}<0.05)$.

The spruce-fir forest (SF) contained $1560 \mathrm{stems} / \mathrm{ha}$, denser than other habitats (Table 4.1; Kruskal-Wallis, $\mathrm{H}=8.15, \mathrm{df}=3, \mathrm{p}<0.05$ ). The proportion of deciduous trees (13\%) was the lowest (Kruskal-Wallis, $\mathrm{H}=9.63$, $\mathrm{df}=3, \mathrm{p}<0.05$ ), and was comprised exclusively of birch. The coniferous part was made up of spruce (39\%), fir (25\%), Siberian pine (17\%), Scots pine (4\%) and larch (2\%). About $2 \%$ of the standing stems were large trees, and 14\% were dead. Signs of past fire were inconspicuous in this habitat, with only about $4 \%$ of the stems showing fire scars (Kruskal-Wallis, $\mathrm{H}=$ 14.61, $\mathrm{df}=3, \mathrm{p}<0.01)$. 
Table 4.1 Stem density (DBH > $5 \mathrm{~cm}$ ), proportion of deciduous stems (= Prop. decid.), proportion of large trees (= Prop. large), proportion of dead trees (= Prop. dead), proportion of trees with fire scars (= Prop. fire) and shrub coverage in each habitat.

\begin{tabular}{lcccccc}
\hline Habitat & $\begin{array}{c}\text { Stem density* } \\
(/ \mathrm{ha})\end{array}$ & $\begin{array}{c}\text { Prop. } \\
\text { decid. }^{*}(\%)\end{array}$ & $\begin{array}{c}\text { Prop. large } \\
(\%)\end{array}$ & $\begin{array}{c}\text { Prop. dead* } \\
(\%)\end{array}$ & $\begin{array}{c}\text { Prop. fire } \\
(\%)\end{array}$ & $\begin{array}{c}\text { Shrub }^{* *} \\
\text { coverage* }^{*}(\%)\end{array}$ \\
\hline BLm & 724.5 & 67.8 & 5.5 & 2.9 & 31.2 & 6.9 \\
BLy & 725.3 & 71.0 & 1.9 & 35.4 & 95.5 & 10.0 \\
RM & 590.7 & 68.8 & 6.5 & 8.9 & 20.7 & 45.6 \\
SF & 1560.2 & 12.9 & 2.5 & 14.4 & 4.0 & 13.1 \\
\hline Grand mean & 900.2 & 56.2 & 4.1 & 15.4 & 37.8 & 18.9 \\
\hline
\end{tabular}

Kruskal-Wallis test, $* \mathrm{p}<0.05, * * \mathrm{p}<0.01$.

Table 4.2 Results of principal component analysis based on 22 habitat variables.

\begin{tabular}{|c|c|c|c|c|c|c|}
\hline & \multicolumn{6}{|c|}{ Component } \\
\hline & 1 & 2 & 3 & 4 & 5 & 6 \\
\hline Eigenvalue & 6.74 & 4.83 & 2.17 & 2.07 & 1.64 & 1.12 \\
\hline$\%$ of total variance & 30.62 & 21.96 & 9.86 & 9.39 & 7.45 & 5.09 \\
\hline Cumulative variance & 30.62 & 52.58 & 62.44 & 71.83 & 79.28 & 84.37 \\
\hline \multicolumn{7}{|l|}{ Component loadings } \\
\hline Elevation & $0.908^{* *}$ & 0.177 & 0.210 & 0.170 & 0.017 & 0.059 \\
\hline Slope & $0.853^{\star *}$ & -0.392 & 0.107 & 0.189 & -0.050 & -0.019 \\
\hline Topographic position & $-0.944^{* *}$ & 0.097 & 0.125 & 0.053 & 0.013 & -0.043 \\
\hline Canopy height & $0.596^{\star}$ & 0.323 & 0.479 & -0.073 & -0.286 & 0.234 \\
\hline Shrub coverage & $-0.767^{* *}$ & 0.219 & 0.042 & 0.397 & 0.141 & 0.301 \\
\hline Lying dead wood & 0.473 & 0.306 & -0.275 & $0.675^{\star}$ & -0.195 & 0.114 \\
\hline Stem density & 0.535 & $0.605^{\star}$ & -0.005 & -0.294 & 0.411 & 0.036 \\
\hline Prop. decid. & $-0.572^{*}$ & $-0.625^{\star}$ & -0.214 & 0.121 & -0.060 & 0.075 \\
\hline Prop. large & -0.539 & -0.110 & -0.067 & 0.130 & $-0.651^{*}$ & -0.010 \\
\hline Prop. dead & 0.351 & -0.412 & 0.141 & $0.624^{*}$ & 0.382 & -0.197 \\
\hline Prop. fire & 0.193 & $-0.868^{\star *}$ & 0.108 & 0.197 & 0.006 & -0.145 \\
\hline Prop. fungi & 0.249 & $-0.722^{* *}$ & 0.019 & 0.484 & 0.249 & -0.075 \\
\hline Birch & 0.158 & -0.542 & $-0.570^{*}$ & -0.181 & 0.236 & 0.241 \\
\hline Aspen & 0.316 & -0.460 & $0.688^{* *}$ & -0.079 & 0.024 & 0.262 \\
\hline Poplar & $-0.718^{\star *}$ & 0.131 & 0.382 & -0.021 & -0.068 & -0.437 \\
\hline Willow & $-0.677^{\star}$ & 0.205 & 0.197 & 0.174 & 0.346 & 0.150 \\
\hline Rowan & -0.531 & 0.155 & 0.004 & 0.331 & 0.063 & $0.660^{*}$ \\
\hline Larch & 0.485 & -0.350 & -0.067 & $-0.586^{\star}$ & 0.088 & 0.246 \\
\hline Scots pine & -0.094 & 0.098 & $0.863^{\star *}$ & -0.093 & 0.177 & 0.031 \\
\hline Siberian pine & 0.525 & $0.638^{*}$ & -0.005 & 0.089 & -0.047 & 0.032 \\
\hline Fir & 0.472 & $0.680^{* *}$ & -0.002 & 0.151 & -0.114 & -0.132 \\
\hline Spruce & 0.444 & $0.747^{\star *}$ & -0.022 & 0.228 & -0.161 & -0.043 \\
\hline
\end{tabular}

Bonferroni probability, $* \mathrm{p}<0.01, * * \mathrm{p}<0.001$. 
From the principal component analysis, the first six principal components had eigenvalues greater than 1, and the first two summarised $52.6 \%$ of the total variance in 22 habitat variables (Table 4.2). Principal component 1 had eigenvalue 6.74 and alone explained $30.6 \%$ of the total variance. This component, with high positive loadings of elevation and slope and high negative loadings of topographic position, shrub coverage and the basal area of poplar, reflected the gradient from the riparian forest to the mountain taiga (Fig. 4.1). The eigenvalue of principal component 2 was 4.83, which accounted for $22.0 \%$ of the total variance. This component, having high positive loadings of the basal areas of spruce and fir and high negative loadings of the proportions of stems with fire scars and fungi conks, indicated the gradient from the light subtaiga to the dark mountain taiga.

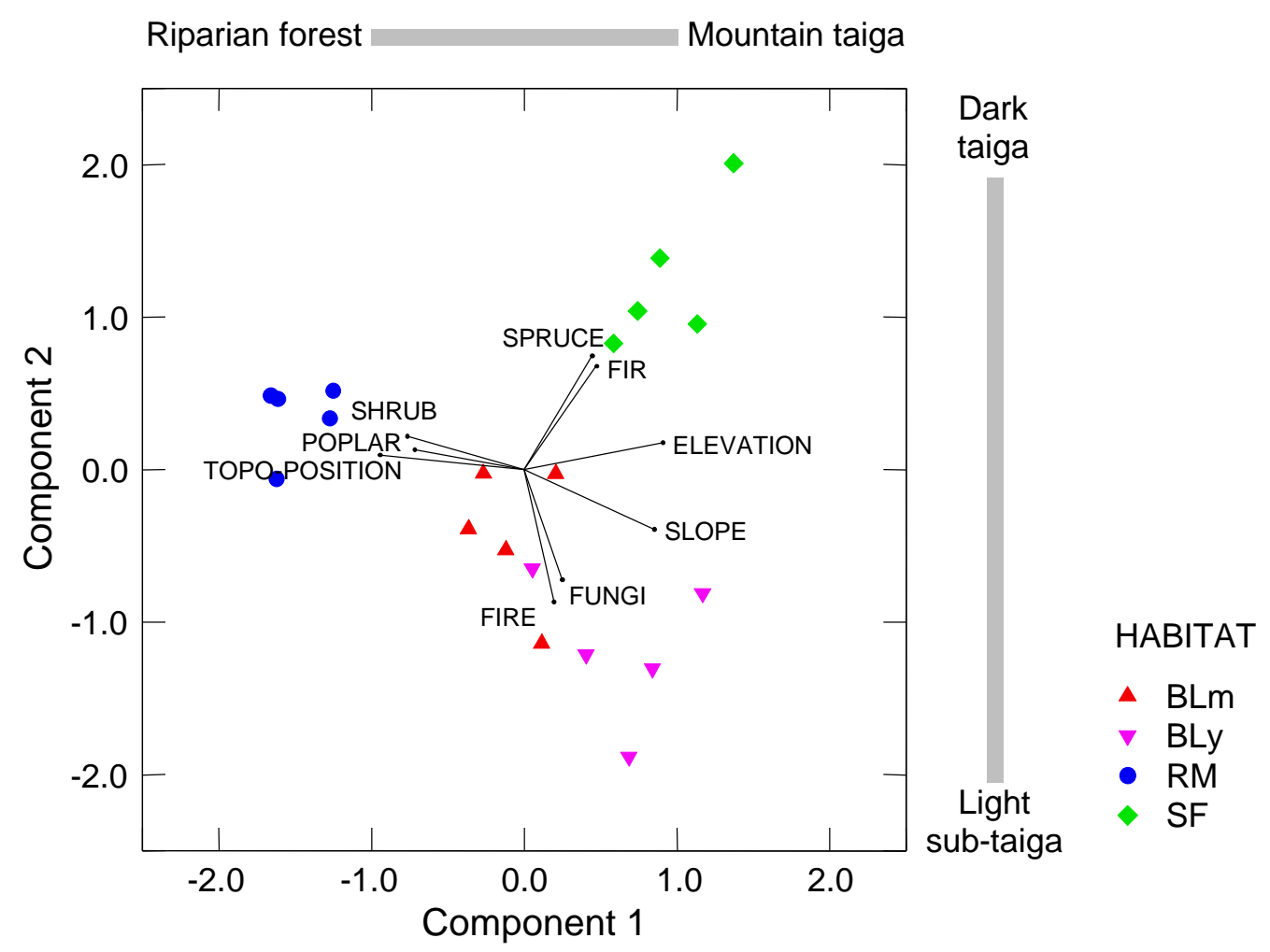

Fig. 4.1 Component loadings and projections of 20 plots onto principal components 1 and 2 , based on the principal component analysis of 22 habitat variables. Only variables of highly significant correlation $(p<0.001)$ to component 1 or 2 were shown. 


\subsection{Cavity Abundance}

The average density of tree cavities in the study area approached 30 cavities/ha (Table 4.3). The most numerous cavity type was branch hole (Kruskal-Wallis, $\mathrm{H}=9.17$, $\mathrm{df}=$ $3, \mathrm{p}<0.05)$. It averaged to 16 cavities/ha, and comprised $54 \%$ of the total cavities found. Bark crevice was the scarcest cavity type (about 1 cavity/ha), which accounted for $5 \%$ of the total. When pooling the cavity types into excavated and non-excavated cavities, there was no significant difference between the abundance of excavated cavities and non-excavated ones (Mann-Whitney, $\mathrm{U}=5.00, \mathrm{df}=1, \mathrm{p}=0.386$ ).

Observing each habitat separately, in both mature and young birch-larch forests, branch hole was the most numerous cavity type (Kruskal-Wallis, $\mathrm{H}=8.77$, $\mathrm{df}=3, \mathrm{p}<$ 0.05 in the mature one; $\mathrm{H}=8.06, \mathrm{df}=3, \mathrm{p}<0.05$ in the young one). It comprised approximately $60 \%$ of the total cavities in both habitats. In the riparian mixed forest, though branch hole was still the most frequent cavity type (48\%), woodpecker hole also showed high abundance $(26 \%)$. And there was no significant difference among the densities of different cavity types (Kruskal-Wallis, $\mathrm{H}=6.04$, $\mathrm{df}=3, \mathrm{p}=0.110$ ). In the spruce-fir forest, other bird-induced holes (49\%) and branch holes (44\%) had similar shares, and the densities of different cavity types did not differ significantly (Kruskal-Wallis, $\mathrm{H}=7.22$, $\mathrm{df}=3, \mathrm{p}=0.065$ ).

Table 4.3 Density (mean \pm SD) of each type of cavity (n/ha) in each habitat.

\begin{tabular}{lcccccc}
\hline & \multicolumn{4}{c}{ Cavity type } & \\
\cline { 2 - 3 } Habitat & \multicolumn{2}{c}{ Excavated } & & Non-excavated $^{2}$ & \\
\cline { 2 - 3 } \cline { 5 - 6 } & $\begin{array}{c}\text { Woodpecker } \\
\text { hole }\end{array}$ & $\begin{array}{c}\text { Other bird- } \\
\text { induced hole }\end{array}$ & & Branch hole $^{1}$ & Bark crevice & Total \\
\hline BLm & $1.2 \pm 2.7$ & $8.0 \pm 10.6$ & & $15.0 \pm 10.6$ & $0.0 \pm 0.0$ & $24.2 \pm 22.0$ \\
BLy & $2.7 \pm 6.1$ & $9.2 \pm 12.0$ & & $22.2 \pm 12.6$ & $2.8 \pm 5.5$ & $36.9 \pm 15.9$ \\
RM & $10.3 \pm 9.4$ & $7.2 \pm 8.0$ & & $18.9 \pm 11.0$ & $2.9 \pm 2.9$ & $39.2 \pm 18.8$ \\
SF & $1.2 \pm 2.0$ & $8.9 \pm 13.5$ & & $7.9 \pm 5.2$ & $0.0 \pm 0.0$ & $18.1 \pm 18.0$ \\
\hline Grand mean & $3.9 \pm 4.3$ & $8.3 \pm 0.9$ & $16.0 \pm 6.1$ & $1.4 \pm 1.6$ & $29.6 \pm 10.1$ \\
\hline
\end{tabular}

${ }^{1}$ BLy $>$ SF; Mann-Whitney, $\mathrm{U}=22.00, \mathrm{df}=1, \mathrm{p}<0.05$.

${ }^{2}$ BLy $>$ SF; Mann-Whitney, $\mathrm{U}=24.00, \mathrm{df}=1, \mathrm{p}<0.05$.

Among the four habitats, the riparian mixed forest had the highest cavity density, approaching 40 cavities/ha, owing to the abundance of woodpecker hole in this 
habitat. Total density in the young birch-larch forest (37 cavities/ha) was close to the former one, due to plentiful branch holes. The spruce-fir forest had lowest cavity density (18 cavities/ha), due to less branch holes in this habitat. The density of other bird-induced hole kept moderate values in all habitats, while the density of bark crevice was low in all habitats. Because cavity density varied greatly among the plots in the same habitat, i.e. having high intra-habitat variance, statistically significant difference only arose in that the young birch-larch forest had more branch hole (Mann-Whitney, $\mathrm{U}=22.00, \mathrm{df}=1, \mathrm{p}<0.05$ ) and non-excavated cavity (MannWhitney, $\mathrm{U}=24.00, \mathrm{df}=1, \mathrm{p}<0.05$ ) than the spruce-fir forest.

Correlating cavity density to habitat variables, the density of woodpecker hole showed high positive correlation with shrub coverage (Table 4.4). The densities of branch hole and non-excavated cavity altogether were positively correlated with the proportion of trees with fire scars. The abundance of other cavity types and the overall density were not significantly correlated with the habitat variables concerned.

Table 4.4 Correlation coefficients between density of each cavity type and habitat features, including proportion of deciduous stems (= Prop. decid.), proportion of large trees (= Prop. large), proportion of dead trees (= Prop. dead), proportions of trees with fire scars (= Prop. fire), shrub coverage, and component scores of principal component 1 (= Prin. comp. 1) and 2 (= Prin. comp. 2).

\begin{tabular}{lccccccccc}
\hline & \multicolumn{3}{c}{ Excavated cavity } & & \multicolumn{3}{c}{ Non-excavated cavity } & \\
\cline { 2 - 3 } & $\begin{array}{c}\text { Woodpecker } \\
\text { hole }\end{array}$ & $\begin{array}{c}\text { Other bird- } \\
\text { induced hole }\end{array}$ & Sum & & $\begin{array}{c}\text { Branch } \\
\text { hole }\end{array}$ & $\begin{array}{c}\text { Bark } \\
\text { crevice }\end{array}$ & Sum & Overall \\
\hline Prop. decid. & 0.297 & -0.213 & -0.019 & & 0.209 & 0.298 & 0.276 & 0.153 \\
Prop. large & 0.313 & -0.333 & -0.109 & & 0.197 & 0.113 & 0.214 & 0.058 \\
Prop. dead & -0.129 & 0.093 & 0.009 & & 0.170 & 0.104 & 0.186 & 0.118 \\
Prop. fire & -0.144 & -0.043 & -0.110 & & $0.404^{*}$ & 0.318 & $0.462^{* *}$ & 0.206 \\
Shrub coverage & $0.801^{* *}$ & -0.152 & 0.293 & & 0.069 & 0.191 & 0.117 & 0.261 \\
Prin. comp. 1 & $-0.552^{* *}$ & 0.149 & -0.166 & & -0.230 & -0.252 & -0.282 & -0.278 \\
Prin. comp. 2 & 0.063 & -0.027 & 0.011 & & -0.355 & -0.217 & $-0.389^{*}$ & -0.227 \\
\hline
\end{tabular}

Bonferroni probability, $* \mathrm{p}<0.1, * * \mathrm{p}<0.05$.

Applying correlation analysis between cavity densities and component scores of the first two principal components, the density of woodpecker hole was correlated with the principal component 1 (Table 4.4 and Fig. 4.2(a)). Higher density of woodpecker hole occurred in the plots with negative scores of component 1 , which were the 
riparian plots. Component 1 could explain $30 \%$ of the variation in the abundance of woodpecker hole. Density of non-excavated cavity was negatively correlated with component 2, due to lower abundance of such cavity in the spruce-fir forest (Table 4.4 and Fig. 4.2(b)). Component 2 summarised $15 \%$ of the variation in the density of non-excavated cavity.

(a)

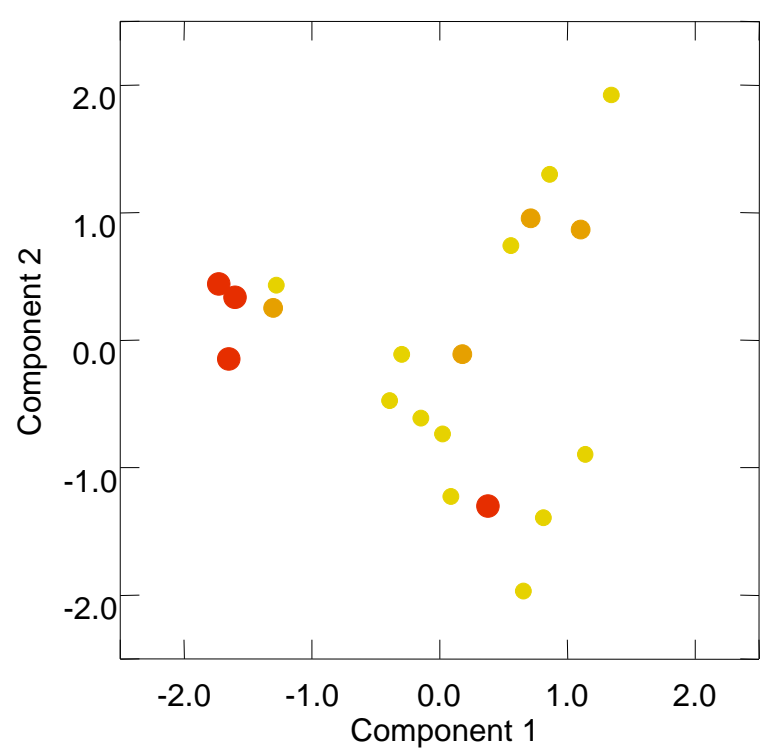

Density of woodpecker hole $(\mathrm{n} / \mathrm{ha})$

0

- $0-10$

$>10$

(b)

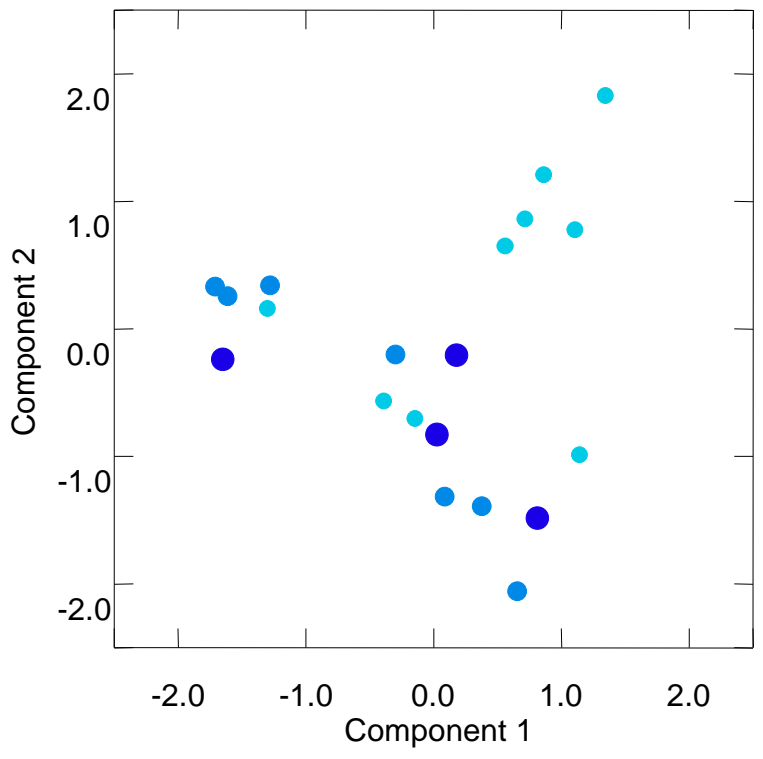

Density of non-excavated cavity (n/ha)

- $<15$

$15-25$

$>25$

Fig. 4.2 Densities of (a) woodpecker hole and (b) non-excavated cavity of each plot projected onto principal components 1 and 2. 


\subsection{Cavity Occurrence and Tree Characters}

\subsubsection{Cavity occurrence and tree species}

Cavities occurred with different frequency in different tree species $\left(?^{2}=248.85, \mathrm{df}=\right.$ $9, \mathrm{p}<0.001)$. Birch was the most important cavity tree. Over $50 \%$ of the cavities were found in this species, which comprised only $37 \%$ of the standing stems (Table 4.5). About $4 \%$ of birch stems hold cavities. Poplar accounted for one fourth of the total cavities. Related to its abundance, poplar was the most cavity-rich tree species $\left(?^{2}\right.$ test with Yates correction, $\mathrm{p}<0.001$ with each of other species except aspen and rowan, which had very small sample sizes). About one third of poplar stems hold cavities, and a poplar with cavity usually had more than one cavity per tree, in average 2.3. Other deciduous tree species, including aspen, willow and rowan, were only seldom sampled. Altogether these trees contributed about $1 \%$ to the total cavities.

Larch was the third important cavity tree species, accounted for $14 \%$ of total cavities. Cavities could be found in about $1 \%$ of larch stems, which was the most cavity-rich conifer species $\left(?^{2}\right.$ test with Yates correction, $\mathrm{p}<0.05$ with Scots pine, $\mathrm{p}<0.01$ with Siberian pine, $\mathrm{p}<0.001$ with fir and spruce). Scots pine contributed $2 \%$ to the total cavities. No cavity was found in Siberian pine, fir and spruce, though these species made up $35 \%$ of the standing stems. In summary, poplar and birch supplied cavities over-proportionally ( $?^{2}$ test with Yates correction, $\mathrm{p}<0.001$ for both), larch and other deciduous trees supplied cavities in proportion to their abundance, while Scots pine, Siberian pine, fir and spruce supplied cavities under-proportionally (? ${ }^{2}$ test with Yates correction, $\mathrm{p}<0.05$ for Scots pine, $\mathrm{p}<0.001$ for others).

Table 4.5 The percentage constitution of all sampled stems ( = Prop. stem), the percentage contribution to total cavities found ( = Prop. cavity), and the cavity holding rate of each tree species.

\begin{tabular}{lcccccccccc}
\hline & \multicolumn{10}{c}{ Tree species } \\
\cline { 2 - 7 } & Poplar & Birch & $\begin{array}{c}\text { Other } \\
\text { deciduous } \\
\text { trees }\end{array}$ & Larch & $\begin{array}{c}\text { Scots } \\
\text { pine }\end{array}$ & $\begin{array}{c}\text { Siberian } \\
\text { pine }\end{array}$ & Fir & Spruce & N \\
\hline Prop. stem & 2.7 & 36.8 & 1.2 & 16.2 & 7.7 & 7.4 & 11.2 & 16.9 & 863 \\
Prop. cavity & 25.8 & 56.9 & 1.0 & 14.3 & 2.0 & 0 & 0 & 0 & 157 \\
Cavity holding rate & 38.4 & 3.8 & 1.1 & 1.2 & 0.3 & 0 & 0 & 0 & 863 \\
\hline
\end{tabular}


Taking cavity type into account, birch hold bulk of both excavated (46\%) and nonexcavated (64\%) cavities (Fig. 4.3). Poplar accounted for $22 \%$ and $28 \%$ of excavated and non-excavated cavities, respectively, and was the most cavity-rich tree species related to its abundance. Larch held similar amount of excavated cavities as poplar (28\%), but stocked relatively less non-excavated ones (6\%). Excavated and nonexcavated cavities showed no significant difference in their distribution across tree species while taking all species into account $\left(?^{2}=0.00, \mathrm{df}=9, \mathrm{p}=1.000\right)$. But when considering only species with cavities found, i.e. willow, poplar, birch, larch and Scots pine, these two types of cavity differed in their occurrence in tree species $\left(?^{2}=\right.$ 17.93, $\mathrm{df}=4, \mathrm{p}<0.01)$. Non-excavated cavity occurred relatively more frequently in birch (Yates corrected $?^{2}=4.52, \mathrm{df}=1, \mathrm{p}<0.05$ ) and less frequently in larch (Yates corrected $\left.?^{2}=11.56, \mathrm{df}=1, \mathrm{p}<0.01\right)$ than excavated one.

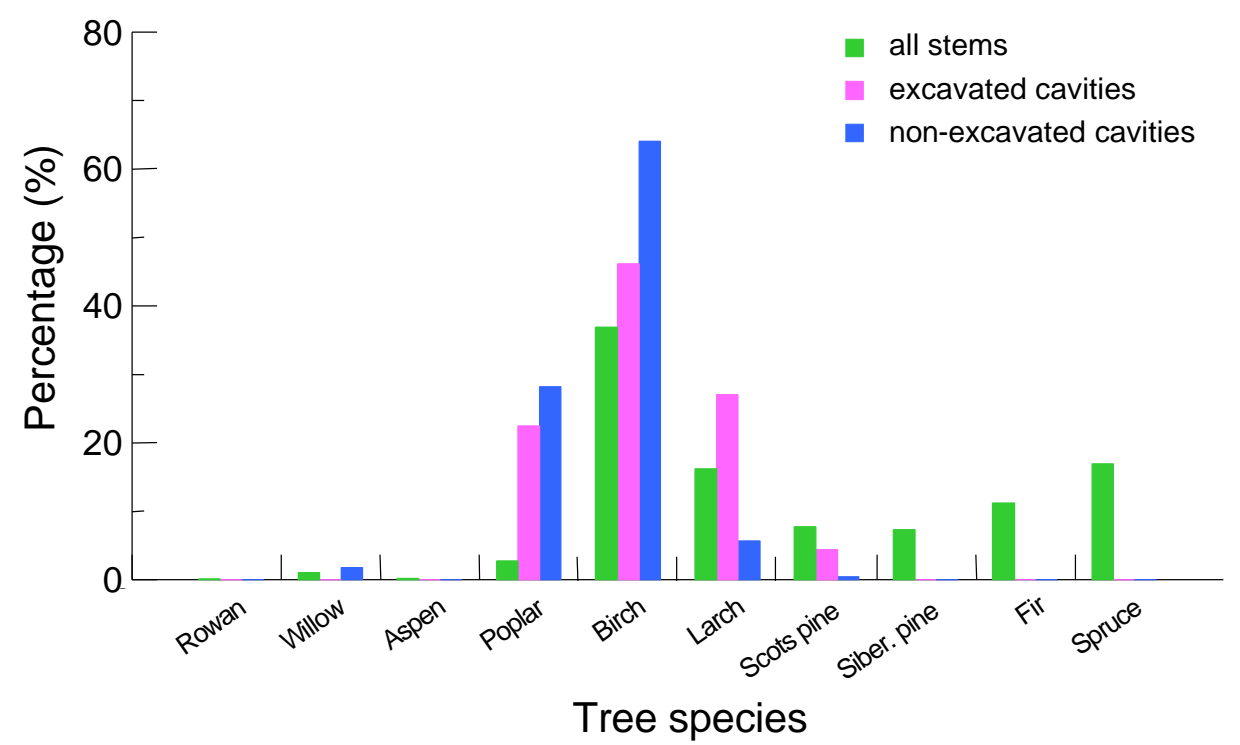

Fig. 4.3 The percentage constitution of all sampled stems (green bars; $n=863$ ), the percentage of excavated cavities (red bars; $n=76$ ), and the percentage of non-excavated cavities (blue bars; $\mathbf{n}=\mathbf{8 1}$ ) according to tree species.

Each tree species played different roles in different habitats due to difference in species composition of each habitat. In the mature birch-larch forest, all the cavities found were located in birch. In the young birch-larch forest, birch also supplied bulk of the cavities (74\%), and larch accounted for $24 \%$. In the riparian forest, poplar was 
the most important cavity tree. $78 \%$ of the cavities found in this habitat were located in poplar, and $16 \%$ in birch. In the spruce-fir forest, birch again served most often as the cavity tree, accounted for $58 \%$ of the cavities found. The remainder cavities in this habitat were located in larch.

\subsubsection{Cavity occurrence and tree DBH}

Cavity occurrence differed significantly across DBH classes (Fig. 4.4; $?^{2}=413.01, \mathrm{df}$ $=4, \mathrm{p}<0.001)$. Cavities presented under-proportionally in trees of $\mathrm{DBH}<15 \mathrm{~cm}$ (Yates corrected $?^{2}=226.25, \mathrm{df}=1, \mathrm{p}<0.001$ ), and over-proportionally in trees of DBH larger than $30 \mathrm{~cm}\left(?^{2}\right.$ test with Yates correction, $\mathrm{p}<0.001$ for each class above $30 \mathrm{~cm}$ ). Trees of DBH $<15 \mathrm{~cm}$ comprised over $60 \%$ of the standing stems, but no cavity was found in them. Most of the cavities (41\%) were located in trees of DBH $30-45 \mathrm{~cm}$, which accounted for only about $5 \%$ of the standing stems. Though just about $9 \%$ of the cavities were found in trees of $\mathrm{DBH}>60 \mathrm{~cm}$, these large trees were most cavity-rich relative to their occurrence in the forest $(0.4 \%)$. About one third of these trees hold cavities. Cavity holding rate rose with ascending DBH (Fig. 4.4, blue line). Excavated cavity and non-excavated cavity did not differ in their occurrence across DBH class (Yates corrected $?^{2}=0.00, \mathrm{df}=4, \mathrm{p}=1.000$ ).

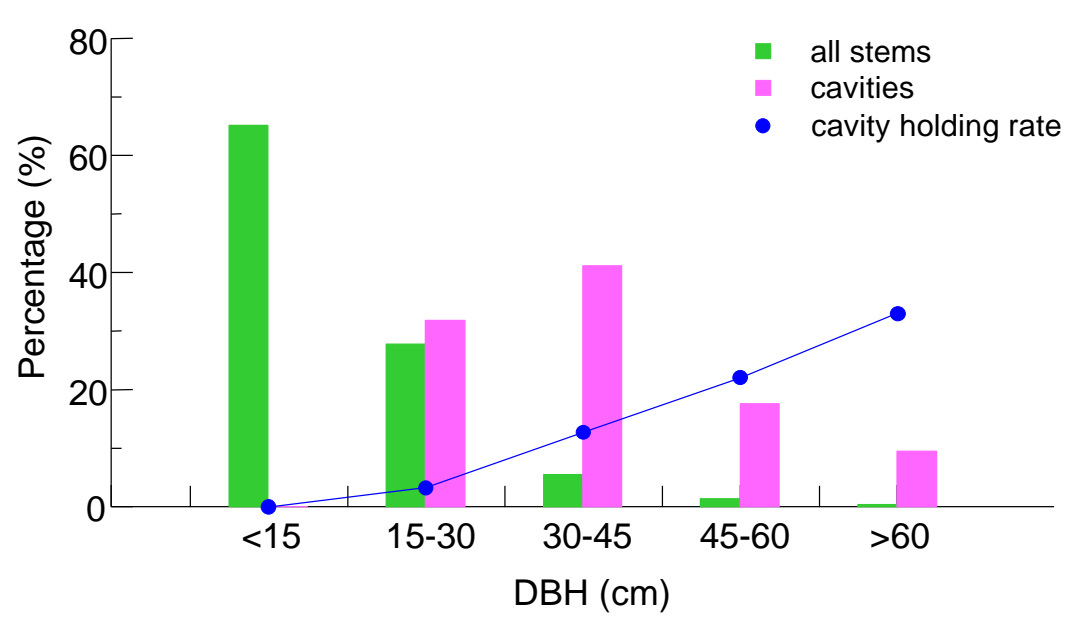

Fig. 4.4 The percentage constitution of all sampled stems (green bars; $n=863$ ), the percentage of total cavities (red bars; $\mathbf{n}=157$ ), and cavity holding rate (blue line; $\mathbf{n}=$ 863) according to tree DBH. 
Consider the main cavity tree species (i.e. poplar, birch, larch and Scots pine) separately, the cavity holding rate increased with raising diameter in all species (Fig. 4.5). But the increase in Scots pine was not significant $\left(?^{2}=24.39\right.$, $\left.\mathrm{df}=4, \mathrm{p}=0.356\right)$, due to very low cavity holding rate in all DBH class. The cavity holding rate did not differ among tree species when DBH was under $30 \mathrm{~cm}\left(?^{2}=2.74, \mathrm{df}=3, \mathrm{p}=0.433\right)$. Above $30 \mathrm{~cm}$, cavity holding rate showed among species differences $\left(?^{2}\right.$ test, $\mathrm{p}<$ 0.001 for each class above $30 \mathrm{~cm}$ ). Poplar and birch acquired cavities more often than larch and Scots pine. In each DBH class, cavity holding rate showed no significant difference between the two deciduous species, nor between the two coniferous species $\left(?^{2}\right.$ test with Yates correction, $\mathrm{p}>0.05$ for each pairwise comparison).

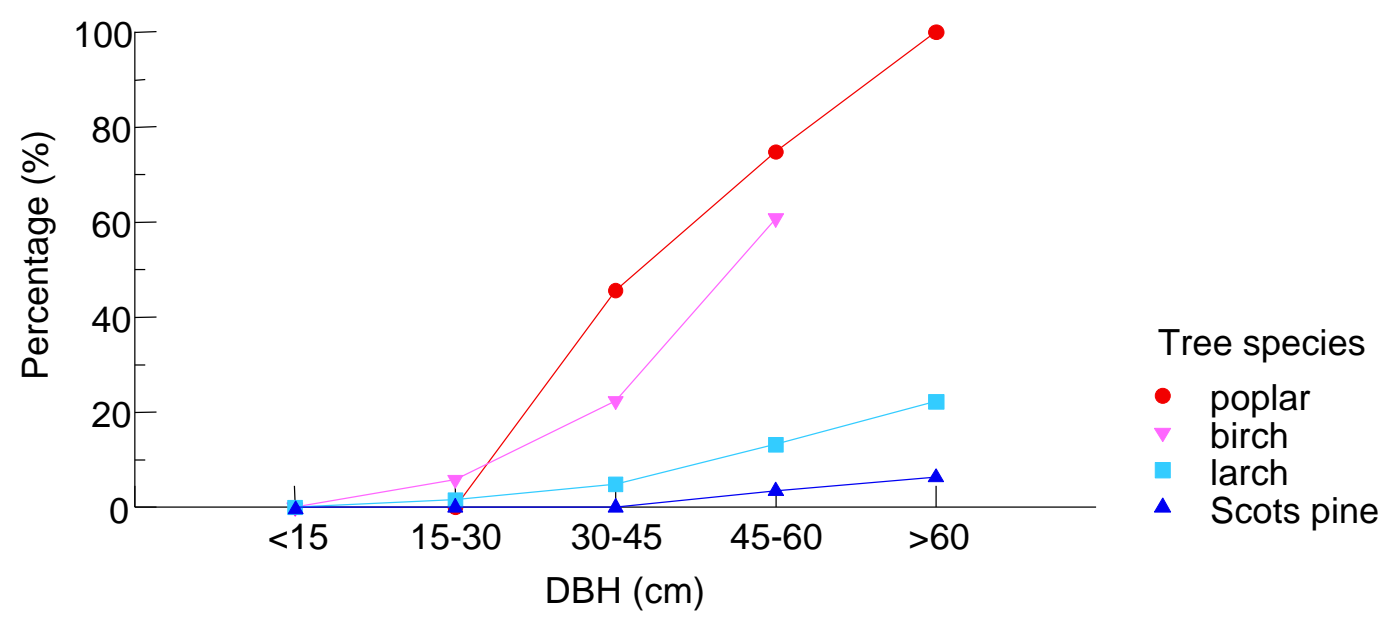

Fig. 4.5 The cavity holding rate of poplar $(n=45)$, birch $(n=327)$, larch $(n=166)$ and Scots pine $(n=125)$ in each DBH class.

The cavity occurrence across DBH classes showed different patterns among habitats (Fig. 4.6), which was shaped by the DBH distribution of each component tree species in each habitat. In the mature birch-larch forest, up to $79 \%$ of the cavities were located in trees of DBH $30-45 \mathrm{~cm}$. In the young birch-larch forest, the bulk of cavities (59\%) occurred in trees of DBH $15-30 \mathrm{~cm}$, because of the higher abundance and higher cavity holding rate of such trees in this habitat. In the riparian forest, most cavities (39\%) were located in trees of DBH 30 - $45 \mathrm{~cm}$, while larger trees (DBH 45 - 
$60 \mathrm{~cm}$ and $\mathrm{DBH}>60 \mathrm{~cm}$ ) had relatively great contribution compared to the former two habitats. This was contributed by the cavity-rich large poplar trees, which occurred only in this habitat. In the spruce-fir forest, the cavity abundance showed a bimodal distribution across DBH class. About $51 \%$ of the cavities found in this habitat were located in trees of DBH $15-30 \mathrm{~cm}$, which were exclusively contributed by birch. Larger birch trees were rare in this habitat. The substantial amount of cavities found in trees of DBH $45-60 \mathrm{~cm} \mathrm{(28 \% )} \mathrm{and} \mathrm{DBH} \mathrm{>} 60 \mathrm{~cm}(14 \%)$ were mainly contributed by old larch trees.

(a)

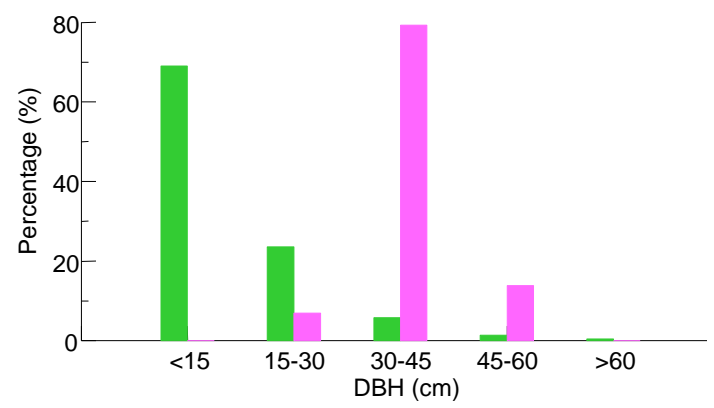

(c)

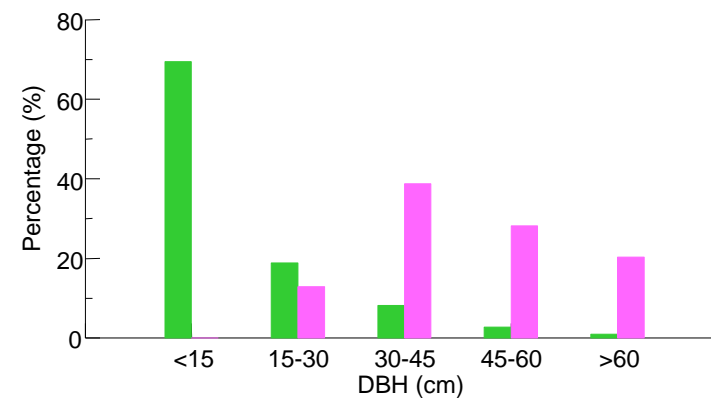

(b)

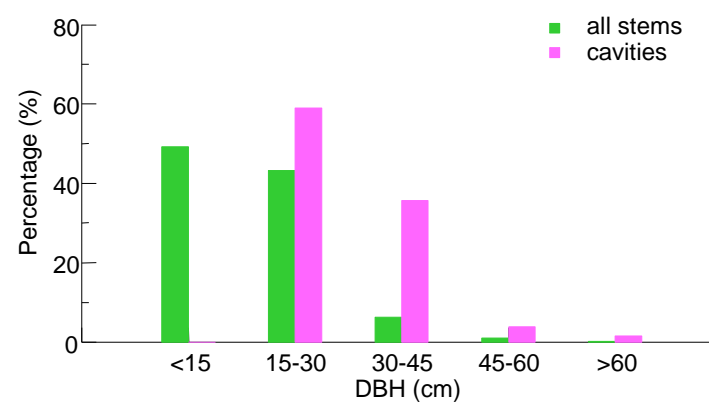

(d)

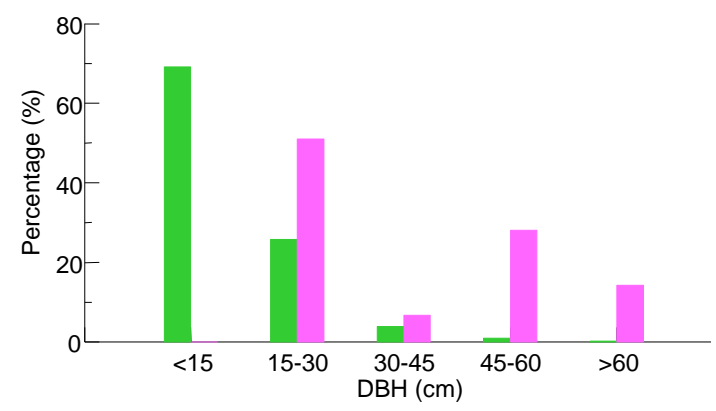

Fig. 4.6 The percentage constitution of all sampled stems (green bars) and the percentage of total cavities (red bars) according to tree DBH in each habitat: (a) the mature birch-larch forest, (b) the young birch-larch forest, (c) the riparian mixed forest and (d) the spruce-fir forest. 


\subsubsection{Cavity occurrence and tree condition}

Most of the cavities (45\%) were found in healthy living trees (class 1; Table 4.6).

Considering the abundance of such stems in the forests (84\%), cavities occurred under-proportionally in such trees (Yates corrected $?^{2}=113.04$, $\mathrm{df}=1, \mathrm{p}<0.001$ ). Tall snags with broken top (class 5), which comprised only about $4 \%$ of the standing stems, accounted for $31 \%$ of total cavities (Yates corrected $?^{2}=137.83$, df $=1, \mathrm{p}<$ 0.001 ). About $12 \%$ of these tall snags had at least one cavity, in average 3.2 cavities/stem. Cavities were also relatively frequently found in living trees in state of decline (class 2; Yates corrected $?^{2}=9.20, \mathrm{df}=1, \mathrm{p}<0.01$ ) and shortened snags (class 6; Yates corrected $?^{2}=18.69, \mathrm{df}=1, \mathrm{p}<0.001$ ).

Table 4.6 The percentage constitution of all sampled stems ( = Prop. stem), the percentage contribution to total cavities found ( = Prop. cavity), and the cavity holding rate of trees in different condition. (Codes for tree condition: 1 . healthy living tree, 2. living tree, in state of decline, 3 . dead tree, branches intact, 4 . dead tree, few or no branches, 5. dead tree, broken top, 6. dead tree, shortened snag.)

\begin{tabular}{lcccccccc}
\hline & \multicolumn{7}{c}{ Tree condition } & \multirow{2}{*}{ N } \\
\cline { 2 - 6 } & 1 & 2 & 3 & 4 & 5 & 6 & \\
\hline Prop. stem & 83.6 & 1.5 & 5.9 & 3.8 & 3.5 & 1.8 & 863 \\
Prop. cavity & 45.0 & 5.8 & 4.3 & 5.5 & 31.3 & 8.1 & 157 \\
Cavity holding rate & 1.3 & 8.3 & 1.0 & 1.7 & 11.9 & 13.6 & 863 \\
\hline
\end{tabular}

Excavated cavities and non-excavated cavities showed different distribution across tree condition (Fig. $4.7 ; ?^{2}=41.40, \mathrm{df}=5, \mathrm{p}<0.001$ ). Though both types of cavity occurred seldom in healthy living trees in relation to the abundance of such trees, excavated cavities were even fewer in theses trees comparing to non-excavated ones (Yates corrected $?^{2}=24.58, \mathrm{df}=1, \mathrm{p}<0.001$ ). $61 \%$ of non-excavated cavities were located in healthy living trees, while only $22 \%$ of excavated cavities were found in them. In tall snags with broken top, both types of cavity were relatively common, but excavated cavities were even more frequent (Yates corrected $?^{2}=17.83, \mathrm{df}=1, \mathrm{p}<$ 0.001 ). These trees accounted for $51 \%$ of excavated cavities and $18 \%$ of nonexcavated ones. Excavated cavities were also relatively more frequent in trees of class 4 (few or no branches, without broken top) than no-excavated ones (Yates corrected $\left.?^{2}=7.87, \mathrm{df}=1, \mathrm{p}<0.01\right)$. 


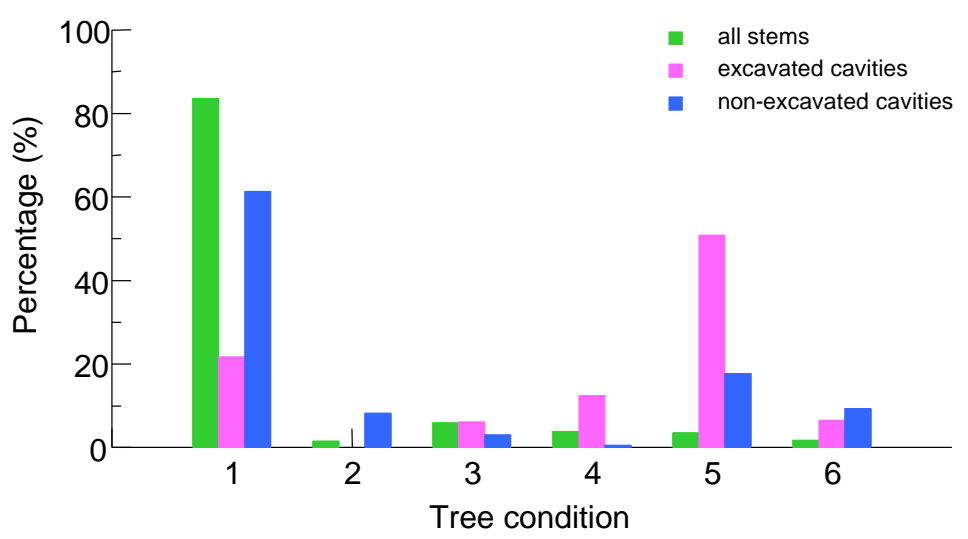

Fig. 4.7 The percentage constitution of all sampled stems (green bars; $n=863$ ), the percentage of excavated cavities ( $r e d$ bars; $n=76$ ), and the percentage of non-excavated cavities (blue bars; $\mathbf{n}=\mathbf{8 1}$ ) according to tree condition.

(a)

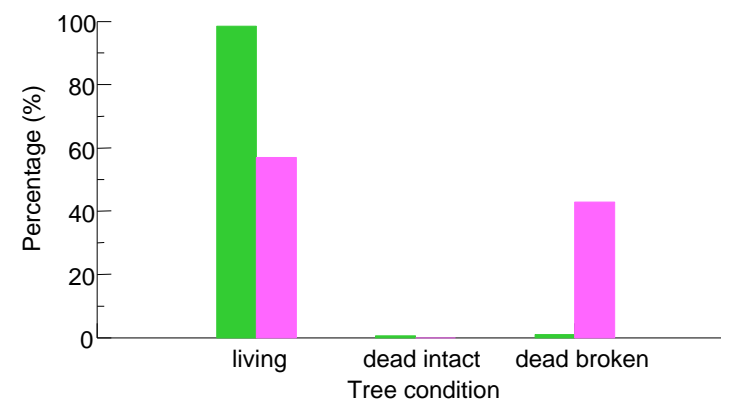

(c)

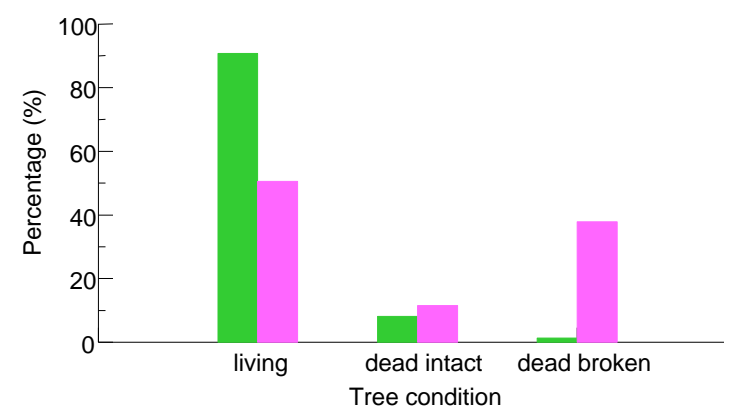

(b)

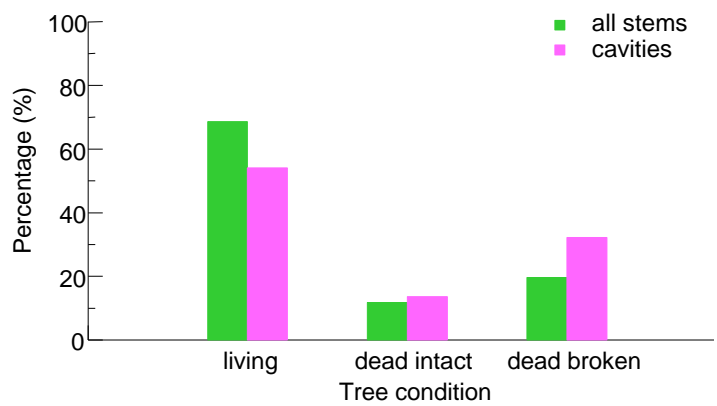

(d)

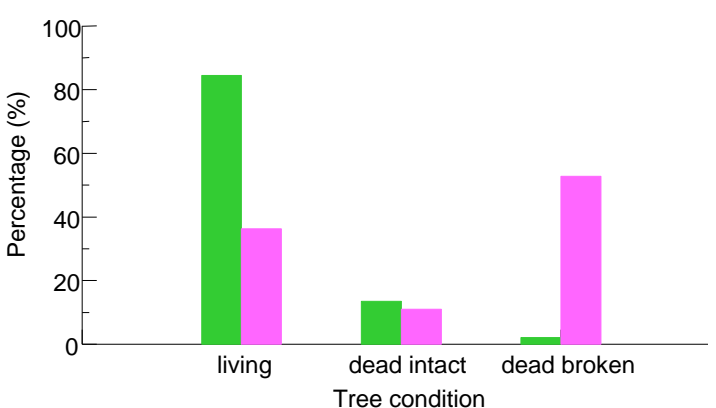

Fig. 4.8 The percentage constitution of all sampled stems (green bars) and the percentage of total cavities (red bars) according to tree condition in each habitat: (a) the mature birch-larch forest, (b) the young birch-larch forest, (c) the riparian mixed forest and (d) the spruce-fir forest. 
To investigate cavity occurrence across tree condition in each habitat, tree condition was further pooled into three classes: living tree, dead tree with intact top and dead tree with broken top, to avoid too small sample size. In all habitats, the cavity occurrence pattern was similar in that most of the cavities were found in living stems and broken snags (Fig. 4.8). In the mature birch-larch forest, the riparian mixed forest and the spruce-fir forest, cavity occurrence across tree condition was not in proportion to the abundance of trees of each condition ( $?^{2}$ test, $\mathrm{p}<0.001$ for each habitat). Living trees supplied cavities under-proportionally while broken snags did overproportionally, as indicated above in the overall pattern. But in the young birch-larch forest, trees of each condition supplied the cavities in proportion to its abundance $\left(?^{2}\right.$ $=2.44, \mathrm{df}=2, \mathrm{p}=0.296$ ). There was a high density of broken snags in this habitat, and the cavity holding rate of these trees was lower than that in other habitats (Yates corrected $\left.?^{2}=5.09, \mathrm{df}=1, \mathrm{p}<0.05\right)$. This was mainly due to that most of the broken snags in this habitat $(71 \%)$ had $\mathrm{DBH}<15 \mathrm{~cm}$, which seldom possessed any cavities.

\subsubsection{Cavity occurrence and fire}

Cavities occurred more frequently in trees with fire scars (Fig. 4.9, Yates corrected ? $=133.64, \mathrm{df}=1, \mathrm{p}<0.001)$. Trees with fire scars comprised only $28 \%$ of the standing stems, while about $76 \%$ of the cavities were located in them. This pattern was similar for both excavated cavities and non-excavated ones (Yates corrected $?^{2}=$ $0.62, \mathrm{df}=1, \mathrm{p}=0.433$ ). The cavity holding rate of trees without fire scars was $0.7 \%$, while that of fire-scarred trees was $5.4 \%$, which was 7 times higher.

This overview might overestimate the influence of fire, however, due to the confounding effects of tree species. Spruce, fir and Siberian pine, in which no cavities were observed, were also rarely scarred by fire $(<1 \%$ of the standing stems of these three species pooled). When considering only the four main cavity tree species (poplar, birch, larch and Scots pine), altogether trees with fire scars comprised $44 \%$ of the standing stems and accounted for $76 \%$ of the total cavities (Yates corrected $?^{2}=$ $53.80, \mathrm{df}=1, \mathrm{p}<0.001)$. The cavity holding rate of these trees was about 5.5\%, 3.8 times higher than those without fire scars $(1.4 \%)$. 


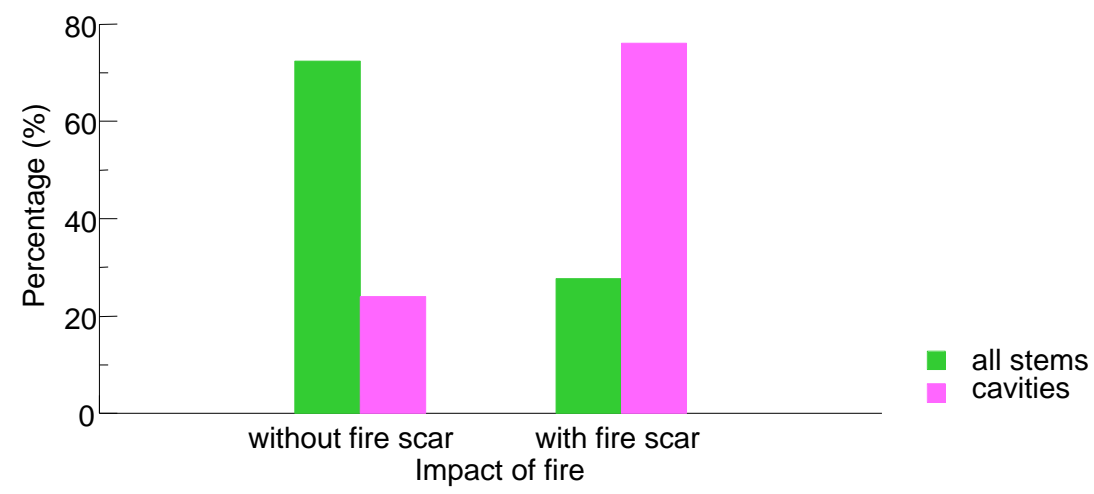

Fig. 4.9 The percentage constitution of all sampled stems (green bars; $n=863$ ) and the percentage of total cavities (red bars; $n=157$ ) according to the presence of fire scars.

Considering these four species separately, larch and Scots pine acquired cavities only in stems with fire scars (Table 4.7). For poplar and birch, the cavity holding rate of trees with fire scars was about 3 times higher than that of trees without fire scars. For all species except Scots pine, cavities occurred more frequently in fire-scarred stems relative to their abundance (Yates corrected ? ${ }^{2}$ test, $\mathrm{df}=1, \mathrm{p}<0.05$ for poplar, $\mathrm{p}<$ 0.001 for birch and larch).

Table 4.7 The cavity holding rate of trees without and with fire scars of each tree species.

\begin{tabular}{lccc}
\hline \multirow{2}{*}{ Tree species } & \multicolumn{2}{c}{ Cavity holding rate of trees } & \multirow{2}{*}{$\mathrm{n}$} \\
\cline { 2 - 3 } & without fire scars & with fire scars & \\
\hline Poplar & 18.9 & 59.8 & 45 \\
Birch & 2.0 & 6.1 & 327 \\
Larch & 0.0 & 3.4 & 166 \\
Scots pine & 0.0 & 0.5 & 125 \\
\hline
\end{tabular}

\subsubsection{Cavity occurrence and fungi}

Cavities occurrence was also related to the presence of fungi conks on the tree (Fig.

4.10). Only about $5 \%$ of the sampled stems had fungi conks, while these trees accounted for $29 \%$ of the total cavities (Yates corrected $?^{2}=90.10, \mathrm{df}=1, \mathrm{p}<0.001$ ). 
The cavity holding rate of conk-bearing stems was $10.8 \%$, seven times higher than that of stems without fungi conks $(1.5 \%)$.

Though both types of cavity were relatively more frequent in conk-bearing stems, excavated cavities had even higher co-occurrence with fungi conks than nonexcavated ones (Fig. 4.10, Yates corrected $?^{2}=10.31, \mathrm{df}=1, \mathrm{p}<0.01$ ). $44 \%$ and $19 \%$ of excavated and non-excavated cavities, respectively, were located in conkbearing stems. For excavated cavities, the cavity holding rate of conk-bearing stems was 16.9 times higher than that of stems without fungi conks. And for non-excavated cavities, the cavity holding rate of conk-bearing stems was only 4.7 times higher.

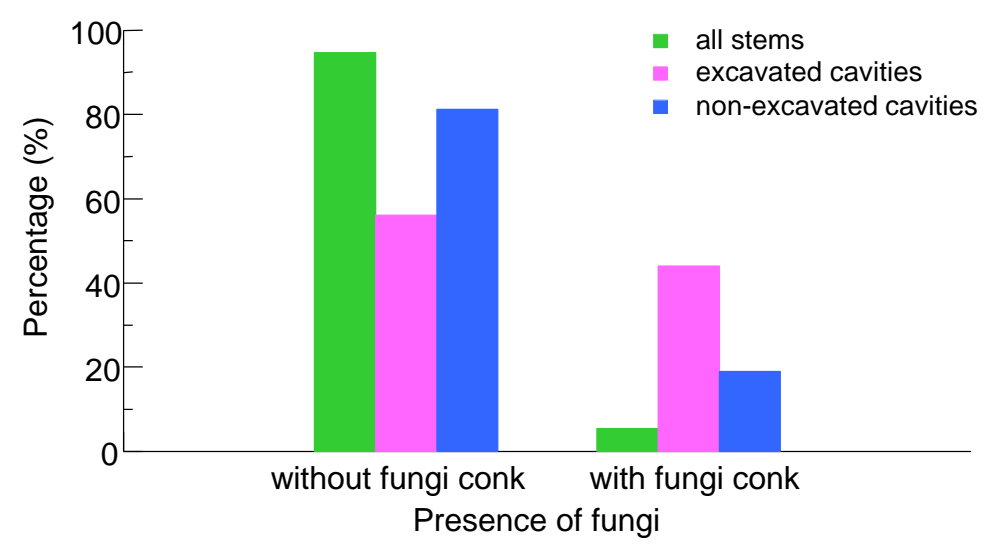

Fig. 4.10 The percentage constitution of all sampled stems (green bars; $n=863$ ), the percentage of excavated cavities (red bars; $n=76$ ), and the percentage of non-excavated cavities (blue bars; $n=81$ ) according to the presence of fungi conks.

Of all sampled stems, fungi conks were only found in poplar, birch, larch and willow. The sample size of willow was too small for analysis. When considering only polar, birch and larch, the percentage of conk-bearing stems was $10 \%$, and accounted for $30 \%$ of cavities (Yates corrected $?^{2}=39.45, \mathrm{df}=1, \mathrm{p}<0.001$ ). The cavity holding rate of conk-bearing stems was four times higher than that of stems without fungi conks. For birch and larch, cavities occurred more frequently in conk-bearing stems relative to their abundance (Yates corrected $?^{2}$ test, $\mathrm{df}=1, \mathrm{p}<0.001$ for both species). While for poplar, the difference was not significant (Yates corrected $?^{2}=1.53, \mathrm{df}=1$, $\mathrm{p}=0.216)$. 


\subsubsection{Predicting cavity occurrence with tree characters}

Applying logistic regression to predict the probability a tree possessing cavities, the backward stepwise selection identified three variables as predictors: if the tree was deciduous, tree DBH and tree condition (Table 4.8; $\log$ likelihood $=-157.62, ?^{2}=$ 222.20, $\mathrm{df}=4, \mathrm{p}<0.001)$. The presence of fire scars and fungi conks, though individually having significant influence to the occurrence of cavities $(\mathrm{p}<0.001$ for each), did not add significant contribution to the multivariate model. The model could correctly predict whether or not a tree holding cavities in $89 \%$ of the cases.

Table 4.8 The coefficient estimates, standard errors, chi-square values and p-values for logistic regression models of the probability a tree holding cavities.

\begin{tabular}{lcccc}
\hline Variable & Coefficient & Std. error & $?^{2}$ & $\mathrm{p}$ \\
\hline Probability a tree holding cavities & & & \\
Deciduous & 3.677 & 0.463 & 7.947 & 0.000 \\
DBH & 1.734 & 0.190 & 9.148 & 0.000 \\
Tree Condition & & & & \\
$\quad$ living & -1.988 & 0.399 & -4.977 & 0.000 \\
$\quad$ dead intact & -0.754 & 0.570 & -1.323 & 0.186 \\
Constant & -8.168 & 0.891 & -9.170 & 0.000 \\
\hline Probability a tree holding excavated cavities & & \\
Deciduous & 1.499 & 0.551 & 2.721 & 0.007 \\
DBH & 1.694 & 0.252 & 6.731 & 0.000 \\
Tree Condition & & & & \\
$\quad$ living & -2.637 & 0.546 & -4.833 & 0.000 \\
$\quad$ dead intact & -0.403 & 0.650 & -0.620 & 0.535 \\
Fungi & 0.899 & 0.564 & 1.594 & 0.111 \\
Constant & -8.021 & 1.160 & -6.914 & 0.000 \\
\hline Probability a tree holding non-excavated cavities & & \\
Deciduous & 4.888 & 0.648 & 7.547 & 0.000 \\
DBH & 1.593 & 0.202 & 7.876 & 0.000 \\
Tree Condition & & & & \\
living & -1.006 & 0.454 & -2.215 & 0.027 \\
$\quad$ dead intact & -0.543 & 0.716 & -0.759 & 0.448 \\
Fire & 0.900 & 0.415 & 2.168 & 0.030 \\
Constant & -10.589 & 1.155 & -9.167 & 0.000 \\
\hline
\end{tabular}


(a)

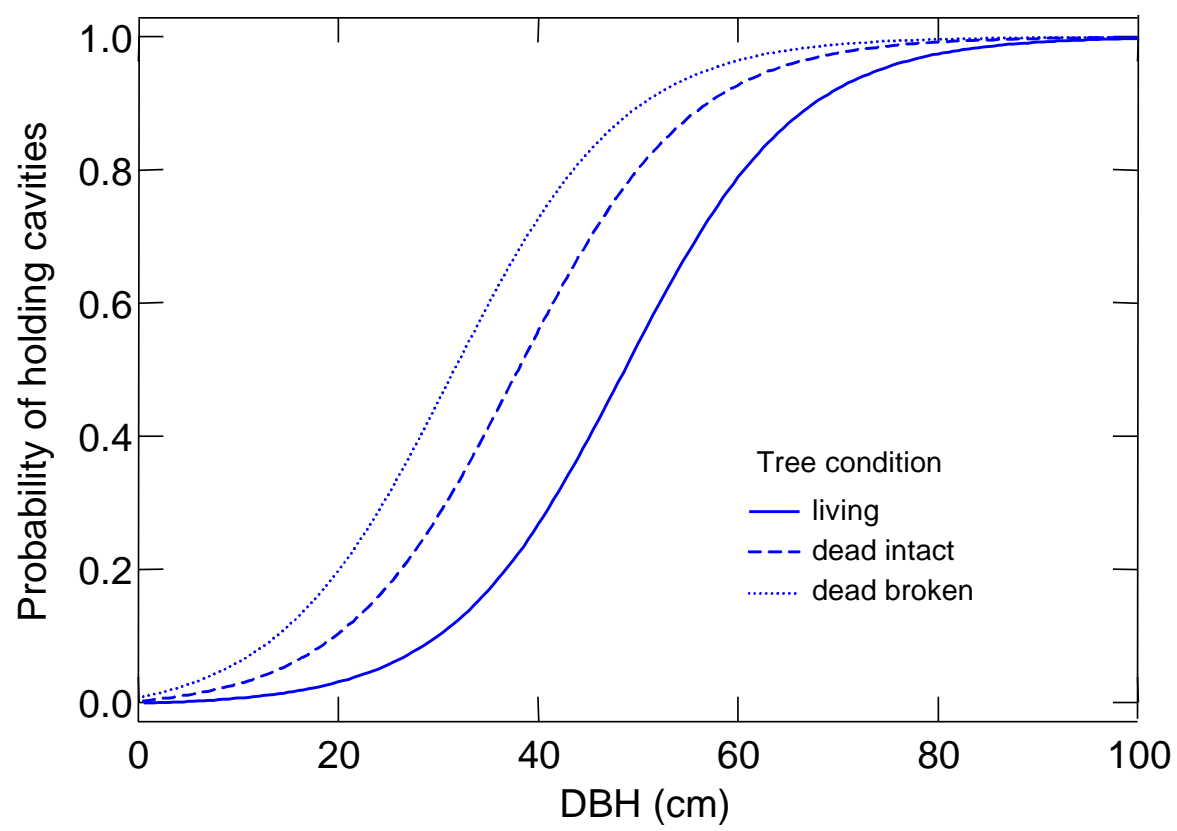

(b)

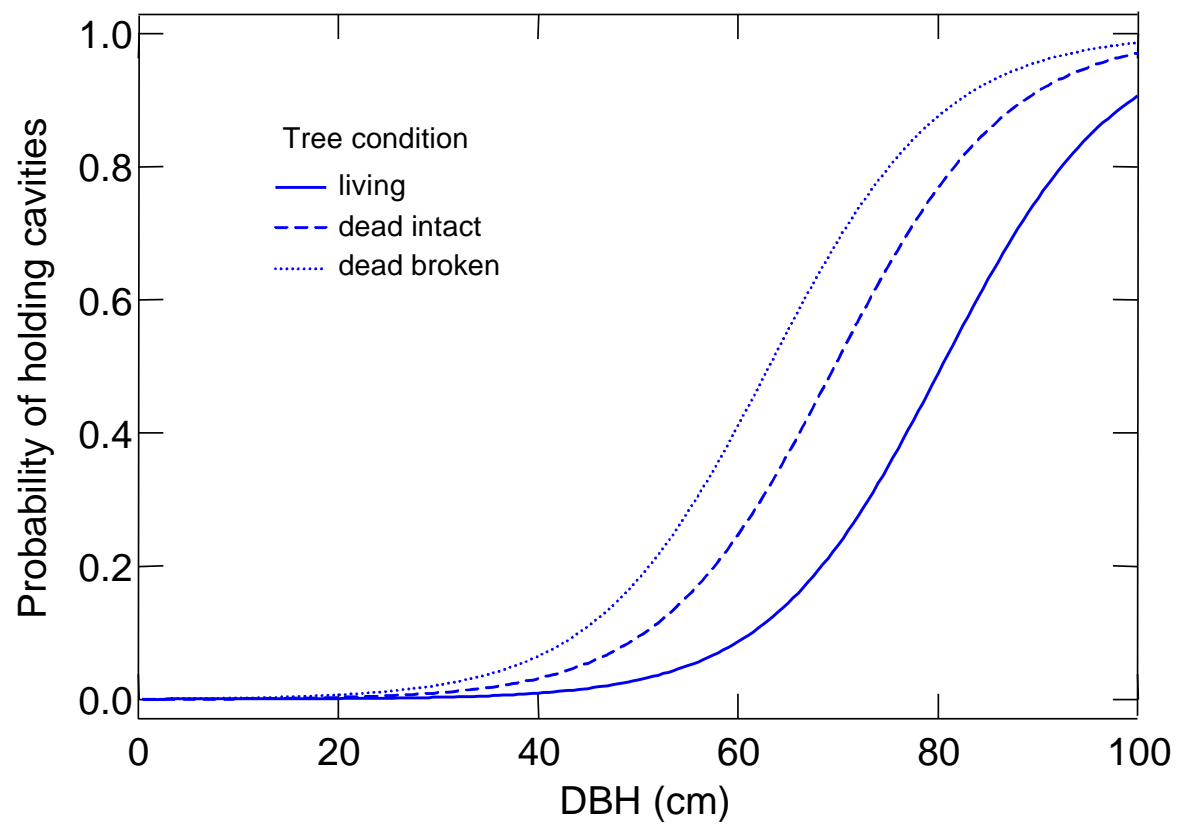

Fig. 4.11 Predicted probability of cavity occurrence in (a) deciduous trees and (b) coniferous trees, in relation to tree DBH and tree condition. 
From this model, it was clear that the probability of holding cavities rose as tree DBH increased (Fig. 4.11). For trees of the same DBH, probability of holding cavities was higher for trees of more decayed condition. Deciduous trees (Fig. 4.11(a)) were much more likely to acquire cavities than coniferous trees (Fig. 4.11(b)) of the same size and the same condition. The probability of holding cavities rose notably at DBH $30-$ $50 \mathrm{~cm}$ for deciduous trees, while for conifers this stage only started at DBH about $60-80 \mathrm{~cm}$.

When modelling the probability a tree holding excavated cavities, the presence of fungi conks was included in the model additionally (Table 4.8; $\log$ likelihood $=-75.90$, $\left.?^{2}=115.32, \mathrm{df}=5, \mathrm{p}<0.001\right)$. This model could correctly predict the occurrence of excavated cavities up to $95 \%$. Tree condition had great influence on the occurrence of excavated cavities (Fig. 4.12). Living trees were much less likely to hold excavated cavities than dead ones, except when the trees were extremely small or large. For trees of DBH $50 \mathrm{~cm}$ without fungi conks, the probability of holding excavated cavities was about 0.07 for living trees, six times less than that of dead intact trees $(0.39)$ and seven times less than that of broken snags (0.49). The presence of fungi conks raised the cavity holding probability. For trees of DBH $50 \mathrm{~cm}$, those with fungi conks were approximately twice more likely to hold excavated cavities than those without.

In the model of the probability a tree holding non-excavated cavities, the presence of fire scars was included instead of the presence of fungi conks (Table 4.8; log likelihood $\left.=-128.15, ?^{2}=194.76, \mathrm{df}=5, \mathrm{p}<0.001\right)$. With this model, whether a tree holding non-excavated cavities or not could be correctly predicted in $92 \%$ of the cases. When compared with the pattern of excavated cavities, the difference resulted from tree condition was relatively less strong (Fig. 4.13). For trees of DBH $50 \mathrm{~cm}$ without fire scars, the probability of holding non-excavated cavities was about 0.35 for living trees, slightly less than that of dead intact trees (0.47) and broken snags $(0.60)$. The presence of fire scars increased the cavity holding probability. Living trees with fire scars had probability of holding non-excavated cavities similar to that of broken snags without fire scars. For trees of DBH $50 \mathrm{~cm}$, those with fire scars were about 1.5 times more likely to hold non-excavated cavities than those without. 


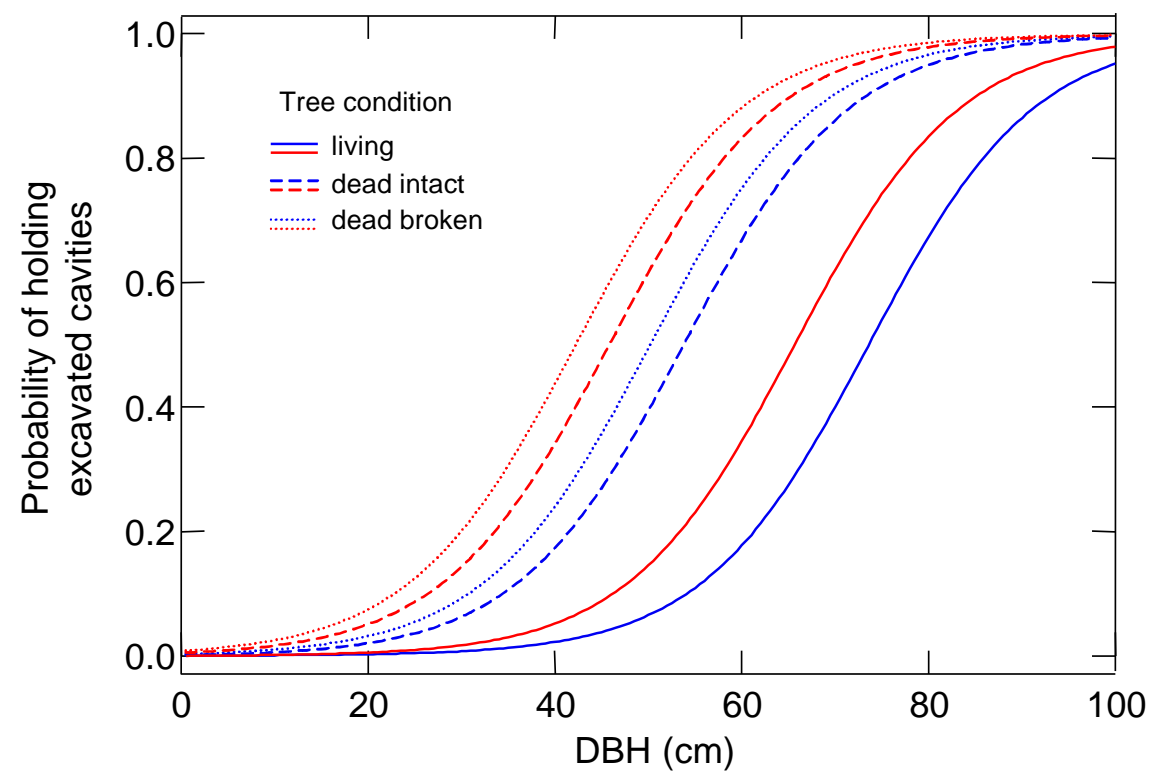

Fig. 4.12 Predicted probability of the occurrence of excavated cavities in deciduous trees with (red) and without (blue) fungi conks, in relation to tree DBH and tree condition.

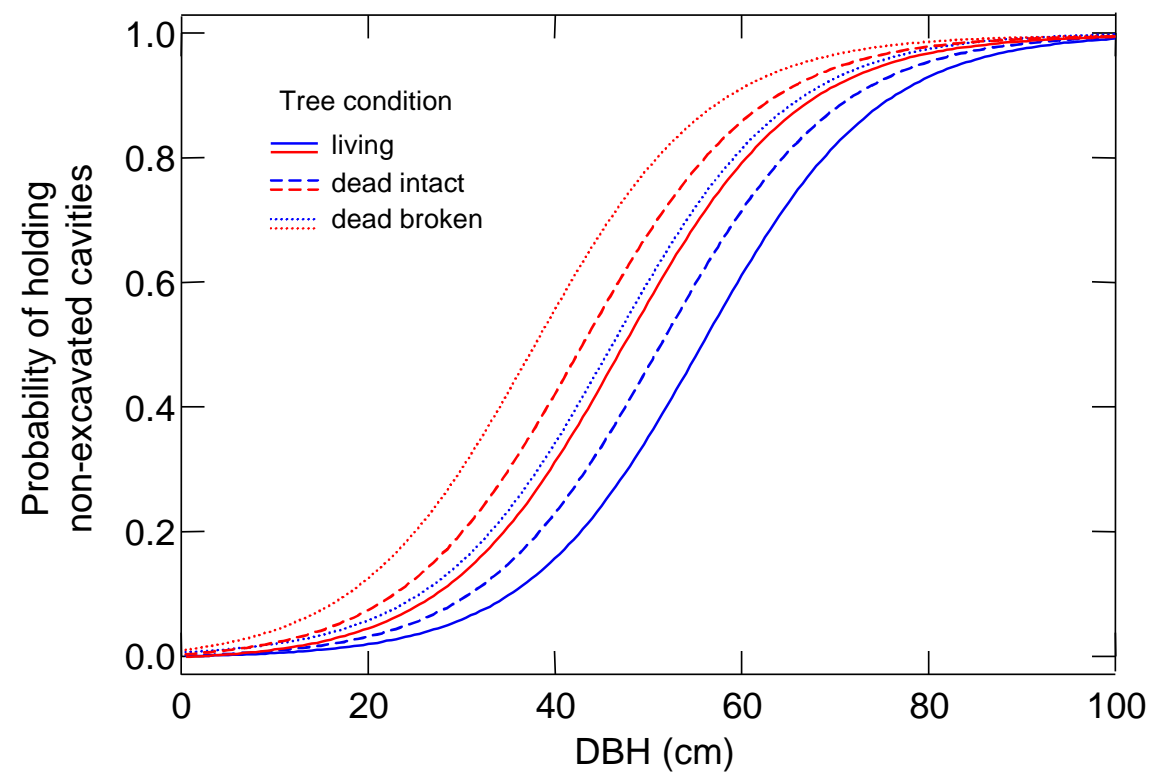

Fig. 4.13 Predicted probability of the occurrence of non-excavated cavities in deciduous trees with (red) and without (blue) fire scars, in relation to tree DBH and tree condition. 


\subsection{Composition of CNB Community}

\subsubsection{CNB composition in the study area}

A total of 259 nests from 16 cavity nesting bird species were found in the study period, including 6 species of primary cavity nesters (PCNs) and 10 species of secondary cavity nesters (SCNs; Table 4.9). 49 and 48 nests were located in the sampling plots (total area $20 \mathrm{ha}$ ) in 2002 and 2003 respectively, and others were found outside the plots. In each habitat, neither the number of nests nor the number of species showed significant difference between years, so the data for both years were pooled.

Table 4.9 Number of nest of each species found in each habitat.

\begin{tabular}{|c|c|c|c|c|c|c|c|c|c|c|c|}
\hline & \multirow{3}{*}{ Bird species } & \multicolumn{8}{|c|}{ Nests in plots } & \multirow{3}{*}{$\begin{array}{l}\text { Nests off } \\
\text { plots }\end{array}$} & \multirow{3}{*}{ Sum } \\
\hline & & \multicolumn{4}{|c|}{2002} & \multicolumn{4}{|c|}{2003} & & \\
\hline & & BLm & BLy & $\mathrm{RM}$ & SF & BLm & BLy & $\mathrm{RM}$ & SF & & \\
\hline \multirow{6}{*}{ Z } & Dryocopus martius & & & 1 & & & & & & 2 & 3 \\
\hline & Picus canus & & & & & 1 & & & & 4 & 5 \\
\hline & Dendrocopos leucotos & & & & & & & & & 3 & 3 \\
\hline & Dendrocopos major & & & & & & 1 & & & 12 & 13 \\
\hline & Dendrocopos minor & 2 & 1 & & & & & 1 & & 9 & 13 \\
\hline & Parus montanus & 2 & 3 & 6 & 2 & 4 & 4 & 5 & 2 & 36 & 64 \\
\hline \multirow{10}{*}{$\begin{array}{l}Z \\
\text { ¿ }\end{array}$} & Bucephala clangula & & & 1 & & & & 1 & & & 2 \\
\hline & Jynx torquilla & & & & & & & & & 2 & 2 \\
\hline & Phoenicurus auroreus & 1 & & 1 & & 1 & 1 & 1 & & 18 & 23 \\
\hline & Phoenicurus phoenicurus & & 1 & & & & & & & 1 & 2 \\
\hline & Turdus ruficollis & & & & & & & & & 3 & 3 \\
\hline & Ficedula albicilla & 1 & 3 & 1 & & 2 & 2 & 2 & & 14 & 25 \\
\hline & Parus ater & 5 & 4 & 5 & 3 & 4 & 3 & 5 & 3 & 21 & 53 \\
\hline & Parus major & 1 & & 1 & & & & 2 & & 12 & 16 \\
\hline & Sitta europaea & & 1 & 1 & & & 1 & 1 & & 17 & 21 \\
\hline & Certhia familiaris & 1 & 1 & & & 1 & & & & 8 & 11 \\
\hline \multirow{2}{*}{\multicolumn{2}{|c|}{$\begin{array}{l}\text { Total number of nests } \\
\text { Total number of species }\end{array}$}} & 13 & 14 & 17 & 5 & 13 & 12 & 18 & 5 & 162 & 259 \\
\hline & & 7 & 7 & 8 & 2 & 6 & 6 & 8 & 2 & 15 & 16 \\
\hline
\end{tabular}

The density of cavity-nesting birds in the study area averaged 2.4 nests/ha, which varied from 1.0 nest/ha in the spruce-fir forest to 3.5 nests/ha in the riparian mixed forest (Table 4.10). The spruce-fir forest had both lower density and fewer species number than the other three habitats (Mann-Whitney U test, $p<0.01$ with each of other habitats), while there were no significant differences among the three deciduous stands. The density of PCNs and the density of SCNs were positively correlated 
(Pearson correlation $\mathrm{r}=0.830, \mathrm{p}<0.05$ ). When considering $P$. montanus separately as WPCN, there were weak positive correlations between PCN and SCN (Pearson correlation $r=0.730, p=0.120$ ) and between WPCN and SCN (Pearson correlation $r$ $=0.662, \mathrm{p}=0.222$ ), while no correlation between PCN and WPCN (Pearson correlation $\mathrm{r}=0.221, \mathrm{p}=1.000)$.

Species composition of the three deciduous habitats was quite similar (Sorensen's similarity coefficient $=0.67-0.71$ ), while the spruce-fir forest was distinct from the others (Sorensen's similarity coefficient $=0.36-0.40$ ).

Table 4.10 Density of nests and hole-nesting species (mean per ha \pm SD) and cavity occupancy (\%) by SCNs in each habitat.

\begin{tabular}{lccc}
\hline Habitat & No. of nests (/ha) & No. of species (/ha) & Cavity occupancy (\%) \\
\hline BLm & $2.6 \pm 0.8$ & $2.4 \pm 0.8$ & 7.0 \\
BLy & $2.6 \pm 1.3$ & $2.4 \pm 1.0$ & 4.6 \\
RM & $3.5 \pm 1.5$ & $3.1 \pm 1.3$ & 5.6 \\
SF & $1.0 \pm 0.7$ & $1.0 \pm 0.7$ & 3.3 \\
\hline Overall & $2.4 \pm 1.0$ & $2.2 \pm 0.9$ & 5.2 \\
\hline
\end{tabular}

Cavity occupancy was estimated by dividing the mean cavity density (Table 4.3) by SCNs density in each habitat. The overall occupancy in the study area was 5.2\%. Occupancy was highest in the mature birch-larch forest and lowest in the spruce-fir forest (Table 4.10).

\subsubsection{Relationship between CNB abundance and habitat variables}

Correlating CNB density with habitat variables, the proportion of deciduous stems and shrub coverage showed significant relationships with CNB density (Table 4.11). Both PCNs and SCNs were more abundant in stands with more deciduous trees. PCNs also had higher density in stands with higher shrub coverage. The densities of neither PCNs nor SCNs were related to cavity abundance. Considering species richness, there were more CNB species in stands with higher deciduous components. 
Table 4.11 Correlation coefficients between density of CNBs, number of CNB species and habitat features, including proportion of deciduous stems (= Prop. decid.), proportion of large trees (= Prop. large), proportion of dead trees (= Prop. dead), proportions of trees with fire scars (= Prop. fire), shrub coverage, component scores of principal component 1 (= Prin. comp. 1) and 2 (= Prin. comp. 2), and cavity density.

\begin{tabular}{lcccc}
\hline & \multicolumn{3}{c}{ Density of } & $\begin{array}{c}\text { Number of } \\
\text { CNB species }\end{array}$ \\
\cline { 2 - 4 } & PCN & SCN & All CNBs & $0.544^{*}$ \\
\cline { 2 - 4 } Prop. decid. & $0.509^{\star}$ & $0.535^{\star}$ & $0.645^{\star *}$ & 0.168 \\
Prop. large & 0.278 & 0.251 & 0.323 & 0.122 \\
Prop. dead & -0.009 & -0.102 & -0.079 & 0.289 \\
Prop. fire & 0.069 & 0.254 & 0.220 & 0.305 \\
Shrub coverage & $0.566^{* *}$ & 0.261 & $0.475^{*}$ & $-0.469^{\star}$ \\
Prin. comp. 1 & $-0.507^{*}$ & $-0.454^{*}$ & $-0.586^{* *}$ & -0.416 \\
Prin. comp. 2 & -0.173 & -0.397 & -0.376 & 0.314 \\
Cavity density & 0.220 & 0.259 & 0.299 & \\
\hline
\end{tabular}

Bonferroni probability, ${ }^{*} \mathrm{p}<0.1, * * \mathrm{p}<0.05$.

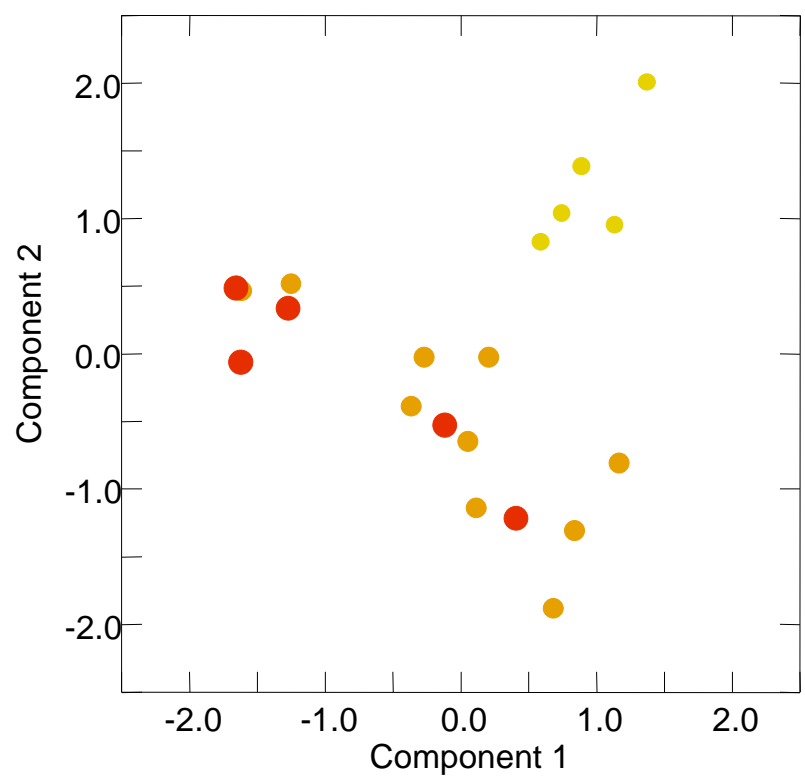

Density of CNBs (n/ha)

$0<2$

$2-3$

$>3$

Fig. 4.14 Densities of cavity-nesting birds of each plot projected onto principal components 1 and 2 . 
The density of CNBs was negatively correlated with principal component 1 (Table 4.11 and Fig. 4.14). Both PCN and SCN densities were higher in the riparian stands, as well as the species richness. Component 1 could explain $34 \%$ of the total variation in overall CNB density. CNB density and number of CNB species were not correlated with principal component 2 when all habitats were considered. However, when excluding the riparian stands and considering only the plots in mountain taiga, both SCN density and overall CNB density were negatively correlated with component 2 (Pearson correlation $r=-0.611, p<0.05$ for SCN, $r=-0.641, p<0.05$ for overall density), as well as the species number (Pearson correlation $\mathrm{r}=-0.581, \mathrm{p}<$ 0.05). Lower CNB density and less CNB species occurred in dark taiga.

\subsubsection{Species abundance distribution}

The species abundance distribution of each habitat could not be examined separately, due to the limited sample size. Since the mature and the young birch-larch forests had similar species composition, and no CNB species showed different abundance in these two habitats (Table 4.9), the data of both birch-larch forests and of both years were pooled and used in the following analysis.

The species abundance pattern in the birch-larch forest was plotted in Fig. 4.15(a). $P$. ater and $P$. montanus were the dominant species. This pattern showed no difference from lognormal distribution $\left(?^{2}=3.11\right.$, df $\left.=4, \mathrm{p}=0.539\right)$, nor from logseries distribution $\left(?^{2}=4.67, \mathrm{df}=4, \mathrm{p}=0.323\right)$.

The species abundance distributions of other seven CNB communities were also plotted for comparison. This included the CNB communities of the natural oak forest in Andersby, Sweden (Fig. 4.15(b); CARLSON et al. 1998), the natural ash-alder forest (Fig. 4.15(c)) and oak-hornbeam forest (Fig. 4.15(d)) in Bialowieza, Poland (WESOLOWSKI et al. 2002), the managed larch-Douglas fir forest in Montana, USA (Fig. 4.15(e); MCCLELLAND et al. 1979), the beech-oak wooded area near Arnhem, Netherlands (Fig. 4.15(f); VAN BALEN et al. 1982), and the CNBs using nest boxes in deciduous wooded area in Hoge Veluwe (Fig. 4.15(g)) and Warnsborn (Fig. 4.15(h)), Netherlands (VAN BALEN et al. 1982). The species abundance distribution of Mongolian birch-larch forest did not differ from that of other CNB communities 
(a)

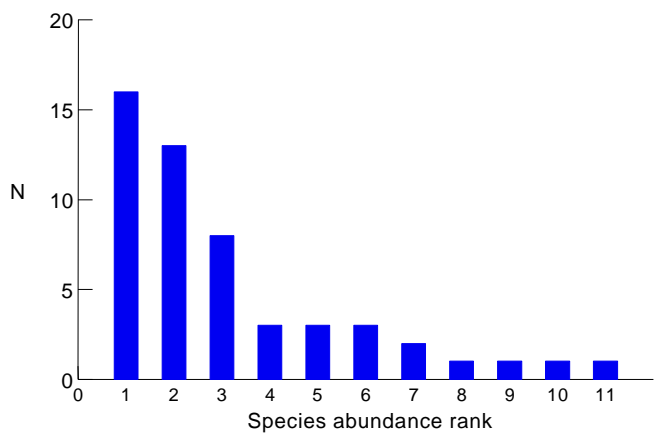

(c)

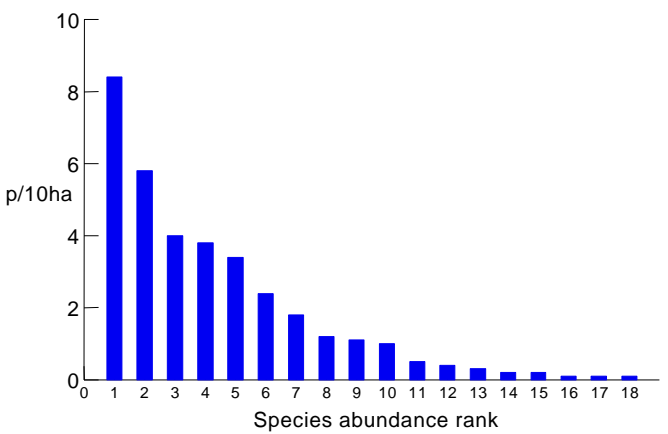

(e)

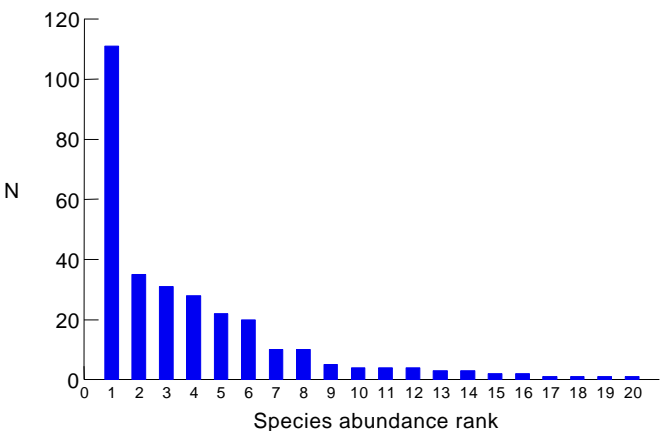

(g)

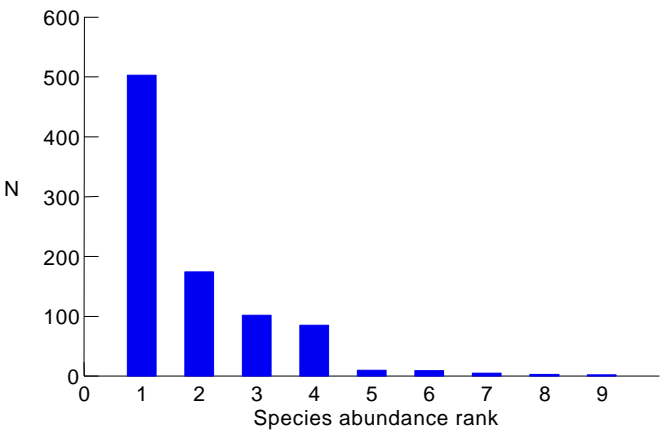

(b)

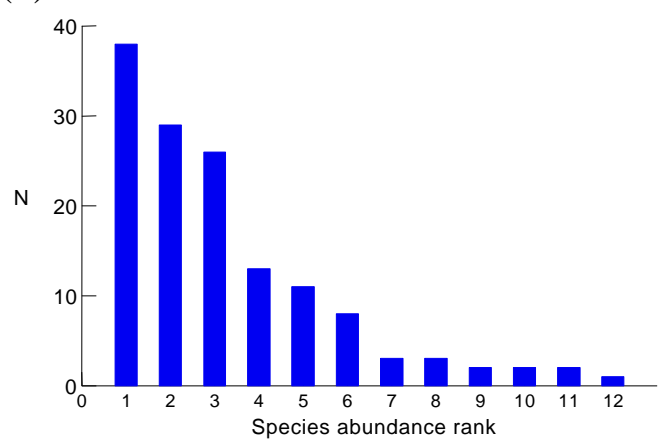

(d)

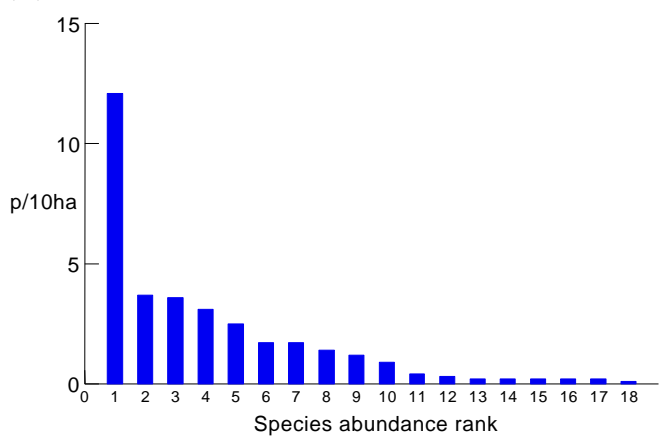

(f)

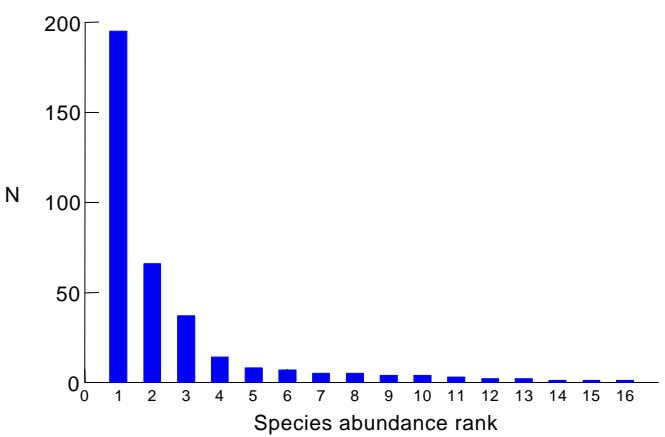

(h)

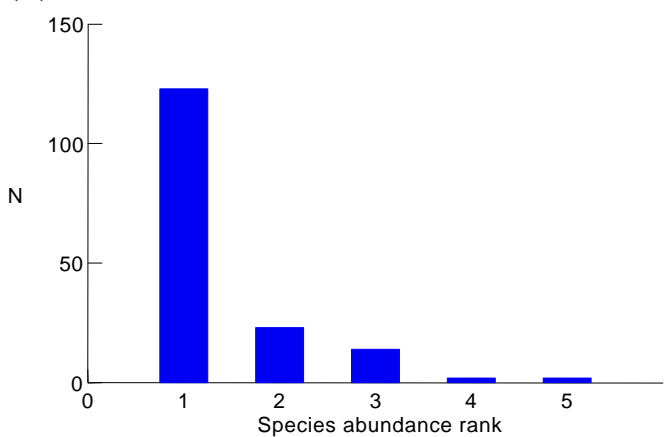

Fig. 4.15 Species abundance distribution of CNBs of (a) birch-larch forest in WestKhentey, (b) natural oak forest in Andersby, Sweden (CARLSON et al. 1998), (c) natural ash-alder forest in Bialowieza, Poland (WESOLOWSKI et al. 2002), (d) natural oakhornbeam forest in Bialowieza, Poland (WESOLOWSKI et al. 2002), (e) managed larchDouglas fir forest in Montana, USA (MCCLELLAND et al. 1979), (f) beech-oak wooded area in Arnhem, Netherlands (VAN BALEN et al. 1982), (g) nest boxes in deciduous wooded area in Hoge Veluwe, Netherlands (VAN BALEN et al. 1982), and (h) nest boxes in deciduous wooded area in Warnsborn, Netherlands (VAN BALEN et al. 1982). 
breeding in natural cavities (Fig. 4.15(b) - (f); ? ${ }^{2}$ test, $\mathrm{p}>0.05$ ), but significantly differed from that of CNBs using nest boxes (Fig. 4.15(g) - (h); ? ${ }^{2}$ test, p < 0.001).

The species abundance pattern of Mongolian birch-larch forest was most similar to those of Swedish natural oak forest and Polish natural ash-alder forest. The species abundance decreased in a gradual manner from common species to rare species (Fig. 4.15(a) - (c)). In Polish natural oak-hornbeam forest, American managed larchDouglas fir forest and Dutch beech-oak wooded area, there were a protrusive dominant species in the CNB community (Fig. 4.15(d) - (f)). This single dominant species accounted for $36 \%, 37 \%$ and $55 \%$ of the individuals in these CNB communities, respectively, and was about three times more abundant than the second common species. While in the first three CNB communities, the abundance of the first dominant species was only about $1.2-1.4$ times of the second one.

Fewer species inhabited nest boxes, and one of them appeared as a protrusive dominant (Fig. 4.15(g) - (h)). The first dominant species represented 56\% and $75 \%$ of all the individuals using nest boxes in the two Dutch wooded areas, and was 3 - 5 times more abundant than the second common species. 


\subsection{Utilisation of Trees and Cavities by CNBs}

\subsubsection{Tree species}

Of the 97 nests located in plots, 68\% were found in birch trees (Table 4.12). Eight out of 13 bird species utilised birch. Poplar was the second important nest tree species, accounted for $13 \%$ of the nests and was used by 6 bird species. No nests were found in rowan, Siberian pine, fir and spruce. PCNs and SCNs showed similar patterns in tree species utilisation $\left(?^{2}=5.63, \mathrm{df}=5, \mathrm{p}=0.344\right)$, and were pooled in the following analysis.

Table 4.12 Species composition (\%) of nest trees used by PCNs and SCNs.

\begin{tabular}{|c|c|c|c|c|c|c|c|}
\hline & \multicolumn{6}{|c|}{ Tree species } & \multirow{2}{*}{$\mathrm{N}$} \\
\hline & Willow & Aspen & Poplar & Birch & Larch & $\begin{array}{l}\text { Scots } \\
\text { pine }\end{array}$ & \\
\hline PCNs & 2.9 & 5.7 & 20.0 & 65.7 & 2.9 & 2.9 & 35 \\
\hline SCNs & 1.6 & 1.6 & 9.7 & 69.4 & 9.7 & 8.1 & 62 \\
\hline Overall & 2.1 & 3.1 & 13.4 & 68.0 & 7.2 & 6.2 & 97 \\
\hline
\end{tabular}

The species composition of nest trees differed from the relative abundance of tree species in the forests $\left(?^{2}=144.10, \mathrm{df}=9, \mathrm{p}<0.001\right)$. Poplar, which comprised only $3 \%$ of the standing stems (Table 4.5), was strongly selected by CNBs (Yates corrected $\left.?^{2}=57.80, \mathrm{df}=1, \mathrm{p}<0.001\right)$. Birch, which was frequent in the forest $(37 \%)$, was also used overproportionally (Yates corrected $?^{2}=34.18, \mathrm{df}=1, \mathrm{p}<0.001$ ). Siberian pine, fir and spruce were used underproportionally $\left(?^{2}\right.$ test with Yates correction, $\mathrm{p}<0.05$ for Siberian pine, $\mathrm{p}<0.001$ for fir and spruce).

Comparing the species composition of cavity trees (Table 4.5) with that of nest trees, no significant difference were found $\left(?^{2}=0.00, \mathrm{df}=9, \mathrm{p}=1.000\right)$. Most of the cavities were located in birch, so were the nests. Poplar and larch were the next important cavity tree species, and were thus frequently served as nest trees.

Tree species differed among habitats, but the utilisation of nest tree species followed some general rules. In each habitat, PCNs and SCNs had similar patterns in their use 
of tree species $\left(?^{2}\right.$ test, $\mathrm{p}>0.05$ in each habitat). And this pattern differed from the tree species composition in the corresponding habitat $\left(?^{2}\right.$ test, $\mathrm{p}<0.01$ in each habitat). In both the mature and the young birch-larch forests, birch was used overproportionally. In the riparian forest, poplar was used overproportionally and birch was only used in proportion to its abundance. In the spruce-fir forest, both birch and larch were used overproportionally, and Siberian pine, spruce and fir were used underproportionally. Species composition of nest trees did not differ from that of cavity trees in each habitat $\left(?^{2}\right.$ test, $\mathrm{p}>0.05$ in each habitat).

\subsubsection{Tree DBH}

Trees of different DBH were used disproportional to their abundance in the forests $\left(?^{2}\right.$ $=232.66, \mathrm{df}=2, \mathrm{p}<0.001)$. Most of the nests $(60 \%)$ were located in trees of DBH $25-50 \mathrm{~cm}$, which accounted for only about $10 \%$ of the standing stems. Trees of DBH larger than $50 \mathrm{~cm}$, containing $13 \%$ of the nests, were even more strongly selected relative to their abundance (1\%). Trees of DBH under $25 \mathrm{~cm}$, accounting for $88 \%$ of the standing stems and $27 \%$ of the nests, were used underproportionally.

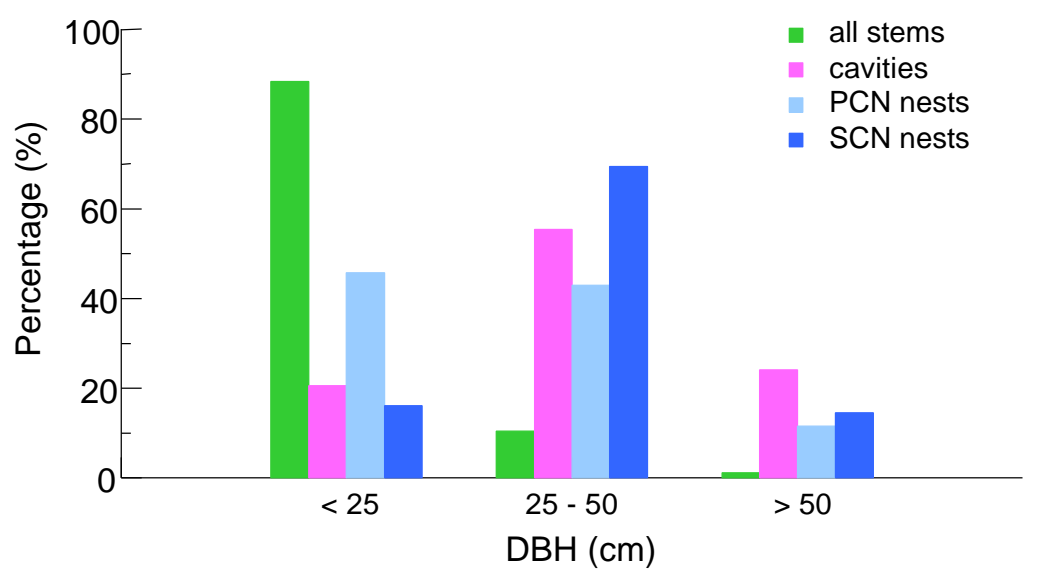

Fig. 4.16 The percentage constitution of all sampled stems (green bars; $n=863$ ), total cavities (red bars; $n=157$ ), nests of PCNs (cyan bars; $n=35$ ) and nests of SCNs (blue bars; $n=62$ ) according to tree $\mathrm{DBH}$.

The DBH distribution of nest trees differed between PCNs and SCNs (Fig. 4.16, cyan and blue bars; $\left.?^{2}=10.09, \mathrm{df}=2, \mathrm{p}<0.01\right)$. Both group of birds used small trees underproportionally (Fig. 4.16, green bars), but SCNs used even less small trees than 
PCNs. $46 \%$ of PCN nests were located in trees of DBH $<25 \mathrm{~cm}$, while only $20 \%$ of $\mathrm{SCN}$ nests were found in these trees (Yates corrected $?^{2}=8.53, \mathrm{df}=1, \mathrm{p}<0.01$ ). The $\mathrm{DBH}$ distribution of SCN nest trees was not significantly different from the DBH distribution of cavity trees (Fig. 4.16 , red bars; $?^{2}=3.82$, df $=2, p=0.148$ ).

\subsubsection{Tree condition}

$63 \%, 13 \%$ and $24 \%$ of CNB nests were located in living trees, intact dead trees and broken snags, respectively. Compared with the tree condition constitution in the forests $(85 \%, 10 \%, 5 \%$, respectively; Fig. 4.17, green bars), living trees were used underproportionally (Yates corrected $?^{2}=28.56$, df $=1, \mathrm{p}<0.001$ ), and broken snags were used overproportionally (Yates corrected $?^{2}=42.56$, $\mathrm{df}=1, \mathrm{p}<0.001$ ). The nest holding rate of broken snags was six times higher than that of living trees, and 3 times higher than that of intact dead trees.

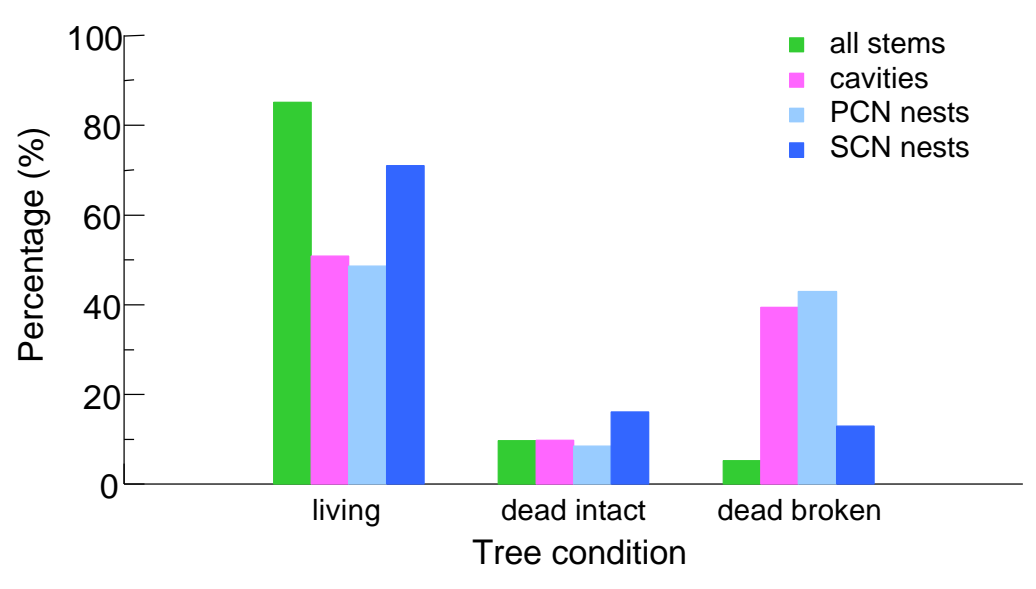

Fig. 4.17 The percentage constitution of all sampled stems (green bars; $n=863$ ), total cavities (red bars; $n=157$ ), nests of PCNs (cyan bars; $n=35$ ) and nests of SCNs (blue bars; $n=62$ ) according to tree condition.

PCNs and SCNs differed in their nest tree condition (Fig. 4.17, cyan and blue bars; $?^{2}$ $=11.20, \mathrm{df}=2, \mathrm{p}<0.01)$. Both group of birds used living trees underproportionally and used broken snags overproportionally, while PCNs avoided living trees and preferred broken snags further than SCNs. Living trees contained $71 \%$ of SCN nests but only $49 \%$ of PCN nests (Yates corrected $?^{2}=3.90, \mathrm{df}=1, \mathrm{p}<0.05$ ). Broken 
snags accounted for $13 \%$ of SCN nests, while $43 \%$ of PCN nests were established in them (Yates corrected $?^{2}=9.50, \mathrm{df}=1, \mathrm{p}<0.01$ ).

SCNs did not use cavities in trees of different condition according to their availability (Fig. 4.17, red bars). Cavities in living trees were used overproportionally (Yates corrected $\left.?^{2}=6.46, \mathrm{df}=1, \mathrm{p}<0.05\right)$, and those in broken snags were used underproportionally (Yates corrected $?^{2}=13.25, \mathrm{df}=1, \mathrm{p}<0.001$ ).

\subsubsection{Presence of fire scars}

Most of the nests (64\%) were located in trees with fire scars, which comprised only $28 \%$ of the standing stems (Yates corrected $\left.?^{2}=51.92, \mathrm{df}=1, \mathrm{p}<0.001\right)$. Nest holding rate of fire-scarred trees was 5 times higher than that of trees without fire scars.

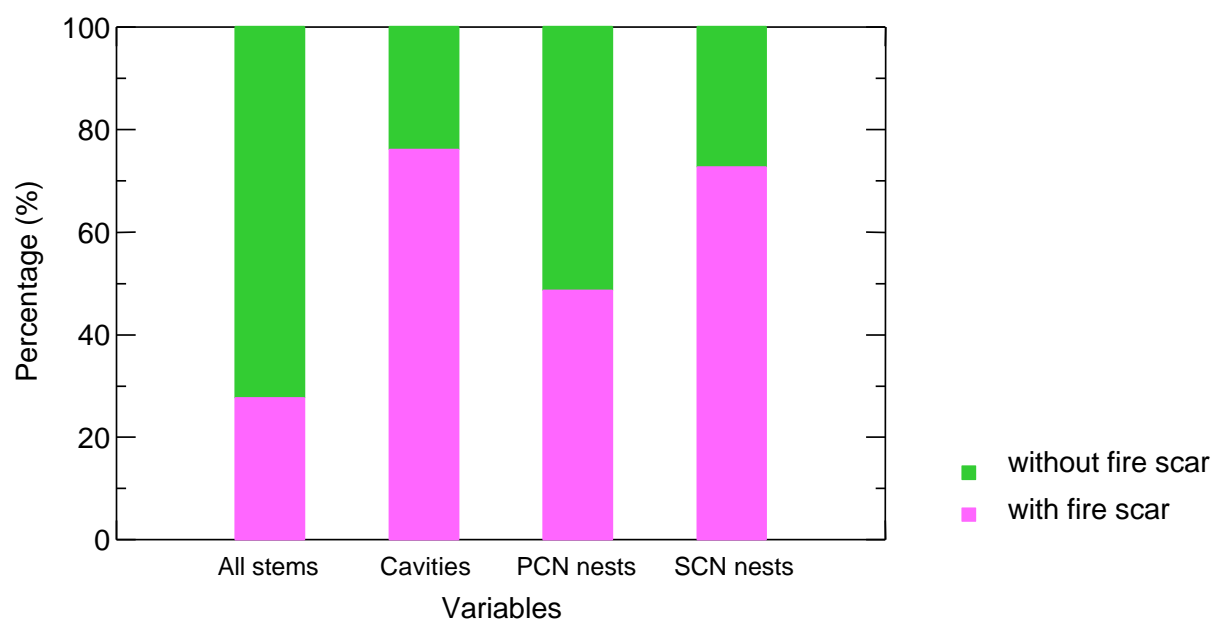

Fig. 4.18 The percentage of all sampled stems $(n=863)$, total cavities $(n=157)$, nests of PCNs $(n=35)$ and nests of SCNs $(n=62)$ according to the presence of fire scars.

Both PCNs and SCNs utilised fire-scarred trees overproportionally (Yates corrected ? ${ }^{2}$ $=6.30, \mathrm{df}=1, \mathrm{p}<0.05$ for PCNs, Yates corrected $?^{2}=53.07, \mathrm{df}=1, \mathrm{p}<0.001$ for SCNs), while SCNs nested in these trees even more frequently than PCNs (Fig. 4.18; Yates corrected $\left.?^{2}=4.60, \mathrm{df}=1, \mathrm{p}<0.05\right)$. For SCN nests, the nest holding rate of 
fire-scarred trees was 7 times higher than that of trees without fire scars, while for PCN nests only about 2 times higher. The extent SCNs using fire-scarred trees (73\%) was similar to the cavity availability in these trees $\left(76 \%\right.$; Yates corrected $?^{2}=0.53$, df $=1, \mathrm{p}=0.468$ ).

\subsubsection{Presence of fungi conks}

$38 \%$ of the nests were found in conk-bearing trees, which accounted for only $5 \%$ of the standing stems (Yates corrected $?^{2}=144.76, \mathrm{df}=1, \mathrm{p}<0.001$ ). Nest holding rate of trees with fungi conks was 11 times higher than that of trees without.

PCNs showed higher tendency to use conk-bearing trees than SCNs (Fig. 4.19; Yates corrected $\left.?^{2}=7.16, \mathrm{df}=1, \mathrm{p}<0.01\right) .57 \%$ and $27 \%$ of PCN and SCN nests, respectively, were established in trees with fungi conks. Conk-bearing stems held PCN nests 23 times more frequently, and held SCN nests 7 times more frequently, than those without conks did. The proportion SCNs using conk-bearing trees was similar to cavity availability in these trees $\left(29 \%\right.$; Yates corrected $?^{2}=0.01$, df $=1, p=$ 0.911).

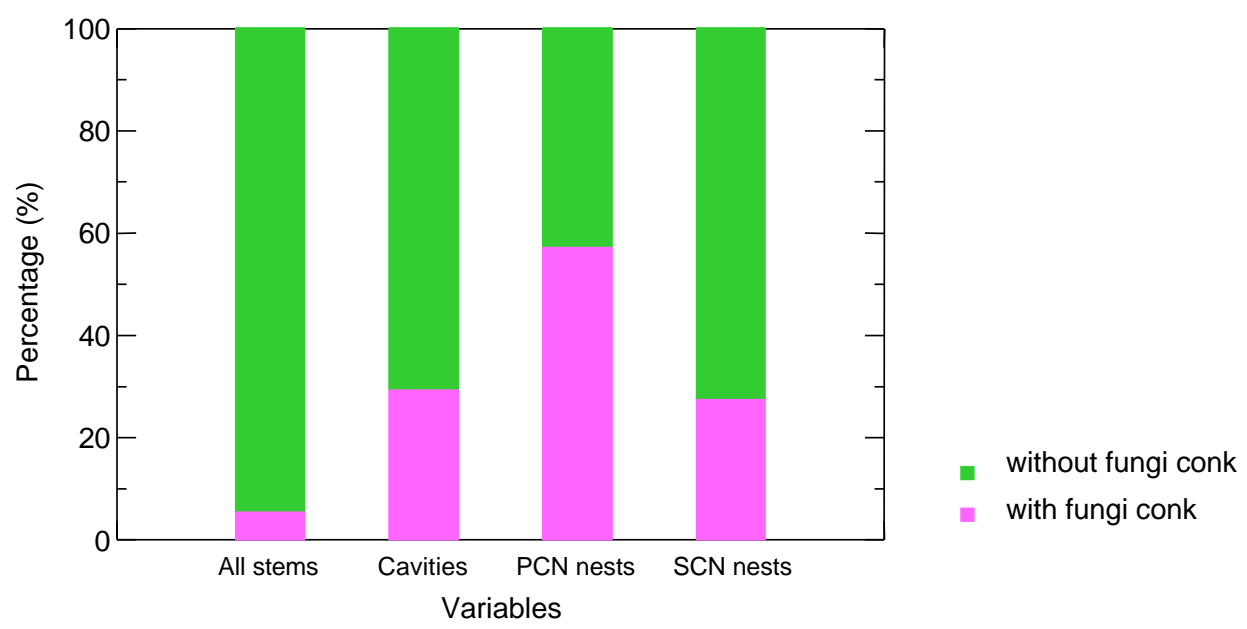

Fig. 4.19 The percentage of all sampled stems $(n=863)$, total cavities $(n=157)$, nests of PCNs $(n=35)$ and nests of SCNs $(n=62)$ according to the presence of fungi conks. 


\subsubsection{Cavity type}

PCNs and SCNs differed in their use of cavity type (Fig. 4.20, cyan and blue bars; ? $=47.69$, df $=3, \mathrm{p}<0.001)$. PCNs mostly nested in cavities excavated by themselves or other PCNs, while in few cases $(11 \%)$ P. montanus also utilised branch hole. For SCNs, the majority $(71 \%)$ of their nests were established in branch hole, and $18 \%$ in woodpecker hole.

In comparison to the relative abundance of each cavity type (Fig. 4.20, red bars), branch hole was used overproportionally (Yates corrected $?^{2}=4.53, \mathrm{df}=1, \mathrm{p}<0.05$ ) and other bird-induced hole was used underproportionally by SCNs (Yates corrected $\left.?^{2}=10.86, \mathrm{df}=1, \mathrm{p}<0.01\right)$. Woodpecker hole and bark crevice were utilised in proportion to their availability (Yates corrected $?^{2}=0.55, \mathrm{df}=1, \mathrm{p}=0.458$ for woodpecker hole, Yates corrected $?^{2}=0.00, \mathrm{df}=1, \mathrm{p}=1.000$ for bark crevice).

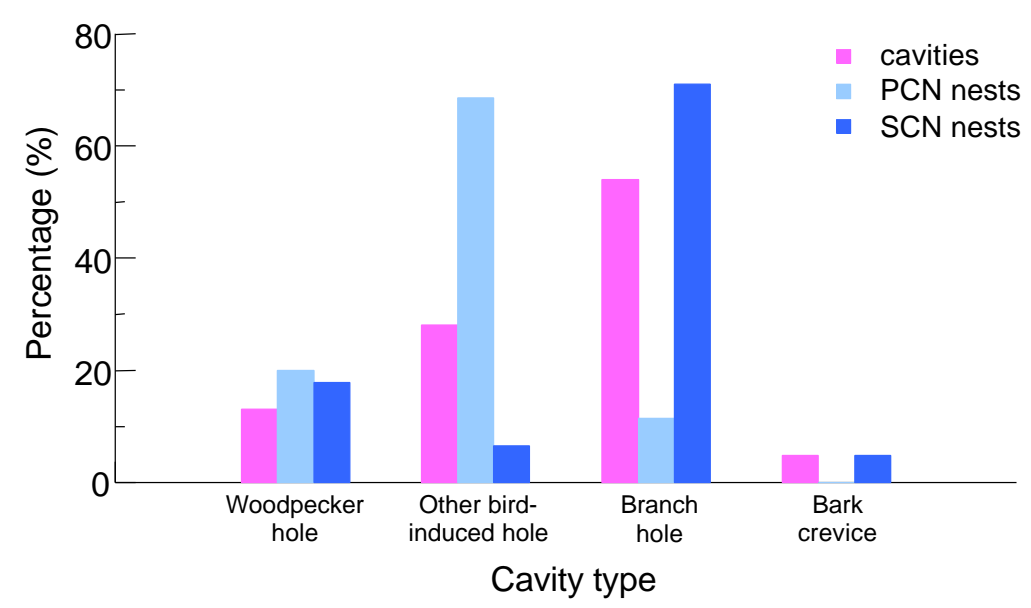

Fig. 4.20 The percentage constitution of total cavities (red bars; $n=157$ ), nests of PCNs (cyan bars; $n=35$ ) and nests of SCNs (blue bars; $n=62$ ) according to cavity type. 


\subsection{Nest Site Selection of Individual Species}

\subsubsection{Selection of nest tree}

\section{$\underline{\text { Tree species }}$}

The preference for nest tree species differed among bird species (Table $4.13 ; ?^{2}=$ 181.60, $\mathrm{df}=40, \mathrm{p}<0.001)$. Three bird species showed patterns distinct from that of others. C. familiaris placed $64 \%$ of its nests in larch, D. major preferred aspen, and $S$. europaea used both larch and aspen overproportionally. All other six species established most of their nests in birch, with proportions from $69 \%$ in $D$. minor to 96\% in F. albicilla. Thus these six species mainly using birch had smaller niche breadth, and showed high niche overlap between each other (Fig. 4.21). C. familiaris, D. major and S. europaea had larger niche breadth, and had less overlap with the former group.

Table 4.13 Species composition of nest trees (in \%) used by each bird species.

\begin{tabular}{|c|c|c|c|c|c|c|c|c|}
\hline \multirow[b]{2}{*}{ Bird species } & \multicolumn{6}{|c|}{ Tree species } & \multirow[b]{2}{*}{$\mathrm{N}$} & \multirow{2}{*}{$\begin{array}{c}\text { Levins' } \\
\text { B }\end{array}$} \\
\hline & Willow & Aspen & Poplar & Birch & Larch & $\begin{array}{c}\text { Scots } \\
\text { pine }\end{array}$ & & \\
\hline Dendrocopos major & - & 53.8 & - & 30.8 & - & 15.4 & 13 & 2.45 \\
\hline D. minor & - & 15.4 & 7.7 & 69.2 & 7.7 & - & 13 & 1.94 \\
\hline Phoenicurus auroreus & 4.3 & - & 4.3 & 73.9 & 17.4 & - & 23 & 1.72 \\
\hline Ficedula albicilla & - & 4.0 & - & 96.0 & - & - & 25 & 1.08 \\
\hline Parus ater & - & 1.9 & 3.8 & 86.8 & 3.8 & 3.8 & 53 & 1.32 \\
\hline P. major & - & - & 18.8 & 81.3 & - & - & 16 & 1.44 \\
\hline P. montanus & 3.1 & - & 12.5 & 81.3 & 3.1 & - & 64 & 1.48 \\
\hline Sitta europaea & - & 23.8 & - & 19.0 & 38.1 & 19.0 & 21 & 3.64 \\
\hline Certhia familiaris & - & 9.1 & - & 18.2 & 63.6 & 9.1 & 11 & 2.20 \\
\hline
\end{tabular}

Birch comprised $13 \%$ to $68 \%$ of the standing stems across different habitats (see Section 4.1), thus the high use rates of birch by $P$. auroreus, $F$. albicilla, $P$. ater, $P$. major and P. montanus suggested use over its availability. Larch, comprising $1 \%$ to $32 \%$ of the standing stems, was overproportionally used by $C$. familiaris. Poplar, which occurred only in the riparian mixed forest and constituted about $8 \%$ of the stems there, was used by P. major and P. montanus overproportionally. Aspen 


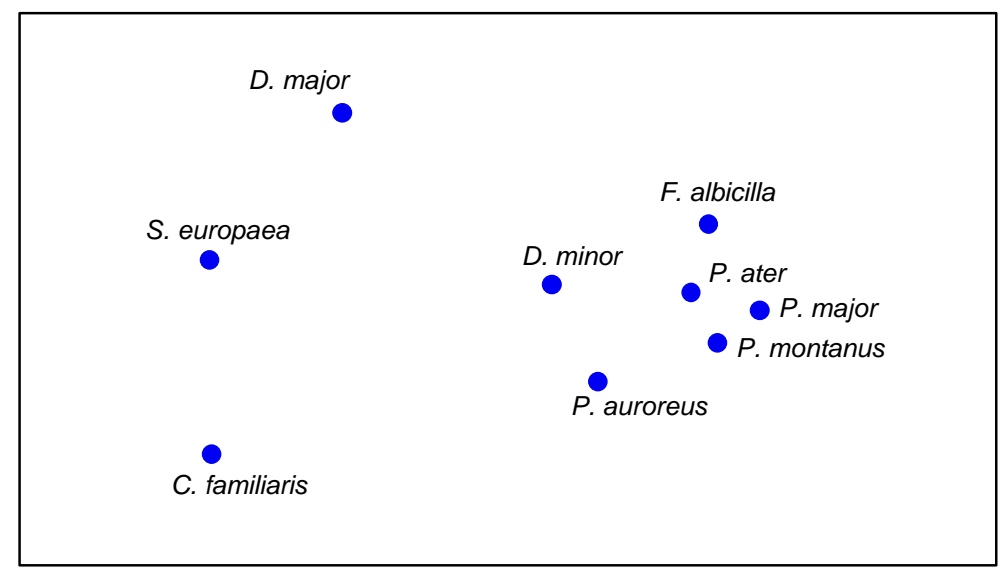

Fig. 4.21 The Renkonen similarity of nest tree species between bird species.

formed small patches in birch-larch forests, and its availability $(0-1 \%)$ could be biased due to its highly patchy distribution and the small sample size. However, the very high use rates of aspen by $D$. major, $D$. minor and $S$. europaea related to its availability suggested an overproportional use. Spruce, fir and Siberian pine occurred mainly in the spruce-fir forest and altogether comprised $81 \%$ of the trees there, but no nest was found in them. D. minor, $P$. auroreus and $P$. major were never observed in this habitat, and F. albicilla occurred only very seldom. For other species, these three conifers were used underproportionally.

Taking cavity availability into consideration, overall 57\% (16 - 100\% across different habitats) of the cavities were located in birch, $26 \%$ (0 - 78\%) in poplar, and no cavities were found in spruce, fir and Siberian pine (see Section 4.3.1). Thus the tree species use of most SCNs reflected the cavity availability in different tree species. The preference for cavity regarding tree species occurred in that $C$. familiaris preferred cavities in larch and S. europaea preferred those in aspen.

\section{$\underline{\text { Tree DBH }}$}

The DBH of nest trees ranged from $12 \mathrm{~cm}$ for $P$. montanus to $91 \mathrm{~cm}$ for $P$. ater. $P$. montanus differed from all other species in that they placed their nests in thinnest trees (Table 4.14; Mann-Whitney U test, $\mathrm{p}<0.05$ with $F$. albicilla, $\mathrm{p}<0.001$ with each of other species). D. major, S. europaea and C. familiaris never utilised trees thinner than $25 \mathrm{~cm}$, and the latter two showed highest preference for large trees (Mann-Whitney U test, $\mathrm{p}<0.001$ with each of other species except D. major). 
Table 4.14 Mean $( \pm$ SD) and the percentage in $25 \mathrm{~cm}$ ranks of nest tree DBH of each bird species.

\begin{tabular}{|c|c|c|c|c|c|}
\hline \multirow{2}{*}{ Bird species } & \multicolumn{4}{|c|}{$\mathrm{DBH}(\mathrm{cm})$} & \multirow{2}{*}{$\mathrm{N}$} \\
\hline & mean & $<25$ & $25-50$ & $>50$ & \\
\hline D. major & $38.5 \pm 7.2$ & 0.0 & 7.7 & 92.3 & 13 \\
\hline D. minor & $33.2 \pm 9.9$ & 15.4 & 7.7 & 76.9 & 13 \\
\hline P. auroreus & $35.0 \pm 11.5$ & 17.4 & 13.0 & 69.6 & 23 \\
\hline F. albicilla & $28.1 \pm 7.8$ & 40.0 & 0.0 & 60.0 & 25 \\
\hline P. ater & $34.0 \pm 15.5$ & 24.5 & 11.3 & 64.2 & 53 \\
\hline P. major & $35.1 \pm 8.5$ & 12.5 & 6.3 & 81.3 & 16 \\
\hline P. montanus & $24.6 \pm 11.1$ & 60.9 & 4.7 & 34.4 & 64 \\
\hline S. europaea & $46.9 \pm 14.5$ & 0.0 & 33.3 & 66.7 & 21 \\
\hline C. familiaris & $46.5 \pm 10.6$ & 0.0 & 27.3 & 72.7 & 11 \\
\hline
\end{tabular}

In the study area, the percentages of trees of DBH $<25 \mathrm{~cm}, 25-50 \mathrm{~cm}$ and $>50 \mathrm{~cm}$ were $88 \%, 10 \%$ and $1 \%$, respectively (see Section 4.5.2). Grouping DBH of nest trees into the same interval for comparison, all species used large trees overproportionally ( $?^{2}$ test, $\mathrm{df}=2, \mathrm{p}<0.001$ for each species). $21 \%, 55 \%$ and $24 \%$ of the cavities were found in trees of $\mathrm{DBH}<25 \mathrm{~cm}, 25-50 \mathrm{~cm}$ and $>50 \mathrm{~cm}$, respectively (see Section 4.5.2). Among SCNs, F. albicilla used cavities in thinner trees overproportionally $\left(?^{2}=9.50, \mathrm{df}=2, \mathrm{p}<0.01\right)$, while the others were not selective to cavities according to tree diameter.

\section{$\underline{\text { Tree condition }}$}

The nest tree condition differed significantly among bird species (Table 4.15; $?^{2}=$ 82.13, df $=16, \mathrm{p}<0.001)$. P. ater and $P$. major highly preferred living trees and thus had smaller niche breadth. They had high niche overlap with each other and were distinct from others (Fig. 4.22). D. major and S. europaea utilised living trees and intact dead trees more often and used broken snags only seldom. P. auroreus, F. albicilla and C. familiaris also placed most of their nests in living trees, while, in contrast to the former two groups, broken snags were often used. D. minor and $P$. montanus established most of their nests in broken snags. 
Table 4.15 Condition of nest trees (in \%) used by each bird species.

\begin{tabular}{lccccc}
\hline \multirow{2}{*}{ Bird species } & \multicolumn{3}{c}{ Tree condition } & N & $\begin{array}{c}\text { Levins' } \\
\text { B }\end{array}$ \\
\cline { 2 - 4 } D. major & living & dead intact & dead broken & & \\
\hline D. minor & 61.5 & 30.8 & 7.7 & 13 & 2.09 \\
P. auroreus & 30.8 & 15.4 & 53.8 & 13 & 2.45 \\
F. albicilla & 47.8 & 13.0 & 39.1 & 23 & 2.51 \\
P. ater & 52.0 & 16.0 & 32.0 & 25 & 2.51 \\
P. major & 96.2 & 3.8 & - & 53 & 1.08 \\
P. montanus & 87.5 & 6.3 & 6.3 & 16 & 1.29 \\
S. europaea & 43.8 & 4.7 & 51.6 & 64 & 2.18 \\
C. familiaris & 45.5 & 33.3 & 4.8 & 21 & 2.01 \\
\hline
\end{tabular}

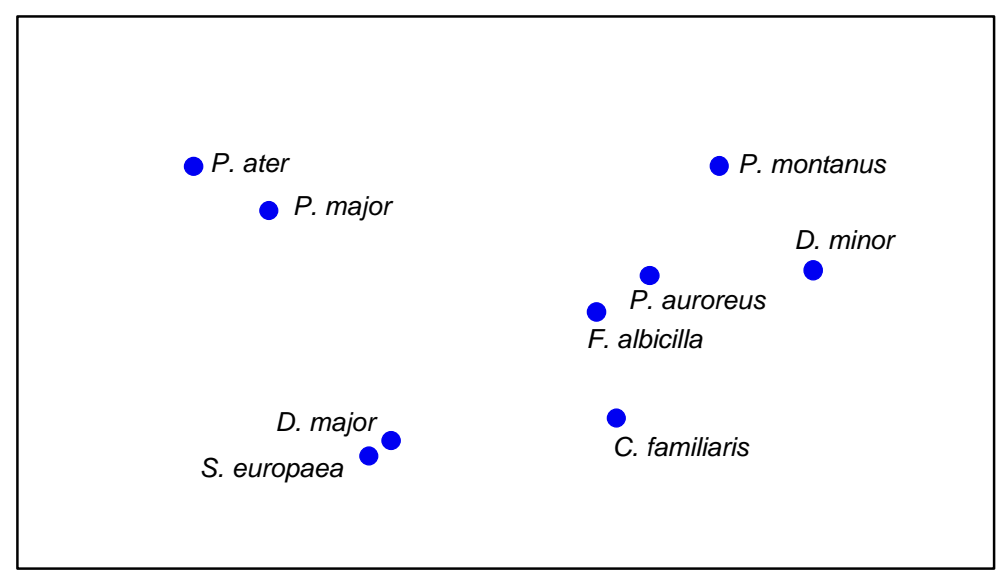

Fig. 4.22 The Renkonen similarity of nest tree condition between bird species.

Living trees, intact dead trees and broken snags comprised $85 \%, 10 \%$ and $5 \%$ of the standing stems, respectively (see Section 4.5.3). Thus all species except $P$. ater and $P$. major utilised living trees underproportionally $\left(?^{2}\right.$ test, $\mathrm{df}=2, \mathrm{p}<0.05$ for $D$. major, $\mathrm{p}<0.01$ for S. europaea, $\mathrm{p}<0.001$ for others). $51 \%, 10 \%$ and $39 \%$ of the cavities were found in living trees, intact dead trees and broken snags, respectively. $P$. ater and $P$. major preferred cavities in living trees $\left(?^{2}=35.5, \mathrm{df}=2, \mathrm{p}<0.001\right.$ in P. ater, $?^{2}=8.1, \mathrm{df}=2, \mathrm{p}<0.05$ in $P$. major), while $S$. europaea preferred cavities in fresh dead trees and avoided those in snags $\left(?^{2}=15.0, \mathrm{df}=2, \mathrm{p}<0.001\right)$. Other SCNs were not selective to cavities according to tree condition. 


\subsubsection{Selection of nest cavity}

\section{Cavity type}

The preferences for cavity type were distinct among most bird species (Table 4.16, ? ${ }^{2}$ $=539.95, \mathrm{df}=24, \mathrm{p}<0.001)$. Woodpecker species were persistent in using woodpecker holes. Though being an excavator as well, only $84 \%$ of $P$. montanus constructed nest cavities by their own. Among them 51 nests were completely excavated by themselves, and 3 were modified from branch holes. One out of the

Table 4.16 Cavity type (in \%) used by each bird species.

\begin{tabular}{|c|c|c|c|c|c|c|}
\hline \multirow[b]{2}{*}{ Bird species } & \multicolumn{4}{|c|}{ Cavity type } & \multirow[b]{2}{*}{$\mathrm{N}$} & \multirow{2}{*}{$\begin{array}{c}\text { Levins } \\
\text { B }\end{array}$} \\
\hline & $\begin{array}{c}\text { woodpecker } \\
\text { hole }\end{array}$ & $\begin{array}{c}\text { other bird- } \\
\text { induced hole }\end{array}$ & $\begin{array}{c}\text { branch } \\
\text { hole }\end{array}$ & others & & \\
\hline D. major & 100.0 & - & - & - & 13 & 1.00 \\
\hline D. minor & 100.0 & - & - & - & 13 & 1.00 \\
\hline P. auroreus & 17.4 & 21.7 & 56.5 & 4.3 & 23 & 2.51 \\
\hline F. albicilla & 32.0 & 56.0 & 12.0 & - & 25 & 2.32 \\
\hline P. ater & - & - & 100.0 & - & 53 & 1.00 \\
\hline P. major & - & - & 100.0 & - & 16 & 1.00 \\
\hline P. montanus & 1.6 & 84.4 & 14.1 & - & 64 & 1.37 \\
\hline S. europaea & 85.7 & - & 14.3 & - & 21 & 1.32 \\
\hline C. familiaris & - & - & - & 100.0 & 11 & 1.00 \\
\hline
\end{tabular}

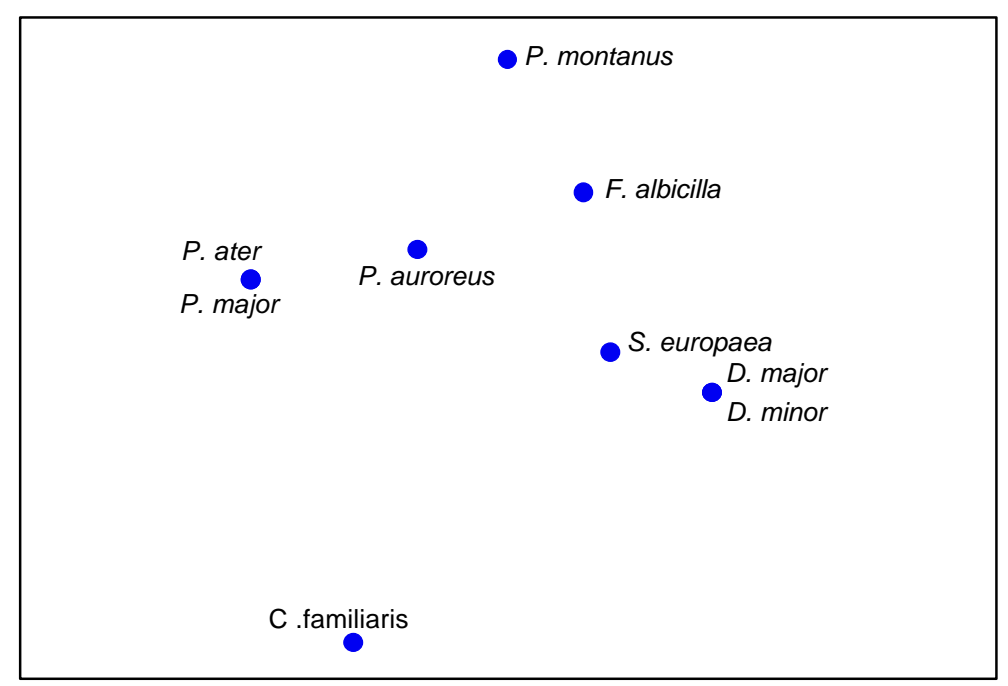

Fig. 4.23 The Renkonen similarity of nest cavity type between bird species. 
total 64 nests of $P$. montanus were found in a woodpecker hole after the entrance modified by S. europaea, and 9 were found in branch holes of which no sign of further excavation was observed. S. europaea preferred using woodpecker holes and had high similarity with woodpeckers (Fig. 4.23). F. albicilla placed most of their nests in other bird-induced holes and thus had high niche overlap with P. montanus. $P$. ater and $P$. major used exclusively branch holes. C. familiaris utilised special cavity types: 8 out of the 11 nests found were located in bark crevices, 2 in vertical slits in trunk due to the shear force when the snag broke, and 1 in trunk fissure originated from side fire. P. auroreus was the only species that utilised all types of cavities. Except for $P$. auroreus and $F$. albicilla, niche breadths for others were small since each preferred specified cavity type. All SCNs except $P$. auroreus utilised cavity types differed from their availability $\left(?^{2}\right.$ test, $\mathrm{df}=2, \mathrm{p}<0.01$ for $P$. major, $\mathrm{p}<$ 0.001 for the others).

\section{Height above ground}

The height above ground of nest cavities varied between $0.1 \mathrm{~m}$ (P. auroreus) and 20 $\mathrm{m}$ (S. europaea). The three PCNs as well as S. europaea and F. albicilla nested in higher cavities (Table 4.17). Among them S. europaea nested higher than D. major (Mann-Whitney $\mathrm{U}=75.00, \mathrm{df}=1, \mathrm{p}<0.05$ ), and $F$. albicilla higher than $P$. montanus (Mann-Whitney $\mathrm{U}=1024.50, \mathrm{df}=1, \mathrm{p}<0.05$ ). D. major, D. minor and S. europaea never nested in cavities lower than $4 \mathrm{~m}$. P. auroreus, $P$. ater, $P$. major and $C$. familiaris utilised lower cavities and showed no difference between each other. $P$. montanus nested in cavities of more variable height than D. major, P. auroreus, $P$. ater and P. major (F test, $\mathrm{p}<0.05)$.

\section{$\underline{\text { Substrate diameter }}$}

The substrate diameter ranged from $8 \mathrm{~cm}$ for $P$. montanus to $96 \mathrm{~cm}$ for $P$. ater. $C$. familiaris nested in thicker part of tree than all other species (Table 4.17; MannWhitney $\mathrm{U}$ test, $\mathrm{p}<0.05$ with each of other species). D. minor, F. albicilla and $P$. montanus established their nests in thinner part of tree than others, while $F$. albicilla and $P$. montanus further used thinner part than D. minor (Mann-Whitney $\mathrm{U}=230.00$, $\mathrm{df}=1, \mathrm{p}<0.05$ for $F$. albicilla, Mann-Whitney $\mathrm{U}=656.00, \mathrm{df}=1, \mathrm{p}<0.01$ for $P$. montanus). Other five species utilised cavities with similar substrate diameter. $P$. 
auroreus, $P$. ater and $C$. familiaris could utilise cavities with more variable substrate diameter than the others ( $\mathrm{F}$ test, $\mathrm{p}<0.05)$.

Table 4.17 Mean ( \pm SD) of cavity height above ground, substrate diameter, cavity opening length and cavity opening width of each bird species.

\begin{tabular}{lccccc}
\hline Bird species & $\begin{array}{c}\text { cavity height } \\
(\mathrm{m})\end{array}$ & $\begin{array}{c}\text { substrate } \\
\text { diameter }(\mathrm{cm})\end{array}$ & $\begin{array}{c}\text { opening length } \\
(\mathrm{cm})\end{array}$ & $\begin{array}{c}\text { opening width } \\
(\mathrm{cm})\end{array}$ & $\mathrm{N}$ \\
\hline D. major & $8.4 \pm 2.2$ & $27.2 \pm 5.4$ & $4.7 \pm 0.3$ & $4.7 \pm 0.3$ & 13 \\
D. minor & $8.8 \pm 3.6$ & $20.9 \pm 4.5$ & $3.4 \pm 0.3$ & $3.4 \pm 0.3$ & 13 \\
P. auroreus & $4.4 \pm 3.0$ & $30.6 \pm 13.6$ & $8.1 \pm 4.6$ & $6.5 \pm 3.2$ & 23 \\
F. albicilla & $9.2 \pm 3.5$ & $17.2 \pm 5.8$ & $3.8 \pm 1.0$ & $3.9 \pm 0.8$ & 25 \\
P. ater & $4.2 \pm 3.2$ & $30.5 \pm 15.1$ & $6.2 \pm 3.1$ & $3.1 \pm 0.7$ & 53 \\
P. major & $5.0 \pm 2.7$ & $27.1 \pm 6.7$ & $7.0 \pm 3.0$ & $4.1 \pm 1.3$ & 16 \\
P. montanus & $7.3 \pm 4.6$ & $15.7 \pm 7.5$ & $3.5 \pm 0.9$ & $3.4 \pm 0.5$ & 64 \\
S. europaea & $11.3 \pm 3.9$ & $29.1 \pm 6.8$ & $5.1 \pm 0.7$ & $4.9 \pm 0.3$ & 21 \\
C. familiaris & $4.3 \pm 3.6$ & $41 \pm 14.1$ & $18 \pm 20.7$ & $3.1 \pm 0.9$ & 11 \\
\hline
\end{tabular}

${ }^{+}$After minimisation by S. europaea.

\section{$\underline{\text { Substrate condition }}$}

$P$. ater differed from all other species in their high preference for cavities in living parts of trees (Table 4.18; $?^{2}$ test with Yates correction, $\mathrm{p}<0.01$ with $P$. major, $\mathrm{p}<$ 0.001 with the others). D. minor, F. albicilla and P. montanus preferred to nest in dead parts. D. minor excavated exclusively in dead substrates. P. montanus used also only dead substrates when they excavated the cavities by themselves, but their nest cavities that were not self-excavated all occurred in living substrates. The comparison with the nest tree condition (Table 4.15) indicated that $F$. albicilla and P. montanus preferred a broken top or a dead branch when using a living tree $\left(?^{2}=9.5, \mathrm{df}=1, \mathrm{p}<\right.$ 0.01 for $F$. albicilla, $?^{2}=10.8, \mathrm{df}=1, \mathrm{p}<0.01$ in $P$. montanus $)$. Other five species used cavities in living or dead substrates more evenly and thus had larger niche breadth. 
Table 4.18 Substrate condition (in \%) used by each bird species.

\begin{tabular}{lcccc}
\hline \multirow{2}{*}{ Bird species } & \multicolumn{2}{c}{ Substrate condition } & \multirow{2}{*}{ N } & Levins' B \\
\cline { 2 - 3 } & living & dead & & \\
\hline D. major & 38.5 & 61.5 & 13 & 1.90 \\
D. minor & - & 100.0 & 13 & 1.00 \\
P. auroreus & 39.1 & 60.9 & 23 & 1.91 \\
F. albicilla & 8.0 & 92.0 & 25 & 1.17 \\
P. ater & 96.2 & 3.8 & 53 & 1.08 \\
P. major & 62.5 & 37.5 & 16 & 1.88 \\
P. montanus & 15.6 & 84.4 & 64 & 1.36 \\
S. europaea & 42.9 & 57.1 & 21 & 1.96 \\
C. familiaris & 45.5 & 54.5 & 11 & 1.98 \\
\hline
\end{tabular}

\section{Dimension and shape of cavity opening}

The length of cavity opening varied greatly (Table 4.17), ranged from $2.4 \mathrm{~cm}(F$. albicilla) to $74 \mathrm{~cm}$ (C. familiaris). D. minor, F. albicilla and $P$. montanus nested in cavities with smallest opening length. S. europaea used cavities with opening length similar to that of D. major, $P$. ater and P. major, but it minimised the opening length to the smallest of all. C. familiaris could utilise cavities with most variable length (F test, $\mathrm{p}<0.001)$, while D. major and D. minor were most strict in opening length (F test, $\mathrm{p}<0.01)$.

Table 4.19 Shape of nest cavity opening (in \%) of each bird species.

\begin{tabular}{lcccccc}
\hline \multirow{2}{*}{ Bird species } & \multicolumn{3}{c}{ Shape of cavity opening } & \multirow{2}{*}{ N } & \multirow{2}{*}{ Levins' B } \\
\cline { 2 - 4 } & flat & round & slit-like & & \\
\hline D. major & - & 100.0 & - & 13 & 1.00 \\
D. minor & - & 100.0 & - & 13 & 1.00 \\
P. auroreus & 17.4 & 26.1 & 56.5 & 23 & 2.39 \\
F. albicilla & 8.0 & 88.0 & 4.0 & 25 & 1.28 \\
P. ater & 7.5 & 15.1 & 77.4 & 53 & 1.60 \\
P. major & 12.5 & 18.8 & 68.8 & 16 & 1.91 \\
P. montanus & 6.3 & 79.7 & 14.1 & 64 & 1.52 \\
S. europaea & - & 90.5 & 9.5 & 21 & 1.21 \\
C. familiaris & - & - & 100 & 11 & 1.00 \\
\hline
\end{tabular}


The width of cavity opening showed less variability than length (Table 4.17), ranged from $2 \mathrm{~cm}$ ( $P$. ater, $P$. montanus and $C$. familiaris) to $18 \mathrm{~cm}(P$. auroreus). $P$. auroreus bred in cavities with widest opening, and was the only species utilised cavities with opening wider than $8 \mathrm{~cm}$. D. major and S. europaea utilised cavities with similar opening width which was wider than that of other six species. $S$. europaea then minimised the opening width to one of the smallest, similar to that of $P$. ater and $C$. familiaris. The nest cavities of $P$. auroreus had the largest variance in opening width (F test, $\mathrm{p}<0.001$ ), while those of D. major, D. minor and S. europaea showed least variance $(\mathrm{F}$ test, $\mathrm{p}<0.05)$.

The preference for cavity opening shape showed two distinct patterns (Table 4.19). D. major, D. minor, F. albicilla, P. montanus and S. europaea preferred cavities with round openings, while others utilised mostly slit-like ones. Cavities with flat opening shape were seldom used by any species.

\subsubsection{Multivariate summary of nest niche overlap}

\section{Cluster analysis}

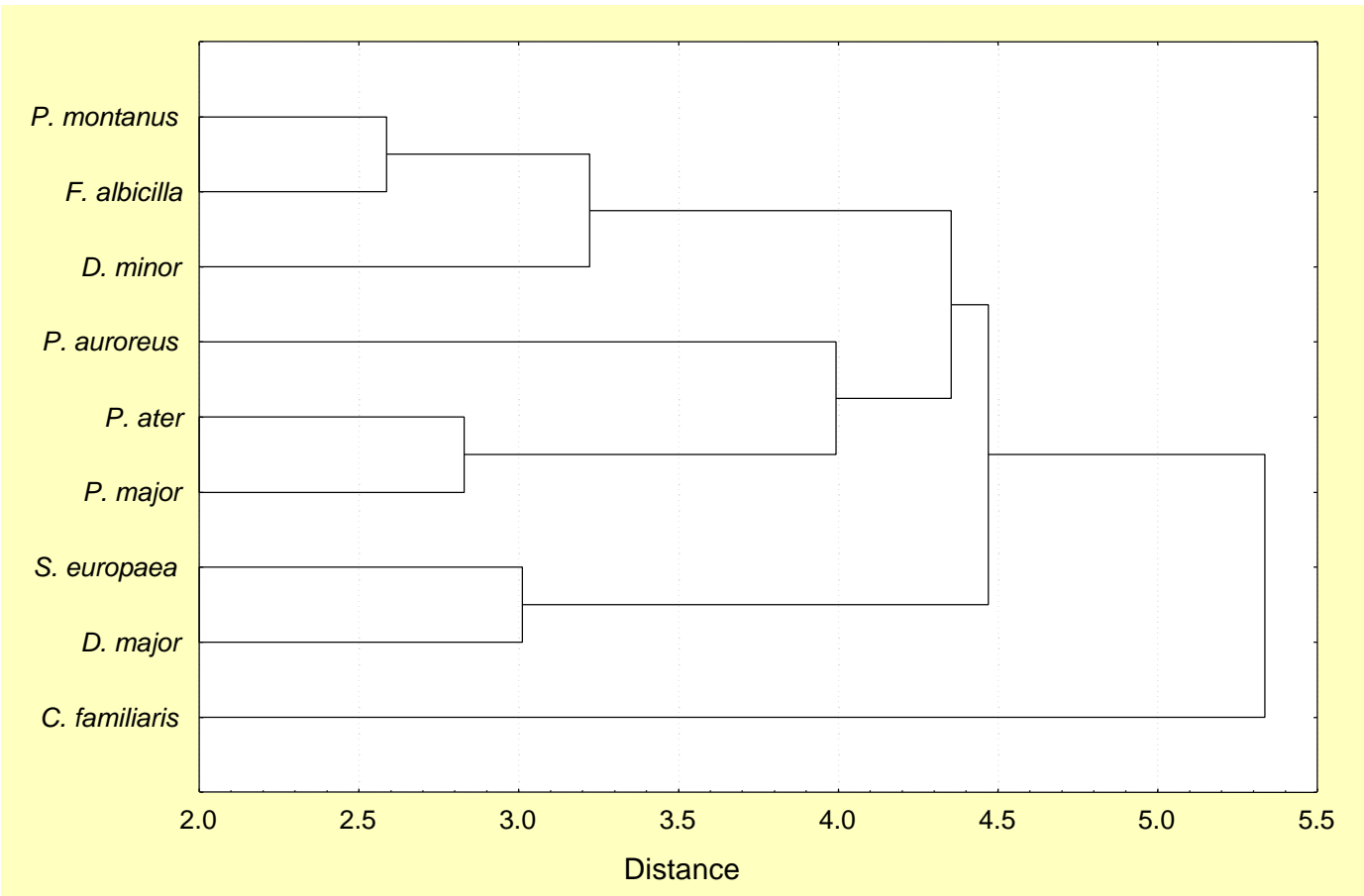

Fig. 4.24 The dendrogram of single linkage cluster analysis. 
The overall similarity of nest sites among bird species was summarised and visualised in the cluster tree (Fig. 4.24). Greatest similarity occurred between F. albicilla and $P$. montanus, while the nest site of $C$. familiaris was most distinct. Four groups could be identified: D. major with S. europaea, D. minor with F. albicilla and P. montanus, $P$. auroreus with $P$. ater and $P$. major, and $C$. familiaris alone.

\section{Discriminant function analysis}

A discriminant function analysis was performed to investigate the extent of niche overlap among species, and to identify the nest attributes most discriminate among species. A full model with all 15 variables resulted in $67 \%$ of correct classification. When a backward stepwise selection was applied, the three cavity type variables and the cavity opening width alone reached an accuracy of $66 \%$, i.e. over $98 \%$ of the discriminant power of the full model. Thus this model was adopted.

From the classification matrix (Table 4.20), the nest sites of D. major and S. europaea were indistinguishable. Low classification accuracy also occurred in P. auroreus, F. albicilla and P. major. The nest site of P. auroreus overlapped with that of P. ater, $P$. major, P. montanus, S. europaea and even $C$. familiaris. The nest site of $F$. albicilla was mainly confounded with that of $P$. montanus, and also overlapped with $D$. minor, $P$. ater and $S$. europaea. The nest site of $P$. major was mainly confounded with $P$. ater.

Table 4.20 Classification matrix from discriminant function analysis based on cavity type and cavity opening width. Boldface marked the diagonal elements of correct classification, and italic type marked the high overlap between species.

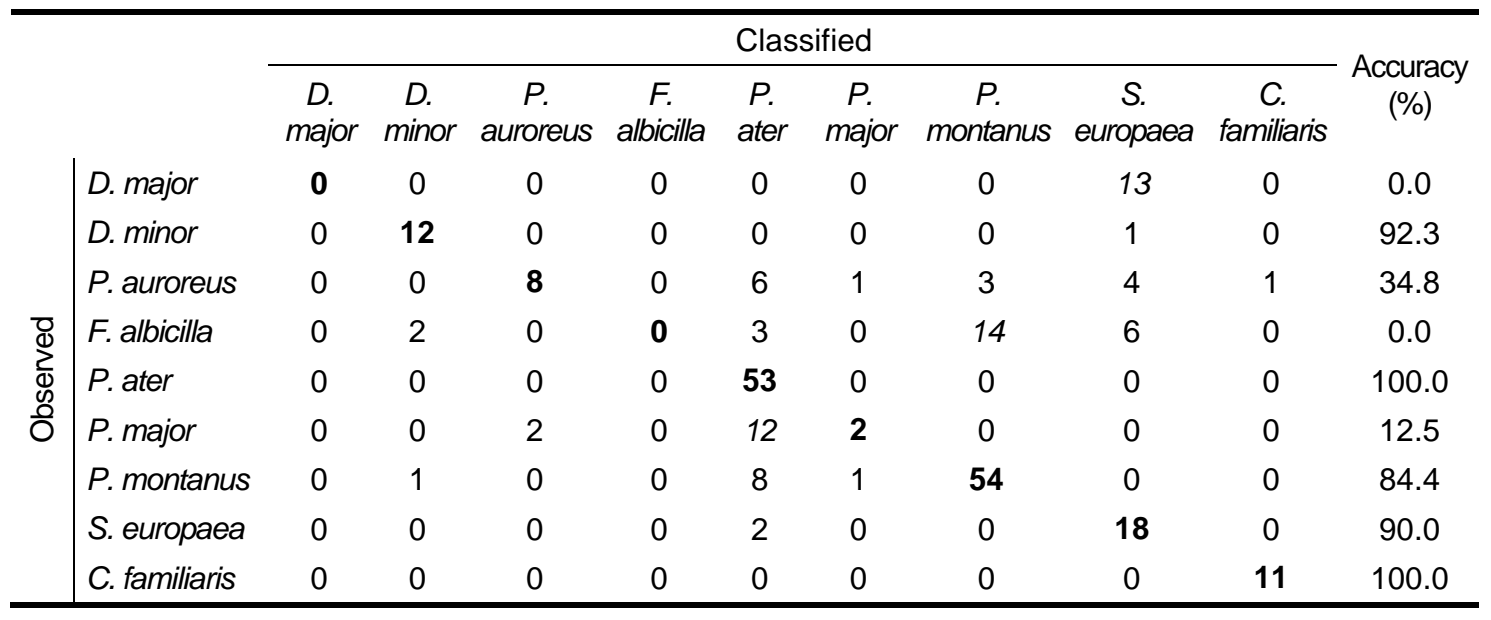




\subsection{Sequential Cavity Use}

\subsubsection{Sequential use at guild level}

$37 \%$ of the nest cavities found in 2002 were reused in 2003. Cavities previously used by PCNs, WPCNs and SCNs had reuse rate 31\%, 16\% and 46\%, respectively (Fig. 4.25). The reuse rate of previous WPCN cavities was significantly lower than that of SCN cavities (Yates corrected $?^{2}=5.85, \mathrm{df}=1, \mathrm{p}<0.05$ ).

Constancy, or reuse of cavities by the same species, for SCN cavities was $45 \%$, higher than that of PCN cavities (Yates corrected $?^{2}=8.89, \mathrm{df}=1, \mathrm{p}<0.01$ ) and WPCN cavities (Yates corrected $?^{2}=19.77, \mathrm{df}=1, \mathrm{p}<0.001$ ). Thus old cavities of PCNs and WPCNs were more available to other bird species, while old SCN cavities tended to be reused by the same species that previously occupied the cavity.

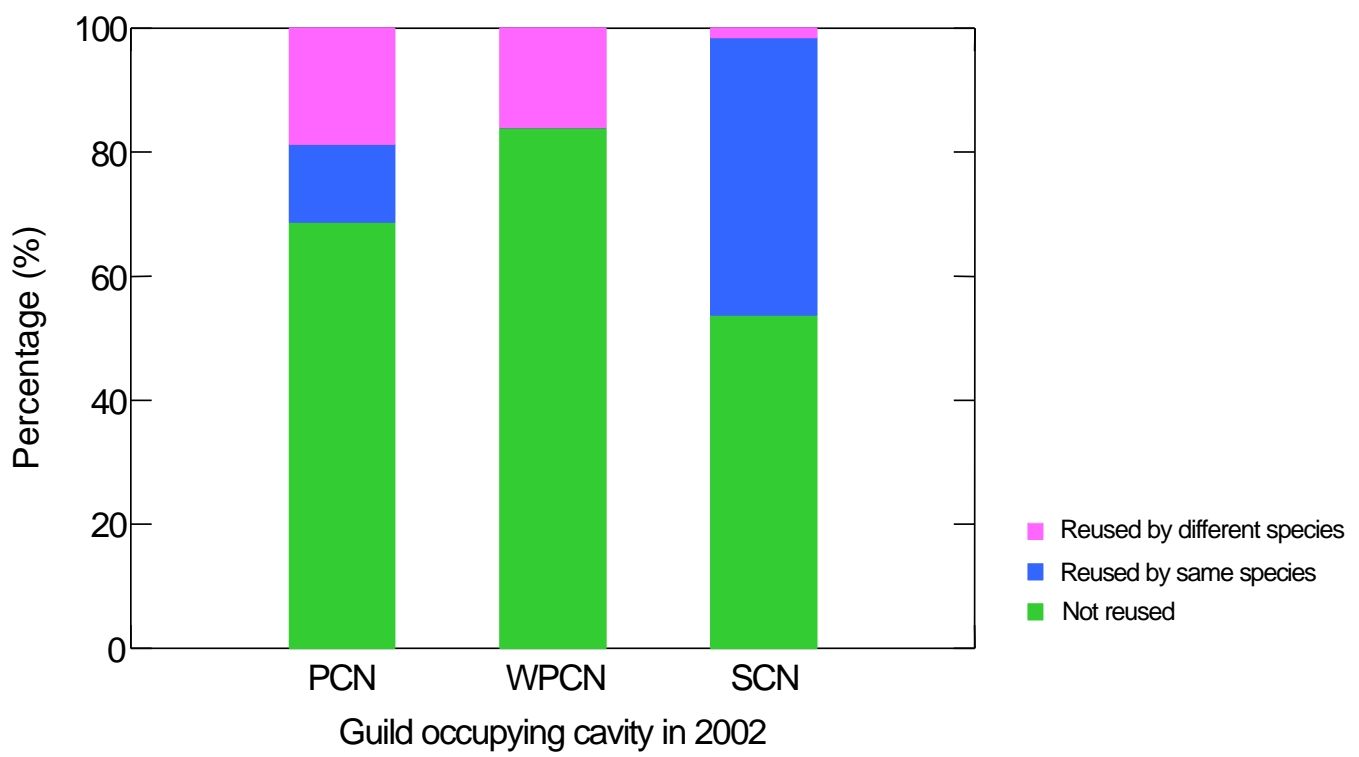

Fig. 4.25 Reuse pattern of nest cavities (in \%) for PCNs $(n=16)$, WPCNs $(n=25)$ and SCNs $(n=67)$. 


\subsubsection{Sequential use at species level}

Among PCNs, cavities previous occupied by D. major were more frequently reused (Table 4.21). It was also the only woodpecker species of which the reuse its own cavity was found in the study period (Fig. 4.26). Two out of 6 D. major nest cavities in 2002 were utilised by the same species in 2003, 2 were utilised by S. europaea, resulted in a reuse rate of $67 \%$. For $D$. minor, of which also 6 nest cavities were found in 2002, only one was used by F. albicilla in the following year, and the reuse rate was $17 \%$. For other woodpecker species, only 1 or 2 nests of each species were found in 2002, due to their lower density in the study area. No difference in the cavity reuse rate between woodpecker species could be found owing to the small sample size. Four out of 25 P. montanus nest cavities in 2002 were occupied in 2003, and the subsequent users were all $F$. albicilla. The reuse rate of $P$. montanus cavity (16\%) was lower than that of D. major (Yates corrected $?^{2}=4.11, \mathrm{df}=1, \mathrm{p}<0.05$ ).

Table 4.21 Reuse pattern of nest cavities (in \%) for each species.

\begin{tabular}{|c|c|c|c|c|}
\hline \multirow[b]{2}{*}{ Occupant 2002} & \multirow{2}{*}{$\begin{array}{l}\text { No. of nests } \\
\text { found in } 2002\end{array}$} & \multicolumn{3}{|c|}{ Reuse (\%) in 2003} \\
\hline & & not reused & $\begin{array}{c}\text { by same } \\
\text { species }\end{array}$ & $\begin{array}{c}\text { by different } \\
\text { species }\end{array}$ \\
\hline \multicolumn{5}{|l|}{ PCN } \\
\hline D. martius & 1 & 100 & 0 & 0 \\
\hline P. canus & 2 & 100 & 0 & 0 \\
\hline D. leucotos & 1 & 100 & 0 & 0 \\
\hline D. major & 6 & 33 & 33 & 33 \\
\hline D. minor & 6 & 83 & 0 & 17 \\
\hline \multicolumn{5}{|l|}{ WPCN } \\
\hline P. montanus & 25 & 84 & 0 & 16 \\
\hline \multicolumn{5}{|l|}{$\mathrm{SCN}$} \\
\hline B. clangula & 1 & 0 & 100 & 0 \\
\hline P. auroreus & 10 & 70 & 30 & 0 \\
\hline P. phoenicurus & 2 & 100 & 0 & 0 \\
\hline T. ruficollis & 1 & 100 & 0 & 0 \\
\hline F. albicilla & 12 & 100 & 0 & 0 \\
\hline P. ater & 26 & 23 & 77 & 0 \\
\hline P. major & 7 & 71 & 29 & 0 \\
\hline S. europaea & 5 & 0 & 80 & 20 \\
\hline C. familiaris & 3 & 100 & 0 & 0 \\
\hline
\end{tabular}




\begin{tabular}{ll}
\hline Occupant 2002 & Occupant 2003 \\
\hline D. martius & D. martius \\
P. canus & P. canus \\
D. leucotos & D. leucotos \\
D. major & D. major \\
D. minor & D. minor \\
P. montanus & P. montanus \\
B. clangula & \\
J. torquilla & B. clangula \\
P. auroreus & J. torquilla \\
P. phoenicurus & P. auroreus \\
T. ruficollis & P. phoenicurus \\
F. albicilla & T. ruficollis \\
P. ater & F. albicilla \\
P. major & P. ater \\
S. europaea & P. major \\
C. familiaris & S. europaea \\
\hline
\end{tabular}

Fig. 4.26 The reuse of nest cavities of 2002 in 2003. Dotted lines: reuse rate $<25 \%$, thin lines: reuse rate $25-50 \%$, thick lines: reuse rate $>50 \%$.

Among the SCNs, the cavities of B. clangula, P. ater and S. europaea showed high constancy. Only one nest of B. clangula was found in 2002 and could not be concluded. Of the $26 P$. ater nest cavities found in 2002, 20 were reused by the same species, and the reuse rate was $77 \%$. All five nest cavities of S. europaea were reused, four by the same species, and one was occupied by P. montanus. This was the only case observed between the two years that a previous SCN nest was reused by a different species. $30 \%$ and $29 \%$ of the nest cavities previously occupied by $P$. auroreus and $P$. major, respectively, were reused by the same species. No reuse of $F$. albicilla cavities was observed, and the reuse rate of previous $F$. albicilla cavities was lower than that of $P$. ater and S. europaea (Yates corrected $?^{2}=16.52, \mathrm{df}=1, \mathrm{p}<$ 0.001 with $P$. ater, Yates corrected $?^{2}=12.52, \mathrm{df}=1, \mathrm{p}<0.001$ with $S$. europaea).

\subsubsection{Characters of reused cavities}

There were significant associations between cavity reuse and tree condition, presence of fungi conks, cavity type and substrate condition (Table 4.22). Most of the reused cavities (80\%) were located in living trees. And cavities in living trees were reused more frequently (47\%) than cavities in broken snags (16\%). Only $27.5 \%$ of reused cavities were situated in trees with fungi conks, while $58.8 \%$ of those not reused were 
Table 4.22 Comparisons of reused and not reused cavities.

\begin{tabular}{|c|c|c|c|c|}
\hline \multirow{2}{*}{ Attributes (in \%) } & \multicolumn{2}{|c|}{ Nest cavities of 2002} & \multirow{2}{*}{$?^{2}$} & \multirow{2}{*}{$p$ value } \\
\hline & reused $(n=40)$ & not reused $(n=68)$ & & \\
\hline Tree condition & & & 9.092 & $<0.05$ \\
\hline living & 80.0 & 51.5 & & \\
\hline dead intact & 7.5 & 11.8 & & \\
\hline dead broken & 12.5 & 36.8 & & \\
\hline Presence of fungi & & & 8.698 & $<0.01$ \\
\hline without fungi conk & 72.5 & 41.2 & & \\
\hline with fungi conk & 27.5 & 58.8 & & \\
\hline Cavity type & & & 12.555 & $<0.01$ \\
\hline woodpecker hole & 27.5 & 22.1 & & \\
\hline other bird-induced & 12.5 & 36.8 & & \\
\hline branch hole & 60.0 & 33.8 & & \\
\hline others & 0.0 & 7.4 & & \\
\hline Substrate condition & & & 16.454 & $<0.001$ \\
\hline living & 70.0 & 27.9 & & \\
\hline dead & 30.0 & 72.1 & & \\
\hline
\end{tabular}

in conk-bearing trees. Regarding cavity type, most reused cavities were branch holes, while other bird-induced holes were reused underproportionally. $42 \%$ and $51 \%$ of woodpecker holes and branch holes in 2002, respectively, were reused in the following year. These were higher than the reuse rate of other bird-induced holes $(16 \%)$. Cavities in living substrates were more frequently reused than those in dead substrates.

No relationship was found between cavity reuse and tree species $\left(?^{2}=8.14, \mathrm{df}=5, \mathrm{p}\right.$ $=0.15)$, tree $\mathrm{DBH}(\mathrm{t}=-0.66, \mathrm{df}=106, \mathrm{p}=0.51)$, presence of fire scars on the tree (Yates corrected $\left.?^{2}=0.00, \mathrm{df}=1, \mathrm{p}=1.00\right)$, cavity height above ground $(\mathrm{t}=0.75, \mathrm{df}$ $=106, \mathrm{p}=0.46)$, substrate diameter $(\mathrm{t}=-1.50, \mathrm{df}=106, \mathrm{p}=0.14)$, cavity opening length $(\mathrm{t}=0.29, \mathrm{df}=106, \mathrm{p}=0.77)$, opening width $(\mathrm{t}=1.04, \mathrm{df}=106, \mathrm{p}=0.30)$ and opening shape $\left(?^{2}=3.10, \mathrm{df}=2, \mathrm{p}=0.21\right)$.

Using backward stepwise logistic regression to determine the variables that could best predict cavity reuse, substrate condition came to be the only significant predictor in the model $\left(\log\right.$ likelihood $\left.=-61.96, ?^{2}=18.46, \mathrm{p}<0.001\right)$. 


\subsection{Nest Web Analysis}

\subsubsection{Nest web of CNB community in West Khentey}

Integrating tree and cavity characteristics across the CNB community, the nest site use of CNBs was summarised in the nest web (Fig. 4.27). The links indicated the proportion of tree or cavity use of each bird species. Such a graphic visualised the linkage and interdependence among species.

Considering the linkage between level one (trees) and level 2 (PCNs, WPCNs and non-excavated cavities), birch played the most important role. All excavating species except $D$. martius utilised birch. D. leucotos, D. minor and $P$. montanus were highly dependent on this tree species, among them the nests of D. leucotos were only found in birch $(\mathrm{n}=3)$. It also supported the majority $(73 \%)$ of the non-excavated cavities

Level 3

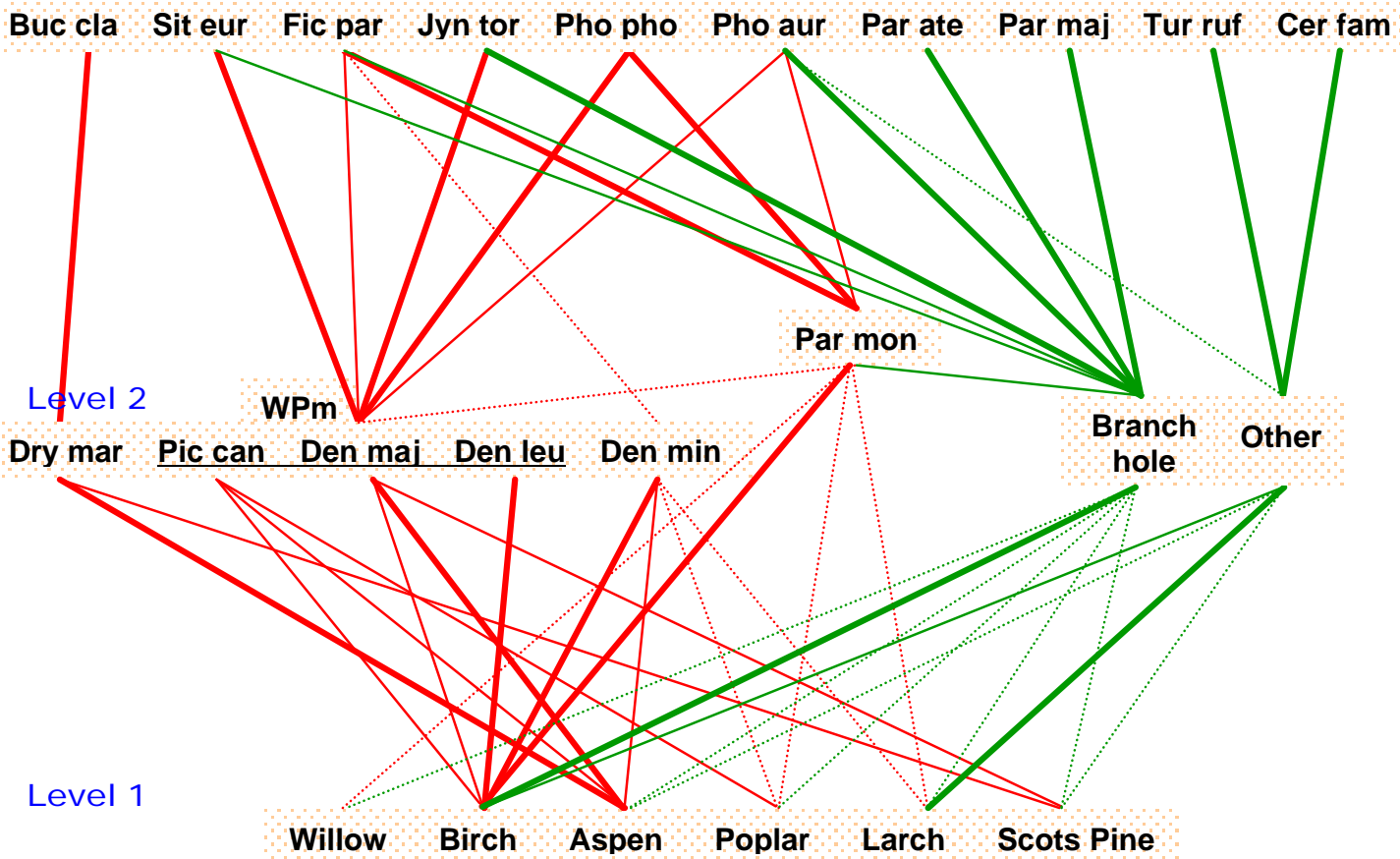

Fig. 4.27 Nest flow in the nest web. Cavity type was indicated by red (excavated cavities) and green (non-excavated cavities). The proportion of nest use was indicated by dotted lines $(<10 \%)$, thin lines $(10-50 \%)$ and thick lines $(>50 \%)$. Bird species were abbreviated by the first three letters of the genus and species names. WPm referred to middle-sized woodpecker holes pooled. 
which were used by SCNs and P. montanus. Aspen was important tree species for $D$. martius and D. major. Spruce, fir and Siberian pine did not enter the nest web, since no nests were found in them.

Between level two and level three (SCNs), the large-sized woodpecker holes from $D$. martius were only used by $B$. clangula, and this duck depended exclusively on this resources $(n=2)$. Middle-sized woodpecker holes supported more diversified users, including S. europaea, F. albicilla, J. torquilla, P. phoenicurus, P. auroreus and the WPCN P. montanus, but none of these users focused entirely on this resource. The sample size for J. torquilla and P. phoenicurus was small ( $\mathrm{n}=2$ for each), and for both species one of the two nests found were in middle-sized woodpecker holes. $S$. europaea showed highest dependence on this resource, in which $86 \%$ of their nests were established. The small-sized woodpecker holes from $D$. minor were only utilised by $F$. albicilla.

Cavities from P. montanus were the main resource for F. albicilla, supporting $56 \%$ of their nests. In some cases, usually after the cavity openings were enlarged by woodpeckers or due to other causes, $P$. montanus cavities were also utilised by $P$. phoenicurus and P. auroreus.

Except B. clangula and $P$. phoenicurus, all other SCNs and $P$. montanus utilised nonexcavated cavities. T. ruficollis was not an obligate cavity nester. P. ater, P. major and $C$. familiaris depended exclusively on this resource, while others had alternative choices.

Among SCNs, F. albicilla and $P$. auroreus used more diversified cavities, behaving as generalists in cavity use. B. clangula, $P$. ater, $P$. major and $C$. familiaris behaved as specialists.

\subsubsection{Simulation I: roles of woodpeckers}

The nest web could be applied to investigate the roles of woodpeckers in the CNB community. Supposing that D. martius was removed from the system, according to the nest web (Fig. 4.27), it was most likely that B. clangula would disappear as well. However, other parts of the CNB community were basically unaffected. 
In the case that all middle-sized woodpecker species were excluded from the CNB community, the influence would be more complicated (Fig. 4.28). First, this could affect other members in the same level. D. minor and $P$. montanus might gain some advantages due to the release of competition for nest substrates. However, their benefit might not be substantial. The preferred nest site of D. major did not greatly overlap with that of D. minor and P. montanus (see Section 4.6). Other middle-sized woodpecker species only appeared with low density in the study area. It also affected the resource availability of SCNs. Of the five SCN species nesting in middle-sized woodpecker holes, none was totally dependent on such cavities. S. europaea, which had the highest preference for middle-sized woodpecker holes, could also well use branch holes.

With the simplified assumption that each of the users of middle-sized woodpecker cavities simply shift to its alternative resources proportionally, the users of $D$. minor

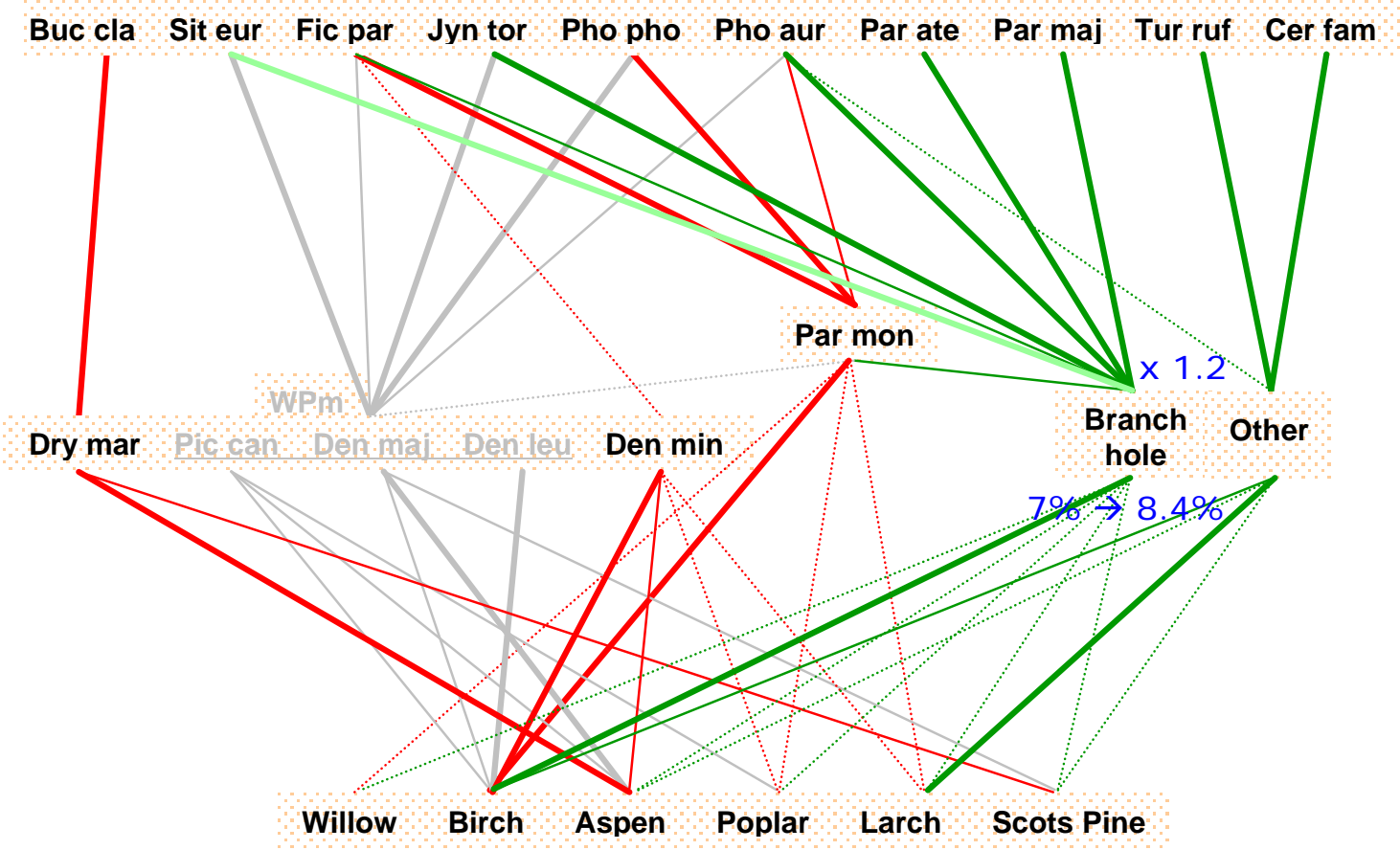

Fig. 4.28 The supposed nest web in the case that middle-sized woodpeckers were excluded from the system. 
cavities and P. montanus cavities would become 1.3 times more, and that of branch holes 1.2 times more. Branch hole was originally the cavity type most heavily used by SCNs (see Section 4.5.6). The original occupancy of branch hole was approximately $7 \%$. This would rise to $8.4 \%$ when middle-sized woodpecker holes were no more available. These numbers indicated that there might still be enough available branch holes to buffer the lost of middle-sized woodpecker holes.

The removal of $D$. minor seemed to cause few stirs to the nest web. Only $F$. albicilla used D. minor holes. And in the study area, there were abundant P. montanus cavities, which served as an alternative for $F$. albicilla.

\subsubsection{Simulation II: roles of some tree species}

Nest web could also be applied to observe the importance of each tree species to the CNB community. From the nest web (Fig. 4.27), it was clear that the removal of spruce, fir and Siberian pine had no direct impact on the CNBs, from the viewpoint of cavity supply.

If birch was removed from the system and replaced by, for example, spruce, farreaching influences could arise (Fig. 4.29). Firstly, birch was the main nesting substrate for several PCNs and WPCNs, supporting 65\% of their nests. D. leucotos, D. minor and P. montanus were highly dependent on birch. Though these excavators could shift their resource use, the impact was not likely to be fully adjusted. Aspen and poplar were the favourite alternatives for D. minor and P. montanus (see Section 4.6.1), but these tree species had either low abundance or limited distribution. Thus the intra- and interspecific competition among PCNs and WPCNs would rise.

Another critical function of birch was that it supplied large amount of non-excavated cavities. About $80 \%$ of the branch holes utilised by SCNs were located in birch. When birch was excluded from the system, the abundance of branch hole would reduced to one-fifth, which indicated the occupancy would rise to five times, given the same amount of users. The original occupancy $7 \%$ would than become $35 \%$, which might lead to strong competition among SCNs for cavities of good quality. $P$. ater and P. major, which nested exclusively in branch hole, might suffer the most. For other species, the opportunity of shifting to other resources would be limited as 


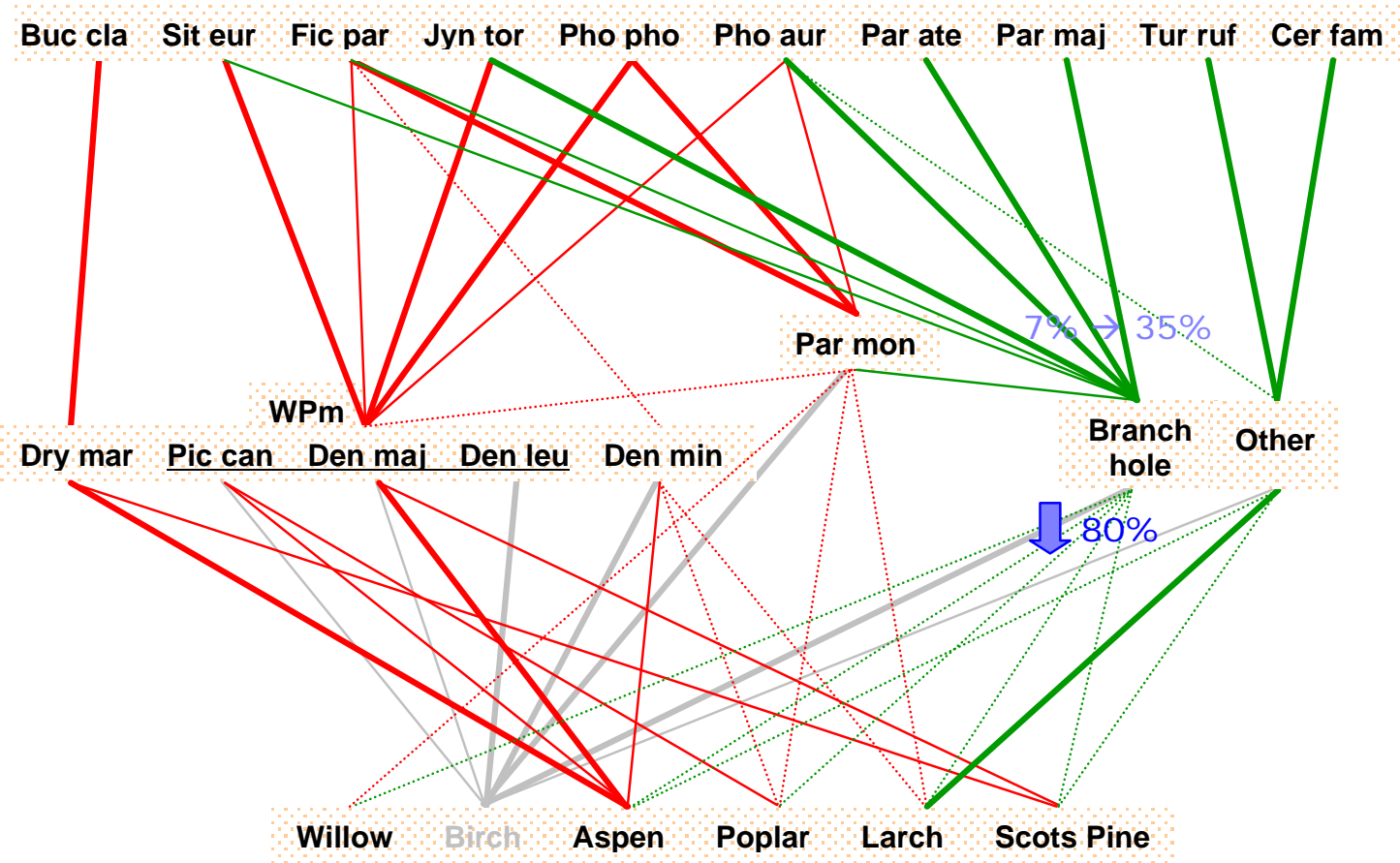

Fig. 4.29 The supposed nest web in the case that birch was excluded from the system.

well, since the availability of PCN and WPCN cavities might also decrease both in number and in spatial distribution.

The removal of aspen would influence mainly D. martius and D. major. D. major was adaptive to diverse tree species. D. martius was more limited by the availability of large trees. Suitable alternatives were, however, likely to be available in its large territory. As the result of the adjustability of these PCNs, the influence on SCNs due to the removal of aspen might not be substantial.

The removal of larch would lead to about $67 \%$ decrease of special non-excavated cavities. Since $T$. ruficollis was not an obligate cavity nester, only $C$. familiars might suffer to a great extent. Other parts of the CNB community were not likely to be substantially affected. 


\section{DISCUSSION}

\subsection{Cavity Abundance in a Forest}

\subsubsection{Cavity abundance in natural boreal forest}

The cavity density estimates reported in the literature ranged widely, from 1 to 60 cavities/ha (Table 5.1). The cavity abundance in the study area (30 cavities/ha) was among the highest reported. Comparisons were approximate as the definitions of cavities and survey methods varied substantially among studies, and locating cavities could be difficult (WATERS et al. 1990). In this study, cavities were located from the ground and inner dimension of cavities was not measured. Thus the cavity abundance might be underestimated due to overlooking some cavities located higher in the trees, while on the other hand might be overestimated due to including some cavities unsuitable for CNBs (e.g. too small chamber, too deep or containing water).

Another constraint for comparisons was the inadequate sample efforts in many studies. Due to the difficulty in locating cavities, most studies had very small sample area or were lack of repeats. Cavities usually occurred in large trees, the density of which in the forests is usually low. Thus insufficient sampling size could not give rise to representative estimates (SANDSTRÖM 1992). As shown in Table 5.1, many studies reported high variance of cavity abundance. In the present study, plotless method was adopted for sampling. This method is efficient in collecting information of large trees and thus especially suitable for surveying cavities (GROSENBAUGH 1952, NOEKE 1989, 1990). But so far this method is more frequently applied in forestry while not wellknown by biologist.

The cavity abundance in a stand is also strongly influenced by tree density, age of trees and tree species composition (VAN BALEN et al. 1982), which further made the comparisons among different study sites obscure. The most comparable study to the present one was conducted in boreal forests in Sweden (SANDSTRÖM 1992). The Swedish forests were composed of tree species closely related to those in the taiga of West Khentey. SANDSTRÖM (1992) reported 41.0 (2 - 72) cavities/ha in the natural stands. One possible reason for the higher value in Sweden than in Mongolia was the absence of cavity-rich oaks in the latter. Oak was the main deciduous tree species in 
Table 5.1 Cavity density estimates (/ha) in the literature.

\begin{tabular}{|c|c|c|c|c|}
\hline $\begin{array}{l}\text { Cavity density } \\
\text { (/ha) }\end{array}$ & Forest type & Natural/Managed & Location & References \\
\hline \multicolumn{5}{|c|}{ Conifer dominated stands } \\
\hline $1-1.5$ & Spruce-pine-beech & Managed & Würzburg, Germany & KNEITZ (1961) \\
\hline $1-3$ & Pine-fir, pine-sage & - & Sierra Nevada, USA & $\begin{array}{l}\text { RAPHAEL \& WHITE } \\
(1984)\end{array}$ \\
\hline $8.7(0-16)$ & Spruce-pine & Managed & $\begin{array}{l}\text { Ulleråkers } \\
\text { Häradsallmänning, } \\
\text { Sweden }\end{array}$ & $\begin{array}{l}\text { SANDSTRÖM } \\
(1992)^{1}\end{array}$ \\
\hline 18.1 & Spruce-fir & Natural & $\begin{array}{l}\text { West Khentey, } \\
\text { Mongolia }\end{array}$ & This study \\
\hline $28.5(2-72)$ & Spruce, pine & Natural & $\begin{array}{l}\text { Fiby and Ola skifte, } \\
\text { Sweden }\end{array}$ & $\begin{array}{l}\text { SANDSTRÖM } \\
(1992)^{1}\end{array}$ \\
\hline \multicolumn{5}{|c|}{ Deciduous dominated and mixed stands } \\
\hline $1.1(0.2-2.1)$ & $\begin{array}{l}\text { Honey mesquite, } \\
\text { cottonwood }\end{array}$ & - & Arizona, USA & BRUSH (1983) \\
\hline $4.1(3.4-4.8)$ & Oak-pine woodland & $\begin{array}{l}\text { Unmanaged; } \\
\text { grazed }\end{array}$ & Sierra Nevada, USA & $\begin{array}{l}\text { WATERS et al. } \\
(1990)^{2}\end{array}$ \\
\hline 4.2 & Cottonwood-willow & - & Colorado, USA & $\begin{array}{l}\text { SEDGWICK \& KNOPF } \\
(1986)^{3}\end{array}$ \\
\hline 6.2 & $\begin{array}{l}\text { Mixed (beech-oak- } \\
\text { spruce) }\end{array}$ & Plantations & Arnhem, Holland & $\begin{array}{l}\text { VAN BALEN et al. } \\
(1982)^{4}\end{array}$ \\
\hline 7.6 & Beech, beech-oak & Managed & Germany & NOEKE (1990) \\
\hline $15.2(8-40)$ & $\begin{array}{l}\text { Beech, mixed, spruce- } \\
\text { pine, pine }\end{array}$ & Managed & Sweden & $\begin{array}{l}\text { SANDSTRÖM } \\
(1992)^{1}\end{array}$ \\
\hline 15.5 & Birch-ash-alder & $\begin{array}{l}\text { Unmanaged for } \\
\text { many years }\end{array}$ & Brecknockshire, UK & $\begin{array}{l}\text { EDINGTON \& } \\
\text { EDINGTON (1972) }\end{array}$ \\
\hline $19(9.4-30.0)$ & Beech-oak & $\begin{array}{l}\text { Old plantations } \\
\text { bordering roads }\end{array}$ & Arnhem, Holland & $\begin{array}{l}\text { VAN BALEN et al. } \\
(1982)^{4}\end{array}$ \\
\hline 21.0 & Beech, beech-oak & Natural & Germany & NOEKE (1990) \\
\hline $33.4(24-39)$ & $\begin{array}{l}\text { Birch-larch, birch-pine- } \\
\text { poplar }\end{array}$ & Natural & $\begin{array}{l}\text { West Khentey, } \\
\text { Mongolia }\end{array}$ & This study \\
\hline $41.0(2-72)$ & $\begin{array}{l}\text { Deciduous, mixed } \\
\text { spruce, spruce-pine }\end{array}$ & Natural & Sweden & $\begin{array}{l}\text { SANDSTRÖM } \\
(1992)^{1}\end{array}$ \\
\hline $52.5(13-92)$ & Beech-oak & - & Wienerwald, Austria & $\begin{array}{l}\text { SACHSLEHNER } \\
(1992)\end{array}$ \\
\hline 60.4 & Oak-maple-lime & Natural & Andersby, Sweden & $\begin{array}{l}\text { CARLSON et al. } \\
(1998)^{5}\end{array}$ \\
\hline
\end{tabular}

${ }^{1}$ Cavity opening diameter at least $25 \mathrm{~mm}$; bottom area at least $22 \mathrm{~cm}^{2}$; smallest diameter inside the cavity at least $40 \mathrm{~mm}$.

${ }^{2}$ Cavity opening diameter $2.5-15 \mathrm{~cm}$; depth $15-50 \mathrm{~cm}$.

${ }^{3}$ Cavity opening diameter $3-12 \mathrm{~cm}$.

${ }^{4}$ Bottom area at least $25 \mathrm{~cm}^{2}$; smallest diameter inside at least $4 \mathrm{~cm}$; distance bottom-top at least $10 \mathrm{~cm}$; cavity opening diameter at least $23 \mathrm{~mm}$ (if circular), or a width at least $18 \mathrm{~mm}$ (if slit like); entrance not so large that the nest is exposed; closed at bottom; without substantial amount of water in the cavity.

${ }^{5}$ Cavity opening diameter at least $25 \mathrm{~mm}$ (if circular), or a width at least $18 \mathrm{~mm}$ (if slit like); bottom area at least $22 \mathrm{~cm}^{2}$; smallest diameter inside at least $40 \mathrm{~mm}$. 
Table 5.2 Mean DBH, proportion of dead stems and cavity holding rate of conspecific or congeneric trees in the boreal forest of Mongolia (this study) and Sweden

(SANDSTRÖM 1992). For comparison, analysis was confined to trees of DBH $=10 \mathrm{~cm}$.

\begin{tabular}{llccc}
\hline Tree species & Location & Mean DBH $(\mathrm{cm})$ & $\begin{array}{c}\text { Proportion of } \\
\text { dead stems (\%) }\end{array}$ & $\begin{array}{c}\text { Cavity holding } \\
\text { rate }(\%)\end{array}$ \\
\hline \multirow{2}{*}{ Populus spp. } & Mongolia & 37.8 & 42 & 34 \\
& Sweden & 34.2 & 20 & 30 \\
Betula spp. & Mongolia & 18.8 & 13 & 5 \\
& Sweden & 23.6 & 16 & 9 \\
\multirow{2}{*}{ Pinus sylvestris } & Mongolia & 23.8 & 4 & 1 \\
& Sweden & 23.9 & 8 & 2 \\
Picea spp. & Mongolia & 18.4 & 10 & 0 \\
& Sweden & 22.9 & 4 & 0.5 \\
\hline
\end{tabular}

several stands of the Swedish study, and the reported cavity holding rate of oak was $18 \%$, which was higher than that of birch (5\%), the main deciduous species in West Khentey. Comparing conspecific or congeneric trees of these two sites, tree DBH and proportion of dead trees were correspondent (Table 5.2). And the cavity holding rates of these related species were strikingly similar (Sweden in brackets): $34 \%$ (30\%) in Populus spp., 5\% (9\%) in Betula spp., 1\% (2\%) in Pinus sylvestris and 0\% (0.5\%) in Picea spp. In the Swedish study, the inner dimension of cavities was measured, and only cavities considered suitable for CNBs were registered. Thus the cavity abundance reported in the present study could be considered as reasonable estimates of available resources for CNBs. And the cavity holding rates could be taken as reference values of the corresponding genus/species in boreal Eurasia.

\subsubsection{Cavity abundance vs. forest type and management}

Cavity density in the spruce-fir forest (18 cavities/ha) was lower than that in the three deciduous stands (24 - 39 cavities/ha). Lower cavities densities in coniferous forests than in deciduous ones has been documented in several studies (KNEITZ 1961, SANDSTRÖM 1992, NEWTON 1994). In the literature, the cavity density reported in conifer dominated stands ranged from 1 to 28.5 cavities/ha (Table 5.1). This variance was to a certain extent due to the proportion and the species of deciduous trees in mixture with the conifers. In the spruce-fir forest of West Khentey, the relatively higher density resulted from the presence of scattered birch. An extreme value of 72 
cavities/ha was reported in one stand of Sweden (SANDSTRÖM 1992). In this riverine forest, cavity-rich aspen interspersed among spruce and accounted for most of the cavities.

In deciduous dominated stands, cavity abundance varied greatly in the literature, ranging from 1 to 60 cavities/ha (Table 5.1). Some lowest values arose from special site conditions. WATERS et al. (1990) counted 4.1 cavities/ha in oak-pine woodlands with very low tree density (54 stems/ha). SEDGWICK \& KNOPF (1986) studied in a cottonwood-willow stand with even sparser trees (23.9 stems/ha), and reported 4.2 cavities/ha. The lowest density (1.1 cavities/ha) was registered by BRUSH (1983) in honey mesquite and cottonwood deltas, of which detailed habitat information was not given. But honey mesquite usually forms sparse large trees or dense shrubs (ANSLEY et al. 1997). Thus data from these studies should not directly be compared with the results of studies conducted in forests.

Another important factor of cavity abundance is the naturalness of the stand (NOEKE 1989, 1990, SANDSTRÖM 1992, NEWTON 1994). Higher densities were mainly recorded in natural forests (Table 5.1). Excluding the sparse study sites described above, cavity abundance was 15 - 60 cavities/ha in natural stands, and $1-19$ cavities/ha in managed sites. Attention should be paid to the high value (19 cavities/ha) in the plantation reported by VAN BALEN et al. (1982). This sample was based on old deciduous trees bordering the roads. Such tree rows situated in areas otherwise unsuitable for nesting could have higher woodpecker hole density than large uniform area with suitable trees. And in some sites along major roads, the decline of tree condition due to car traffic caused higher cavity holding rate. Thus the linear areas were not representative of forest areas with the same composition (VAN BALEN et al. 1982). The highest cavity density (40 cavities/ha) in the managed forest was documented in one area in Sweden. The author noted that the data were collected from patches difficult to access for forest machines because of the terrain, thus many large deciduous trees were left (SANDSTRÖM 1992).

KNEITZ (1961) concluded that the density of cavity trees was $1-1.5$ trees/ha in coniferous stands, 5 - 6 trees/ha in mixed stands, and 7 - 10 trees/ha in deciduous dominated stands. This was, however, the picture in managed forests in Germany. WESOLOWSKI (1989) summarised that the cavity density reported in most European 
deciduous stands was 5 - 17 cavities/ha, and should be higher in Bialowieza primeval forest. The present study suggested that in primeval boreal forest, 20 - 40 cavities/ha could be considered as a common value in deciduous stands. In coniferous stands with more than $10 \%$ of deciduous components, cavity abundance could also well above 10 cavities/ha. In natural old-growth forest containing large snags, МсCOMB \& NoBLE (1981) proposed cavity density might exceed 40 cavities/ha.

\subsubsection{Abundance of each cavity type}

The figures above referred to the total amount of cavities. Taking cavity type into consideration, the abundance of woodpecker holes in the literature ranged from 2.1 to 14.4 cavities/ha (SCHIERMANN 1934, KNEITZ 1961, PRILl 1987, HARESTAD \& KEISKER 1989, NOEKE 1990, WATERS et al. 1990, SANDSTRÖM 1992, DOBKIN et al. 1995, CARLSON et al. 1998, HART \& HART 2001). The mean density of woodpecker holes in West Khentey was about 4 cavities/ha, which was not high compared to the documented values. Highest abundance of woodpecker holes was found in the riparian forest (10.3 cavities/ha). DoBKIN et al. (1995) reported 7.7 woodpecker cavities/ha as an average in riparian and snowpocket aspen woodland, and HART \& HART (2001) recorded 14.1 cavities/ha in riverine aspen stands. The highest woodpecker hole density also occurred in the riverine stand among the diverse forest types studied by SANDSTRÖM (1992).

KNEITZ (1961) suggested lower abundance of woodpecker holes in coniferous forests than in deciduous ones. This could not be confirmed by the present study, since woodpecker hole density in the spruce-fir forest was similar to that in birch-larch forests. This could be partly due to the limitation of small sample size. Another reason might be that in the spruce-fir forest studied, there were enough large larches and Scots pines which supplied suitable nest sites for woodpeckers. In the study of SANDSTRÖM (1992), abundance of woodpecker holes was also not lower in coniferous stands.

The mean density of branch holes in West Khentey was approximately 16 cavities/ha, one of the highest among the documented values 1.3 - 32 cavities/ha (NOEKE 1990, WATERS et al. 1990, SANDSTRÖM 1992, CARLSON et al. 1998). The forest in West Khentey was not composed of especially large trees compared to most European or 
American study sites. The possible reasons for the branch hole abundance were the frequent forest fire and extreme climate conditions in the study area. Fire may create openings in trees which initiate cavity formation or form cavities directly (MCCAW 1983, GiBBONS et al. 2002; see also Section 5.2.4). In forests at high latitudes, heavy snow leading to limb breakage may also initiate cavity formation (LOWNEY \& HILL 1989). In areas where temperature fluctuations are extreme, which is characteristic in West Khentey, another powerful mechanism of creating cavities is frost crack (Fig. 5.1). The great tension between the frozen outer layers and unfrozen inner layers of wood may lead to the sudden break of wood at a previous wound. When warmer temperatures arrive, the frozen tissues thaw and absorb more water, and the crack closes. However, the heartwood tissues at the crack zone never seal completely, providing the entrance for decay fungi deep into the tree (PIRONE et al. 1988, MARKOVETS 2003).

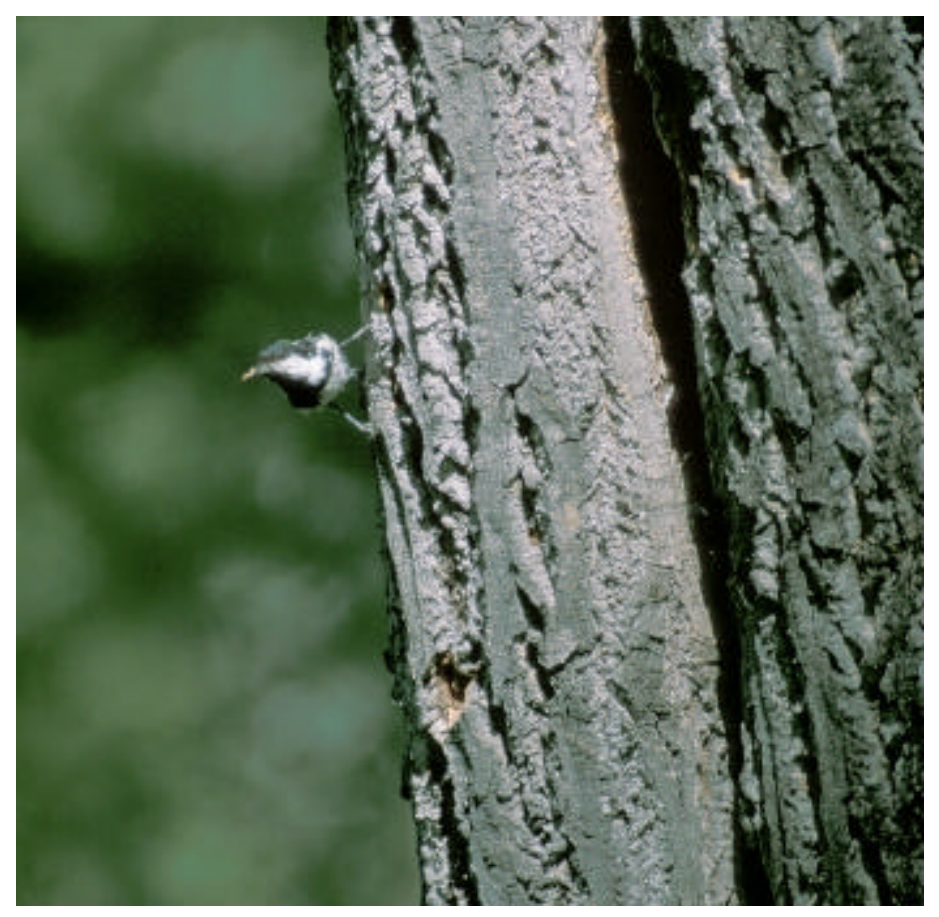

Fig. 5.1 A nest cavity of $P$. ater formed through frost crack. 


\subsubsection{Cavity abundance and habitat-level variables}

The density of woodpecker holes was positively correlated to shrub coverage of the stand. There could be at least two possible explanations for such a relationship. One is, the higher coverage of shrubs indicates food-rich habitats and profitable nest sites for woodpeckers. In the study area, high shrub coverage and high woodpecker hole density co-occurred in the riparian forest. The periodical flooding in the riparian forest results in nutrient-rich soils, while at the same time such anaerobic condition suppresses the development of dense tree canopy. The fertile soil and sufficient light provide optimum environment for shrub layer development. Riparian forests are usually composed of fine mosaics of different tree and shrub species, due to various soil condition and water level at a relative fine scale. The high structural diversity and species diversity of vegetation form abundant food resources for animals (HUBBARD 1977, BRINSON et al. 1981, MALANSON 1993). Invertebrate communities are usually diverse and abundant in riparian forests, which then support plentiful insectivorous birds (Iwata et al. 2003, Romanuk \& LEVIngs 2003). Hogstad \& StENBERG (1994) suggested that food resources might be the most important factor of the habitat choice of woodpeckers. Thus riparian forests have been reported as important habitats for many woodpecker species (BLUME 1961, AULÉN 1988, SPITZNAGEL 1990, ANTHONY et al. 1996).

The correlation between shrub coverage and woodpecker hole density could also be explained by simply coincidence. Riparian forests are typically small or linear patches at the alluvial side of rivers. In the study area, they were mostly isolated woodlands surrounded by meadows or bushes, which were unsuitable for woodpeckers nesting but provide food. Thus the density of woodpecker holes might be higher in such linear patches than in large homogeneous areas of similar structure. This was similar to that VAN BALEN et al. (1982) found high woodpecker hole density in tree rows bordering roads. Another suggestion is that the inner condition of trees in riparian areas supports rapid fungal development, and is thus more suitable for cavity excavation (JACKSON \& JACKSON 2004). All above explanations may play some roles in the higher woodpecker hole density in the riparian forest.

The abundance of branch holes and non-excavated cavities pooled were positively correlated to the proportion of fire-scarred stems in the stand. Fire is known to cause 
tree wounds which initiate cavity formation (MCCAW 1983; see also Section 5.2.4). No significant correlation was found between cavity abundance and the proportion of deciduous stems, the proportion of large trees or the proportion of dead trees in the stand. As shown in Section 4.3, these variables (if a tree is deciduous, tree DBH and tree condition) are important factors of cavity occurrence at single tree level. At habitat level, however, these factors interact and the individual effect is blurred. The proportions of deciduous stems were similar in the young birch-larch forest, the mature birch-larch forest and the riparian forest. However, the impact of fire in the young birch-larch forest and the abundance of cavity-rich poplars in the riparian forest caused higher cavity density in these two habitats. SANDSTRÖM (1992) also didn't find significant correlation between cavity density and the proportion of deciduous stems. At single tree level, cavities are more frequent in larger trees. However, the young birch-larch forest, which was composed of relatively less large trees, had abundant cavities due to fire. SANDSTRÖM (1992) reported positive correlation between cavity abundance and density of dying and dead wood (including dying stems, snags, stumps and old windthrows). In the present study, the proportion of dead trees was higher in the spruce-fir forest than in the mature birch-larch forest and the riparian forest. However, the dead stems in the spruce-fir forest were mostly young conifers and didn't contribute to cavity abundance.

In managed forests, the role of one single factor to cavity abundance might be more easily revealed, due to the control of other variables: fires are usually suppressed, dying and dead trees are largely removed, and stands are often even-aged and comprised of single or few species. In natural forests, however, cavity abundance is the outcome co-acted by diverse factors, the combination of which resulted from various stand condition and history. Thus it is difficult to be derived from single habitat-level variable. The multifactor consideration with a large amount of data is necessary for understanding the natural patterns.

\subsubsection{Cavity abundance and succession}

The abundance of woodpecker holes was negatively correlated with the first principal component of environment variables, i.e. the gradient from riparian forest to mountain taiga. The higher woodpecker hole abundance in the riparian forest has been 
discussed in the previous section, as the consequence of rich habitat and/or isolated suitable patch.

The abundance of non-excavated cavities was negatively correlated with the gradient from light taiga to dark taiga. Concerning cavity abundance and natural forest succession, NEWTON (1994) suggested two hypothetical models. Fig. 5.2(a) illustrates the condition under the long-term absence of fire or other catastrophes. In the beginning period of stand establishment, cavities are absent since trees are too young for decay to process and too thin for woodpeckers to excavate. Cavity numbers increase progressively as large trees age and die, and then stabilise as large tree mortality rates stabilise. At equilibrium, the annual additions of new cavities (arising mainly through decay and woodpecker activities) approximately match the annual losses (mainly through branch and tree fall). In Fig. 5.2(b), many large trees are periodically killed by fire, and then progressively fall over several decades as new forest develops around them. Years later, another fire sweeps through and the process

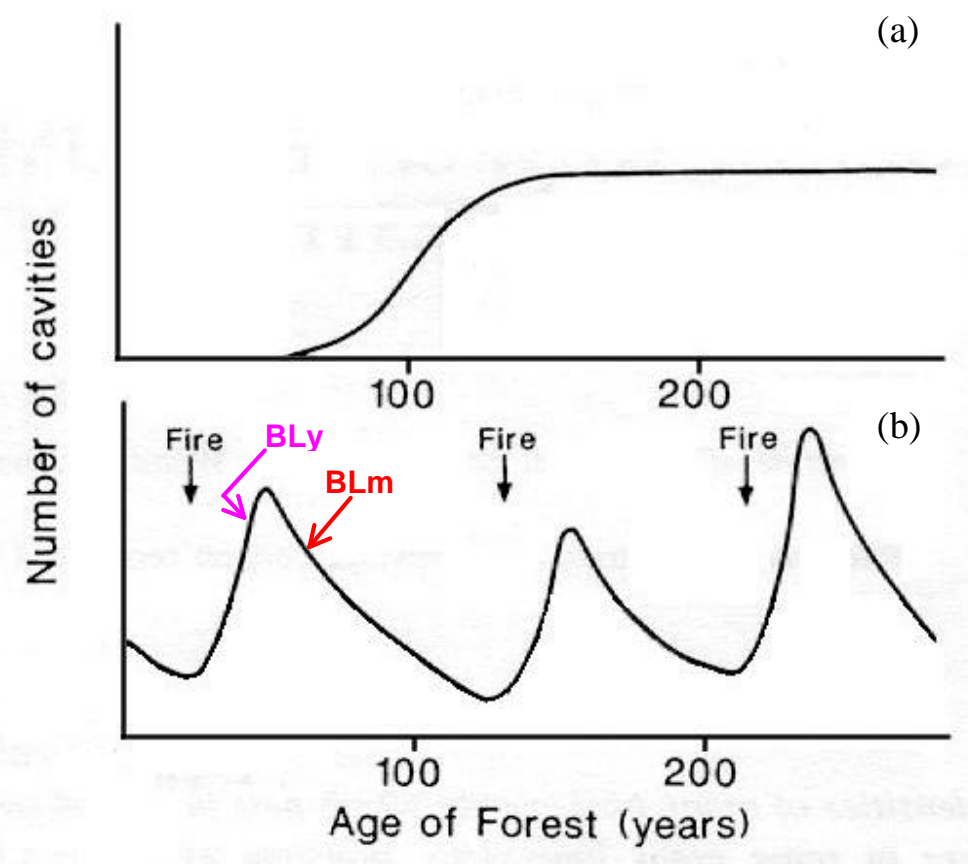

Fig. 5.2 Hypothetical models of the changing numbers of cavities during natural forest succession: (a) from establishment to maturity in the absence of fire or other catastrophes; and (b) an established forest under the influence of periodic fires. The time scale is set roughly for forest in north temperate regions, but would vary with tree species (modified from NEWTON 1994). 
is repeated. In each cycle, cavity numbers reach a peak some years after fire, as dead standing trees rot, and then decline as these trees fall. The exact pattern depends on the proportion of trees killed by each fire, and on the intervals between successive fires. If fires are too frequent, they prevent any trees from being big enough to provide usable cavities (NEWTON 1994).

In West Khentey, the birch-larch stands, the forests under the influence of periodic fires, may fit to the second model. In the young birch-larch forest of the present study, the cavity density might be close to its peak value. Without measuring the annual addition and loss, it is not clear whether the cavity density is in its increasing or declining phase. In the mature birch-larch forest, many trees scarred by the last fire already fell and new generation develops, thus the cavity density might be in the declining stage (Fig. 5.2(b)).

However, the spruce-fir forest, which represents a condition under the long-term absence of fire, does not fit to the first model. In NEWTON's model, the change of tree species composition during succession, which is the case of the majority of natural successions, is not taken into consideration. Thus here a modified model for boreal Eurasia is proposed (Fig. 5.3). In the beginning period of stand establishment, the

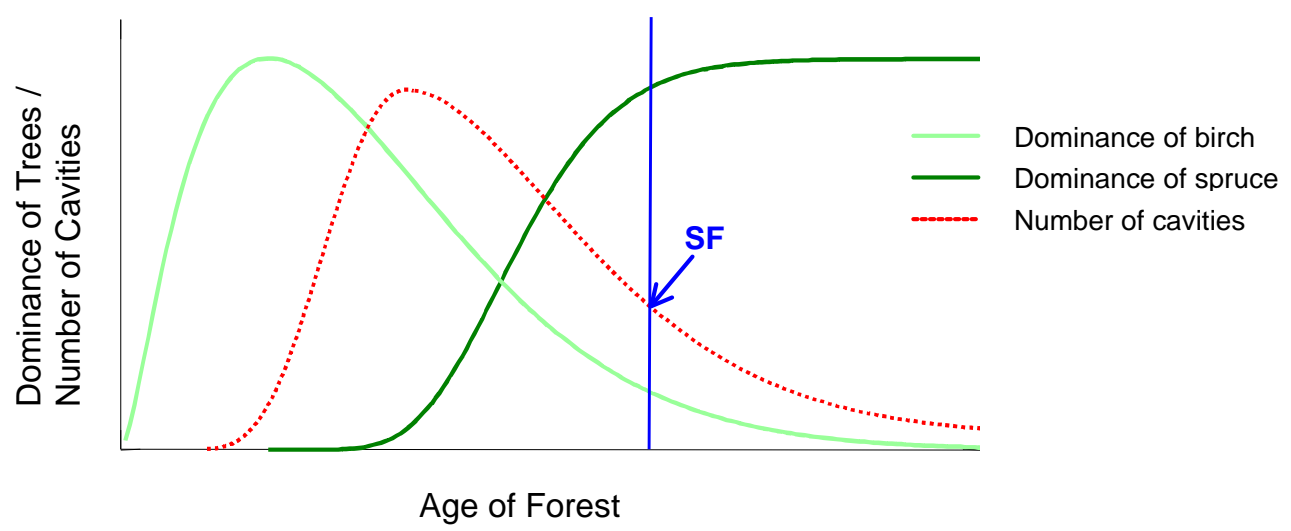

Fig. 5.3 Hypothetical model of the changing numbers of tree species and cavities during natural forest succession. The blue line indicates the approximate stage of the spruce-fir forest in this study (composed of about $13 \%$ birch trees), and the arrow marks the theoretical cavity abundance of this stage. 
pioneer species, birch, develops. Cavity numbers increase as birches age, weaken and die. The shade-tolerant spruce gradually takes over the forest as succession proceeds. The regeneration of birch cannot recruit the fall of old birch trees, and the spruce is less rich in cavities, thus cavity abundance decreases. In the climax forest, cavities are held by spruce and the scattered birch trees regenerating at forest gaps caused by windthrows. The equilibrium is reached when cavity additions match cavity losses in both spruce and birch parts, with a slower turnover rate in the former and a more rapid turnover in the latter.

\subsection{Factors Influencing Cavity Formation in a Tree}

\subsubsection{Tree species}

Deciduous trees are in general more cavity-rich than conifers, corresponding to other studies (VAN BALEN et al. 1982, WATERS et al. 1990, SANDSTRÖM 1992, CARLSON et al. 1998). The most common way decay fungi invading a tree's heartwood is through wounds left by fallen limbs. When a limb of a deciduous tree falls, a protective layer of gum-filled cells develops at the base of the limb. This layer is limited to the sapwood (the living wood tissue), rounding the edges of the wound, leaving the heartwood unprotected from invasion by insects and decay fungi. Conifers develop a protective zone of resin at the base of dead limbs. This resin is not limited to the sapwood but also spreads to the heartwood, providing a greater protection against decay fungi (PEACE 1962, SHIGO \& MARX 1977). Thus cavities are more likely to develop in deciduous trees.

Among the deciduous species in this study, poplar has the highest cavity holding rate. Populus species (including aspen, poplar and cottonwood) are especially prone to attack by heartrot fungi (HIRATSUKA \& LOMAN 1984; PIRONE et al. 1988), and the high cavity occurrence in Populus has been frequently documented (CARLSON et al. 1998, MARTIN \& EADIE 1999, HART \& HART 2001). Birch is the most important cavity tree in West Khentey, holding over $50 \%$ of total cavities. It has high cavity holding rate and is common in diverse habitats. Birch accounts for bulk of the cavities in birch-larch forests and plays the subordinate part in the riparian forest. But the most critical role it plays might be in the spruce-fir forest. In a climax coniferous 
forest with a slight admixture of deciduous trees, most cavities are located in deciduous trees (HAAPANEN 1965). In the natural boreal forests of Mongolia, it is mainly birch that establishes itself in the gaps of coniferous stands with its very light seeds well capable for dispersal. The distribution of birch (Betula spp.) covers most of Scandinavia, the north and middle of Asia and America, and reaches as northward as to the tree line (JALAS \& SUOMINEN 1972, SANDSTRÖM 1992, HORA 1993, FARRAR 1995). Birch might be an important cavity tree species in boreal forests in general.

Excavated cavities are also associated with wood decay, because excavators usually prefer to excavate in parts of tree where the wood has been softened by decay (CONNER et al. 1976, HART \& HART 2001). Thus excavated and non-excavated cavities are generally similar in their occurrence in tree species. In Sweden, cavities found in aspen were mainly woodpecker holes (SANDSTRÖM 1992). While in West Khentey, non-excavated cavities were frequent in poplar as well. The only difference found is that non-excavated cavities were relatively more frequent in birch and less frequent in larch than excavated ones. This might be related to frost crack, a cavity forming mechanism which may occur in trees without remarkable proceeding of decay and is more common in trees of thin bark (PIRONE et al. 1988). Another reason might be that larch can develop to the size that birch seldom reaches, which allows larger-sized excavators to place their nests.

\subsubsection{Tree DBH}

Cavity occurrence increases notably with tree DBH. Such association has been well documented (KNEITZ 1961, van BALEN et al. 1982, SEDGWICK \& KNOPF 1986, NoEKE 1990, SANDSTRÖM 1992, LindENMAYER et al. 1993, PARKS et al. 1999, GibBONS et al. 2000, LEHMKUHL et al. 2003). Cavity formation is partly a deterministic process, because trees are predisposed to form cavities as they age, subsequently weaken and senesce. Cavity formation can also be generated by stochastic process (e.g. fire), and therefore cavities can also develop in young trees. However, older trees are more likely to have been exposed to more of such events (GIBBONS et al. 2002). In areas without considerable difference in soil condition, trunk circumference could probably be used as a measure of age (VAN BALEN et al. 1982), thus cavity occurrence increases with tree DBH. In West Khentey, $68 \%$ of the cavities were located in trees of DBH > 
$30 \mathrm{~cm}$. While in Swedish boreal forest, a very similar value $67 \%$ was reported (SANDSTRÖM 1992).

For trees of DBH under $30 \mathrm{~cm}$, cavity holding rate is generally low and does not differ significantly between tree species, though birch seems to acquire cavities more often than others at the DBH class $15-30 \mathrm{~cm}$. When tree $\mathrm{DBH}$ is above $30 \mathrm{~cm}$, the cavity holding rate starts to differentiate among tree species. The cavity holding rate of deciduous trees (poplar and birch) rises remarkably, over the conifers. Birch, when looking each DBH class separately, has cavity holding rate approaching that of poplar. But birch seldom develops to the size which poplar can do, thus the overall cavity holding rate of birch is much lower than that of poplar. It should also be noticed that the relationship between $\mathrm{DBH}$ and tree age differs from species to species. Populus species are characteristic in their fast growing (PIRONE et al. 1988, HoRA 1993). In European managed stands, a 20-year-old Populus may reach mean diameter of about $30 \mathrm{~cm}$, while a Betula tree of similar size would be already around 80 years old. Larix and Pinus sylvestris have growth rate approaching or slower than Betula, depending on site conditions (SCHOBER 1995). Thus Populus can hold cavities at much younger stage than other species, and is much richer in cavities than other species of the same age. In fact, such rapid growth might be related to the characteristic porous, light and soft wood of Populus, which leads to more frequent cavity formation.

Due to different site condition and stand history, the DBH distribution of cavity trees differed in different habitats. In the young birch-larch forest, more young trees acquired cavities because of fire. In the riparian forest, many cavities were located in large poplars. While in the spruce-fir forest, cavities occurred either in young birches or in old larches. A cavity in a young living tree could be expected to exist longer, with gradually changing size and shape following the tree's growing up, and might be utilised by different CNBs for following decades. However, if decay proceeds too rapid in a small tree, wind or snow may lead to tree fall at an early stage and cause cavity loss (PARKS et al. 1999). Larger trees remain standing longer even after their death, and can keep cavity stock for longer term (MORRISON \& RAPHAEL 1993). Thus DBH distribution of cavity trees in a habitat would influence future cavity availability. 
It might also influence the performance of some CNBs that have preference for certain nest tree size (see Section 5.5.2).

\subsubsection{Tree condition}

Living trees in state of decline have higher cavity holding rate than healthy living trees. A tree of weak physiological condition has a reduced capacity to occlude wounds, and, reciprocally, the invasion of decaying organisms further weaken the tree (GIBBONS et al. 2000). It is well understandable that dead trees have more cavities than living ones, since cavity development proceeds and the number of cavities accumulates, though occasionally there might be loss due to the fall of tree parts containing cavities. Living trees in state of decline (class 2) had higher cavity holding rate than intact dead trees (class 3 and 4). Because most of the trees in the former class already had a broken top and would be grouped into broken tall snags (class 5) as soon as they die.

Occurrence of cavities is in close association with broken top. A broken top not only exposes the heartwood to the invasion of decay organisms, but also often accumulates rain water which further promotes decomposition process (LEHMKUHL et al. 2003). Excavated cavities are relatively even more frequent in tall broken snags than nonexcavated ones. MCCLELLAND et al. (1979) suggested that a broken top might be an obvious cue for excavators indicating decayed heartwood in combination with firm sapwood shell.

Due to fire, the living trees in the young birch-larch forest held cavities more frequently than those in other habitats. Cavities in living trees might be valuable, since the expectance of the time they remaining in the forest, and thus usable for CNBs, is longer than those in dead trees. Living trees can isolate fungi-infected sapwood, a process called compartmentalisation. The isolation includes both physical barriers, such as blocking xylem vessels with gum and other tree products, and chemical barriers, such as tannins and phenols (JACKSON \& JACKSON 2004). Therefore, though cavity formation progresses very slowly in living trees, a usable cavity in a living tree is long lasting, while cavities in dead tree undergo rapid decay and are prone to loss due to tree or limb fall. But for some tree species with strong compartmentalisation ability, cavities in living trees could also loss due to the sealing 
of cavity openings by sapwood growth (SEDGWICK \& KNOPF 1991, WESOLOWSKI 1995b). The constitution of cavity tree condition is thus important for cavity dynamics. It might also influence the breeding performance of CNBs since different bird species have different preference for nest tree condition (see Section 5.5.2).

\subsubsection{Fire}

In West Khentey, about $76 \%$ of the cavities were located in trees with fire scars. For the main cavity tree species, fire-scarred trees acquired cavities three to four times more often than those without fire scars. Fire may directly excavate cavities in trees. This often leads to special cavity types which could be utilised by CNBs or other animals. But more often fire causes tree wounds and predisposes trees to the invasion of fungi and termites. Trees with physiological conditions weakened by fire also have reduced recovering capacity against the invasion of decay-causing organisms (MCCAw 1983, GibBOns et al. 2002, HunTER \& MAZUREK 2003).

Though fire may increase cavity occurrence significantly and allow cavity formation in younger trees, heavily wounded trees might stand only few years in the forest (PARKs et al. 1999, White \& SEginaK 2000, LehmKuhl et al. 2003). The intensity and type of fire, as well as the pre-burned forest structure, have to be taken into consideration to access the influence of fire to cavity availability.

\subsubsection{Fungi}

Trees with the presence of fungi conks acquire cavities much more often than those without. In West Khentey, conk-bearing trees, which made up only about $5 \%$ of the standing stems, accounted for $29 \%$ of the cavities. This is not surprising since fungi are the main decay-causing organisms, which lead to the formation of non-excavated cavities and minimise the excavation burdens of excavators. In aspen woodland, DoBKIN et al. (1995) reported that $75 \%$ of cavity holding living trees supported visible fungi.

An interesting phenomenon is that excavated cavities are more closely associated with the presence of fungi conks than non-excavated ones. Many studies have reported the preference for conk-bearing trees of excavators, and the explanation is usually the 
dependence of excavators on fungi-softened wood (ERSKINE \& MCLAREN 1972, CONNER \& LOCKE 1982, WinTERNITZ \& CAHN 1983, HOOPER et al. 1991, HART \& HART 2001). But if the occurrence of non-excavated cavities could to certain extent indicates the process of fungi-caused decay, then the higher association between excavated cavity and fungi conks suggests that wood softness might not be the only factor. Presence of fungal conks may provide excavators with a visual cue of a suitable nest tree (KILHAM 1971, CROCKETT \& HADOW 1975). Excavators may sometimes also become a vector for fungi. Both nest excavation and foraging excavation activities provide openings for invasion of microorganisms. Excavators may further infect the sites they excavate with hyphae or spores that adhere to their bills or feathers (JACKSON 1977, FARRIS et al. 2004).

Type of fungi is important in such associations. Wood-decaying fungi are often specific in their use of tree species, tissues, and sites of entrance. Heartwood fungi and sapwood fungi are usually different, and the previous group is typically more important for excavators (JACKSON \& JACKSON 2004). Such fungi cause extensive decay of the heartwood while the sapwood remains intact, protecting the nest cavity (HART \& HART 2001). The way fungi invading trees also influence the nest site of excavators. Fungi invading trees from the broken top often lead to excavated cavities formed close to the broken top. New cavities in the same snag are usually excavated below the cavity of the previous year, as the fugal decay grows downwards (CONNER et al. 1975). The root fomes Heterobasidium annosum invades spruce from root injuries and can develop up to 5-6 m. Consequently woodpecker holes are found in lower parts of trees, and successive cavities are often above previous ones due to the upward growth of fungi (WIESNER 2001).

As the result of all above ecological interactions, certain fungi and certain species of excavators could be intimately linked. In America, the red ring rot fungus Phellinus pini is closely associated with the cavity trees of the endangered Red-cockaded Woodpeckers Picoides borealis (CONNER et al. 1976, CONNER \& LOCKE 1982). Several sapsucker species Sphyrapicus spp. select aspen with fruit bodies of the aspen bracket fungi Phellinus tremulae (CROCKETT \& HADOW 1975, WINTERNITZ \& CAHN 1983). In West Khentey, a primary inventory on wood-decaying fungi has been conducted, and 37 species were identified (SUNJIDMAA et al. 2003). Excavated 
cavities were mainly associated with hoof fungus Fomes fomentarius specializing on birch trees (pers. obs.; Fig. 5.4). The detailed species-specific interaction is in need for further study.

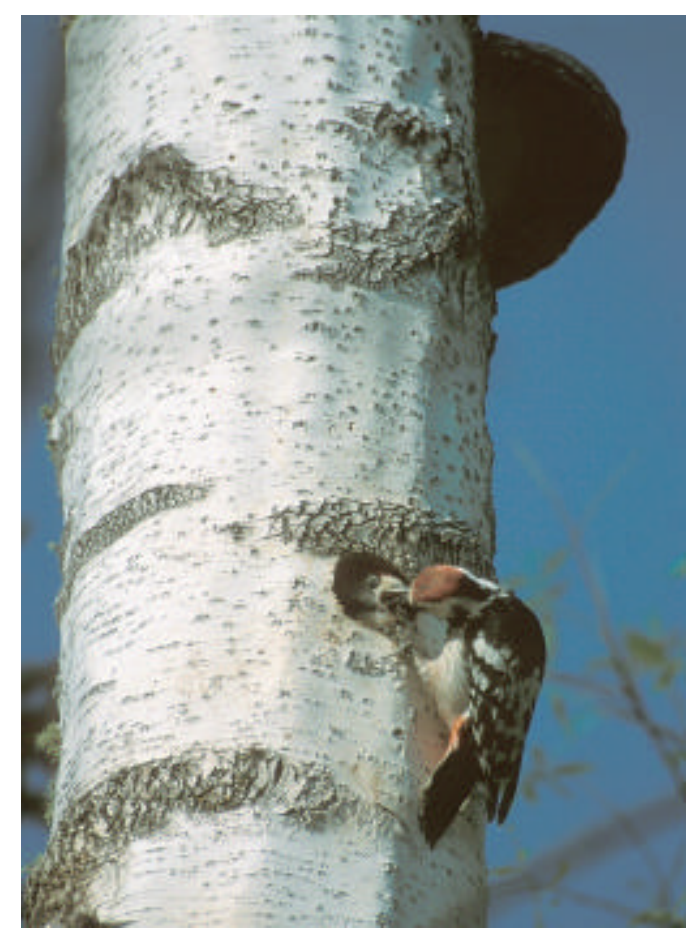

Fig. 5.4 A nest cavity of D. leucotos in a birch tree bearing the fruit body of hoof fungus Fomes fomentarius.

\subsubsection{Predictive model of cavity occurrence}

Though cavity abundance of a stand was difficult to quantify by habitat-level variables (see Section 5.1.4), cavity occurrence in a tree could be properly predicted by tree-level variables. The logistic regression models developed here not only summarised the relationship between cavity-holding rate and individual tree characters, but also clarified and integrated the multivariate interactions. Such predictive models are useful tool for conservation and management. They provide quantified estimates of a tree's value, in term of supplying cavities, and could be applied to the practice of snag creation and wildlife tree retention (PARKS et al. 1999). Further models about the longevity of cavity trees should also be generated and taken into consideration when framing conservational plans (BULL 1983). 


\subsection{Composition of CNBs}

\subsubsection{Species richness of CNBs}

The assemblage of CNBs is rich in West Khentey. During the study period of two breeding seasons, nests of 16 CNB species were found in the study sites. Potentially, this area contains at least $31 \mathrm{CNB}$ species, representing $24 \%$ of the breeding bird species (Wichmann \& Pokrovskaya 2004; Appendix). Among which 24 species are obligate cavity nesters. This includes seven species of woodpeckers (Picidae, including Wryneck), which may occur sympatrically and represent all possible woodpecker species existing in the biogeographic region. It has been suggested that in non-tropical regions of North America and Eurasia, four to five sympatric woodpecker species are typical, while up to eight species may occur at where trees are diverse (SHORT \& HORNE 1990). However, the tree species composition in West Khentey is relatively simple.

The total number of $30 \mathrm{CNB}$ species is also one of the highest in the literature. However, comparison is rough since the method differed a lot among studies, and most studies did not consider the entire CNB community. Some studies reported CNB species by conducting census or inventory, while others did through locating nests or identifying traces left in cavities. The definition of CNBs might also differ in including or excluding non-obligatory cavity nesters and/or species nesting in halfcavities or chimneys. Time and spatial scale varied from study to study, and could cause great differences in the number of species found.

In Swedish deciduous forest, 12 CNB species were recorded, including three species of woodpeckers and nine SCNs (CARLSON et al. 1998). In five managed stands in Sweden, 8 CNB species were censused (SANDSTRÖM 1992). Across Norway, seven species of woodpeckers produce cavities used by 21 species of birds and mammals, but not all species live sympatrically (AANDERAA et al. 1996). In German beech forests, eight to ten CNB species were registered (PEITZMEIER 1969, WEISS 1987). In cultural landscape of Netherlands, nests of three PCN and 13 SCN species were found (VAN BALEN et al. 1982). In the primeval temperate forest in Bialowieza, Poland, 25 CNB species were recorded (WESOLOWSKI 1989). In Canadian mixed forest, a rich number of $31 \mathrm{CNB}$ species was reported, including eight species of woodpeckers 
(MARTIN et al. 2004). In United States, 20 CNB species were registered in Douglas fir forest (MCCLELLAND et al. 1979), 15 species (6 PCN + 9 SCN) in mixed forest (LI \& MARTIN 1991), 12 species in post-fire pine-Douglas fir forest (SAAB et al. 2004), 11 species $(5 \mathrm{PCN}+6 \mathrm{SCN})$ in cottonwood bottomland (SEDGWICK \& Knopf 1992), 8 species (3 PCN + 5 SCN) in aspen woodland (LAWLER \& EDWARDS JR. 2002), and 8 diurnal SCN species in oak-pine woodland (WATERS et al. 1990). GIBBS et al. (1993) reported that, in New World forests, the number of CNB species increased with decreasing latitude, averaging 33.6 species in tropical and subtropical forests versus 14.8 species in temperate and boreal forests. The number of PCN species was similar between low latitude forests ( 8.2 species) and high latitude forests (6.0 species).

The mosaic landscape and the naturalness of the study area might contribute to the high CNB species richness. In West Khentey, forest, steppe and shrub form fine natural mosaics. Even inside forests, there are often shrubby or grassy patches due to fire or topography. Dead trees and fire-scarred trees are abundant in natural forests, and are composed of various species, size, height and decay stage. Natural cavities are presented in variable height, inner dimension, opening size and shape. These factors could result in diverse foraging and nesting niches for CNBs, which allow different species to coexist.

\subsubsection{CNB density vs. forest type and management}

The density of CNBs in the study area averaged 2.4 breeding pairs/ha. This was highest in the riparian forest (3.5 pairs/ha), though the difference to the birch-larch forests (2.6 pairs/ha for both mature and young stands) was not significant. The spruce-fir coniferous forest had lower CNB density (1.0 pair/ha) than the deciduous stands. No apparent fluctuation of CNB density was observed in the study period.

The CNB density in West Khentey corresponded well to the documented values. In Sweden, NILSSON (1979) reported 3.7 territories/ha in natural deciduous forest, and 1.1 territories/ha in managed spruce-pine forest with an admixture of deciduous trees. SANDSTRÖM (1992) found an average of 3.2 pairs/ha in deciduous dominated stands, and 1.1 pairs/ha in conifer dominated ones. In Poland, 2.3 pairs/ha in forest interior and 3.8 pairs/ha at forest edge were reported in Bialowieza (TOMIALOJC et al. 1984). WESOLOWSKI (2002) further documented 3.0 - 3.8 pairs/ha in ash-alder swamp plots, 
2.9 - 3.5 pairs/ha in oak-hornbeam plots and $1.3-1.4$ pairs/ha in coniferous plots. 1.2 pairs/ha was reported in spruce-fir forest in United States (SCOTT et al. 1978).

Coniferous forests generally has lower CNB density than deciduous forests, and the occurrence of deciduous trees in a coniferous forest may be crucial for the abundance of CNBs. In Finland, HAAPANEN (1965) found CNB density in a spruce forest with an admixture of aspen and birch (1.1 pairs/ha) was about twice than in an almost pure spruce stand (0.6 pairs/ha). In United States, both the densities of PCNs and SCNs were higher in pine-oak stands than in pine stands (ROSENSTOCK 1998).

CNB density is usually lower in managed forests. In Finnish pine forests, HAAPANEN (1965) reported 0.4 pairs/ha in natural stands and $0.07-0.2$ in managed ones. In Sweden, natural forests had, on average, 2.1 - 2.8 times higher density than managed forests (SANDSTRÖM 1992).

Distribution of species abundance is often a more sensitive measure of environmental disturbance than species richness or density alone (MAGURRAN 1988). In natural forests, there are usually not one superior dominant in CNB community (but the high abundance of $F$. albicollis in oak-hornbeam forest in Poland, see WESOLOWSKI et al. 2002). While in managed forests, most of the cavities are usually occupied by one superior dominant species, which, in Europe, is mostly Starling S. vulgaris or $P$. major. Nest boxes usually represent an impoverished assemblage. Different species response differently to the addition of nest boxes (BRAWN \& BALDA 1988, PURCELL et al. 1997). Except the boxes specially designed for target species, P. major or the Pied Flycatcher Ficedula hypoleuca usually becomes the superior box nester in most part of Europe (PERRINS 1979, vAN BALEN et al. 1982, CZESZCZEWIK 2004).

\subsubsection{CNB abundance and habitat-level variables}

In West Khentey, proportion of deciduous trees and shrub coverage were related to the CNB density of a stand. Both PCN and SCN density and number of CNB species were positively correlated with the abundance of deciduous trees. Positive correlation between CNB density and proportion of deciduous trees was also found in Swedish forests (SANDSTRÖM 1992). Deciduous trees hold cavities much more frequent than conifers (see Section 5.2.1). Deciduous trees usually support more invertebrate food 
than conifers do (HUHTA et al. 1998). Solitary deciduous trees growing in coniferous forests may increase the species richness of invertebrates by several magnitudes (SANDSTRÖM 1992). Thus deciduous trees are important for CNBs in satisfying both their nesting and foraging needs. This is in accordance with the higher CNB density in deciduous forests and the importance of deciduous trees in coniferous forests to CNB density described in previous section. This also partly explained the lower CNB density in managed forests, since deciduous trees are mostly removed in forestry practice.

PCN density and pooled CNB density were positively correlated with shrub coverage. This was in accordance with the higher abundance of woodpecker holes found in stands with higher shrub coverage, mainly the riparian stands in the study area. And this might be resulted from more than one factor, including rich food resources, edge effect, and fungi-feasible tree condition in riparian sites (see Section 5.1.4). Density of shrubs was found to be associated with the abundance of many bird species, including several CNBs (FLACK 1976, BRAWN 1988, HoBSON \& BAYNE 2000). The artificial thinning practice in silviculture, which stimulated vigorous shrub growth, was also suggested to be highly beneficial to numerous breeding bird species (SIEGEL \& DESANTE 2003). These observations supported the idea that sites with welldeveloped shrub understories as richer habitats. Several CNB species were found to prefer nesting near forest edges for reduced travelling time to foraging patches, though also some species preferred forest interior (JOHNSSON et al. 1993, DOBKIN et al. 1995, MARTIN et al. 2004). MARTIN \& EADIE (1999) reported that the overall CNB abundance showed positive edge effect in a natural fragmented landscape.

No significant correlation was found between CNB density and the proportion of dead trees. In Sweden, SANDSTRÖM (1992) also found no relationship between density of dying and dead wood and abundance of CNBs. While in plots with different intensity of silvicultural snag removal, ZARNOWITZ \& MANUWAL (1985) found both CNB species richness and density increased with increasing snag densities. SHOWALTER \& WHITMORE (2002) recorded that the trend of CNB abundance over 16 years followed the abundance of snags killed by Gypsy moth Lymantria dispar. In three snag density treatments, HAGGARD \& GAINES (2001) reported that stands with medium snag density treatment (15 - 35 snags/ha) had the highest abundance, species richness, and 
nesting population of CNBs. RAPHAEL \& WHITE (1984) found correlations between CNB density and snag density, with most birds in the plots where there were most snags. But beyond a density of about 7 large snags/ha, bird density levelled off. Thus in most part of the West Khentey forests, the snag density might be high enough and did not become the limiting factor of CNB density.

\subsubsection{Cavity occupancy - Are cavities limiting?}

In the study area, about $5 \%$ of the cavities were occupied by SCNs in each year. The documented cavity occupancy varied greatly, from less than $10 \%$ to more than $90 \%$. In unmanaged deciduous forest in Sweden, occupancy of $5.3-9.1 \%$ was reported (CARLSON et al. 1998). SANDSTRÖM (1992) found about $7 \%$ of cavities were occupied by CNBs in both natural and managed forests (6.5 - 7.2 in natural, 6.3 - 6.9 in managed). Occupancy of less than $10 \%$ was also reported in mixed hardwood stand (MCCOMB \& NoBle 1981). Most documented values lay, however, between, $20 \%$ and $60 \%$. In United States, cavity occupancy of $21 \%$ was reported in birch-ash woodland (EDINGTON \& EDINGTON 1972), 28.9 - 45\% in pine-oak woodlands (WATERS et al. 1990), and 38.5 - 46\% in cottonwood bottomland (SEDGWICK 1997). In parkland with Douglas fir, pine and aspen in Canada, 57\% of the cavities were occupied (PETERSON \& GAUTHIER 1985). In Germany, cavity occupancy between $32.6-44 \%$ was found in beech-fir forest (HOHLFELD 1995), and between $50-64.1 \%$ was documented in pine forest (SCHIERMANN 1934). Some highest values was reported in Netherlands by VAN BALEN et al. (1982), ranged from 54\% to $93 \%$ in different years and areas. It was argued that the linear tree rows of the study site probably promoted high occupation, in that birds of a large adjacent area concentrated their breeding attempts in the small strip (VAN BALEN et al. 1982).

The cavity occupancy of West Khentey was among the lowest in the literature. The low occupancy of only $5.2 \%$ indicated a large proportion of unoccupied holes, and thus cavity availability might not be a limiting factor of the breeding density of SCNs. The presence of unoccupied cavities has been frequently used as the argument that cavities are not limiting (e.g. EDINGTON \& EDINGTON 1972, PETERSON \& GAUTHIER 1985, RENDELL \& ROBERTSON 1989). However, the inner dimension of cavities was not measured in the present study, and many might be unsuitable or unavailable for SCNs. Some cavities identified from ground might have chambers too shallow or too 
narrow to contain a nest. Some cavities might contain rain water at the bottom, have heavy parasite load, or be filled by nesting materials from previous breeding attempts. The acquisition to cavities might also be limited due to the territoriality of birds or the occupation by insects or mammals. Thus the actual availability of nest cavities is often less than the apparent availability, determined simply by counting (NEWTON 1994).

Therefore, the possibility cavity availability as the limiting factor was also discussed through other approaches. First, SCN density was not significantly correlated with cavity abundance in the study area. Positive associations between relative abundance of CNBs and numbers of cavities were reported in some studies regarding natural nest sites (RAPHAEL \& WHITE 1983, DOBKIN et al. 1995). Other numerous evidences of positive correlation between SCN density and nest-site availability was mainly based on artificially providing nest boxes. The addition of nest boxes usually resulted in the increase of breeding population of target species (e.g. VON HAARTMAN 1957, ENEMAR \& SJÖSTRAND 1972, BRUSH 1983, BRAWN \& BALDA 1988, TÖRÖK \& TOTH 1988, JÄRVINEN 1989, GUSTAFSSON 1998). However, most of these studies were conducted in forests where previous long-term management might have impoverished the stock of cavities and led to the shortage of nest sites. BRAWN \& BALDA (1988) found that CNB density increased after the addition of nest boxes in two plots with intermediate numbers or few natural cavities, bur remained unchanged in the plot with abundant natural cavities. The installation of nest boxes in Bialowieza National Park also caused no increase in Paridae density (WALANKIEWICZ 1991). Nest boxes are often less vulnerable to predation and give rise to higher breeding success (NILSSON 1984a, 1984b). Most western European forest forests contain a lower diversity of predator species, and near human settlement bird food is often provided in winter (TOMIALOJC et al. 1984, WESOLOWSKI et al. 1987). Thus the nest box population may be unnaturally high, due to the release of certain limiting agents which might come into play under natural conditions.

Second, if assuming the proportion of unsuitable cavities was similar among habitats, some clues could be drawn through the comparison of cavity occupancy. Between the mature and young birch-larch forests, which had similar forest composition, the latter possessed more cavities than the former, but the density of SCNs was identical in both 
habitats, which resulted in a lower occupancy in the latter. Thus there might be other factors limiting bird populations in the young birch-larch forest. On the other hand, if cavity availability was the limiting factor of SCN density, competition should be the strongest in the spruce-fir forest, where cavities were most scarce. Yet the occupancy in this habitat was the lowest, suggesting that other factors suppressed the bird density.

Third, in comparison with other studies conducted in unmanaged forests, the occupancy in the study area was in accordance to that of Swedish natural forest (5.3 $9.1 \%$ ), in which the inner dimensions of all cavities were measured, and more than $50 \%$ of them were considered as suitable for nesting (CARLSON et al. 1998). Studies in Bialowieza also suggested that cavity availability was not the limiting factor of SCN density in primeval forest (WESOLOWSKI 1989, WALANKIEWICZ 1991).

Predation, food supply and weather conditions are other possible alternative factors limiting CNB populations. Though tree cavities are usually considered as a safer nesting site than open ones, it is not always safe (NILSSON 1986, MøLLER 1989, MARTin \& Li 1992, MARTin \& Clobert 1996, WALANKIEWicz 2002a, 2002b). Nest predation was found to be a major factor influencing breeding success of several CNB species, and the predation rate is higher in natural cavities than in nest boxes, in natural forests than in managed ones. In Sweden, the predation by the Pine Marten Martes martes was the main cause of nesting failure of the nests established in Dryocopus martius holes (JOHNSSON et al. 1993). In Bialowieza, predation led to $56 \%$ of the brood loss of the Collared Flycatcher Ficedula albicollis (WALANKIEWICZ 1991) and $47 \%$ of the Pied Flycatcher Ficedula hypoleuca (CZESZCZEWIK 2004). The nest site selection of the Marsh Tit Parus palustris was best explained by antipredator adaptations, which also suggested a strong predation pressure (WESOLOWSKI 2002).

Food abundance may also influence CNB density in areas where natural cavities are abundant (HAAPANEN 1965, WATERS et al. 1990). Winter food availability was suggested to be more important in determining Parus major density than nest site availability (NILSSON 1979). The yearly variation of the breeding numbers of $C$. familiaris was positively correlated with the abundance of leaf-eating caterpillars (WESOLOWSKI 1994). Population density of S. europaea was positively correlated 
with the beech crop in the previous year (ZANG 2003). Winter temperatures were found critical for the survival of S. europaea and P. major (SLAGSVOLD 1975, NILSSON 1987). The breeding densities of D. martius, D. major and D. minor correlated positively with temperatures of preceding winter in Finland (HAVELKA \& RUGE 1993), but in Poland the breeding density of $D$. major was not correlated with temperatures of preceding winter (WESOLOWSKI \& TOMIALOJC 1986). In the present study, the fact that CNB density was positively associated with proportion of deciduous trees and shrub coverage might suggest the importance of food availability. And winter climate in West Khentey is extremely harsh. Thus several factors may coact in limiting CNB density, and different species might be influenced by different factors to different extent.

\subsubsection{CNB abundance and succession}

The abundance of CNBs decreased along the gradient from riparian forest to mountain taiga. The higher CNB density in riparian sites has been discussed in the previous sections (see Section 5.1.4 and 5.3.3). When considering the mountain taiga alone, both the density and species richness of CNBs were higher in the light taiga and lower in the late successional stage, dark taiga.

Post-fire forests have been documented as important habitats for CNB community (Bock et al. 1978, RAPHAEL \& White 1984, HutTo 1995, SAAB \& DudLey 1998, KREISEL \& STEIN 1999). Fire-scarred trees supply plenty of nesting substrates for PCNs and cavities for SCNs (see Section 5.2.4). Fire-killed snags are rich in larvae of bark beetles and wood-boring beetles (YANOVSKI \& KISELEV 1996, MURPHY \& LEHNHAUSEN 1998). Fire also further influences nutrient dynamics, changes the composition and distribution of vegetation, and alters insect community. Vegetation regrowth after wildfire generally results in rapid increases of arthropod populations (BEST 1979). Mammal and reptile nest predators are likely absent or have reduced numbers in large, recently burned forests, possibly allowing for higher reproductive success of CNBs (SAAB \& VIERLING 2001). Therefore early post fire habitats provide more nesting and foraging opportunities and a reduced risk of predation.

This is only the approximate pattern, however. The responses of bird community to fire vary with size, severity and type of fire, as well as pre- and post-fire cover types 
and landscape context of burns (SAAB \& DUDLEY 1998, KOTLIAR et al. 2002).

Different bird species may also have different response, due to differences in preferred prey abundance or the preferred decay stage of cavity tree, and thus occur in different post-fire successional stages (JAMES et al. 1997, MURPHY \& LEHNHAUSEN 1998, SAAB et al. 2004).

Newton (1994) applied the models of changing numbers of cavities during natural succession (see Section 5.1.5) to explain the role of nest site availability as the limiting factor to CNB density (Fig. 5.5). L indicates the level below which CNBs are limited by shortage of nest sites, and above which they are limited by other factors. In Fig. 5.5(a), which illustrates the trend from stand establishment to maturity in the absence of fire or other catastrophes, in period a-b cavities are absent, b-c increasing, and c-d present in excess. So in period a-b CNBs are absent as breeders, in b-c they are present but limited by nest sites, and in c-d present but limited by other factors

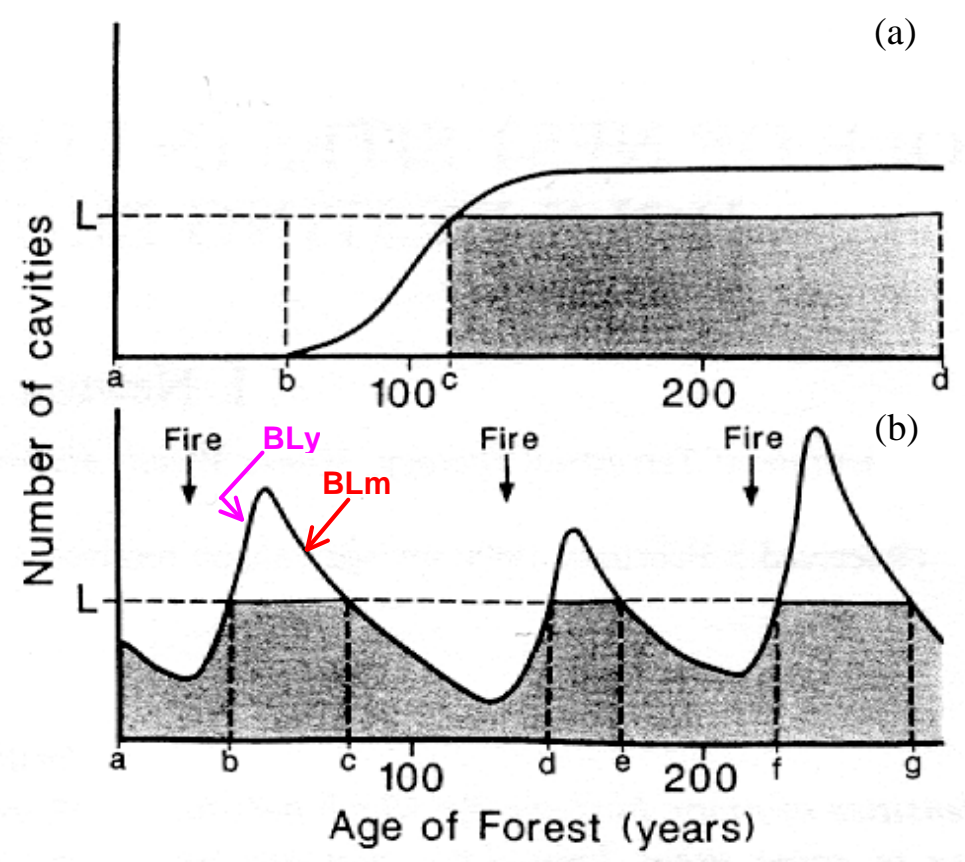

Fig. 5.5 Hypothetical models of the changing numbers of cavities and cavity-nesting birds during natural forest succession: (a) from establishment to maturity in the absence of fire or other catastrophes; and (b) an established forest under the influence of periodic fires. On the vertical scale, $L$ indicates the level below which cavity-nesting birds are limited by shortage of nest sites, and above which they are limited by other factors (modified from NEWTON 1994). 
below the level that nest sites would permit. Managed forests are usually felled before stage $\mathrm{c}$, and some even before $\mathrm{b}$, therefore the shortage of nest sites is often observed. In Fig. 5.5(b), where cavity abundance fluctuates due to periodic fires, CNBs are limited by nest site availability in periods a-b, c-d and e-f, and by other factors in periods b-c, d-e and f-g, when cavities are surplus to needs.

The birch-larch forests in the present study may fit to the second model. Cavity abundance is higher in the young birch-larch forest than in mature one, but is above $\mathrm{L}$ in both stands. CNB abundance is similar in the two habitats, limited by other factors, and doesn't exploit all available cavities.

For the spruce-fir forest, which represents a stage of the natural succession with changing tree species composition, the modified model proposed in Section 5.1.5 should be applied. During such type of succession (Fig. 5.6), CNBs might be limited by cavity availability both in the early phase of stand establishment (period a-b) and in the late stage of almost pure conifers (period c-d). In period b-c, cavities are surplus and CNB density is limited by other factors. This model should be further improved, since during succession with such great change of forest composition, L, the point at which other limiting factors come into play, is not likely to keep constant

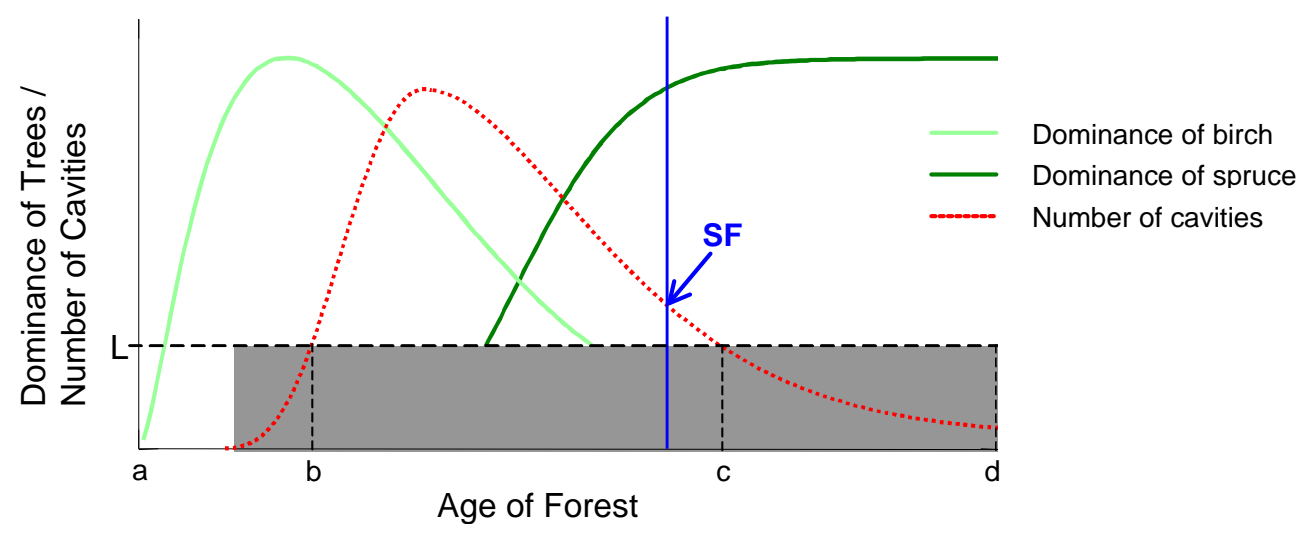

Fig. 5.6 Hypothetical model of the changing numbers of tree species, cavities and cavity-nesting birds during natural forest succession. The blue line indicates the approximate stage of the spruce-fir forest in this study. 
throughout every stage. Coniferous forest might have more limited food supply than deciduous or mixed forest, thus keeps CNBs at a lower density even when cavities are still sufficient, which suggests a lowered L. The exact condition may be dependent on the characteristics of the composition tree species and bird species, as well as specific site conditions. And the detailed information of such systems is still largely unknown.

\subsection{Factors influencing Tree and Cavity Use}

\subsubsection{Tree species}

Deciduous trees were used overproportionally by both PCN and SCN, consistent with other studies (VAN BALEN et al. 1982, AULÉn 1988, WESOLOWSKI 1989, STENBERG 1996). PCNs preferred to excavate in decay-feasible deciduous trees, as has been discussed in Section 5.2.1. SCNs, however, did not really have a preference for deciduous trees. The tree species composition of SCN nest trees showed no difference to that of cavity trees, indicating that SCNs were not selective on cavities according to tree species. Thus their overproportional use of certain species simply reflected the higher availability of cavities in these trees. The tree species utilisation of CNBs has been extensively studied, but most studies did not survey the availability of tree species and cavities or did not separated PCNs and SCNs, thus failed to clarify the role of tree species.

WESOLOWSKI (1989) found that, through comparison from two habitats and from the literature, SCNs can utilise totally different tree species, and suggested that tree species was not important factors influencing their nest-site selection. GIBBONS et al. (2002), by identifying animal traces in the cavities in felled trees, found that cavity tree occupancy (including all vertebrate fauna) did not differ significantly between tree species. GUTZWILLER \& ANDERSON (1987) and SAAB et al. (2004) also reported tree species was unimportant for cavity occupancy (including both PCNs and SCNs). CARLSON et al. (1998), instead, found cavities in aspen were most frequently used by CNBs. A further examination of this data set showed that SCNs alone still preferred cavities in aspen. 
Birch was the most important nest tree species in West Khentey, in that it supported up to two third of CNB nests. Poplar was most extensively used relative to its abundance. Many Populus species has been found to be favoured by diverse woodpecker species (AULÉN 1988, HARESTAD \& KEISKER 1989, STENBERG 1990, JOHNSSON et al. 1993, CARLSON et al. 1998, AITKEN et al. 2002), as well as important nest tree for CNBs in general (LI \& MARTIN 1991, DOBKIN et al. 1995, MARTIN \& EADIE 1999).

\subsubsection{Tree DBH}

Relative to tree abundance, both PCNs and SCNs used large trees overproportionally (DoBKIN et al. 1995). Larger trees, which are usually older, are more often in a weakened stage, at least partly. Large diameter also means higher structural stability of the tree, which may release the risk of tree fall during breeding season. With increasing DBH, the nest cavities can usually be excavated in higher tree positions (WIESNER 2001). Thus large trees were favoured by PCNs. SCNs, however, were not selective on tree DBH. Cavities in trees of different DBH were utilised to a similar extent by SCNs. Thus most of SCN nests were placed in trees of DBH $25-50 \mathrm{~cm}$, since large trees were rare and cavities in small trees were few or might be too small.

In Poland, WESOLOWSKI (1989) also found most SCN nests in medium-sized trees (DBH $32-47 \mathrm{~cm}$ ), and suggested this reflecting the cavity availability. In Sweden, CARLSON et al. (1998) reported that tree DBH was unimportant to cavity occupancy (including both PCNs and SCNs). While in Australia, by identifying animal traces in the cavities, a weak positive correlation between cavity occupancy (including all vertebrates) and tree DBH was found (GIBBONS et al. 2002).

SCNs used less small trees than PCNs did in the study area. This partly reflected the rarity of cavities in small trees. Since compared to excavation, formation of nonexcavated cavities is a very slow process, and more likely to progress to a usable size in old trees. While excavation can in principal occur in a small tree, as long as the tree is large enough to contain a nest and is in a proper decay stage. However, the difference did not reflect in the tree DBH distribution of excavated and non-excavated cavities (Section 4.3.2). Besides the limited sample size, this might be because most of the excavated cavities in small snags were lost in few years, while those in large 
trees still remain. Thus the tree DBH distribution of cavities in stock was different from that of nest cavities in use of a certain year.

\subsubsection{Tree condition}

Both PCNs and SCNs used dead trees overproportionally. The importance of snags for CNBs has been frequently addressed (MORRISON et al. 1983, SCOTT \& OldeMEYer 1983, PetiT et al. 1985, GiBBS et al. 1993, DobKIN et al. 1995, HutTO 1995, BRANDEIS et al. 2002, LAWLER \& EDWARDS JR. 2002, MARTIN et al. 2004). And broken snags were considered important for supplying nest sites (SCOTT et al. 1978). However, in the study area, cavities in living trees were preferred by SCNs, while those in broken snags were used underproportionally. In the study of the reuse of D. major cavities in German beech and spruce forests, cavities in living trees were found to be occupied more often (GüNTHER \& HELLMANN 1995).

Nesting in living trees has been suggested to have several advantages. Living trees have higher structural stability and are less prone to tree fall. Nests placed in living part of trees suffer less predation (AlBANO 1992, ChristMAN \& DHONDT 1997, WESOLOWSKI 2002). Larger predators that could not reach the nest through cavity entrance usually destroy the cavity wall, which is less likely to happen when the cavity is surrounded by solid living wood. In the study area, some nests were observed to be lost due to the predation by Dendrocopos major or the nest tree falling, and such events happened almost exclusively on snags. Therefore security could be an important advantage of nesting in a living tree. Microclimate inside cavities in living substrates has also been suggested to be more stable. Cavities in decayed substrates reach higher maximum temperatures and have greater daily fluctuations than those in harder wood (WIEBE 2001).

However, for PCNs, excavating in living trees is more energetically costly. Softer wood of a dead tree may allow a larger cavity for a given expenditure. Shorter excavation period means the possibility of earlier breeding and less danger of exposing the excavating adult or nest site. Thus the trade-off may be different among PCN species and study sites, depending on physical excavation ability of the species and environmental conditions. In the study area, about half of the PCN nests were found in living trees. While in the aspen stand in United States, at least $84 \%$ of the 
cavities were constructed when the tree was alive, since Sapsuckers Sphyrapicus spp. and the Hairy Woodpeckers Picoides villosus, which nested almost exclusively in living trees, were the main PCNs of the area (CROCKETT \& HADOW 1975, HART \& HART 2001).

\subsubsection{Fire}

PCNs used fire-scarred trees overproportionally. This was largely in correspondence to the tree condition, since trees were often strongly weakened or killed by fire, and consequently invaded by fungi or other decay organism, giving rise to plenty of potential nest sites. Fire may also directly induce cavities in trees (Fig. 5.7). SCNs showed even stronger overproportional use of fire-scarred trees, which accorded with the abundance of cavities. Thus SCNs were not selective to cavities according to whether or not the tree was burned. GIBBONS et al. (2002), however, reported that cavity trees with fire scars were occupied by vertebrates more often in Australia.
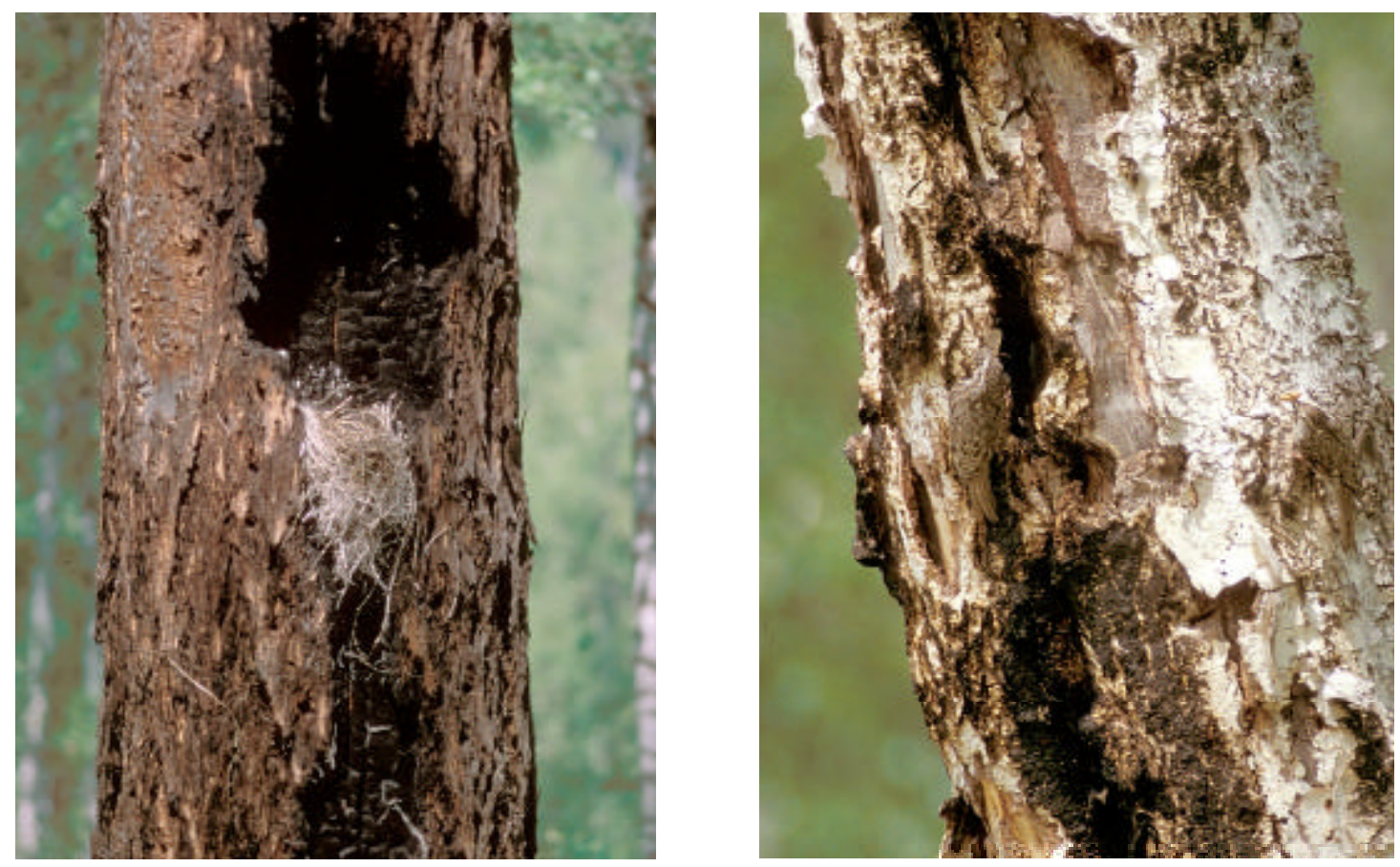

Fig. 5.7 A nest of $T$. ruficollis (left) and a nest of $C$. familiaris (right) located in special types of cavities induced by fire. 


\subsubsection{Fungi}

PCNs strongly preferred trees with fungi conks. This was in correspondence to that more excavated cavities were found in conk-bearing trees (Section 4.3.5). The presence of fungi conks not only indicates a tree in decay, but may also be a visual clue of a suitable nest tree for PCNs (KILHAM 1971, CROCKETT \& HADOw 1975). The preference for conk-bearing trees of many PCN species has been reported (KILHAM 1971, ERSKINE \& MCLAREN 1972, CROCKETT \& HADOW 1975, WinTERNITZ \& CAHN 1983, HART \& HART 2001, WIESNER 2001; see Section 5.2.5 for more detailed discussion). SCNs also used trees with fungi conks overproportionally, to the same extent of cavity occurrence in such trees. Thus SCNs showed no real preference for conk-bearing trees, but simply utilise the trees according to cavity availability.

\subsubsection{Cavity type}

In the study area, branch hole was the most important cavity type, which supported $71 \%$ of SCN nests and was utilised overproportionally. Woodpecker hole was utilised in proportion to its availability, accounting for about $18 \%$ of SCN nests. Other birdinduced hole was used underproportionally, which may be partly related to the fact that such cavities occurred mostly in snags.

As woodpecker hole was not preferred and support less than one fifth of the SCNs, the generally accepted doctrine of woodpeckers as keystone species (ANGELSTAM 1990) was not supported by this study (more detailed discussion in Section 5.7.2). Instead, branch hole is a more important resource for SCNs in West Khentey. This utilisation proportion of cavity types is similar to that found in natural forests in Sweden: $65 \%$ and $22 \%$ of SCN nests in branch holes and woodpecker holes, respectively (CARLSON et al. 1998). Therefore this might to certain extent represent the general pattern in boreal Eurasia, at least in deciduous dominated forests. 


\subsection{Nest Site selection of Individual Species}

\subsubsection{Nest site selection of PCN species}

Aspen, poplar and birch were important nest tree species for the three PCN species studied. The relative preference for Populus species over birch was D. major, D. minor and P. montanus in descending order. Populus spp. are susceptible to heartrot, which provides a soft substrate for excavation, while retains a firm sapwood shell, that gives stability for the cavity, and are thus well documented for their importance for woodpeckers (CONNER et al. 1976, WESOLOWSKI \& TOMIALOJC 1986, STENBERG 1996, HART \& HART 2001). However, the nests of $P$. montanus were rarely found in aspen. This might be partly due to the difference in their territory size and the patchy distribution of aspen in the study area. D. major and D. minor usually utilised any suitable aspen in their birch-dominated territory, while the small territory of $P$. montanus would limit its acquisition to this scarce resource. The firm sapwood of Populus might also cause higher burden to the smaller D. minor and P. montanus. The high preference for Populus of D. major could also be related to its larger body size. Populus have much larger mean diameter than birch in the study area (Table 5.2), which could support the spacious nest cavity of D. major.

All three PCN species studied preferred large trees, and the association to large trees formed again the descending order of D. major, D. minor and P. montanus. Large trees have higher structural stability, and it is possible to nest higher in larger trees. However, suitable large trees might be rare. D. major utilised largest trees and never nested in trees of DBH less than $25 \mathrm{~cm}$, reflecting its needs of building more spacious cavities because of its larger body size. P. montanus used smaller trees than other two species, which might be due to the scarcity of suitable large trees in its small territory.

The same constraints were also reflected in the nest substrate diameter, thus $D$. major excavated in the thickest substrate and $P$. montanus utilised the thinnest. By nesting in thinner part of trees, nests could be placed higher, but there might be a disadvantage of reduced thermal isolation due to thinner walls. Building in thinner substrate may also reduce the effort of excavating through thick bark and cambium. The nests of $P$. montanus were placed in thinner substrates when the nest cavity was 
excavated by itself, and in thicker parts when it utilised branch holes. This was partly due to that such cavities usually occurred in older, and thus thicker, part of trees.

Living trees were used underproportionally by all PCNs. D. major preferred fresh dead trees overproportional to their availability, which offered a compromise between structural stability and the burden of excavation (STENBERG 1996). As less strong excavators, $D$. minor and $P$. montanus highly preferred broken snags. The condition of nest substrate also revealed the difference of excavating ability. About $40 \%$ of $D$. major excavated in living part of trees, with the cost of heavier excavation burden and the benefit of lower predation rate and stable microclimate. D. minor excavated only in dead substrates. P. montanus, when behaving as an excavator, also used dead substrates exclusively.

The nest cavities of these three PCN species showed no difference in their height above ground. And their nests were in general higher than that of SCNs, which is usually explained as an adaptation against nest predation. Nest predation rate was found to decrease with cavity height (NILSSON 1984b, LI \& MARTIN 1991). Higher nests are less likely to be found by predators from ground, and have an increased energy cost for predators to reach them. Higher nests also raise the ability of parents to detect and deter potential predators (MARTIN \& LI 1992). But predation might not be the only explanation. Excavating low in a tall snag would largely reduce the structural stability of the tree and lead to a high risk of tree break at the cavity location. The downward decay due to fungi invasion from the broken top may also make excavating close to broken top energetically profitable (JACKSON \& JACKSON 2004).

PCNs usually build their cavity opening as small as possible, just fitting to their own body size. This could decrease the detection and access by predators as well as minimise the energy cost of excavation. The opening shape was close to round, which is the most efficient shape. The cavity opening dimensions of D. major and $D$. minor had very small intraspecific variances. P. montanus, as a less skilful excavator, had less standardised cavity openings, which were usually not perfectly round and had less smooth edge. 
In the present study, $16 \%$ of $P$. montanus didn't excavate nest cavities by themselves. This option eliminated the burden of excavation and provided the advantages of nesting in living substrates and earlier fledging. However, it might encounter the competition with SCNs, and these usually lower holes could increase the predation risk.

In summary, these three PCN species had some adaptations in common, i.e. cavities high in the tree with opening shape close to round and minimised opening dimension. While they also showed different adaptations in nest tree and nest substrate selection, which were shaped by their different excavation ability, body size and territory size.

\subsubsection{Nest site selection of SCN species}

\section{$\underline{\text { S. europaea }}$}

In the study area, S. europaea showed highest preference for woodpecker holes compared to other SCN species, and utilised this resource overproportionally (Fig. 5.8). More than $80 \%$ of $S$. europaea nests were established in woodpecker holes. In Bialowieza National Park, Poland, S. europaea also showed relative preference for woodpecker holes, but the reported using rate was much lower than in this study, $32.8 \%$ in ash-alder stands and $41.4 \%$ in oak-hornbeam stands (WESOLOWSKI 1989). This might be partially caused by the competition from the S. vulgaris. S. vulgaris was the main second user of woodpecker holes in Bialowieza, placing $56 \%$ of its nests in woodpecker holes. And the density of S. vulgaris was higher in ash-alder stands than in oak-hornbeam stands (WESOLOWSKI et al. 2002).

Since S. europaea highly preferred middle-sized woodpecker holes, which in the study area were mainly excavated by $D$. major, the nest site of $S$. europaea consequently resembled that of D. major. S. europaea used cavities in aspen overproportionally. This largely reflected the cavity availability of aspen-preferring D. major, instead of direct selection on tree species of S. europaea. It also used fresh dead trees overproportionally, placed its nest higher than all other SCNs, and bred in cavities with round opening shape with little variance in opening dimension, which were all characteristic for D. major. The only difference between $S$. europaea and $D$. major nest sites was that on average $S$. europaea nested in higher cavities than $D$. 
major did. This was probably because that S. europaea selected higher ones from available old $D$. major holes, with the advantage of reduced predation of higher nests. In Europe, S. europaea was often reported as one of the SCNs which had highest nest sites (VAN BALEN et al. 1982, NILSSON 1984b, WESOLOWSKI 1989).
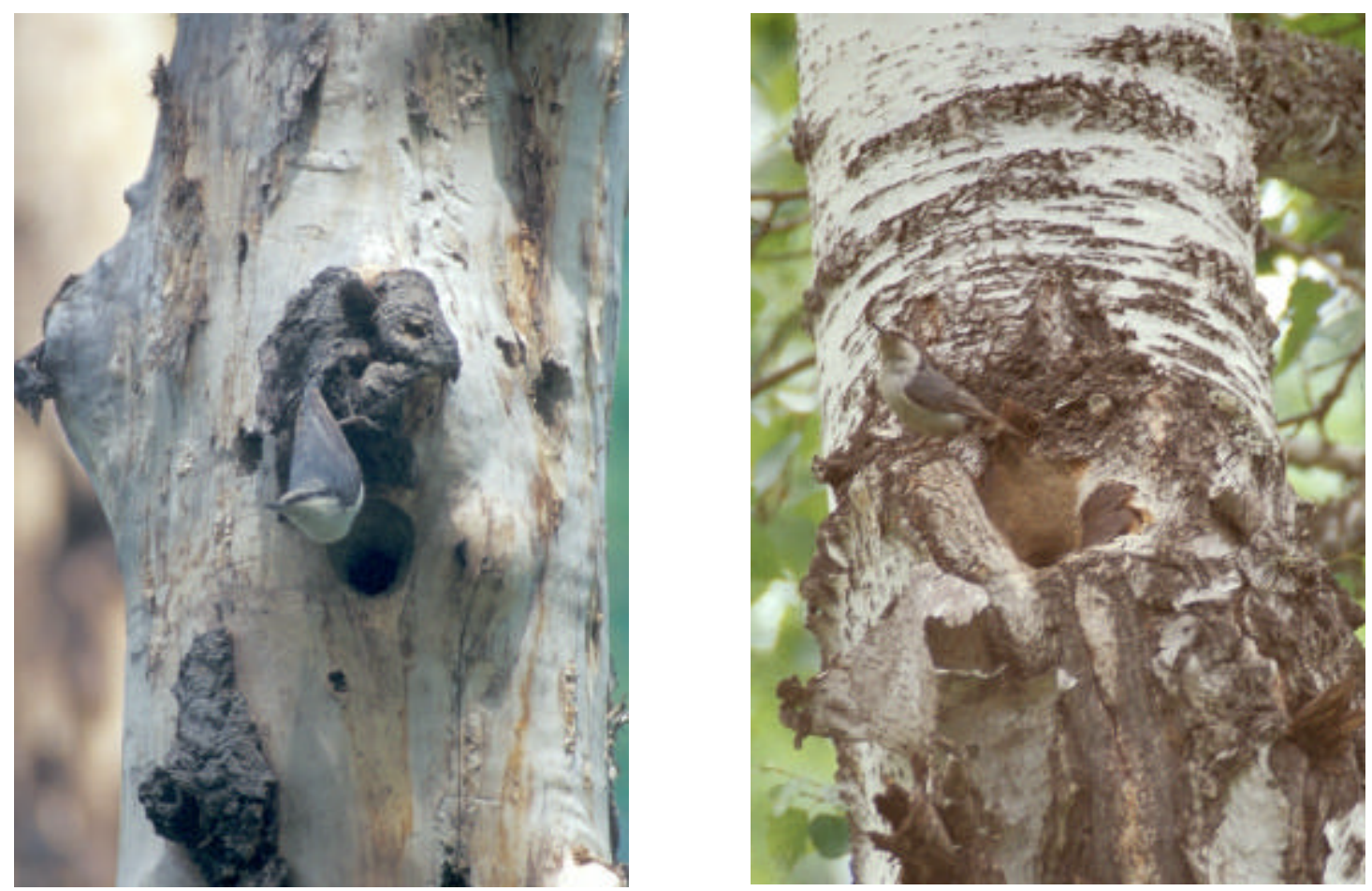

Fig. 5.8 Nests of S. europaea in a woodpecker hole (left) and in a branch hole (right).

\section{$\underline{\text { F. albicilla }}$}

Similar to S. europaea, F. albicilla also nested mainly in excavated cavities. Of the two types of excavated cavities, $F$. albicilla used woodpecker holes and other birdinduced holes according to their abundance. But the abundance of the latter was about twice as many, thus most of $F$. albicilla nests were placed in other bird-induced holes, which were mainly excavated by $P$. montanus in the study area. As a consequence, the tree use and nest cavity characters of $F$. albicilla largely resembled those of $P$. montanus. Thus among the six SCN species studied, F. albicilla used the smallest trees, nested in cavities higher than all others except S. europaea, and its nest 
cavities located mostly in dead substrate and had mainly round openings. On average, $F$. albicilla bred in higher cavities than $P$. montanus did, indicating that $F$. albicilla selected higher cavities from the available ones, possibly an adaptation against predation (NILSSON 1984b). The mean nest tree diameter of $F$. albicilla was larger than that of $P$. montanus, which was mainly because of some $F$. albicilla utilising woodpecker holes or branch holes.

Till few years ago, F. albicilla was considered as a subspecies of Red-breasted Flycatcher $F$. parva, with $F$. p. parva in west Palaearctic and $F$. p. albicilla in east Palaearctic. They were then separated into two species based on that the latter has different winter quarters (India instead of Africa), much lighter weight, almost unspotted white eggs, distinctly different song, and a more complete pre-breeding moult leading to the appearance of the orange patch in males at their first spring, and the patch never reaching the breast (BOURSKI, pers. com.).

These two closely related species also use completely different nest sites. In consistence with the present study, the studies in Central-Siberian Biosphere Reserve documented $F$. albicilla as an excavated cavity user. RoGACHEVA et al. (1991) reported that 9 out of $11 F$. albicilla nests were arranged in $P$. montanus holes, and the others were in holes of D. major or D. minor. Recent $15-20$ observations by the authors were basically in agreement, with some few nests found in branch holes (BOURSKI, pers. com.). In contrast, F. parva used mainly chimneys and half cavities, with relatively low nest height above ground (MIERA 1978, GLUTZ VON BLOTZHEIM \& BAUER 1993, Mitrus \& Socko 2004). Only 9 out of 49 nests near St. Petersburg were reported in "partially destroyed" woodpecker and $P$. montanus holes (MAlCheVsKi \& PUKINSKI 1983).

What might be the selection force leading to such distinct nest site use of these two closely related species? The availability of excavated cavities may play an important role. P. montanus is numerous in Siberia, and almost no other species competes with F. albicilla to be a secondary user (BOURSKI, pers. com.). However, though $P$. montanus is less numerous in Europe, its distribution covers almost all the breeding range of $F$. parva, and the density is still in general higher than the latter. Several European SCN species have been observed using $P$. montanus cavities, but mostly as accidental cases (GLUTZ VON BLOTZHEIM \& BAUER 1993). Thus it is not yet clear if 
the availabilities of $P$. montanus cavities for $F$. albicilla and for $F$. parva differ to a great extent.

\section{$\underline{\text { P. ater and P. major }}$}

Opposite to above two species, $P$. ater and $P$. major behaved as branch hole specialists (Fig. 5.9). They were not selective with respect to tree species or tree diameter, as they frequently use deciduous trees and large trees, following the higher availability of holes in such trees. However, they showed high preference for cavities in living trees and in living substrates. Tit species breeding almost exclusively in living trees was also reported in Europe (WESOLOWSKI 1989, 1996, GÜNTHER \& HeLlmanN 1995). As described above (Section 5.4.3), the structural stability of living trees is higher, and cavities in living substrates had less predation risk and more favourable microclimate. Another factor could be that many cavities in dead substrates might have been too heavily decomposed and become unsuitable. Thus cavities with suitable inner conditions in dead trees should have been overestimated.

As branch hole specialists, the nest cavity characters of $P$. ater and $P$. major followed the appearance of such cavities. Such cavities usually occurred lower in thicker parts

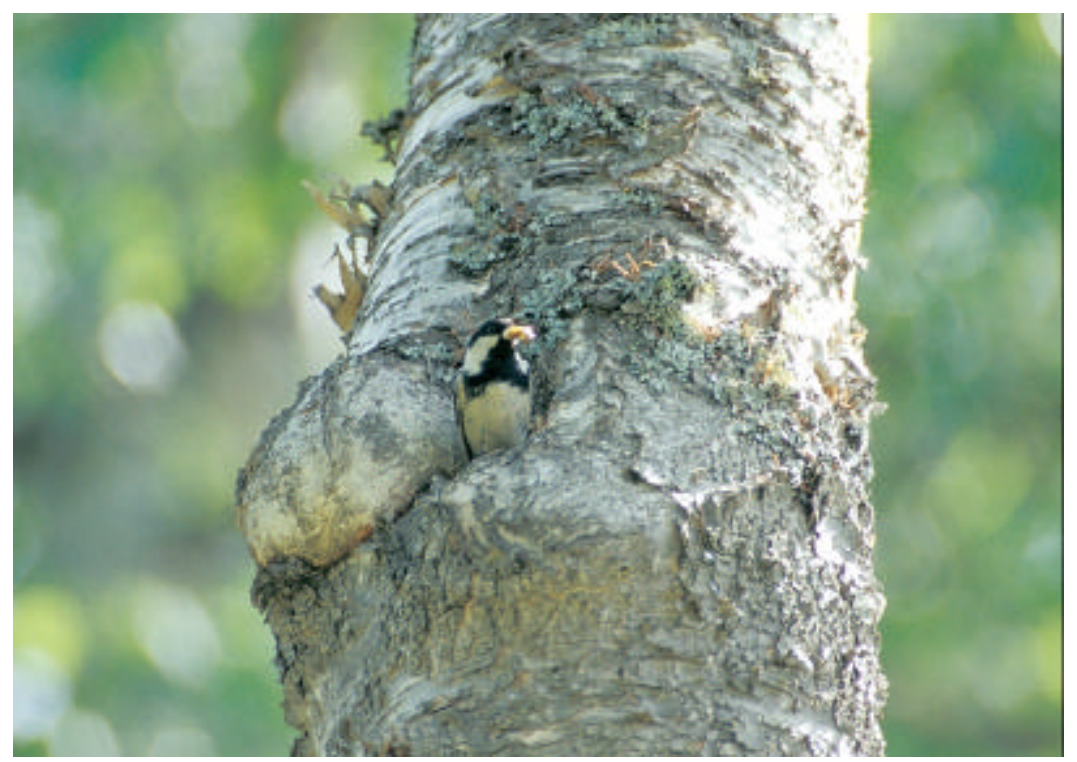

Fig. 5.9 P. ater prefers nesting in branch holes in living trees. 
of trees, which had undergone a longer time enough for cavities to develop. Such cavities also mostly had slit-like opening shape, due to the nature of branch fall and wood texture, as well as the mechanism of frost crack. Such nest site characters of non-excavating tit species were frequently documented in Europe (VAN BALEN et al. 1982, WeSOlOWSKI 1989, 1996, SANDSTRÖM 1992). In the study of the Marsh Tit Parus palustris in Poland, such patterns of nest-site use were suggested as antipredator adaptations (WESOLOWSKI 2002).

\section{C. familiaris}

Distinct from all others, $C$. familiaris specialised on slit-like cavities, and most of its tree use could be explained by the availability of such cavities. It preferred larch in comparison with other CNB species, and used cavities in larch overproportionally. This mainly reflected the fact that long crevices mostly occurred behind the thick bark of larch. It nested in larger trees than other SCNs except S. europaea, since bark crevices occurred mainly in old trees, and old larch trees could develop very large diameters. When slits were formed in smaller trees, as encountered in this study due to fire fissure and shear force when snags broke, it utilised small trees as well. It accepted a very wide range of cavity opening length, while the cavity opening width was generally very small.

\section{$\underline{\text { P. auroreus }}$}

P. auroreus behaved as a generalist in many aspects. It utilised tree species, tree DBH and tree condition according to cavity availability, indicating that it was not selective to these tree attributes. It was the only SCN species having no specific preference for certain cavity type, even one nest was found in a ground hole at the river bank. P. auroreus also used cavities of most variable opening dimensions and opening shape. The Common Redstart Phoenicurus phoenicurus in Europe appeared less selective in nest sites as well (VAN BALEN et al. 1982, GLUTZ VON BLOTZHEIM \& BAUER 1993). Using diverse nest sites could be more likely to develop in such later breeding migrants.

In summary, though overlap existed, the preferences were still distinct between most of these SCN species. As demonstrated by the discriminant function analysis, nest cavity type was the most important variable for distinguishing species. The inner 
dimensions of cavities, which was suggested to be an important factor of cavity occupancy and often differs among species (van Balen et al. 1982, Johnsson et al. 1993, Carlson et al. 1998), were not measured in this study. Different types of natural cavities could reflect differences in inner dimensions to certain extent. Except $P$. auroreus, all SCNs had specific preference for a certain cavity type, and their nest tree use and nest site characters reflected mainly the occurrence of such cavities. This emphasised that the attributes of natural cavities are usually diverse and correlated, very different from nest boxes, which tend to be uniform.

\subsubsection{Niche overlap and role of competition}

Among the three PCN species, D. major had larger niche breadth, in terms of its ability of excavating in diverse tree species and substrate of different condition. However, it was confined to using substrates above certain diameter and thus needed larger trees. The two smaller PCNs, D. minor and P. montanus, were not likely to suffer from competition with D. major, since their preferred nest sites were distinct. As dead wood specialists, the nest sites of $D$. minor and $P$. montanus were similar to some extent. However, on average $P$. montanus used smaller trees and excavated in thinner substrate. It also appeared to associate with more heavily decayed wood than D. minor. Thus competition for nest sites between these two species was not observed in the study period. Snag availability was not likely to be a limiting factor for these two species. In the young birch-larch forest, where birch snags were abundant, the density of both species was not higher than that in the mature birchlarch forest and the riparian forest. Territoriality, predation or food supply were possible factors limiting their populations.

Among SCNs, C. familiaris bred earliest, and it utilised unique niche, thus it was basically free from inter-specific nest site competition. S. europaea, also as an early breeder, encountered little nest site competition from other species as well. Its nestsite, mostly in living or freshly dead large trees, placed high up with the cavity opening minimised by itself, seemed an optimum in terms of both reduced predation and favourable microclimate. From preliminary observations, S. europaea appeared to have higher breeding success than P. montanus, F. albicilla and P. auroreus. 
The specialisation on branch holes of $P$. ater and $P$. major did not appear to be forced by the competition of S. europaea. There were always some usable woodpecker holes left for the later-coming $P$. auroreus and $F$. albicilla. Moreover, in fact, without the ability of minimising cavity opening, middle-sized woodpecker holes were not likely to be a good breeding place. In Bialowieza, some P. palustris bred in woodpecker holes, and such nests were depredated more often than the nests in branch holes (WESOLOWSKI 2002). It is interesting that both $P$. ater and $P$. major were never found using the old nests of $P$. montanus, which were a plentiful resource and located high with small opening. P. ater and P. major had to make the choice of nesting low but in living or at least more intact substrates, or nesting high in decayed wood. And they gave the priority to the former. PERRINS (1979) explained low nesting height of $P$. major by preferred foraging sites in the breeding season. However, this didn't fit to $P$. ater, which usually foraged high in thin twigs (GLUTZ VON BLOTZHEIM \& BAUER 1993).

Competition was most likely to occur between theses two species. Though on average $P$. ater used cavities of smaller opening than that of $P$. major, certain overlap existed. Competition for nest sites between them were observed a few times during the study. The dominant competitor, $P$. major, had relatively low density in most of the study area. In fragmented West European stands where nest boxes were supplemented, its density frequently reached 35 pairs/10 ha (DHONDT \& SCHILLEMANS 1983, VAN BALEN 1984, WESOLOWSKI et al. 1987). While in the birchlarch forests of the study area, its density was lower than 2 pairs/10 ha. In Bialowieza, a similar low density of $2-3.5$ pairs/10 ha was also reported (TOMIALOJC et al. 1984, WESOLOWSKI et al. 1987). The low density of this dominant competitor should not be due to cavity availability, since many usable nest sites were left for $P$. ater. And for $P$. ater, the constraint on nest site acquisition was more likely due to intraspecific territoriality rather than interspecific competition.

F. albicilla, facing the same choice of nesting in branch holes or excavated holes, gave the priority to the latter. It was possible that, for this latest-breeding migrant, most of the favourable branch holes were already occupied by P. ater and P. major. However, this pattern might be more likely to reflect the different trade-offs of different species. As a canopy fly-catcher, nesting high would be advantageous for 
reduced exposure of adult birds and nest sites to predators. Since branch holes were rare in higher parts of trees, $F$. albicilla used more woodpecker holes and $P$. montanus holes. Despite the distinct nest site use of $F$. parva in Europe, other two European Ficedula species, $F$. albicollis and $F$. hypoleuca, also often nest high above ground when they use natural cavities (SACHSLEHNER 1995, CZESZCZEWIK \& WALANKIEWICZ 2003; but NILSSON 1984b). In Bialowieza, where cavities were abundant, $F$. hypoleuca still nested higher than Parus species (CZESZCZEWIK \& WALANKIEWICZ 2003).

$P$. auroreus, being a nest site generalist, had certain extent of overlap with most of other SCN species, as indicated by the confounding results of discriminant function analysis. The nest-site selection of this species was most likely to be shaped by interspecific competition, as it often utilised cavities with unnecessarily large openings. Nevertheless, its density might not be limited by the availability of cavities, since many cavities occupied by the later-coming $F$. albicilla could be usable for $P$. auroreus as well. Its density was low in most of the study area, mainly due to its association with open area and shrubs. Experimental manipulation would be necessary to investigate whether its nest site use was shaped by ongoing competition, or being less selective in nest site had become an adaptation of this migrant.

In general, the role of interspecific competition in shaping nest-site selection and limiting population density appeared much less important than that reported in other studies. Many of such results could arise from impoverished nest site availability in managed forests (Brawn \& Balda 1988). Moreover, most of the superior competitors in other studies were edge species or introduced species, with the association of human activities. In the Netherlands, competition of $S$. vulgaris shaped nest-site use and population size of $P$. major (VAN BALEN et al. 1982). In Sweden, the dominance of Jackdaws Corvus monedula forced other users of D. martius holes to use shallower and lower cavities, and made Stock Doves Columba oenas used cavities deeper in forest (JOHNSSON et al. 1993). In United States, the nest niche of introduced $S$. vulgaris and House Sparrow Passer domesticus overlapped with Bluebirds Sialia spp., and caused great decline of Salia populations (ERSKINE \& MCLAREN 1976, Pogue \& SCHNELl 1994, SEDGWICK 1997). The competition with S. vulgaris also limited Tree Swallows Tachycineta bicolour to smaller cavities and nest sites farther 
from woodland edges (PETERSON \& GAUTHIER 1985, RENDELl \& ROBERTSON 1989, DoBKIN et al. 1995). The aggressiveness of $S$. vulgaris could exert selection on other CNBs to shift their nesting phenology and behaviour (KoENIG 2003). In Bialowieza, WESOLOWSKI (1989) also suggested that interspecific competition, though playing some role in cavity selection (sequential use of the same cavity, interspecific fight), could be less important than in managed forest.

\subsection{Sequential Cavity Use}

Cavity reuse was often studied by observing the sequential use of the cavities of specific woodpecker species (e.g. KÜHLKE 1985, JOHNSSON et al. 1993, BONAR 2000, MEYER \& MEYER 2001, WIESNER 2001, KOTAKA \& MATSUOKA 2002), while only very few have considered the reuse pattern of the whole CNB community. The overall reuse rate in the present study was $37 \%$, very similar to the few available documented values: 36\% in pine-Douglas fir forest (SAAB et al. 2004), 37\% in boreal pine-Douglas fir forest (AITKEN et al. 2002), and 38\% - 56\% in cottonwood bottomland (SEDGWICK 1997). The comparison was influenced slightly by whether the authors included unusable cavities in the analysis, but the proportion of unusable cavities was usually less than 5\%. The reuse rates reported by all studies should be considered as the minimum of the reality, since the use by nocturnal species were generally underestimated, and the nesting attempts failed at an early stage could be difficult to detect.

\subsubsection{Reuse at guild level}

The rate of reuse old nest cavities presumably depends on costs and benefits of using old cavities and on availability of suitable excavating substrates or cavities (SEDGWICK 1997, AITKEN et al. 2002). Cavities not occupied in the previous year may have fewer parasites or debris (SHORT 1979, RENDELL\& VERBEEK 1996). These cavities may also be less susceptible to predation, since some predators may learn the location of old nest sites and revisit them (SONERUD 1985, NILSSON et al. 1991). Therefore, it might be advantageous to use cavities not occupied in the previous year. However, most previously unoccupied cavities may indicate a lower quality of inner 
dimension or surroundings, and competition for the few qualified and previously unoccupied ones may be strong. For PCNs, reusing old cavities has further benefit in saving considerable time and energy for excavation that could be allocated to reproduction. However, cavity excavation is suggested to be an integral component of courtship, functioning in pair bond formation and maintenance (LAWRENCE 1967), thus many PCNs excavate one or even more new cavities each year. The reuse of WPCNs may be shaped by both the availability of suitable excavating substrate and the competition with SCNs.

Since the costs and benefits of reuse differ among guilds, the reuse pattern of each guilds may be different. The reuse rate of each guild, however, appeared discordant among studies (Table 5.3). In West Khentey, cavities previously used by SCNs had the highest reuse rate, previous WPCN cavities were seldom reused, and previous PCN cavities were reused to an intermediate extent. This pattern was most similar to another boreal study site (AITKEN et al. 2002). But in other two study sites, on the contrary, previous WPCN cavities had highest reuse rate (SEDGWICK 1997, SAAB et al. 2004).

Table 5.3 Guild level cavity reuse pattern in the literature.

\begin{tabular}{|c|c|c|c|c|}
\hline \multirow{2}{*}{ Location } & \multirow{2}{*}{$\begin{array}{l}\text { Original } \\
\text { occupant }\end{array}$} & \multicolumn{3}{|c|}{ Cavity reuse (\%) } \\
\hline & & by different species & by same species & not reused \\
\hline \multirow{3}{*}{$\begin{array}{l}\text { West Khentey, } \\
\text { Mongolia } \\
\text { (this study) }\end{array}$} & $\mathrm{PCN}$ & 19 & 13 & 69 \\
\hline & WPCN & 16 & 0 & 84 \\
\hline & SCN & 1 & 45 & 54 \\
\hline \multirow{3}{*}{$\begin{array}{l}\text { Colorado, USA } \\
\text { (SEDGWICK 1997) }^{1}\end{array}$} & PCN & 33 & 23 & 44 \\
\hline & WPCN & 58 & 8 & 34 \\
\hline & SCN & 18 & 35 & 47 \\
\hline \multirow{3}{*}{$\begin{array}{l}\text { British Columbia, } \\
\text { Canada } \\
\text { (AITKEN et al. 2002) }\end{array}$} & $\mathrm{PCN}$ & 21 & 7 & 72 \\
\hline & WPCN & 6 & 11 & 83 \\
\hline & SCN & 18 & 30 & 53 \\
\hline \multirow{3}{*}{$\begin{array}{l}\text { Idaho, USA } \\
\text { (SAAB et al. 2004) }^{2}\end{array}$} & PCN & 22 & 2 & 76 \\
\hline & WPCN & 9 & 47 & 45 \\
\hline & SCN & 16 & 22 & 62 \\
\hline
\end{tabular}

${ }^{1}$ Only the reuse of 1985 cavities in 1986 was presented, since the data of between year reuse of 1986 and 1987 were not presented (Table 1 in SEDGWICK 1997). Black-capped Chickadee Poecile atricapillus was grouped as WPCN according to AITKEN et al. 2002.

${ }^{2}$ Two mammal species were included in SCNs. 
The reuse pattern also differed among studies, again with most disagreement in WPCNs. AITKEN et al. (2002) suggested that, WPCN cavities were generally more shallow and with entrances too small for some SCNs, thus they were not favoured by SCNs. WPCNs might be less able to compete with the larger SCNs, thus they reuse their own cavities. Therefore the reuse of WPCN cavities should be low and mainly by the same species. However, this could not be generalised to different sites. In West Khentey, reuse of WPCN cavities was low, but all were used by SCNs. This might be owing to enough suitable snags for excavation, thus almost all WPCNs constructed new cavities. And the smaller cavities of WPCNs were still usable by small SCN species. In the study of SEDGWICK (1997), reuse rate of WPCN cavities was high, and they were mostly reused by SCNs. This was resulted from that the smallest SCN species House Wren Troglodytes aeddon frequently used the smaller cavities of the only WPCN Black-capped Chickadee Poecile atricapillus. The competition for cavities was considered strong in that study site (SEDGWICK \& KNOPF 1992), and strong competition often leads to small species using smaller cavities to reduce the chance of eviction by a larger competitor (PETERSON \& GAUTHIER 1985, RENDELL \& ROBERTSON 1989). In the study of SAAB et al. (2004), WPCN cavities had high reuse rate, and were mostly reused by the same species. This was the consequence of that the WPCN Lewis's Woodpecker Melanerpes lewis frequently occupied a nest cavity over several years. The authors explained this with its very poor excavator morphology.

It was corresponding among the four studies, that the reuse of previous PCN cavities were mainly by other species, while the reuse of previous SCN cavities were mainly by the same species (Table 5.3). In Europe, WESOLOWSKI (1989) reported that woodpeckers hardly ever reused their own cavities, while SCNs often bred in cavities previously utilised by their own species. VAN BALEN et al. (1982) observed that woodpecker holes were always used by another species in the year after excavation, which indicated the high cavity demand in this Dutch study site with highest cavity occupancy ever documented (see Section 5.3.4). The constancy of the ten SCN species there averaged 64\%, also higher than reported in other studies (Table 5.3).

The reuse of SCN cavities by different species may indicate the extent of nest niche overlap. Then the very low interspecific cavity reuse of SCNs in West Khentey 
compared to other studies might imply more distinct niche partition and less competition among SCN species. The reuse of PCN or WPCN cavities by different species shows the excavator-secondary user relationships, while under some circumstances it may imply competition as well. The most often documented case was that, in North America, the aggressive invader S. vulgaris overtook the nest cavities of woodpeckers and forced the latter to excavate new ones or reuse the older ones (TroetsChLER 1976, INGOLD 1989, 1996). The snatch of PCN or WPCN nest cavities by SCN species has not been observed in West Khentey.

\subsubsection{Reuse at species level}

Capability of excavation, ability for nest site competition or quality and abundance of preferred cavity type also differ among species, thus the tendency for reuse of each species may differ as well. In the present study, the interpretation of reuse at species level was largely limited by the sample size of each species. Among PCNs, D. major appeared to reuse its nest cavities more often. Excavator species vary in their propensity to excavate. The ultimate factor is often supposed to be their difference in morphology. Species with weak skull and bill morphology are considered to have higher propensity to use existing cavities. They depend on particular soft substrate for excavation. If soft wood is not available, then existing cavities are used (MARTIN \& Li 1992, MARTIN 1993, SAAB et al. 2004). This was not supported by the present study. D. leucotos and D. minor, which had weak excavation morphology (MEYER et al. 1993) and depended highly on soft substrate, did not use existing cavities. This could be explained by the abundance of snags in the study area and the limited number of observations, therefore reuse was not observed. However, throughout the literature, these species rarely use existing cavities (WESOLOWSKI \& TOMIALOJC 1986, AUlÉN 1988, GLUTZ VON BLOTZHEIM \& BAUER 1993, WinKLER et al. 1995). When soft substrate is not available, they decline in numbers or disappear from the habitat, instead of using existing cavities (AULÉN 1988, BLUME 1990, PECHACEK 1995, Mikusinski \& ANGelstam 1997, CARLson 2000).

The proximate causes to the extent of reuse may include habitat factors and inter- and intraspecific interactions. AITKEN et al. (2002) found that, among PCNs, the reuse by the same species was highest for the most abundant woodpecker species Northern Flicker Colaptes auratus. And the authors pointed out that intraspecific competition 
and availability of suitable excavating substrates might be part of the explanations. For D. major, VAN BALEN et al. (1982) found no use of existing cavities in the four observations. WESOLOWSKI \& TOMIALOJC (1986) documented 3.8\% of its breeding attempts in existing cavities. In Japan, KoTAKA \& MATSUOKA (2002) reported no reuse of $D$. major cavity by itself in urban area $(n=24)$, and a $20 \%$ reuse rate in suburban area $(\mathrm{n}=12)$. In Germany, $14-70 \%$ of $D$. major were found to nest in old cavities instead of building new ones (BLUME 1977, WiTT 2004). Due to the limited sample size in the present and other studies, as well as very few information about habitat and local CNB community in the literature, it was difficult to generalise the factors influencing the rate D. major using old cavities.

The cavities of $D$. major were often occupied by $S$. europaea, in consistence with other studies (WESOLOWSKI 1989, GÜNTHER \& HELLMANN 1997, KOTAKA \& MATSUOKA 2002). In Europe, S. vulgaris appeared to have the priority to D. major cavities over $S$. europaea. In areas where the competition of $S$. vulgaris was strong, $S$. vulgaris usually accessed the cavities in the following year of $D$. major nesting, and $S$. europaea used the cavities after the occupation of $S$. vulgaris (VAN BALEN et al. 1982).

P. montanus never reused its own old cavities, and its cavities were sometimes reused by $F$. albicilla. The reuse rate of $P$. montanus cavities was lower than that of $D$. major cavities. This might be partially explained by the smaller opening size and inner dimension of $P$. montanus cavities, limiting the species able to use them. Most of these cavities were located in heavily decayed substrates, thus might deteriorate rapidly and became unsuitable for breeding in the following year.

Among SCNs, despite of those with too few data, the cavities of S. europaea and $P$. ater were reused by the same species most frequently, while cavities previously occupied by $F$. albicilla were never reused. This might be partly explained by the quality and the abundance of their preferred nest sites. S. europaea nested high and seldom in snags, $P$. ater nested in living trees and mostly in sound substrates, both might be advantageous in having less predation rate, higher structural stability and steadier microclimate. Therefore the high reuse rate might be related to the high cavity quality, as nest site fidelity developed after successful breeding attempts have been reported for several CNB species and other birds (KORPIMAKI 1993, HAAS 
1998). Beside quality, these cavities in sound wood also had longer usability over years.

In contrary, F. albicilla nests were located mainly in decayed substrates, which could result in lower breeding success and reduce the propensity to reuse. Such cavities might also undergo too rapid decay, the quality decreasing with time, and soon become unsuitable. While in the same time P. montanus, which was at least twice as abundant as $F$. albicilla in the study area, supplied newer cavities each year. $F$. albicilla pairs usually visited several cavities before choosing one for breeding, and the abundant newer cavities were more likely to be used. The study with nest boxes also suggested that nest site fidelity of Eastern Bluebird Sialia sialis depended on the quality of alternative resources (STANBACK \& ROCKWELL 2003).

Observing the pattern of sequential cavity use is also another way to study the interspecific similarity of preference for certain cavities (VAN BALEN et al. 1982). Sequential use of cavities between different species may indicate niche overlap and the potential for competition. In the study area, no interspecific reuse between SCNs was observed in the study period, even between $P$. ater and $P$. major, which had very similar nest sites (Section 5.5). This might be owing to the very low density of $P$. major in most of the study area. Or there might be some nest site variables not measured in the present study, e.g. cavity inner dimension, which distinguished the nest sites of these two species. In the 33 observations of $P$. major nest cavities by VAN BALEN et al. (1982), one was previously used by P. ater. P. major and S. europaea were found reusing previous cavities of each other (WESOLOWSKI 1989), which was also not observed during the period of this study. One interesting reuse case was that a branch hole nested by S. europaea in 2002 was used by the WPCN $P$. montanus in the following year. And one P. montanus nest in 2002 was placed in a middle-sized woodpecker hole, the entrance of which showed apparent modification by $S$. europaea. In both cases, the original cavity opening sizes were too large and might not be preferred by $P$. montanus. Presumably the previous occupation and cavity opening minimisation by $S$. europaea had made these cavities profitable for $P$. montanus, and in the same time limited the usability of these cavities by larger species. 


\subsubsection{Characters of reused cavities}

In the study area, cavities in living substrates were more frequently reused than those in dead substrates, and branch holes and woodpecker holes were reused more frequently than other bird-induced holes. This to a certain extent reflected the nest site preference of S. europaea and P. ater (Section 5.5.2), which were abundant and had high propensity to reuse. In the study of the reuse of D. major holes in Germany, GÜNTHER \& HELLMANN (1997) also found cavities in living trees were more attractive to SCNs.

In Canada, AITKEN et al. (2002) found higher reuse of cavities with large opening and inner dimension. Cavities in aspen and cavities near forest edge were also reused more often. This pattern was mainly generated by the nesting preferences of dominant PCN Northern Flicker Colaptes auratus and dominant SCN S. vulgaris. Both species had comparatively larger size and strongly preferred edges. The higher reuse of cavities in aspen was mainly because aspen was an edge-associated tree species (AITKEN et al. 2002).

In the study of D. martius holes in Sweden, cavity height above ground was important to cavity reuse (JOHNSSON et al. 1993). Higher cavities were used more often, and the dominant species Jackdaw Corvus monedula used the highest ones. The high abundance of edge-associated C. monedula also resulted in higher reuse rate of cavities at forest edge.

Cavities with high reuse rate may indicate good qualities and/or more limited availability of such cavities. The "good qualities" include not only the characteristics of the cavity or cavity tree itself, but also surrounding habitat or landscape attributes such as the proximity to other resources. Thus what are the "good qualities" may differ from species to species. And the reuse pattern of the whole CNB community is further shaped by its characteristic species composition and the distribution of available cavities. Therefore, the characters of highly reused cavities showed inconsistency among studies.

Since cavities in more decayed wood had higher maximum temperatures and greater daily temperature fluctuations (WIEB 2001), nesting in sound substrate might be especially profitable in West Khentey, where temperature fluctuation was extreme, 
compared to other sites. Higher reuse of cavities in living wood might also indicate that, in this area, main predation pressure was from predators which foraged by chewing or ripping open cavities. However, it could also be possible that the higher reuse of cavities in living substrates was simply because they were physically longer usable, compared to those in dead substrates. Since cavities in living trees had higher occupancy than those in dead trees (Section 4.5.3), and branch holes had higher occupancy than other bird-induced holes (Section 4.5.6), the frequent reuse of cavities in living trees and branch holes could also be explained by that there were less free alternatives. Further detailed information about breeding success, predation rate and the quality and abundance of alternative cavities is necessary to clarify the factors shaping reuse patterns.

\subsection{Nest Web}

\subsubsection{Structure of the nest web in West Khentey}

Based on the characteristics of the resource (cavities), the nest web of the CNB community in the study area could be divided into two subwebs: the excavated cavity subweb and the non-excavated cavity subweb. The former could be further split up into three chains: the large-sized, the middle-sized and small-sized excavated cavity chains. D. martius was the centre of the large-sized excavated cavity chain. As for the tree species involved, the active $D$. martius nests were only observed in aspen and Scots pine in the study period. But unoccupied old cavities were also found in poplar and larch, indicating the tree species that might develop to diameters large enough could be used. B. clangula was the only secondary user recorded. But the observations of such cavities were few, and more cryptic users, such as Strigidae and Anatidae, might be overlooked. D. major, D. leucotos and P. canus were the excavating species in the middle-sized excavated cavity chain, and potentially $P$. tridactylus should also be included. D. major produced larger effects than the others, as it was more numerous in the study area and constructed most of this resource. Both birch and aspen were important in this chain. While aspen had an overproportional importance relative to its abundance, due to the preference of $D$. major. Six secondary users were involved in this chain. The excavators in small-sized excavated cavity chain were $D$. minor and $P$. montanus, and the latter accounted for most of the 
resource in this chain, due to its high abundance. The key tree species was birch. Three SCN species were involved in this chain.

The non-excavated cavity subweb was comprised of branch hole chain and other distinct and rare cavity types. The branch hole chain was largely based on birch, and was used by up to seven species. Other special cavity types were mostly provided by larch, and involved three SCN species.

Nest cavity characters and reuse patterns discussed in previous sections could be incorporated with the nest web. The nest sites of the members of excavated chains located higher and had round cavity openings, while the nest sites of the members of non-excavated chains located lower and had slit-like cavity openings. For the smallsized excavated cavity chain, the cavities were mostly in dead substrates, and the reuse rate was generally low. This chain also had higher turnover rate, in terms of higher cavity recruitment (higher excavator density and mostly constructing new nest cavities) and higher cavity loss (frequent nest tree/substrate fall and rapid deterioration). For the other two excavated chains and the branch hole chain, cavities were placed in sounder wood, and the reuse rate was high. The turnover rate of middle-sized excavated cavity chain should be moderate, due to moderated excavator density, frequent construction of new cavities, and a moderate rate of cavity loss. Large-sized excavated cavity chain and branch hole chain should have lowest turnover, as the result of relatively lower recruitment (low density of D. martius and slow formation of non-excavated cavities) and lower cavity loss (usually in living and large trees).

Beside West Khentey, the only nest web studied was in British Columbia, Canada (Martin \& EAdie 1999, Martin et al. 2004). Trembling aspen Populus tremuloides was the key tree species for the nest web in British Columbia, as it was the main deciduous species in the system. Another distinct difference was that, in British Columbia, only about $7.5 \%$ of the nests were located in non-excavated cavities. There was no bird species specialised on non-excavated cavities, and only one species preferred non-excavated cavities over excavated ones. Two woodpecker species, the Red-naped Sapsucker Sphyrapicus nuchalis and the Northern Flicker Colaptes auratus, created about $74 \%$ of all utilised cavities. This differed greatly from the 
significant role of non-excavated cavities in West Khentey, where $44 \%$ of all observed nests were located in non-excavated cavities.

\subsubsection{The role of woodpeckers}

Based on the simulations with nest web, the widely accepted idea that woodpeckers are keystone species for CNB communities (ANGELSTAM 1990) was not generally supported in this study. Cavities of $D$. martius might be a highly valuable resource, because large non-excavated cavities were very rare. In the boreal forest in Canada, BONAR (2000) searched the cavities with size comparable to that of the Pileated Woodpecker Dryocopus pileatus, which was similar to that of D. martius. Only less than $2 \%$ of such cavities were not excavated, while others were constructed by $D$. pileatus. This underlined the importance of large woodpecker species. In the present study, only B. clangula was observed nesting in D. martius cavities. The rare and cryptic users, such as owls and ducks, were not adequately sampled, therefore the importance of $D$. martius might be underestimated. Nevertheless, several large owl and duck species in the study area are not obligate cavity nesters (Appendix; GLUTZ VON BLOTZHEIM \& BAUER 1993). Therefore, D. martius may be crucial to $B$. clangula and the Goosander Mergus merganser, but it doesn't exhibit far-reaching influence over the structure and function of the CNB community. D. martius is often referred as a keystone species in Europe (KÜHLKE 1985, JOHNSSON 1993, ROLSTAD et al. 2000). Several large and obligate European CNB species, e.g. Jackdaw Corvus monedula, Stock Dove Columba oenas and Tawny Owl Strix aluco, were not recorded in the study area. Thus $D$. martius might play a more important role in the CNB community in Europe than in that in West Khentey.

Middle-sized woodpecker species did not play key roles in the CNB community. No SCN depended exclusively on the resource they supplied. Only S. europaea utilised it to a higher extent, and this species could well adapt to branch holes. It also breeds earlier than most of other SCNs and has the special behaviour of minimising the nest cavity opening, which reduced its suffering from the competition for branch holes with other SCNs. And the abundance of branch holes was able to accommodate such nest use shifts. The usability of $D$. minor holes was limited by its opening dimension. And its importance in the nest web was largely diluted by $P$. montanus, which supplied similar resource in larger amount. 
In Europe, several studies also considered that the importance of woodpeckers in general as keystone species in producing holes for CNBs should be re-evaluated. In Germany, it was suggested that the value of $D$. major holes might be overestimated, as they only supported a minor proportion and species diversity of SCNs (GÜNTHER \& Hellmann 1997, 2001). In Bialowieza, Poland, all SCN species except $S$. vulgaris placed the majority of their nests in branch holes, and in average only about $16 \%$ of SCN nest cavities were made by woodpeckers (WESOLOWSKI 1989). In Sweden, branch holes rather than woodpecker holes were considered as an important resource for SCNs (SANDSTRÖM 1992, CARLSON et al. 1998).

The studies in North America, instead, often indicated highly significant role of woodpeckers. In Canada, more than $90 \%$ of CNB nests were located in excavated cavities (MARTIN \& EAdIE 1999). In United States, STAUFFER \& BEST (1982) found $70-80 \%$ of SCN nests in excavated cavities. DoBKIN et al. (1995) documented that almost all cavities showed some signs of excavation or substantial modification by woodpeckers. Thus woodpeckers are more likely to act as keystone species in these systems. As studies covering the whole CNB community were few, it is not yet clear if such difference is general between the two biogeographic regions.

Some studies used the positive association between woodpecker abundance and SCN abundance to demonstrate woodpeckers as nest providers for SCNs (e.g. DOBKIN \& WILCOX 1986, MARTIN \& EADIE 1999). In the present study, such positive correlation also existed, but it probably indicated common habitat preference rather than nest site relationship. Thus woodpeckers appeared as indicators of habitat quality and SCN abundance instead of as keystone species.

\subsubsection{The role of birch}

The simulation with nest web revealed a widespread effect in the CNB community after the removal of birch. This was the consequence of both the high cavity-holding rate of birch and its high abundance in the study area. A keystone species has to act on the system with effects much larger than would be predicted from its relative abundance (KREBS 2001). In the study area, this was more likely true for birch in the spruce-fir forest. But the present data did not allow the analysis for each habitat separately. 
Though birch could not be asserted as a keystone species for the CNB community, the nest web analysis outlined the far-reaching influence when birch was replaced by conifers. And that was what has happened in large areas of boreal and hemiboreal forests (SANDSTRÖM 1992, ANGELSTAM \& MiKUSINSKI 1994, HAUSNER et al. 2003). Due to the transformation of deciduous forests into coniferous plantations, or through the suppress of fire in managed forest which inhibited the natural regeneration of secondary deciduous forest, the abundance of birch was decreasing in Scandinavia till 1980s. Afterwards it started to increase as the result of increasing demand of pulp industry. But it was usually felled at DBH about $20-25 \mathrm{~cm}$, before it could become useful to CNBs (SANDSTRÖM 1992).

Though birch is interconnected with most of the CNB species, it rarely reaches the size large enough for $D$. martius to nest, and thus can not support the large-sized excavated cavity chain. It also rarely holds suitable crevices for $C$. familiaris. Thus the admixture of large trees and thick bark conifers was important to sustain a diversified CNB community.

It was contended that there are several advantages of a nest web perspective. First, a nest web analysis reveals the kind of links that might exist among all the species in the community. It allows a broader community focus instead of the common attention which is usually paid only to single or several species in the community. Secondly, it outlines the direct and indirect interactions which are critical to predict the response of the community to perturbations or change. Thirdly, it may help to identify keystone species or keystone interactions. Finally, some existing ecological theory on food webs might be applied to predict the structure, stability and resilience of CNB communities, or, in another way round, the analysis of nest webs might be used to test the food web theory in a new and perhaps more tractable system (MARTIN \& EADIE 1999). However, it should be noticed that such simulations were simply based on one dimension, i.e. nest site, of the requirements of CNBs. The change of tree species composition would also alter the food items and abundance, as well as habitat structure. The removal of a bird species might not only influence the nest site availability of others, but also change the extent of food competition and predation pressure. Such interactions are beyond the analysis scope of nest web. 


\section{SUMMARY}

Cavity-nesting birds (CNBs) comprise a major component of many forest bird communities. For their close association with trees and cavities, they are highly sensitive to the alteration of forest structure. Therefore they are considered as indicators of several forest qualities and forest bird diversity, and many CNB species have declined due to modern forestry and anthropogenic landscape alterations.

Though CNBs have been intensively studied, most information was gathered with nest boxes and in managed forests, which might not represent the natural conditions. Forest structure and cavity availability, which are critical in investigating the nest-site selection of and competition among CNBs, were seldom sufficiently quantified. And most studies focused only on single species. Community-level approaches were few, and the interspecific relationships were largely ignored. Therefore the objectives of this study were to investigate cavity abundance in different types of natural boreal forest and the characteristics of cavity trees, to survey CNB composition and the characteristics of trees and cavities utilised by CNBs, to study the nest-site selection of individual bird species, and to investigate interspecific interactions through the pattern of sequential cavity use and the nest web analysis.

The study site was Khan Khentey Strictly Protected Area $\left(48-49^{\circ} \mathrm{N}, 107-110^{\circ} \mathrm{E}\right)$, northeast Mongolia. It is situated in the transition zone of Siberian taiga and Central Asian steppe. The environment is characterised by undulating terrains, harsh continental climates and mosaic land covers of forest and steppe. The field work was carried out in four different habitats: the mature birch-larch forest, the young birchlarch forest, the riparian mixed forest and the spruce-fir coniferous forest.

In each habitat, five 1 ha plots $(50 \mathrm{~m} \times 200 \mathrm{~m})$ were established. Two points in each plot were taken systematically for taking habitat measurements. At each point, standing stems $(=5 \mathrm{~cm}$ diameter at breast height $(\mathrm{DBH}))$ were sampled by plotless method. For each sampled tree, tree species, DBH, tree condition and if the tree carried fire scars and fungi conks were recorded. Each sampled stem was also searched for cavities. Cavities were classified into woodpecker hole, other birdinduced hole, branch hole or bark crevice. Nests of all CNB species were searched in 2002 and 2003. A nest cavity was defined when an adult bird was observed bringing 
in nesting material or food. In the quantitative plots, nest search was confirmed with territory mapping, in order to locate all the nest cavities in the plots. Nest cavities found outside the plots were also recorded. For each nest, the species, DBH, condition and the presence of fire scars and fungi conks of the nest tree were recorded, as well as nest cavity type, cavity height above ground, substrate diameter, substrate condition and cavity opening length and width.

The cavity abundance in the study area averaged 30 cavities/ha. The spruce-fir forest had lowest cavity density (18 cavities/ha), due to less branch holes in this habitat. Cavity occurrence was related to tree species, tree $\mathrm{DBH}$, tree condition and the occurrence of fire scars and fungi conks. Over $50 \%$ of the cavities were found in birch, while poplar was the most cavity-rich tree species related to its abundance. Cavity holding rate rose with ascending DBH. Cavities, especially excavated ones, occurred overproportionally in tall snags. Both the occurrence of fire scars and fungi conks showed positive association with the occurrence of cavities.

The density of CNBs in the study area averaged 2.4 nests/ha, lower in the spruce-fir forest than in other three deciduous-dominated forest. The overall cavity occupancy in the study area was approximately $5 \%$. CNB density was positively correlated with the proportion of deciduous stems and shrub coverage in the stand. Deciduous trees, larger trees, dead trees and trees with fire scars and fungi conks were preferred by primary cavity nesters (PCNs). Secondary cavity nesters (SCNs) also used such trees overproportionally, which mostly in accordance with cavity availability in these trees.

For individual species, the nest sites of $D$. minor, $P$. montanus and F. albicilla had high similarity, as they nested in excavated cavities with small and round openings located high in thin and broken snags. The nest sites of D. major and S. europaea were similar in that they both bred in cavities with round openings of diameter $4-5 \mathrm{~cm}$ located high in large and living or intact dead trees. Both $P$. ater and P. major preferred branch holes with slit-like openings, located low in living trees. P. auroreus utilised a wide range of cavities, while $C$. familiaris was distinct from others in specialising on long slits.

The observation of sequential cavity use showed that the cavities previously occupied by $D$. major and P. montanus were frequently used by $S$. europaea and $F$. parva, 
respectively, in the following year. Previous $S$. europaea and $P$. ater cavities were frequently reused by the same species. Cavities in living substrates were reused more often than those in dead ones. Nest web analysis suggested that no SCN species was completely dependent on middle- or small-sized woodpecker holes. They could switch to branch holes when woodpecker holes were lacking. The removal of birch would, however, strongly influence the structure of CNB community.

The cavity abundance in the study area was high compared to literature. The cavity holding rates were very similar to related species in Sweden, which might represent characteristic values in boreal Eurasia. The naturalness of the study area, in terms of both natural forest structure with abundant deciduous, old and decayed trees and natural process of fire dynamic and fungi decay, presumably led to the high cavity abundance. The CNB density in the study area corresponded well to the documented values, which resulted in a low cavity occupancy compared to documented values.

The nest sites of PCN species showed some attributes in common, i.e. cavities high in the tree with round opening shape and minimised opening dimension, as possible adaptations against predation and minimising excavation burdens. While they also showed differences in nest tree and nest substrate selection, shaped by their different excavation ability, body size and territory size. Most SCNs had a preferred cavity type, and their nest tree use and nest site characters reflected mainly the occurrence such cavities. The extent of interspecific competition shaping nest-site selection and limiting population density appeared less intense than that reported in other studies.

Higher reuse rate of cavities in living substrates might reflect cavity usability and quality. Such cavities had more favourable microclimates and were safer from predation. Woodpeckers in general as keystone species for CNB communities was not supported in this study. Only D. martius might have irreplaceable function in producing large cavities. Birch had fundamental importance in the study area, as the consequence of both its high cavity-holding rate and its high abundance. And the nest web analysis outlined what might happen, and has happened in large areas of boreal and hemiboreal forests, when birch forests were transformed into coniferous plantations. 


\section{ZUSAMMENFASSUNG}

Höhlenbrütende Vogelarten stellen einen bedeutenden Anteil vieler

Waldvogelgemeinschaften. Wegen ihrer engen Bindung an entsprechende Habitatstrukturen sind sie sehr empfindlich gegenüber Veränderungen der Waldstruktur. Daher werden sie als Indikatoren für Habitatqualitäten und Vogeldiversität aufgefasst und viele höhlenbrütende Vogelarten haben infolge moderner Forstwirtschaft und anthropogener Landschaftsveränderung im Bestand abgenommen.

Obwohl höhlenbrütende Vögel sehr intensiv untersucht wurden, basieren die meisten Erkenntnisse auf Untersuchungen mittels Nistkästen und in bewirtschafteten Wäldern. Die Verhältnisse unter natürlichen Bedingungen könnten sich jedoch anders darstellen.

Die Waldstruktur und Verfügbarkeit von Baumhöhlen, welche entscheidend für die Untersuchung der Brutplatzwahl und Konkurrenz unter Höhlenbrütern sind, wurden selten ausreichend quantifiziert. Und die meisten Studien betrachteten nur eine einzelne Art. Ansätze zur Untersuchung der entsprechenden Artengemeinschaften und ihrer interspezifischen Beziehungen wurden meist vernachlässigt. Daher war die Zielsetzung dieser Studie die Baumhöhlenabundanz verschiedener, borealer Naturwaldtypen und die Beschaffenheit der Baumhöhlen zu untersuchen, die Zusammensetzung der Artengemeinschaften von höhlenbrütenden Vogelarten sowie die Charakteristiken genutzter Bäume und Baumhöhlen zu erfassen und die interspezifischen Interaktionen über Muster der Folgenutzung und nest web Analyse zu bestimmen.

Das Untersuchungsgebiet war das streng geschützte Reservat Kahn Khentey im Nordosten der Mongolei (49-49 $\left.{ }^{\circ} \mathrm{N}, 107-110^{\circ} \mathrm{O}\right)$. Es liegt in der Übergangszone der Sibirischen Taiga und der zentralasiatischen Steppe. Die Landschaft ist durch hügeliges Terrain, raues, kontinentales Klima und ein Mosaik aus Wald und Steppe charakterisiert. Die Untersuchungen wurden in vier verschiedenen Habitaten durchgeführt: alter Birken-Lärchen-Wald, junger Birken-Lärchen-Wald, Aumischwald und Fichten-Tannen-Wald. 
In jedem Habitat wurden fünf ein Hektar große (50mx200m) Untersuchungsflächen eingerichtet. In zwei systematisch ausgewählten Punkten in jeder Untersuchungsfläche wurden systematisch Habitatparameter erfasst. An jedem Punkt wurden stehende Baumstämme ( $\geq 5 \mathrm{~cm}$ Brusthöhendurchmesser (BHD)) mittels Winkelzählprobe ausgewählt. Für jeden ausgewählten Stamm wurden Baumart, BHD, Vitalität und das Vorhandensein von Feuernarben, Pilzkonsolen und Baumhöhlen aufgenommen. Die Höhlen wurden klassifiziert in Spechthöhlen, durch andere Vogelarten aktiv angelegte Höhlen, Astlöcher oder Rindenspalten. Nester aller höhlenbrütenden Vogelarten wurden in 2002 und 2003 gesucht. Ein Brutnachweis wurde angenommen, wenn adulte Vögel Nestmaterial oder Futter eintrugen. In den fünf quantitativen Untersuchungsflächen wurde unterstützend eine Revierkartierung vorgenommen um eine vollständige Erfassung der Bruthöhlen zu gewährleisten. Hinsichtlich ihrer qualitativen Merkmale wurden auch wurden außerhalb der Untersuchungsflächen gelegene Bruthöhlen aufgenommen. Für jeden Baumstamm mit Bruthöhle wurden Baumart, BHD, Vitalität und das Vorhandensein von Feuerschäden und Pilzkonsolen erfasst. Ebenso wurden Höhlentyp, Höhe der Bruthöhle über dem Boden, Substratdurchmesser, Substratzustand und Höhe und Weite der Höhlenöffnung erfasst.

Die durchschnittliche Baumhöhlenabundanz belief sich auf 30 Höhlen je Hektar. Die Höhlenabundanz war im Fichten-Tannen-Wald am geringsten (18 Höhlen/ha) infolge des geringeren Vorkommens von Astlöchern in diesem Habitat. Das Vorhandensein von Baumhöhlen stand in Relation zu Baumart, BHD, Baumzustand und dem Vorhandensein von Feuernarben und Pilzkonsolen. Über 50\% der Höhlen befanden sich in Birken, während Pappel in Relation zu ihrer Abundanz die höhlenreichste Baumart darstellte. Die prozentuale Verteilung der Baumhöhlen stieg mit zunehmendem BHD. Baumhöhlen, insbesondere die aktiv angelegten, waren überproportional häufig in hohen Baumstümpfen. Das Vorhandensein von Baumhöhlen stand sowohl mit dem Vorhandensein von Feuernarben als auch dem von Pilzkonsolen in Zusammenhang.

Die Dichte höhlenbrütender Vögel betrug im Mittel 2,4 Brutpaare je ha und war geringer im Fichten-Tannen-Wald als in den anderen drei Habitaten mit höherem Laubholzanteil. Insgesamt betrug die Höhlennutzungsrate im Untersuchungsgebiet 
ungefähr 5\%. Die Dichte höhlenbrütender Vögel war positiv korreliert mit dem Anteil an Laubholzstämmen und der Deckung der Strauchschicht in dem Waldbestand. Laubholzarten, größere Bäume, tote Bäume und Bäume mit Feuernarben und Pilzkonsolen wurden von primären Höhlennutzern bevorzugt. Sekundäre Höhlennutzer nutzen solche Bäume ebenfalls überproportional, meistens in Übereinstimmung mit der Höhlenverfügbarkeit in diesen Bäumen.

In bezug auf einzelne Arten zeigte die Brutplatzwahl von D. minor, P. montanus und F. albicilla hohe Similarität. Diese Arten nisteten in aktiv angelegten Höhlen mit kleinen, runden Öffnungen, die sich hoch in dünnen und gebrochenen Baumstümpfen befanden. Die Nistplätze von D. major und S. europaea waren einander ähnlich, da beide Arten in Höhlen mit runden Öffnungen von etwa 4-5 cm Durchmesser brüteten, die sich hoch in großen und lebenden Bäumen oder intakten Stämmen toter Bäume befanden. Sowohl P. ater als auch P. major bevorzugten Astlöcher mit schlitzartigen Öffnungen, die sich in geringer Höhe in lebenden Bäumen befanden. P. auroreus nutzte eine breite Palette unterschiedlich beschaffener Höhlen, während C. familiaris sich von den anderen Arten durch die Spezialisierung auf lange Schlitze unterschied.

Die Beobachtung der Folgenutzungen zeigte, dass Höhlen, die zuvor von D. major und P. montanus benutzt wurden, häufig jeweils von S. europaea und F. parva im Folgejahr genutzt wurden. Vormals von S. europaea und P. ater besetzte Höhlen wurden häufig von denselben Arten wiederbesetzt. Höhlen in lebendem Substrat wurden häufiger wiederbesetzt als solche in toten Bäumen. Anhand der Ergebnisse der nest web Analyse konnte für keine Art der Gruppe der sekundären Höhlenutzer ein vollständige Abhängigkeit von mittelgroßen oder kleinen Spechthöhlen angenommen werden. Diese Arten konnten Astlöcher nutzen, wenn Spechthöhlen fehlten. Das Entfernen der Birke würde hingegen die Struktur der Artengemeinschaft höhlenbrütender Vögel deutlich beeinflussen.

Die Baumhöhlenabundanz in dem Untersuchungsgebiet war im Vergleich zu Literaturangaben hoch. Die prozentuale Verteilung der Höhlen nach Baumarten war vergleichbar mit denen verwandter Arten in Schweden. Dies könnte eine charakteristische Eigenart der borealen Wälder in Eurasien sein. Die hohe Baumhöhlenabundnaz dieses Untersuchungsgebiets lag vermutlich in seiner Natürlichkeit, sowohl hinsichtlich der Naturwaldstrukturen mit hohen Abundanzen 
von Laubhölzern, alten und zerfallenden Bäumen als auch der natürlichen Prozesse von Feuerdynamik und Pilzbefall, begründet. Die Siedlungsdichte der untersuchten Vogelartengemeinschaft korrespondierte deutlich mit diesen Eigenschaften, woraus eine im Vergleich zu berichteten Werten geringe Höhlenbesetzungsrate resultierte.

Die Nistplätze der primären Höhlennutzer zeigte einige Gemeinsamkeiten, wie z.B. die Anlage von Baumhöhlen hoch über dem Boden mit runden Öffnungen und minimierter Öffnungsweite, als mögliche Adaptationen gegenüber Prädation und Aufwandsminimierung bei der Höhlenanlage. Ebenso zeigten diese Arten Unterschiede bei der Wahl von Baumart und Substrat, bedingt durch die unterschiedlichen körperlichen Fähigkeiten zur Höhlenanlage, Körpergröße und Reviergröße. Die meisten sekundären Höhlennutzer zeigten Präferenz für einen bestimmten Höhlentyp und in der Nistbaumnutzung und Höhlensubstratnutzung spiegelte sich hauptsächlich die Häufigkeit solcher Höhlen wieder. Das Ausmaß einer die Nistplatzwahl und Populationsdichte bestimmenden interspezifischen Konkurrenz erschien geringer als in anderen Studien berichtet.

Die höhere Folgenutzungsrate von Höhlen in lebendem Substrat könnte die Qualität und Nutzbarkeit dieser wiederspiegeln. Solche Höhlen wiesen ein günstigeres Mikroklima auf und waren sicherer vor Prädation. Die Annahme, Spechte seien generell Schlüsselarten für die Artengemeinschaften höhlenbrütender Vögel, konnte in dieser Studie nicht belegt werden. Lediglich D. martius könnte eine unersetzbare Funktion in der Anlage großer Höhlen spielen. Die Birke hatte eine fundamentale Bedeutung in dem Untersuchungsgebiet als Konsequenz sowohl ihrer hohen Höhlenbürtigkeitsrate als auch ihrer hohen Abundanz. Und die nest web Analyse stellte heraus, welche Folgen eintreten könnten und in großen Flächen borealer und hemiborealer Wälder eingetreten sind, wenn Birken-(Misch)wälder in Nadelholzplantagen umgewandelt würden. 


\section{LITERATURE}

AanderaA, R., Rolstad, J. \& Sognen, S.M. (1996): Biological Diversity in Forests. A/S Landbruksforlaget, Oslo.

ABRAMS, P. (1980): Some comments on measuring niche overlap. Ecology 61: 44-49.

AitKEN, K.E.H., WiEBE, K.L. \& MARTIN, K. (2002): Nest-site reuse patterns for a cavity-nesting bird community in interior British Columbia. Auk 119: 391-402.

AKÇA, A. (2000): Forest Inventory. Institute of Forest Management and Yield Sciences, Göttingen University, Göttingen.

Alatalo, R.V., LundBerg, A. \& Glynn, C. (1986): Female Pied Flycatchers choose territory quality and not male characteristics. Nature 323: 152-153.

AlbanO, D.J. (1992): Nesting mortality of Carolina chickadees breeding in natural cavities. Condor 94: 371-382.

Alerstam, T. \& HögSTEDT, G. (1981): Evolution of hole-nesting in birds. Ornis Scandinavica 12: 188-193.

ANGELSTAM, P. (1990): Factors determining the composition and persistence of local woodpecker assemblages in taiga forest in Sweden - A case for landscape ecological studies. pp. 147-166 in CARLSON, A. \& AULÉN, G. (eds.): Conservation and Management of Woodpecker Populations, Report 17, Swedish University of Agricultural Science, Department of Wildlife Ecology, Uppsala.

ANGElSTAM, P. \& MiKUSINSKI, G. (1994): Woodpecker assemblages in natural and managed boreal and hemiboreal forest - a review. Annales Zoologici Fennici 31: 157-172.

ANSLEY, R.J., HudDLE, J.A. \& KRAMP, B.A. (1997): Mesquite ecology. pp. 21-25 in Rollins,D., UECKERT, D.N. \& BROWN, C.G. (eds.): Brush Sculptors: Innovations for Tailoring Brushy Rangelands to Enhance Wildlife Habitat and Recreational Value, TAMU Agricultural Research \& Extension Center, San Angelo.

Anthony, R.G., Green, G.A., Forsman, E.D. \& Nelson, S.K. (1996): Avian abundance in riparian zones of three forest types in the Cascade Mountains, Oregon. Wilson Bulletin 108: 280-291.

AULÉN, G. (1988): Ecology and distribution history of the White-backed Woodpecker Dendrocopos leucotos in Sweden. Report 14, Department of Wildlife Ecology, Swedish University of Agricultural Science, Uppsala.

BARCLAY, R.M.R. (1988): Variation in the costs, benefits and frequency of nest reuse by Barn Swallows (Hirundo rustica). Auk 105: 53-60.

Bauer, H.G., Berthold, P., Boye, P., Knief, W., SÜdbeck, P. \& WitT, K. (2002): Rote Liste der Brutvögel Deutschlands. Berichte zum Vogelschutz 39: 13-60.

BEDNARZ, J.C., RIPPER, D. \& RADLEY, P.M. (2004): Emerging concepts and research directions in the study of cavity-nesting birds: keystone ecological processes. Condor 106: 1-4.

BELTHOFF, J.R. \& RitchisOn, G. (1990): Nest-site selection by eastern screech-owls 
in central Kentucky. Condor 92: 982-990.

Best, L.B. (1979): Effects of fire on a Field Sparrow population. American Midland Naturalist 101: 434-442.

BLUME, D. (1961): Über die Lebensweise einiger Spechtarten. Journal für Ornithologie 102: 7-115.

Blume, D. (1977): Die Buntspechte. Ziemsen Verlag, Wittenberg.

Blume, D. (1990): Die Bedeutung des Alt- und Totholzes fuer heimische Spechte Folgerungen für die Forstwirtschaft. pp. 48-50 in STRACKE, B. (collaborator): Ökologische Bedeutung von Alt- und Totholz in Wald und Feldflur, NZ NRW Seminarberichte H. 10, Naturschutzzentrum Nordrhein-Westfalen, Recklinghausen.

Bock, C.E., RAPHAEL, M. \& BOCK, J.H. (1978): Changing avian community structure during early post-fire succession in the Sierra Nevada. Wilson Bulletin 90: 119123.

BolD, A. (1984): Die Vögel des Chentij und ihre praktische Bedeutung. Wissenschaftliche Beiträge Universität Halle-Wittenberg 4: 132-151.

BONAR, R.L. (2000): Availability of pileated woodpecker cavities and use by other species. Journal of Wildlife Management 64: 52-59.

Brandeis, T.J., Newton, M., FiliP, G.M. \& Cole, E.C. (2002): Cavity nester habitat development in artificially made Douglas fir snags. Journal of Wildlife Management 66: 625-633.

BRAWN, J.D. (1988): Selectivity and ecological consequences of cavity nesters using natural vs artificial nest sites. Auk 105: 789-791.

BRAWN, J.D. \& BALDA, R.P. (1988): Population biology of cavity nesters in northern Arizona: do nest sites limit breeding densities? Condor 90: 61-71.

Brinson, M.M., Swift, B.L., Plantico, R.C. \& Barclay, J.S. (1981): Riparian Ecosystems: Their Ecology and Status. USA Fish and Wildlife Service OBS$81 / 17$, Washington.

BRUSH, T. (1983): Cavity use by secondary cavity-nesting birds and response to manipulations. Condor 85: 461-466.

BULL, E.L. (1983): Longevity of snags and their use by woodpeckers. pp. 64-67 in DAVIS, J.W., GOODWIN, G.A. \& OCKENFELS, R.A. (technical coordinators): Snag Habitat Management: Proceedings of the Symposium, USDA Forest Service General Technical Report RM-99, Flagstaff, Arizona.

CARLSON, A. (2000): The effect of habitat loss on a deciduous forest specialist species: The White-backed Woodpecker (Dendrocopos leucotos). Forest Ecology and Management 131: 215-221.

CARlson, A., SAndström, U. \& Olsson, O. (1998): Availability and use of natural tree holes by cavity nesting birds in a Swedish deciduous forest. Ardea 86: 109119.

Chandler, C., Cheney, P., Thomas, P., Trabaud, L. \& Williams, D. (1983): Fire in forestry: Forest fire behavior and effects. John Wiley \& Sons, Inc., New York. 
Christman, B.J. \& DHONDT, A.A. (1997): Nest predation in Black-capped Chickadees: how safe are cavity nests? Auk 114: 769-773.

ConNer, R.N., HoOPER, R.G., CraWFORD, H.S. \& Mosby, H.S. (1975): Woodpecker nesting habitat in cut and uncut woodlands in Virginia. Journal of Wildlife Management 39: 144-150.

Conner, R.N., MiLler, JR.O.K. \& AKISSON, C.S. (1976): Woodpecker dependence on trees infected by fungal heart rots. Wilson Bulletin 88: 575-581.

CONNER, R.N. \& LOCKE, B.A. (1982): Fungi and red-cockaded woodpecker cavity trees. Wilson Bulletin 94: 64-70.

CrocketT, A.B. \& Hadow, H.H. (1975): Nest site selection by Williamson and Rednaped Sapsuckers. Condor 77: 365-368.

CzeszCZEwiK, D. (2004): Breeding success and timing of the Pied Flycatcher Ficedula hypoleuca nesting in natural holes and nest-boxes in the Bialowieza Forest, Poland. Acta Ornithologica 39: 15-20.

CzeszCZewik, D., Walankiewicz, W., Mitrus, C. \& Nowakowski, W. (1999): Nest-box data of Pied Flycatcher Ficedula hypoleuca may lead to erroneous generalizations. Vogelwelt 120, Suppl.: 361-365.

CzeszCZEwiK, D. \& Walankiewicz, W. (2003): Natural nest sites of the Pied Flycatcher Ficedula hypoleuca in a primeval forest. Ardea 91: 221-230.

DAILY, G.C. (1993): Heartwood decay and vertical distribution of Red-naped Sapsucker nest cavities. Wilson Bulletin 105: 674-679.

DhondT, A.A. \& Schillemans, J. (1983): Reproductive success of the Great Tit in relation to its territorial status. Animal Behaviour 31: 902-912.

Dobkin, D.S., Rich, A.C., Pretare, J.A. \& Pyle, W.H. (1995): Nest-site relationships among cavity-nesting birds of riparian and snowpocket aspen woodlands in the northwestern Great Basin. Condor 97: 694-707.

DoBKIN, D.S. \& WILCOX, B.A. (1986): Analysis of natural forest fragments: riparian birds in the Toiyabe Mountains, Nevada. pp. 293-299 in VERNER, J., MORRISON, M.L. \& RALPH, C.J. (eds.): Wildlife 2000: modeling habitat reationships of terrestrial vertebrates, University of Wisconsin Press, Madison.

Dölle, M., Fischer, S., Funke, H., HAhn, N. \& HAuswiRTH, M. (2002): Mongolei "Strictly protected area" Khan Khentii - Wälder und Waldsteppen borealer Breiten. Zentrum für Naturschutz, Universität Göttingen, Göttingen.

Dow, H. \& FREDGA, S. (1985): Selection of nest sites by a hole-nesting duck, the goldeneye Bucephala clangula. Ibis 127: 16-30.

DulamsuREN, CH. (2004): Floristische Diversität, Vegetation und Standortbedingungen in der Gebirgstaiga des Westkhentej, Nordmongolei. Georg-August-Universität Göttingen, Göttingen.

EBERHARD, J.R. (2002): Cavity adoption and the evolution of coloniality in cavitynesting birds. Condor 104: 240-247.

Edington, J.M. \& EDINGTON. M. A. (1972): Spatial patterns and habitat partition in the breeding birds of an upland wood. Journal of Animal Ecology 41: 331-357.

ENEMAR, A. \& SJÖSTRAND, B. (1972): Effects of the introduction of pied flycatchers 
(Ficedula hypoleuca) on the composition of a passerine bird community. Ornis Scandinavica 3: 79-89.

ERSKINE, A.J. \& MCLAREN, W.D. (1972): Sapsucker nest holes and their use by other species. Canadian Field Naturalist 86: 357-361.

ERSKINE, A.J. \& MCLAREN, W.D. (1976): Comparative nesting biology of some holenesting birds in the Cariboo parklands, British Columbia. Wilson Bulletin 88: 611-620.

Evans, M.R., LANK, D.B., Boyd, W.S. \& CoOKE, F. (2002): A comparison of the characteristics and fate of Barrow's Goldeneye and Bufflehead nests in nest boxes and natural cavities. Condor 104: 610-619.

FARRAR, J.L. (1995): Trees of the northern United States and Canada. Iowa State University Press, Ames.

FARRIS, K.L., HuSS, M.J. \& ZACK, S. (2004): The role of foraging woodpeckers in the decomposition of ponderosa pine snags. Condor 106: 50-59.

Figuerola, J. \& GREEN, A.J. (2000): The evolution of sexual dimorphism in relation to mating patterns, cavity nesting, insularity and sympatry in the Anseriformes. Functional Ecology 14: 701-710.

FLACK, J.A.D. (1976): Bird populations of aspen forests in western North America. Ornithological Monograph 19: 1-97.

FUJIMORI T. (2001): Ecological and silvicultural strategies for sustainable forest management. Elsevier Science, Amsterdam.

GibBons, P., LindenMaYer, D.B., BARRY, S.C. \& TANTON, M.T. (2000): Hollow formation in eucalypts from temperate forests in southeastern Australia. Pacific Conservation Biology 6: 218-228.

GibBons, P., Lindenmayer, D.B., BARRY, S.C. \& TANTON, M.T. (2002): Hollow selection by vertebrate fauna in forests of southeastern Australia and implications for forest management. Biological Conservation 103: 1-12.

GiBBS, J.P., HunTER, M.L.JR. \& MELvin, S.M. (1993): Snag availability and communities of cavity nesting birds in tropical versus temperate forests. Biotropica 25: 236-241.

GlutZ Von Blotzheim, U.N. \& BAUER, K.M. (1993): Handbuch der Vögel Mitteleuropas. Aula Verlag, Wiesbaden.

GoldAMMER, J.G. \& FurYAEV, V.V. (1996): Fire in ecosystems of boreal Eurasia: Ecological impacts and links to the global system. pp. 1-20 in GOLDAMMER, J.G. \& FURYAEV, V.V. (eds.): Fire in ecosystems of boreal Eurasia, Kluwer Academic Publishers, Dordrecht.

GRANSTROM, A. (2001): Fire management for biodiversity in the European boreal forest. Scandinavian Journal of Forest Research Suppl. 3: 62-69.

Graves, A.T., FaJvan, M.A. \& Miller, G.W. (2000): The effects of thinning intensity on snag and cavity tree abundance in an Appalachian hardwood stand. Canadian Journal of Forest Research 308: 1214-1220.

GREENwoOD, J.J.D. (1985): Comments on hole-nesting in birds. Ornis Scandinavica 16: $153-158$. 
GRosenBAUGH, L.R. (1952): Plotless timber estimates - new, fast, easy. Journal of Forestry 50: 32-37.

GunN, J.S. \& HAGAN, J.M. (2000): Woodpecker abundance and tree use in unevenaged managed, and unmanaged, forest in northern Maine. Forest Ecology and Management 126: 1-12.

GÜNTHER, E. \& Hellmann, M. (1995): Die Entwicklung von Höhlen der Buntspechte (Picoides) in naturnahen Laubwäldern des nordöstlichen Harzes (Sachsen-Anhalt). Ornithologische Jahresberichte des Museum Heineanum 13: 27-52.

GÜNTHER, E. \& HellmanN, M. (1997): Die Höhlen des Buntspechts - haben wir ihre Bedeutung für die Nachnutzer überschätzt? Naturschutz im Land Sachsen Anhalt 34: 15-24.

GÜNTHER, E. \& HELlMANN, M. (2001): Spechte als "Schluesselarten" - ein Schluessel fuer wen? pp. 7-22 in Günther, E., Nicolai, B., PeChaceK, P. \& SÜdbeck, P. (eds.): Spechte, Wald und Hohlennutzung, Abhandlungen und Berichte aus dem Museum Heineanum 5, Sonderheft, Foerderkreis Museum Heineanum, Halberstadt.

GUSTAFSSON, L. (1986): Lifetime reproductive success and heritability: empirical support for Fisher's fundamental theorem. American Naturalist 128: 761-764.

GUSTAFSSON, L. (1998): Inter- and intraspecific competition for nest holes in a population of the collared flycatcher Ficedula albicollis. Ibis 130: 11-16.

GutZWILlER, K.J. \& ANDERSON, S.H. (1987): Multiscale associations between cavity-nesting birds and features of Wyoming streamside woodlands. Condor 89: 534-548.

HAAPANEN, A. (1965): Bird fauna of the Finnish forests in relation to forest succession. I. Annales Zoologici Fennici 2: 153-196.

Haas, C.A. (1998): Effects of prior nesting on site fidelity and breeding dispersal: An experimental approach. Auk 115: 929-936.

HAGGARD, M. \& GAINES, W.L. (2001): Effects of stand-replacement fire and salvage logging on a cavity-nesting bird community in eastern Cascades, Washington.

Northwest Science 75: 387-396.

HÅland, A. \& UgELVIK, M. (1990): The status and management of the White-backed Woodpecker Dendrocopos leucotos (L.) in Norway. pp. 29-35 in CARLSON, A. \& AulÉN, G. (eds.): Conservation and Management of Woodpecker Populations, Report 17, Department of Wildlife Ecology, Swedish University of Agricultural Science, Uppsala.

Hansen, A.J., Spies, T.A., Swanson F. J. \& OHMAnN, J.L. (1991): Lessons from natural forests: Implications for conserving biodiversity in natural forests. BioScience 41: 382-392.

HARESTAD, A.S. \& KeISKER, D.G. (1989): Nest tree use by primary cavity-nesting birds in south central British Columbia. Canadian Journal of Zoology 67: 1067-1073.

HART, J.H. \& HART, D.L. (2001): Heartrot fungi's role in creating picid nesting sites in living aspen. pp. 207-213 in SHEPPERD, W.D. (collaborator): Sustaining 
Aspen in Western Landscapes : Symposium Proceedings, RMRS-P-18, Rocky Mountain Research Station, Grand Junction, Colorado.

HaUsner, V.H., Yoccoz, N.G. \& IMS, R.A. (2003): Selecting indicator traits for monitoring land use impacts: Birds in northern coastal birch forests. Ecological Applications 13: 999-1012.

HavelKa, P. \& Ruge, K. (1993): Trends der Populationsentwicklung bei Spechten (Picidae) in der Bundesrepublik Deutschland. Beihefte zu den Veröffentlichungen für Naturschutz und Landschaftspflege in BadenWürttemberg 67: 33-38.

Helle, P. \& NIEMI, G.J. (1996): Bird community dynamics in boreal forests. pp. 209-234 in DEGRAAF, R.M. \& MiLlER, R.L. (eds.): Conservation of Faunal Diversity in Forested Landscapes, Chapman and Hall, London.

HiRATSUKA, Y. \& LOMAN, A.A. (1984): Decay of aspen and balsam poplar in Alberta. Canadian Forest Service Information Report NOR-X-262,

HobSON, K.A. \& BAYNE, E. (2000): The effects of stand age on avian communities in aspen-dominated forests of central Saskatchewan, Canada. Forest Ecology and Management 136: 121-134.

Hogstad, O. \& STENBERG, I. (1994): Habitat selection of a viable population of White-backed woodpeckers Dendrocopos leucotos . Fauna Norvegica Series C Cinclus 17: 75-94.

HOHLFELD, F. (1995): Untersuchungen zur Siedlungsdichte der Brutvögel eines Bannwaldgebietes unter besonderer Berücksichtigung des Höhlenangebotes für Höhlenbrüter. Ornithologische Jahreshefte für Baden-Württemberg 11: 1-62.

Hooper, R.G., LenNartz, M.R. \& Muse, H.D. (1991): Heart rot and cavity tree selection by Red-cockaded Woodpeckers. Journal of Wildlife Management 55:

HoRA, B. (1993): Bäume der Welt: eine Enzyklopädie. DRW-Verlag, Stuttgart.

HUBBARD, J.P. (1977): Importance of riparian ecosystems: Biotic considerations. pp. 14-18 in JOHNSON, R.R. \& JONES, D.A. (technical coordinators): Importance, Preservation and Management of Riparian Habitat: A Symposium, USDA Forest Service General Technical Report RM-43, Tucson.

HuHTA, E., JOKIMÄKI, J. \& RAHKO, P. (1998): Distribution and reproductive success of the pied flycatcher Ficedula hypoleuca in relation to forest patch size and vegetation characteristics; the effect of scale. Ibis 140: 214-222.

HunTER, J.E. \& MAZUREK, M.J. (2003): Characteristics of trees used by nesting and roosting Vaux's Swifts in northwestern California. Western Birds 34: 225-229.

HuTTO, R.L. (1995): Composition of bird communities following stand-replacement fires in Northern Rocky Mountain (U.S.A.) conifer forests. Conservation Biology 9: 1041-1058.

IMBEAU, L., SAVARD, J.P.L. \& GAGNON, R. (1999): Comparing bird assemblages in successional black spruce stands originating from fire and logging. Canadian Journal of Zoology 77: 1850-1860.

IMBEAU, L., MÖNKKÖNEN, M. \& DESROCHERS, A. (2001): Long-term effects of forestry on birds of the eastern Canadian boreal forests: A comparison with Fennoscandia. Conservation Biology 15: 1151-1162. 
INGOLD, D.J. (1989): Nesting phenology and competition for nest sites among Redheaded and Red-bellied Woodpeckers and European Starlings. Auk 106: 209217.

INGOLD, D.J. (1996): Delayed nesting decreases reproductive success in Northern Flickers: implications for competition with European Starlings. Journal of Field Ornithology 67: 321-326.

IwATA, T., NAKANO, S. \& MuRAKAMI, M. (2003): Stream meanders increase insectivorous bird abundance in riparian deciduous forests. Ecography 26: 325337.

JACKSON, J.A. (1977): Red-cockaded woodpeckers and pine red heart disease. Auk 94: $160-163$.

JACKSON, J.A. \& JACKSON, B.J.S. (2004): Ecological relationships between fungi and woodpecker cavity sites. Condor 106: 37-49.

JALAS, J. \& SUOMINEN, J. (1972): Atlas florae Europaeae: Distribution of vascular plants in Europe. I. Pteridophyta (Psilotaceae to Azollaceae). Suomalaisen Kirjallisuunden Kirjapaino, Helsinki.

JAMES, F.C., HeSS, C.A. \& KUFRIN, D. (1997): Species-centered environmental analysis: indirect effects of fire history on Red-cockaded Woodpeckers. Ecological Applications 7: 118-129.

JÄRVINEN, A. (1989): Patterns and causes of long-term variation in reproductive traits of the pied flycatcher (Ficedula hypoleuca) in Finnish Lapland. Ornis Fennica 66: 24-31.

JEDICKE, E. (1997): Spechte als Zielarten des Naturschutzes: Ökologie und Verbreitung, Eignung als Indikatoren, Methoden der Gefährdungsanalyse. Vogelkundliche Hefte Edertal 23: 5-43.

Jobson, J.D. (1992): Applied Multivariate Data Analysis. Vol. II: Categorical and Multivariate Methods. Springer-Verlag, New York.

JoHnsson, K. (1993): The Black Woodpecker Dryocopus martius as a keystone species in forest. Report 24, Department of Wildlife Ecology, Swedish University of Agricultural Science, Uppsala.

Johnsson, K., Nilsson, S.G. \& TJERnBerG, M. (1993): Characteristics and utilization of old Black Woodpecker Dryocopus martius holes by hole-nesting species. Ibis 135: 410-416.

KILHAM, L. (1971): Reproductive Behavior of Yellow-bellied Sapsuckers. I. Preference for nesting in Fomes-infected aspens and nest hole interrelations with flying squirrels, raccoons, and other animals. Wilson Bulletin 83: 159-171.

KNEITZ, G. (1961): Zur Frage der Verteilung von Spechthöhlen und die Ausrichtung des Fluglochs. Waldhygiene 4: 80-120.

KoENIG, W.D. (2003): European Starlings and their effect on native cavity-nesting birds. Conservation Biology 17: 1134-1140.

KoROL, J.J. \& HUTTO, R.L. (1984): Factors affecting nest site location in Gila woodpeckers. Condor 86: 73-78.

KORPIMAKI, E. (1993): Does nest-hole quality, poor breeding success, or food 
depletion drive the breeding dispersal if Tengmalm's Owls? Journal of Animal Ecology 62: 606-613.

Kotaka, N. \& MatsuoKa, S. (2002): Secondary users of Great Spotted Woodpecker (Dendrocopos major) nest cavities in urban and suburban forests in Sapporo City, northern Japan. Ornithological Science 1: 117-122.

Kotliar, N.B., HeJl, S.J., Hutto, R.L., SaAb, V.A., Melcher, C.P. \& McFadzen, M.E. (2002): Effects of fire and post-fire salvage logging on avian communities in conifer-dominated forests of the western United States. Studies in Avian Biology 25: 49-64.

KreBS, C.J. (1989): Ecological Methodology. Harper Collins Publishers, New York.

KREBS, C.J. (2001): Ecology: the Experimental Analysis of Distribution and Abundance. Banjamin Cummings, San Francisco.

KREISEL, K.J. \& STEIN, S.J. (1999): Bird use of burned and unburned coniferous forests during winter. Wilson Bulletin 111: 243-250.

KRIŠTín, A. \& ŽILINEC, M. (1997): Nest box occupancy and breeding success of holenesting passerines at various conditions in beech forests. Folia Zoologica 46: 229-241.

KÜHLKE, D. (1985): Höhlenangebot und Siedlungsdichte von Schwarzspecht (Dryocopus martius), Rauhfußkauz (Aegolius funereus) und Hohltaube (Columba oenas). Vogelwelt 106: 81-93.

LACK, D. (1966): Population studies of birds . Clarendon Press, Oxford.

LAMMERTINK, M. (2004): A multiple-site comparison of woodpecker communities in Bornean lowland and hill forests. Conservation Biology 18: 746-757.

LAVRENKO, E.M. (1979): Karta rastitel'nosti Mongol'skoj Narodnoj respubliki. Moskow.

LAWLER, J.J. \& EDWARDS JR., T.C. (2002): Composition of cavity-nesting bird communities in montane aspen woodland fragments: the roles of landscape context and forest structure. Condor 104: 890-896.

LAWRENCE, L.D.K. (1967): A comparative life-history study of four species of woodpeckers. Ornithological Monographs 5: 1-156.

LehMKUhl, J.F., Everett, R.L., SchellhaAs, R., OHLSON, P., KeENUM, D., RIESTERER, H. \& SPURBECK, D. (2003): Cavities in snags along a wildfire chronosequence in eastern Washington. Journal of Wildlife Management 67: 219-228.

LI, P. \& MARTIN, T.E. (1991): Nest-site selection and nesting success of cavitynesting birds in high elevation forest drainages. Auk 108: 405-418.

Lindenmayer, D.B., Cunningham, R.B., Donnelly, C.F., TAnton, M.T. \& NiX, H.A. (1993): The abundance and development of cavities in Eucalyptus trees - a case study in the montane forests of Victoria, southeastern Australia. Forest Ecology and Management 60: 77-104.

LOWNEY, M.S. \& HILL, E.P. (1989): Wood duck nest sites in bottomland hardwood forests of Mississippi. Journal of Wildlife Management 53: 378-382.

MagurRan, A.E. (1988): Ecological 'diversity and its Measurement. Princeton 
University Press, Princeton.

MaLAnson, G.P. (1993): Riparian Landscapes. Cambridge University Press, Cambridge.

Malchevski, A.S. \& PUKInSKI, YU.B. (1983): Ptitsy Leningradskoi oblasti i sopredelnyh territoriy: istoria, biologia, ohrana - in Russian. Leningrad University Press, Leningrad.

MARKOVETS, M. (2003): Frost cracks as a breeding niche for small passerines. Vogelwarte 42: 58-59.

MARTIN, K. \& EADIE, J.M. (1999): Nest webs: A community-wide approach to the management and conservation of cavity-nesting forest birds. Forest Ecology and Management 115: 243-257.

MARTin, K., AitKen, K.E.H. \& WiEBE, K.L. (2004): Nest sites and nest webs for cavity-nesting communities in interior British Columbia, Canada: nest characteristics and niche partitioning. Condor 106: 5-19.

MARTIN, T.E. (1993): Evolutionary determinants of clutch size in cavity-nesting birds: nest predation or limited breeding opportunities? American Naturalist 142: 937-946.

MARTIN, T.E. \& LI, P. (1992): Life history traits of open- vs. cavity-nesting birds. Ecology 73: 579-592.

MARTIN, T.E. \& BADYAEV, A.V. (1996): Sexual dichromatism in birds: importance of nest predation and nest location for females versus males. Evolution 50: 24542460.

MARTin, T.E. \& CloberT, J. (1996): Nest predation and avian life-history evolution in Europe versus North America: A possible role of humans? American Naturalist 147: 1028-1046.

MARTIN, T.E. \& GHALAMBOR, C.K. (1999): Males feeding females during incubation. I. Required by microclimate or constrained by nest predation? American Naturalist 153: 131-139.

Maser, C., Cline, S.P., Cromack, Jr.K., Trappe, J.M. \& Hansen, E. (1988): What we know about large trees that fall to the forest floor . pp. 25-45 in MASER, C., TARrant, R.F., Trappe, J.M. \& FrankLIn, J.F. (eds.): From the Forest to the Sea: A Story of Fallen Trees, General Technical Report PNW-GTR-229, Pacific Northwest Research Station, U.S. Department of Agriculture, Forest Service, Portland.

MAZGAJSKI, T.D. (2003): Nest sites choice in relation to the presence of old nests and cavity depth in the starling Sturnus vulgaris. Ethology, Ecology and Evolution 15: $273-281$.

MCCAw, W.L. (1983): Wood decay associated with fire scars on Jarrah. Australian Forest Research 13: 261-266.

McClelland, B.R., Frissell, S.S., Fischer, W.C. \& Halvorson, C.H. (1979):

Habitat management for hole-nesting birds in forests of western larch and Douglas-fir. Journal of Forestry 77: 480-483.

MсCомв, W.C. \& NoBLE, R.E. (1981): Nest-box and natural-cavity use in three midsouth forest habitats. Journal of Wildlife Management 45: 93-101. 
McGarigal, K., Cushman, S. \& STAFFord, S. (2000): Multivariate statistics for wildlife and ecology research. Springer, New York.

MCRAE, D.J. \& LYNHAM, T.J. (2000): Fire management impacts on boreal forest process and health. pp. 365-372 in CONRAD, S.G. (ed.): Disturbances in Boreal Forest Ecosystems: Human Impacts and Natural Resources, General Technical Report NC-209, North Central Research Station, U.S. Forest Service, St Paul, USA.

Meyer, W., Bartels, T., Neurand, K. \& Lange, N. (1993): Specific structural features of the woodpecker bill, as revealed by direct magnifying microfocal radiography (Aves, Piciformes). European Archives of Biology 104: 149-155.

MEYER, W. \& MEYER, B. (2001): Bau und Nutzung von Schwarzspechthöhlen in Thüringen. pp. 121-131 in GÜNTHER, E., NiCOLAI, B., PECHACEK, P. \& SüDBECK, P. (eds.): Spechte, Wald und Hohlennutzung, Abhandlungen und Berichte aus dem Museum Heineanum 5, Sonderheft, Foerderkreis Museum Heineanum, Halberstadt.

MiERA, C. (1978): Zur Brutbiologie des Zwergschnäppers. Falke 25: 120-127.

MiKUSINSKI, G. (1995): Population trends in black woodpecker in relation to changes and characteristics of European forests. Ecography 18: 363-369.

Mikusinski, G. (1997): Woodpeckers in Time and Space: The Role of Natural and Anthropogenic Factors. Dissertation, Department of Conservation Biology, Swedish University of Agricultural Science, Uppsala, Sweden.

MiKUSINSKI, G. \& ANGELSTAM, P. (1997): European woodpeckers and anthropogenic habitat change: A review. Vogelwelt 118: 277-283.

MiKusinsKi, G. \& ANGELSTAM, P. (1998): Economic geography, forest distribution, and woodpecker diversity in central Europe. Conservation Biology 12: 200208.

Mikusinski, G., GromadzKi, M. \& ChYlarecki, P. (2001): Woodpeckers as indicators of forest bird diversity. Conservation Biology 15: 208-217.

MinOT, E.O. (1981): Effects of interspecific competition for food in breeding Blue and Great Tits. Journal of Animal Ecology 50: 375-385.

MitRus, C. (2003): A comparison of the breeding ecology of Collared Flycatchers nesting in boxes and natural cavities. Journal of Field Ornithology 74: 293-299.

Mitrus, C. \& Socko, B. (2004): Natural nest sites of the Red-breasted Flycatcher Ficedula parva in a primeval forest. Acta Ornithologica 39: 53-57.

MNE (1996): Biodiversity Conservation Action Plan for Mongolia. Ministry for Nature and the Environment of Mongolia, Ulaanbaatar.

MNE, UNDP \& GEF (1998): Biological Diversity in Mongolia. (First National Report). Ministry for Nature and the Environment of Mongolia, Ulaanbaatar.

MNE, UNDP, GEF \& WWF (1996): Mongolia's Wild Heritage. Ministry for Nature and the Environment of Mongolia, Ulaanbaatar.

MNE \& WWF (1994): Naturerbe der Mongolei: Nationalpark Chan Chentie. Ministry for Nature and the Environment of Mongolia, Ulaanbaatar.

MøLLER, A.P. (1989): Parasites, predators and nest boxes: fact and artifacts in nest 
box studies of birds? Oikos 56: 421-424.

MoRiaRTY, J.J. \& MCCOMB, W.C. (1983): The long-term effect of timber stand improvement on snag and cavity densities in the central Appalachians. pp. 4044 in DAVIS, J.W., GoOdwIN, G.A. \& OCKENFELS, R.A. (technical coordinators): Snag Habitat Management: Proceedings of the Symposium, USDA Forest Service General Technical Report RM-99, Flagstaff, Arizona.

MorRison, M.L. \& RAPHAEL, M.G. (1993): Modeling the dynamics of snags. Ecological Applications 3: 322-330.

MORRISON, M.L., RAPHAEL, M.G. \& HEALD, R.C. (1983): The use of high-cut stumps by cavity-nesting birds. pp. 73-79 in DAVIS, J.W., GoODWIN, G.A. \& OCKENFELS, R.A. (technical coordinators): Snag Habitat Management:

Proceedings of the Symposium, USDA Forest Service General Technical Report RM-99, Flagstaff, Arizona.

MüHlenberg, M., Slowik, J., von Velsen-Zerweck, M., Melchert, P., SAmuaA, R. \& CHOIMAA, D. (2001): Research and conservation in the watershed area of the Baikal, north Mongolia, Khan Khentie. pp. 118-119 in KeIENBURG, T., SteIN, I. \& Werder, U. (eds.): Proceedings International Baikal Conference 1999, NNA Reports, Schneverdingen.

Muldal, A., GibBS, H.L. \& RoberTson, R.J. (1985): Preferred nest spacing of an obligate cavity nesting bird, the tree swallow. Condor 87: 356-363.

MurPhy, E.C. \& LEHNHAUSEN, W.A. (1998): Density and foraging ecology of woodpeckers following a stand-replacement fire. Journal of Wildlife Management 62: 1359-1372.

Myagmarsuren, D. (2000): Special Protected Areas of Mongolia. Ulaanbaatar.

NEWTON, I. (1994): The role of nest site in limiting the numbers of hole nesting birds: a review. Biological Conservation 70: 265-276.

NILSSON, S.G. (1979): Effects of forest management on the breeding bird community in southern Sweden. Biological Conservation 16: 135-143.

NiLsson, S.G. (1984a): Clutch size and breeding success of the Pied Flycatcher Ficedula hypoleuca in natural tree-holes. Ibis 126: 407-410.

NILSSON, S.G. (1984b): The evolution of nest-site selection among hole-nesting birds: the importance of nest predation and competition. Ornis Scandinavica 15: 167175.

NILSSON, S.G. (1986): Evolution of hole-nesting in birds: on balancing selection pressures. Auk 103: 432-435.

NILSSON, S.G. (1987): Limitation and regulation of population density in the Nuthatch Sitta europaea (Aves) breeding in natural cavities. Journal of Animal Ecology 56: 921-937.

NiLsson, S.G., Johnsson, K. \& TJERnBERG, M. (1991): Is avoidance by Black Woodpeckers of old nest holes due to predators? Animal Behaviour 41: 439441.

NiLSSON, S.G., HEDIN, J. \& NiKLASSON, M. (2001): Biodiversity and its assessment in boreal and nemoral forests. Scandinavian Journal of Forest Research Suppl. 3: $10-26$. 
NoeKe, G. (1989): Baumhöhlen in Buchenbeständen - Welche Rolle spielt das Bestandesalter? LÖLF-Mitteilungen 3: 20-22.

NoEKE, G. (1990): Abhängigkeit der Dichte natürlicher Baumhöhlen von Bestandesalter und Totholzangebote. pp. 51-53 in STRACKE, B. (collaborator): Ökologische Bedeutung von Alt- und Totholz in Wald und Feldflur, NZ NRW Seminarberichte H. 10, Naturschutzzentrum Nordrhein-Westfalen, Recklinghausen.

NuR, N. (1986): Is clutch size variation in the Blue Tit (Parus caeruleus) adaptive? Journal of Animal Ecology 55: 983-999.

OYunkHAnd, B. (2001): Physical map of Mongolia. Cartographic enterprise of the state administration of geodesy and cartography, Ulaanbaatar.

PARKs, C.G., CONKLIN, D.A., BEDNAR, L. \& MAFFEI, H. (1999): Woodpecker use and fall rates of snags created by killing ponderosa pine infected with dwarf mistletoe. U.S. Department of Agriculture, Forest Service, Pacific Northwest Research Station, Portland.

PEACE, T.R. (1962): Pathology of trees and shrubs. Clarendon Press, Oxford.

PeCHACEK, P. (1995): Spechte (Picidae) im Nationalpark Berchtesgarden: Habitatwahl, Nahrungsökologie, Populationsdichte. Forschungsberichte 31, Nationalpark Berchtesgarden, Berchtesgarden.

PeITZMeIER, J. (1969): Avifauna von Westfalen. Abhandlungen aus dem Landesmuseum für Naturkunde zu Münster in Westfalen 31: 1-480.

PERRINS, C.M. (1979): British tits. Collins, London.

PeTERS, W.D. \& GRUBB, T.C.JR. (1983): An experimental analysis of sex-specific foraging in the Downy Woodpecker, Picoides pubescens. Ecology 64(6): 14371443.

Peterson, B. \& GAuthier, G. (1985): Nest site use by cavity-nesting birds of the Cariboo Parkland, British Columbia. Wilson Bulletin 97: 319-331.

Petit, D.R., Petit, K.E., GrubB, T.C.J. \& ReichHARDT, L.J. (1985): Habitat and snag selection by woodpeckers in a clear-cut: an analysis using artificial snags. Wilson Bulletin 97: 525-533.

PetTERsson, B. (1985): Extinction of an isolated population of the middle spotted woodpecker Dendrocopos medius (L.) in Sweden and its relation to general theories on extinction. Biological Conservation 32: 335-353.

Pirone, P.P., Hartman, J.R., Sall, M.A. \& Pirone, T.P. (1988): Tree Maintenance. Oxford Unversity Press, New York.

Pogue, D.W. \& SCHNELL, G.D. (1994): Habitat characterization of secondary cavitynesting birds in Oklahoma. Wilson Bulletin 106: 203-226.

POYSA, H. \& POYSA, S. (2002): Nest-site limitation and density dependence of reproductive output in the Common Goldeneye Bucephala clangula: implications for the management of cavity-nesting birds. Journal of Applied Ecology 39: 502-510.

PRILL, H. (1987): Zur Nestbauaktivität der Spechte (Picidae) im Totalreservat des Naturschutzgebietes Serrahn, Kreis Neustrelitz. Archiv für Naturschutz und 
Landschaftsforschung 27: 57-61.

PURCELL, K.L., VERNER, J. \& ORING, L.W. (1997): A comparison of the breeding ecology of birds nesting in boxes and tree cavities. Auk 114: 646-656.

RAPHAEL, M.G. \& WHITE, M. (1984): Use of snags by cavity-nesting birds in the Sierra Nevada. Wildlife Monographs 86: 1-66.

REED, J.M. (1990): The dynamics of Red-Cockaded Woodpecker rarity and conservation. pp. 37-56 in CARLsOn, A. \& AUlÉN, G. (eds.): Conservation and Management of Woodpecker Populations, Report 17, Department of Wildlife Ecology, Swedish University of Agricultural Science, Uppsala.

RENDELL, W.B. \& RoBERTSON, R.J. (1989): Nest-site characteristics, reproductive success and cavity availability for tree swallows breeding in natural cavities. Condor 91: 875-885.

RENDELL, W.B. \& VERBEEK, N.A.M. (1996): Old nest material in nestboxes of tree swallows: Effects on reproductive success. Condor 98: 142-152.

Rogacheva, H.V., SyroechKovski, E.E., Bourski, O.V., Moroz, A.A. \& SHEFTEL, B.I. (1991): Birds of the Central-Siberian Biosphere Reserve. 2. Passerine birds. pp. 32-152 in Institute of Animal Morphology and Ecology (ed.): Biological resources and biocenoses of the Yenisey taiga. (Biologicheskie resursy i biocenozy Eniseiskoi taigi - in Russian), USSR Academy of Science, Moscow.

Rolstad, J., Rolstad, E. \& SAETEREN, O. (2000): Black woodpecker nest sites: Characteristics, selection, and reproductive success. Journal of Wildlife Management 64 : 1053-1066.

RomanuK, T.N. \& LEVINGS, C.D. (2003): Associations between arthropods and the supralittoral ecotone: Dependence of aquatic and terrestrial taxa on riparian vegetation. Environmental Entomology 32: 1343-1353.

RoSENSTOCK, S.S. (1998): Influence of Gambel oak on breeding birds in ponderosa pine forests of Northern Arizona. Condor 100: 485-492.

ROTENBERRY, J.T. \& WIENS, J.A. (1998): Foraging patch selection by shrubsteppe sparrows. Ecology 79(4): 1160-1173.

RUDOLPH, D.C. \& CONNER, R.N. (1991): Cavity tree selection by red-cockaded woodpeckers in relation to tree age. Wilson Bulletin 103: 458-467.

RugE, K. (1993): Europäische Spechte - Ökologie, Verhalten, Bedrohung, Hilfen. Beihefte zu den Veröffentlichungen für Naturschutz und Landschaftspflege in Baden-Württemberg 67: 13-25.

SAAB, V.A. \& DUDLEY, J.G. (1998): Responses of cavity-nesting birds to standreplacement fire and salvage logging in ponderosa pine/Douglas-fir forests of southwestern Idaho. U.S. Forest Service, Rocky Mountain Research Station Research Paper RMRS-RP-11, Ogden.

SAAB, V.A. \& VIERLING, K. (2001): Reproductive success of Lewis's Woodpecker in burned pine and cottonwood riparian forests. Condor 103: 491-501.

SAAB, V.A., DudLEY, J. \& THOMPSON, W.L. (2004): Factors influencing occupancy of nest cavities in recently burned forests. Condor 106: 20-36. 
SAARI, L. \& MiKUSINSKI, G. (1996): Population fluctuations of woodpecker species on the Baltic island of Aasla, SW Finland. Ornis Fennica 73: 168-178.

SACHSLEHNER, L.M. (1992): Zur Siedlungsdichte der Fliegenschnäpper (Muscicapinae s. str.) auf stadtnahen Wienerwaldflächen mit Aspekten des Waldsterbens und der Durchforstung. Egretta 35: 121-153.

SACHSLEHNER, L.M. (1995): Reviermerkmale und Brutplatzwahl in einer Naturhöhlen-Population des Halsbandschnäppers Ficedula albicollis im Wienerwald, Österreich. Vogelwelt 116: 245-254.

SANDSTRÖM, U. (1991): Enhanced predation rates on cavity bird nests at deciduous forest edges - an experimental study. Ornis Fennica 68: 93-98.

SANDSTRÖM, U. (1992): Cavities in trees: their occurrence, formation and importance for hole-nesting birds in relation to silvicultural practice. Swedish University of Agricultural Science, Department of Wildlife Ecology, Report 24, Uppsala.

SANIGA, M. (2003): Clutch and chick losses in model forest-dwelling birds in the West Carpathians. Vogelwelt 124: 103-108.

SCHERZINGER, W. (1998): Sind Spechte "gute" Indikatoren der ökologischen Situation von Wäldern? Vogelwelt 119: 1-6.

SCHIERMANN, G. (1934): Studien über die Siedlungsdichte im Brutgebiet II. Der brandenburgische Kiefernwald. Journal für Ornithologie 82: 455-486.

SCHOBER, R. (1995): Ertragstafeln wichtiger Baumarten. Sauerländers Verlag, Frankfurt a. M.

SCOTT, V.E. \& OLDEMEYER, J.L. (1983): Cavity-nesting bird requirements and response to snag cutting in ponderosa pine. pp. 19-23 in DAVIS, J.W., GoODwIN, G.A. \& OCKENFELS, R.A. (technical coordinators): Snag Habitat Management: Proceedings of the Symposium, USDA Forest Service General Technical Report RM-99, Flagstaff, Arizona.

SCOTT, V.E., Whelan, J.A. \& AlEXANDER, R.R. (1978): Dead trees used by cavitynesting birds on the Fraser Experimental Forest: a case history. U.S.

Department of Agriculture, Forest Service, Rocky Mountain Forest and Range Experiment Station Research Note RM-360, Fort Collins.

SEDGWICK, J.A. (1997): Sequential cavity use in a cottonwood bottomland. Condor 99: 880-887.

SEDGWICK, J.A. \& KNOPF, F.L. (1986): Cavity-nesting birds and the cavity-tree resource in plains cottonwood bottomlands. Journal of Wildlife Management 50: 247-252.

SEDGWICK, J.A. \& KNOPF, F.L. (1991): The loss of avian cavities by injury compartmentalization. Condor 93: 781-783.

SEDGWICK, J.A. \& KNOPF, F.L. (1992): Cavity turnover and equilibrium cavity densities in a cottonwood bottomland. Journal of Wildlife Management 56: 477-484.

ShigO, A.L. \& MARX, H.G. (1977): Compartmentalization of Decay in Trees. USDA Forest Service Agriculture Information Bulletin 405, Washington. D. C.

SHORT, L.L. (1979): Burdens of the Picid hole-excavating habit. Wilson Bulletin 91: 
$16-28$.

SHORT, L.L. \& HORNE, J.F.M. (1990): Woodpeckers - a world perspective and conservation concerns. pp. 5-12 in CARLSON, A. \& AULÉN, G. (eds.):

Conservation and Management of Woodpecker Populations, Report 17, Swedish University of Agricultural Science, Department of Wildlife Ecology, Uppsala.

Showalter, C.R. \& WhitMore, R.C. (2002): The effect of gypsy moth defoliation on cavity-nesting bird communities. Forest Science 48: 273-281.

SIEGEL, R.B. \& DESANTE, D.F. (2003): Bird communities in thinned versus unthinned Sierran mixed conifer stands. Wilson Bulletin 115: 155-165.

SIGURJÓNSDÓTTIR, H. (1981): The evolution of sexual size dimorphism in gamebirds, waterfowl and raptors. Ornis Scandinavica 12: 249-260.

Slagsvold, T. (1975): Critical period for regulation of Great Tit (Parus major L.) populations. Norwegian Journal of Zoology 23: 51-72.

SLAGSVOLD, T. (1982): Clutch size variation in passerine birds: the nest predation hypothesis. Oecologia 54: 159-169.

SMITH, K.W. (1997): Nest site selection of the great spotted woodpecker Dendrocopos major in two oak woods in southern England and its implications for woodland management. Biological Conservation 80: 283-288.

SONERUD, G.A. (1985): Nest hole shift in Tengmalm's owl Aegolius funereus as defence against nest predation involving long term memory in the predator. Journal of Animal Ecology 54: 179-192.

SPITZNAGEL, A. (1990): The influence of forest management on woodpecker density and habitat use in floodplain forests of the Upper Rhine valley. pp. 117-145 in CARLSON, A. \& AulÉN, G. (eds.): Conservation and Management of Woodpecker Populations, Report 17, Department of Wildlife Ecology, Swedish University of Agricultural Science, Uppsala.

StAnbaCK, M.T. \& RockwELL, E.K. (2003): Nest-site fidelity in eastern bluebirds (Sialia sialis) depends on the quality of alternate cavities. Auk 120: 1029-1032.

STAUFFER, D.F. \& BEST, L.B. (1982): Nest-site selection by cavity-nesting birds of riparian habitats in Iowa. Wilson Bulletin 94: 329-337.

STENBERG, I. (1990): Preliminary results of a study on woodpeckers in Møreand Romsdal county, Western Norway. pp. 67-79 in CARLSON, A. \& AulÉN, G. (eds.): Conservation and Management of Woodpecker Populations, Report 17, Swedish University of Agricultural Science, Department of Wildlife Ecology, Uppsala.

STENBERG, I. (1996): Nest site selection in six woodpecker species. Fauna Norvegica Series C Cinclus 19: 21-38.

SunjidmaA, R., MüHLenberg, M. \& SANCHIR, CH. (2004): Holzbewohnende Pilze in der Forschungsregion "Khoninnuga". pp. 10-21 in MÜHLENBERG, M., SAMJAA, R., Sheftel, B., Dgebuadze, Y., Pokroskaya, I., Alexandrov, D., Slowik, J., Dulamsuren, Ch., GantigmaA, Ch., Bai, M.L., PurevdorJ, S., SunjidmaA, R., Solongo, B., TserendavaA, P., EnkHMAA, A. \& Wichmann, F. (eds.): Ecology and Dynamics of a Southern Taiga System. Report 2003 of 
activities and research at the ecological university station Khonin Nuga, WestKhentii, northern Mongolia, Centre for Nature Conservation, University of Göttingen, Göttingen.

TOMialojC, L., Wesolowski, T. \& WALANKIEWICZ, W. (1984): Breeding bird community of a primaeval temperate forest (Bialowieza National Park, Poland). Acta Ornithologica 20: 241-310.

TÖRÖK, J. \& TOTH, L. (1988): Density dependence in reproduction of the collared flycatcher (Ficedula albicollis) at high population levels. Journal of Animal Ecology 57: 251-258.

TRIPET, F. \& RICHNER, H. (1997): The coevolutionary potential of a 'generalist' parasite, the hen flea Ceratophyllus gallinae. Parasitology 115: 419-427.

TROETSCHLER, R.G. (1976): Acorn Woodpecker breeding strategy as affected by starling nest-hole competition. Condor 78: 151-165.

VAN BALEN, J.H. (1984): The relationship between nest-box size, occupation and breeding parameters of the Great Tit Parus major and some other hole-nesting birds. Ardea 72: 163-175.

VAN BALEN, J.H., Booy, C.J.H., van FraneKer, J.A. \& OsIECK, E.R. (1982): Studies on hole-nesting birds in natural nest sites 1 . Availability and occupation of natural nest sites. Ardea 70: 1-24.

VON HAARTMAN, L. (1957): Adaptation in hole-nesting birds. Evolution 11: 339-347.

VON Velsen-ZERWECK, M. (2002): Socio-Economic Causes of Forest Loss in Mongolia. Wissenschaftsverlag Vauk Kiel KG, Kiel.

WALANKIEWICZ, W. (1991): Do secondary cavity-nesting birds suffer more from competition for cavities or from predation in a primeval deciduous forest? Natural Areas Journal 11: 203-212.

WalankiEwiCZ, W. (2002a): Breeding losses in the Collared Flycatcher Ficedula albicollis caused by nest predators in the Bialowieza National Park (Poland). Acta Ornithologica 37: 21-26.

WALANKIEWICZ, W. (2002B): Nest predation as a limiting factor to the breeding population size of the Collared Flycatcher Ficedula albicollis in the Bialowieza National Park (NE Poland). Acta Ornithologica 37: 91-106.

WATERS, J.R., NoOn, B.R. \& Verner, J. (1990): Lack of nest site limitation in a cavity-nesting bird community. Journal of Wildlife Management 54: 239-245.

WEISS, J. (1987): Höhlen im Baum - hohle Bäume. Unterricht Biologie 126: 18-22.

WEISS, J. (1990): Schwarzspechthöhlen als Indikatoren für Altholz-Bewertung und Erhaltung. pp. 59-61 in STRACKE, B. (collaborator): Oekologische Bedeutung von Alt- und Totholz in Wald und Feldflur, NZ NRW Seminarberichte H. 10, Naturschutzzentrum Nordrhein-Westfalen, Recklinghausen.

WesolowsKi, T. (1989): Nest-sites of hole-nesters in a primaeval temperate forest (Bialowieza National Park, Poland). Acta Ornithologica 25: 321-351.

WESOLOWSKI, T. (1994): Variation in the numbers of resident birds in a primaeval temperate forest: Are winter weather, seed crop, caterpillars and interspecific competition involved? pp. 203-211 in HAGEMEIJER, E.J.M. \& VERSTRAEL, T.J. 
(eds.): Bird numbers 1992, Statistics Netherlands, Heerlen.

WeSOlOWsKI, T. (1995a): Value of Bialowieza forest for the conservation of Whitebacked Woodpecker Dendrocopos leucotos in Poland. Biological Conservation 71: 69-75.

WESOLOWSKI, T. (1995b): The loss of avian cavities by injury compartmentalization in a primeval European forest. Condor 97: 256-257.

Wesolowski, T. (1996): Natural nest sites of marsh tit ( Parus palustris) in a primaeval forest (Bialowieza National Park, Poland). Vogelwarte 38: 235-249.

WesolowsKI, T. (2002): Anti-predator adaptations in nesting Marsh Tits Parus palustris: the role of nest-site security. Ibis 144: 593-601.

Wesolowski, T. \& TOMIALOJC, L. (1986): The breeding ecology of woodpeckers in a temperate primaeval forest - preliminary data. Acta Ornithologica 22: 1-21.

Wesolowski, T., TOMialojC, L. \& STAWARCZYK, T. (1987): Why low numbers of Parus major in Bialowieza forest - removal experiments. Acta Ornithologica 23: 303-316.

WesolowsKi, T. \& STANSKA, M. (2001): High ectoparasite loads in hole-nesting birds: A nestbox bias? Journal of Avian Biology 32: 281-285.

Wesolowski, T., Tomialojc, L., Mitrus, C., Rowinski P. \& Czeszczewik D. (2002): The breeding bird community of a primaeval temperate forest (Bialowieza National Park, Poland) at the end of the 20th century. Acta Ornithologica 37: 27-45.

White, D.H. \& SEGINAK, J.T. (2000): Nest box use and productivity of Great Crested Flycatchers in prescribed-burned longleaf pine forests. Journal of Field Ornithology 71: 147-152.

Wichmann, F. (2001): Analyse der Vogelgemeinschaften in Habitatmosaic einer Naturlandschaft im Norden der Mongolei, Westchentie. Georg-AugustUniversität Göttingen, Göttingen.

Wichmann, F. \& PoKrovskaya, I. (2004): Birds - Ornithology, species list of Khonin Nuga. pp. 48-53 in MüHLEnBERG, M. \& WiChMANN, F. (eds.): Inventory of Species of Khonin Nuga, West Khentii, Zentrum für Naturschutz, Universität Göttingen, Göttingen.

WIEBE, K.L. (2001): Microclimate of tree cavity nests: Is it important for reproductive success in Northern Flickers? Auk 118: 412-421.

WIESNER, J. (2001): Die Nachnutzung von Buntspechthöhlen unter besonderer Berücksichtigung des Sperlingskauzes in Thüringen. pp. 79-94 in GüNTHER, E., Nicolai, B., PechaceK, P. \& SüdBeck, P. (eds.): Spechte, Wald und Höhlennutzung, Abhandlungen und Berichte aus dem Museum Heineanum 5, Sonderheft, Förderkreis Museum Heineanum, Halberstadt.

WiKTANDER, U., Olsson, O. \& Nilsson, S.G. (2001): Seasonal variation in homerange size, and habitat area requirement of the Lesser Spotted Woodpecker (Dendrocopos minor) in southern Sweden. Biological Conservation 100: 387395.

WINKEL, W. (1996): The Brunswick research project of the "Vogelwarte Helgoland" on cavity-nesting birds. Vogelwelt 117: 269-275. 
WinkLeR, D., ChristiE, D.A. \& NuRnEY, D. (1995): Woodpeckers: a guide to the woodpeckers, piculets and wrynecks of the world. Pica Press, South Africa.

WinTERNITZ, B.L. \& CAHN, H. (1983): Nestholes in live and dead aspen. pp. 102-106 in DAVIS, J.W., GoODWIN, G.A. \& OCKENFELS, R.A. (technical coordinators): Snag Habitat Management: Proceedings of the Symposium, USDA Forest Service General Technical Report RM-99, Flagstaff, Arizona.

WITT, K. (2004): Bruthöhlennutzung des Buntspechts Picoides major in einem Berliner Waldpark 1985-2004 (mit Notizen zu anderen Spechtarten). Vogelwelt 125: 99-104.

WÜBBENHORST, J. \& SÜDBECK, P. (2003): Woodpeckers as indicators for sustainable forestry? First results of a study from Lower Saxony. Nationalpark Berchtesgaden Forschungsbericht 48: 179-192.

YANOVSKI, V.M. \& KISELEV, V.V. (1996): Response of the endemic insect fauna to fire damage in forest ecosystems. pp. 409-413 in GOLDAMMER, J.G. \& FuryaEv, V.V. (eds.): Fire in Ecosystems of Boreal Eurasia, Kluwer Academic Publishers, Dordrecht.

ZANG, H. (2003): Wie beeinflussen Fruktifikationen der Rotbuche Fagus sylvatica Bestandsdichte und Brutbiologie des Kleibers Sitta europaea im Harz? Vogelwelt 124: 193-200.

ZAR, J.H. (1999): Biostatistical Analysis. Prentice Hall, Upper Saddler River.

ZARNOWITZ, J.E. \& MANUWAL, D.A. (1985): The effects of forest management on cavity-nesting birds in northwestern Washington. Journal of Wildlife Management 49: 255-263.

ZEEDYK, W.D. (1983): Managing snag habitats in southwestern national forests. pp. 2-3 in DAVIS, J.W., GoOdWIN, G.A. \& OCKENFELS, R.A. (technical coordinators): Snag Habitat Management: Proceedings of the Symposium, USDA Forest Service General Technical Report RM-99, Flagstaff, Arizona. 


\section{LIST OF TABLES}

Table 3.1 The habitat variables recorded in each sampling point ......................... 18

Table 4.1 Vegetation attributes in each habitat..................................................... 31

Table 4.2 Results of principal component analysis ............................................. 31

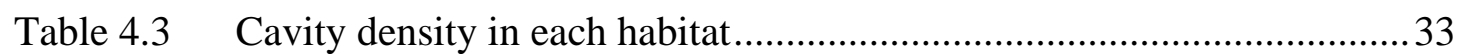

Table 4.4 Correlation between cavity density and habitat features ........................ 34

Table 4.5 The percentage constitution of all sampled stems, total cavities and cavity holding rate according to tree species ................................................... 36

Table 4.6 The percentage constitution of all sampled stems, total cavities and cavity holding rate according to tree condition............................................... 41

Table 4.7 The cavity holding rate according to tree species and presence of fire scars

Table 4.8 The estimates for logistic regression models of the probability a tree holding cavities

Table 4.9 Number of nest of each bird species found in each habitat ....................50

Table 4.10 Density of CNBs and cavity occupancy in each habitat

Table 4.11 Correlation coefficients between CNB density, number of CNB species

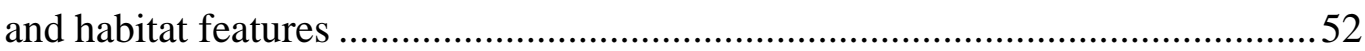

Table 4.12 Species composition of nest trees used by PCNs and SCNs ..................56

Table 4.13 Species composition of nest trees used by each bird species .................62

Table 4.14 Nest tree DBH of each bird species ....................................................64

Table 4.15 Nest tree condition of each bird species ............................................65

Table 4.16 Nest cavity type of each bird species ..................................................6 66

Table 4.17 Cavity height above ground, substrate diameter, cavity opening length and cavity opening width of each bird species .................................................6 68

Table 4.18 Nest substrate condition of each bird species .......................................69

Table 4.19 Shape of nest cavity opening of each bird species ...............................69 
Table 4.20 Classification matrix from discriminant function analysis based on cavity type and cavity opening width

Table 4.21 Reuse pattern of nest cavities for each species ....................................73

Table 4.22 Comparisons of reused and not reused cavities .................................... 75

Table 5.1 Cavity density estimates in the literature .............................................8 82

Table 5.2 Mean DBH, proportion of dead stems and cavity holding rate of conspecific or congeneric trees in Mongolia and in Sweden 83

Table 5.3 Guild level cavity reuse pattern in the literature 124 


\section{LIST OF FIGURES}

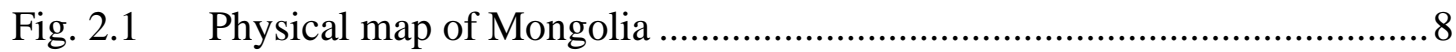

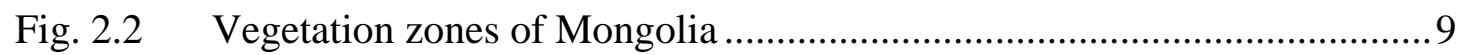

Fig. 2.3 Location of Khan Khentey Strictly Protected Area ................................. 11

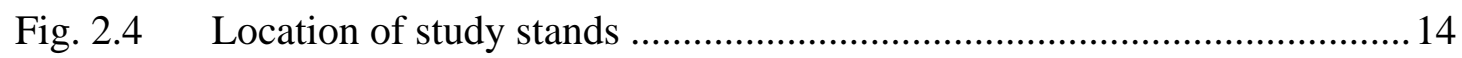

Fig. 2.5 Study stands: (a) the mature birch-larch forest, (b) the young birch-larch forest, (c) the riparian mixed forest and (d) the spruce-fir coniferous forest....... 16

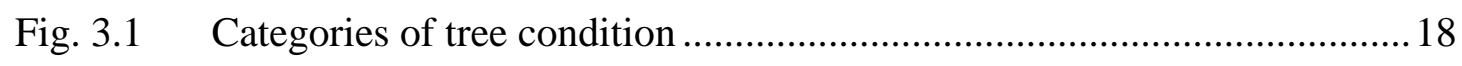

Fig. 3.2 Different cavity types: (a) woodpecker hole, (b) other bird-induced hole,

(c) branch hole and (d) bark crevice

Fig. 4.1 Component loadings and projections of 20 plots onto principal components 1 and 2

Fig. 4.2 Densities of (a) woodpecker hole and (b) non-excavated cavity of each plot projected onto principal components 1 and 2 ......................................... 35

Fig. 4.3 The percentage constitution of all sampled stems, excavated cavities and non-excavated cavities according to tree species.

Fig. 4.4 The percentage constitution of all sampled stems, total cavities and cavity holding rate according to tree $\mathrm{DBH}$ 38

Fig. 4.5 The cavity holding rate of poplar, birch, larch and Scots pine in each DBH class

Fig. 4.6 The percentage constitution of all sampled stems and the percentage of total cavities according to tree $\mathrm{DBH}$ in each habitat. 40

Fig. 4.7 The percentage constitution of all sampled stems, excavated cavities and non-excavated cavities according to tree condition

Fig. 4.8 The percentage constitution of all sampled stems and the percentage of total cavities according to tree condition in each habitat.

Fig. 4.9 The percentage constitution of all sampled stems and the percentage of total cavities according to the presence of fire scars. 
Fig. 4.10 The percentage constitution of all sampled stems, excavated cavities and non-excavated cavities according to the presence of fungi conks

Fig. 4.11 Predicted probability of cavity occurrence in (a) deciduous trees and (b) coniferous trees, in relation to tree $\mathrm{DBH}$ and tree condition

Fig. 4.12 Predicted probability of the occurrence of excavated cavities in deciduous trees, in relation to tree $\mathrm{DBH}$, tree condition and fungi conks

Fig. 4.13 Predicted probability of the occurrence of non-excavated cavities in deciduous trees, in relation to tree $\mathrm{DBH}$, tree condition and fire scars

Fig. 4.14 Densities of cavity-nesting birds of each plot projected onto principal components 1 and 2

Fig. 4.15 Species abundance distribution of CNBs in different studies 54

Fig. 4.16 The percentage constitution of all sampled stems, total cavities, nests of PCNs and nests of SCNs according to tree DBH

Fig. 4.17 The percentage constitution of all sampled stems, total cavities, nests of PCNs and nests of SCNs according to tree condition.

Fig. 4.18 The percentage constitution of all sampled stems, total cavities, nests of PCNs and nests of SCNs according to the presence of fire scars

Fig. 4.19 The percentage constitution of all sampled stems, total cavities, nests of PCNs and nests of SCNs according to the presence of fungi conks.

Fig. 4.20 The percentage constitution of total cavities, nests of PCNs and nests of SCNs according to cavity type.

Fig. 4.21 The Renkonen similarity of nest tree species between bird species

Fig. 4.22 The Renkonen similarity of nest tree condition between bird species......65

Fig. 4.23 The Renkonen similarity of nest cavity type between bird species ..........66

Fig. 4.24 The dendrogram of single linkage cluster analysis ................................ 70

Fig. 4.25 Reuse pattern of nest cavities for PCNs, WPCNs and SCNs................... 72

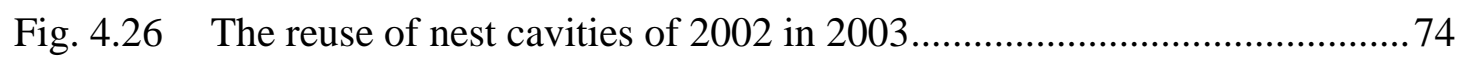

Fig. 4.27 Nest web of the CNB community ....................................................... 76 
Fig. 4.28 The supposed nest web when middle-sized woodpeckers were absent .... 78

Fig. 4.29 The supposed nest web when birch was absent. 80

Fig. 5.1 A nest cavity of $P$. ater formed through frost crack 86

Fig. 5.2 Hypothetical models of the changing numbers of cavities during natural forest succession 89

Fig. 5.3 Hypothetical model of the changing numbers of tree species and cavities during natural forest succession. 90

Fig. 5.4 A nest cavity of D. leucotos in a birch tree bearing the fruit body of hoof fungus Fomes fomentarius. 97

Fig. 5.5 Hypothetical models of the changing numbers of cavities and cavitynesting birds during natural forest succession 106

Fig. 5.6 Hypothetical model of the changing numbers of tree species, cavities and cavity-nesting birds during natural forest succession.... 107

Fig. 5.7 A nest of T. ruficollis and a nest of $C$. familiaris located in special types of cavities induced by fire. 111

Fig. 5.8 Nests of S. europaea in a woodpecker hole and in a branch hole. 116

Fig. $5.9 P$. ater prefers nesting in branch holes in living trees. 118 


\section{ABBREVIATIONS}

$\begin{array}{ll}\text { CNB } & \text { Cavity Nesting Bird } \\ \text { DBH } & \text { Diameter at Breast Height } \\ \text { GEF } & \text { Global Environment Facility } \\ \text { KKSPA } & \text { Khan Khentey Strictly Protected Area } \\ \text { MNE } & \text { Ministry for Nature and the Environment of Mongolia } \\ \text { PCN } & \text { Primary Cavity Nester } \\ \text { SCN } & \text { Secondary Cavity Nester } \\ \text { UNDP } & \text { United Nations Development Programme } \\ \text { WWF } & \text { World Wildlife Fund }\end{array}$




\section{APPENDIX}

\section{List of cavity nesting birds in West Khentey, Mongolia}

\begin{tabular}{ll}
\hline Latin name & English name \\
\hline Tadorna ferruginea & Ruddy Shelduck \\
Anas platyrhynchos & Mallard \\
Bucephala clangula & Common Goldeneye \\
Mergus merganser & Common Merganser \\
Surnia ulula & Northern Hawk-Owl \\
Glaucidium passerinum & Eurasian Pygmy-Owl \\
Strix uralensis & Ural Owl \\
S. nebulosa & Great Gray Owl \\
Hirundapus caudacutus & White-throated Needletail \\
Apus pacificus & Pacific Swift \\
Upupa epops & Hoopoe \\
Jynx torquilla & Wryneck \\
Picus canus & Gray-headed Woodpecker \\
Dryocopus martius & Black Woodpecker \\
Dendrocopus major & Great spotted Woodpecker \\
D. minor & Lesser spotted Woodpecker \\
D. leucotos & White-backed Woodpecker \\
Picoides tridactylus & Northern Three-toed Woodpecker \\
Motacilla alba & White Wagtail \\
Tarsiger cyanurus & Red-flanked Bluetail \\
Phoenicurus phoenicurus & Eurasian Redstart \\
P. auroreus & Daurian Redstart \\
Turdus ruficollis & Dark-throated Thrush \\
Ficedula albicilla & Red-throated Flycatcher \\
F. mugimaki & Mugimaki Flycatcher \\
Parus montanus & Willow Tit \\
P. ater & Coal Tit \\
P. major & Great Tit \\
\hline Certhia familiaris & Siberian Tit \\
\hline
\end{tabular}

* non-obligatory cavity nesters. 


\section{ACKNOWLEDGEMENTS}

This work was accomplished with the help of many kind people. Here I would like to express my deep gratitude towards them.

First of all I have to thank Prof. Dr. M. Mühlenberg, who gave me the opportunity to conduct my field work in Mongolia and to complete my study in the Centre for Nature Conservation. Because of the field station Khonin Nuga, which he established with Prof. Dr. R. Samjaa, the field study could be carried out with minimum difficulties. He kindly supported the travel and living cost during the field work. I also greatly benefited from his supervision and encourage throughout these four years. Therefore I am heartily grateful for all his support.

I would like to thank all dear companions in Khonin Nuga. Frank Wichmann instructed me into the bird world with his always-cheerful passion towards Nature. He and other ornithologists in Khonin Nuga, Dr. Boris Scheftel, Dr. Irina Pokrovskaya, Z. Uuganbaatar, Peter Biedermann and Dr. Andy Barkow, assisted me in the field work and provided useful and exciting discussions. D. Myagmarsuren, the ranger of Khonin Nuga, gave me fatherly supervision and care. I am also deeply grateful to Prof. Dr. R. Samjaa, Prof. Dr. M. Woyciechowski, Dr. Ch. Gantigmaa, P. Tserendavaa, B. Solongo, Dr. Ch. Dulamsuren, Lilly Nockemann, Michaela Dölle, A. Enkhmaa, S. Purevdorj, R. Sunjidmaa, J. Slowik, Bold, Ulaana, Mitga and Bairaa, and many other companions in Khonin Nuga. The little friends, Khulan, Baku, Anka, Lauri, Entschik, Pujee and Monta, were the delight of my field life. Thank all these Khonin Nuga companions for their accompany, help and encouragement. What I've learned from these beloved persons will cheer me up throughout my life.

Several persons gave valuable discussion and insightful comments during the study period. For that I am grateful to Prof. Dr. Tomasz Wesolowski, Dr. O. Bourski, Dr. Boris Scheftel, Dr. Richard Noske, Dr. Hermann Hondong, Dr. Matthias Waltert, Thorsten Späth and Frank Wichmann.

The colleagues in the Centre for Nature Conservation altogether created a pleasant working environment. Many thanks to the secretaries Monika Deseniß and Andrea Lambertz, their efforts kept our Centre moving in order. Special thanks to Elisabeth 
Opielka, for I ever caused many computer problems but she was still always so patient and helping. Thanks Thorsten, who took great efforts to work out the German abstract. I am also grateful to all the colleagues in the Centre, for their discussion, help and friendship.

My parents supported me spiritually and materially, even though they didn't like my disappearance in the field. My sister always gave encouraging words and undertook family responsibilities together with my brother. Without them my study abroad was not possible. I send my deepest gratitude to them.

Life of these years was enriched by many dear friends. They brought beautiful moments into my life, shared the pleasure and encouraged me through the frustrating time. Sincere thanks to Tseka, Gantigmaa, Frank, Tsai-shiou, Eh, Hsin-Ling, WeiJiun, Yue-Lin, Shan, Ying-Chau, Yue-Ya, Prof. Dr. Pei-Feng Lee, and the special one, Thorsten. 


\section{LEBENSLAUF}

Persönliche Daten:

$\begin{array}{ll}\text { Vorname: } & \text { Mei-Ling } \\ \text { Nachname: } & \text { Bai } \\ \text { Adresse: } & \begin{array}{l}\text { Zentrum für Naturschutz, Von-Siebold-Str. 2, } \\ 37075 \text { Göttingen }\end{array} \\ \text { Geburtstag: } & \text { 6. April } 1975 \\ \text { Geburtsort: } & \text { Taipei, Taiwan } \\ \text { Staatsangehörigkeit: } & \text { taiwanesische }\end{array}$

Wissenschaftlicher Bildungsgang:

September 1993 - Juli 1997

September 1997 - Juli 1999

Juli 1999 - September 2000

Oktober 2000 - April 2001

April 2001 - März 2005
Studentin der Nationaluniversität Taiwan, Physikalische Fakultät, Taipei, Taiwan

Studentin des Masterstudiengang Ökologie an der Nationaluniversität Taiwan, Zoologische Fakultät, Taipei, Taiwan

Wissenschaftliche Assistentin an der Nationaluniversität Taiwan, Zoologische Fakultät, Taipei, Taiwan

Studentin des Masterstudiengang Forstwissenschaften in den Tropen und Subtropen an der Georg-August Universität Göttingen, Fakultät für Forstwissenschaften und Waldökologie

Promotionsstudentin an der Georg-August Universität Göttingen, Zentrum für Naturschutz 